\title{
INFRASTRUCTURE AND EQUIPMENT FOR UNPAID CARE WORK: HOUSEHOLD SURVEY FINDINGS FROM THE PHILIPPINES, UGANDA AND ZIMBABWE \\ 2017 Household Care Survey Report
}

WE-CARE

WOMEN'S

ECONOMIC EMPOWERMENT AND CARE 


\title{
INFRASTRUCTURE AND EQUIPMENT FOR UNPAID CARE WORK: HOUSEHOLD SURVEY FINDINGS FROM THE PHILIPPINES, UGANDA AND ZIMBABWE
}

\author{
2017 Household Care \\ Survey Report
}

\section{Lucia Rost and Sandrine Koissy-Kpein}

Care work is essential for personal wellbeing and for maintaining societies and a significant component of the economy. But across the world, it is overwhelmingly done by women, which restricts their opportunities for education, employment, political engagement and leisure. Policy makers rarely recognize the public responsibility for facilitating unpaid care and domestic work through investments in infrastructure and care services. In 2017, Oxfam's Women's Economic Empowerment and Care (WE-Care) initiative conducted a Household Care Survey (HCS), collecting data in the Philippines, Uganda and Zimbabwe, to inform the design of public policies and local development programmes. Based on responses from 4,734 women, men, boys and girls from 1,688 households, the study tests which infrastructure, equipment and other factors influence care-work patterns. The research finds that access to improved water sources is associated with reductions in hours of care work, and household equipment facilitates men's participation in care. Women report injuries and harm linked to heavy workloads. Perceptions of care work, community expectations and fear of sanctions for deviating from gendered care roles, i.e. social norms regarding gendered care roles, play an essential part in maintaining the gendered division of care work. The report suggests that further research is needed to explore in more detail the effect of public infrastructure and equipment on care-work divisions.

In 2017, the HCS was conducted in the new districts of the Philippines, Zimbabwe and Uganda with support from Unilever, its laundry brand Surf and William and Flora Hewlett Foundation. 


\section{ACKNOWLEDGEMENTS}

We would like to thank all the people who contributed to the 2017 Household Care Survey research, data collection and the writing of this report. Firstly, we would like to thank the survey respondents and enumerators who collected the data. We acknowledge the country teams involved and their commitment. The data collection was coordinated by Leah Payud and Ferdinand Deriquito in the Philippines; Dr Madina Guloba and Dr Miriam Katunze from the Economic Policy Research Centre, and Charity Namara in Uganda; and Nomthandazo Jones and Tinashe Kapisa in Zimbabwe. We would also like to thank the local partner organizations for their invaluable contributions: SIM-CARRD, SIKAT, COM, PRRM and RDISK in the Philippines and SHDF, Kunzwana, Bekezela and AWC in Zimbabwe. We also want to express our gratitude to the global WE-Care team and other Oxfam staff who contributed to the research, especially to Thalia Kidder, Imogen Davies, Jane Remme, Anna Giolitto, Andrea Azevedo, Miranda Morgan, Man-Kwun Chan, Louise Medland, Emily Tomkis Valteri, Anam Parvez, Rose Atim and Martin Walsh.

Finally we would like to thank our partners, Unilever, their laundry brand Surf and the William and Flora Hewlett foundation for the financial contribution to the wider WE-Care programme in Zimbabwe, Uganda and the Philippines including this research.
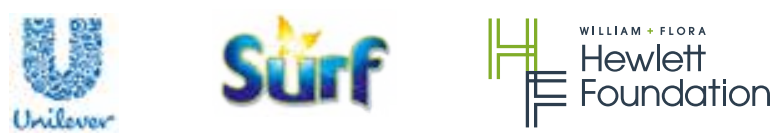

\section{ABBREVIATIONS}

DFID

GBV

HCS

IMAGES

RCA

TLSE

WASH

WEAI

WE-Care
Department for International Development Gender-Based Violence Household Care Survey International Men and Gender Equality Survey Rapid Care Analysis Time- and labour-saving equipment Water, Sanitation and Hygiene Women's Empowerment in Agriculture Index Women's Economic Empowerment and Care 


\section{CONTENTS}

1. INTRODUCTION

2. BACKGROUND 14

$\begin{array}{ll}\text { Unpaid care and domestic work } & 14\end{array}$

$\begin{array}{ll}\text { Policy and unpaid care work } & 14\end{array}$

Oxfam's approach to unpaid care and domestic work 15

The Household Care Survey $\quad 15$

3. CONCEPTUAL FRAMEWORK $\quad 18$

4. FINDINGS

Overview of the sample $\quad 22$

Adults' time use $\quad 23$

Care work 23

Water collection for laundry $\quad 24$

Paid/productive work and non-work $\quad 25$

Young people's time use $\quad 26$

Ages 8 to 12 years $\quad 27$

Ages 13 to 17 years $\quad 27$

Ages 18 to 21 years $\quad 27$

Comparing age groups $\quad 27$

Adults' care work and young people's time use $\quad 27$

Factors influencing care work $\quad 27$

Household/personal characteristics 28

Time- and labour-saving equipment $\quad 29$

Infrastructure and services 31

Social norms and perceptions $\quad 34$

Women's decision making $\quad 43$

Wellbeing, time constraints and care work $\quad 44$

Women's wellbeing $\quad 44$

Time constraints $\quad 45$

5. HIGHLIGHTS AND SUGGESTIONS $\quad 46$

$\begin{array}{ll}\text { Philippines } & 47\end{array}$

$\begin{array}{ll}\text { Uganda } & 48\end{array}$

Zimbabwe $\quad 49$

6. CONCLUSION

7. RECOMMENDATIONS

BIBLIOGRAPHY

NOTES $\quad 55$

APPENDIX

Descriptive statistics tables $\quad 57$

$\begin{array}{ll}\text { Regression analysis tables } & 71\end{array}$ 


\section{LIST OF TABLES}

Table 1: Distribution of respondents by gender and country

Table 2: Ratio of time spent by adult women relative to time spent by adult men on primary and any care in samples from three countries, 2017

Table 3: Hours spent on different care activities by adult women and men in samples from three countries, 2017

Table 4: Hours spent on different activities (care work, paid work, education, and leisure and sleep) by girls and boys (aged 8 to 21) in samples from three countries, $2017 \quad 26$

Table 5: Ownership of TLSE for water in samples in Philippines and Zimbabwe, 2017

Table 6: Ranking of care activities according to the value attributed to them by adult women and men in samples from three countries, 2017

Table 7: Ranking of care activities according to the perceived skills required to perform them by adult women and men in samples from three countries, 2017

Table 8: Care activities viewed as most problematic by adult women and men in samples from three countries, 2017

Table 9: Satisfaction with the division of labour by adult women and men in samples from three countries, 2017

Table 10: Share of adult men who reported childhood exposure to care work (seeing father's engagement in care work or were taught to do care work) in samples from three countries, 2017

Table 11: Proportion of adult women and men who consider community expectations when defining personal behaviour on unpaid care work in samples from three countries, 2017

Table 12: Share of adult women and men in samples from three countries who felt gender-based violence/harsh criticism was an acceptable response to women's perceived failure to carry out at least one care-related task, or that mocking was an acceptable response to men's engagement in at least one care-related task, 2017

Table 13: Proportion of adult women who reported harm related to unpaid care work in samples from three countries, 2017

\section{LIST OF FIGURES}

Figure 1: Proportion of time spent by adult women and men on primary care, primary or secondary care, any care and multi-tasking care, 2017

Figure 2: Mean hours of paid work, non-work and total work by adult women and men in samples from three countries, 2017

Figure 3: Vignettes on division of labour (women's perspective) 


\section{EXECUTIVE SUMMARY}

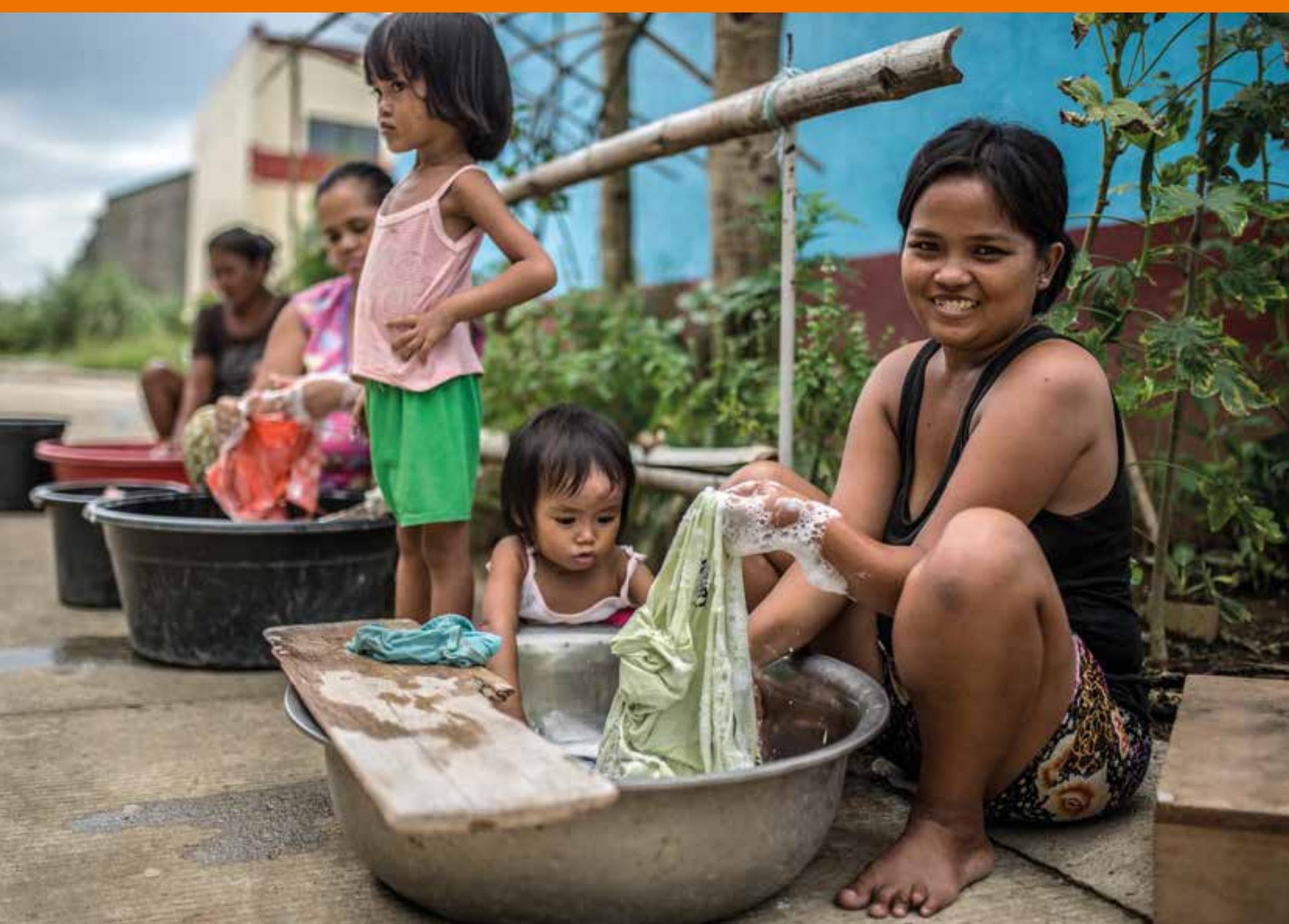


Care work is essential for personal wellbeing and for maintaining societies. But across the world, it is overwhelmingly done by women, which restricts their opportunities for education, employment, political engagement and leisure.

Unpaid care work is a significant component of the economy, underpinning and contributing to the market economy, and maintaining a healthy, productive workforce. However, government and private sector policy makers rarely recognize their duty to address unequal unpaid care work, nor the public responsibility they have to facilitate unpaid care and domestic work through investments in infrastructure and care services. ${ }^{1}$

Since 2013, Oxfam's Women's Economic Empowerment and Care (WE-Care) initiative has worked to produce new methodologies and context-specific evidence about care work to enable development actors to address heavy and unequal care work for women in development initiatives and policy proposals. This report summarizes the findings from the 2017 Household Care Survey (HCS) conducted in project areas in the Philippines, Uganda and Zimbabwe.
Governments and the private sector have a role to play in addressing unpaid care work. Because this role is so important, the 2017 HCS research concentrates on building evidence about the impact of public services on the level and the distribution of unpaid care and domestic work between women and men in poor communities. The $2017 \mathrm{HCS}$ also looks at features such as women's decision-making power and social norms around care to build a comprehensive picture of the factors that influence care-work patterns, and explores the impact of care workloads on women's health and wellbeing. Communities, governments, the media, development practitioners and the private sector must be aware of the different implications of heavy and unequal care work for women's lives, their families and communities, so they can act together to recognize, reduce and redistribute care work and improve representation of carers in decisionmaking processes.

\section{THE HOUSEHOLD CARE SURVEY}

The 2014 Household Care Survey (HCS) was devised to provide rigorous evidence on women's time use for the design of local initiatives for women's empowerment and care, in selected rural communities in Colombia, Ethiopia, the Philippines, Malawi, Uganda and Zimbabwe.

In 2015, a second round of the HCS in the same districts of Ethiopia and Zimbabwe and in other areas in Colombia, Uganda and the Philippines included methodological improvements such as in-depth investigation of social norms and perceptions of unpaid care work, and provided an end line for the We-Care pilot.

In 2017, the HCS was conducted in new districts of the Philippines, Uganda and Zimbabwe. From April to July 2017, data was collected from randomly sampled households within communities where We-Care is operating. A total of 4,734 respondents were interviewed: 541 in the Philippines, 3,114 in Uganda and 1,079 in Zimbabwe. The sample is not nationally representative, nor does it control for seasonality; it includes five districts in the Philippines, three districts in Uganda and five districts in Zimbabwe. Most households were low-income and rural. For brevity, findings are discussed as for a 'country', which should always be understood as the survey sample from districts in the country. The 2017 HCS improved data collection by interviewing 1,679 children, adolescents and young adults between 8 to 21 years old as well as their parents. The analysis used both descriptive and multivariate statistics. 


\section{KEY FINDINGS}

- Women do more hours of care work than men do in all situations; on average women spent 4.5 to 6.5 hours a day on care as a primary activity. When supervision of dependants and secondary activities are included, women's average hours of care responsibility increase to 11 to 12 hours per day.

- In households with an improved water source, women reported significantly lower total hours of care work than in households without. This finding implies that a single intervention, providing access to an improved water source, could potentially reduce women's average unpaid care workload by 1 to 4 hours a day in the districts in three countries where the survey was conducted.

- Heavy care work can affect women's wellbeing. The findings show an association between more hours of care work and women reporting injury and illness linked to these tasks, and that women who reported spending more time on care work experienced more time constraints with care of adult dependants.

- From responses on social norms related to unpaid care work, what matters most is not what people think community members do, but what they think community members believe. Women and men were most likely to say that men would do care work in situations where the community considered it acceptable. Additional analysis conducted with data from the 2017 HCS shows that positive social norms are associated with a more equal gendered distribution of care work, i.e. women and men sharing unpaid care work more equally within the household.

\section{TIME USE}

Time use is a central element of the HCS. The main indicators for time use are 'primary care', or the number of hours respondents spent on care as a primary activity the day before the survey, and 'any care', or the number of hours respondents spent on care as either a primary or secondary activity le.g. leaving food cooking while tending farm animals) or a supervision activity (e.g. supervising children while selling products in the market).

\section{Women do more care hours than men in any situation} (primary care or any care). Women in all three countries ${ }^{2}$ spent on average 4.5 to 6.5 hours a day on care as a primary activity. When 'any care' is calculated, women's total hours with care responsibility more than double, reaching an average of 11 to 12 hours a day. Including hours of care as a 'secondary activity' and 'responsibility for supervision' more accurately reflects the reality of women's lives, as compared to only counting hours of care as a primary activity. Women's mobility, choices and productivity are clearly limited by any care responsibility', even supervising a sleeping child. Interventions that reduce women's care workloads contribute to their wellbeing and reduce time poverty.
Women's total hours of work (primary care and paid work) are, on average, about 1 hour more a day than men's in Uganda and Zimbabwe. Men reported additional hours of care when their hours of 'any care responsibility' are included, but findings show that even when hours of 'supervision' are included, women's hours with responsibility for care were, on average, 6.5 to 8 hours longer per day than men's hours. Between $9 \%$ and $52 \%$ of men across the three country samples reported no time spent on any kind of care activity the day before the survey.

Unequal distribution of unpaid care work begins in childhood, and it persists over time. Girls as young as 8 to 12 spent about 2 hours a day more on care work than boys. We find that girls in all countries and in all age groups spent more time on total work (paid and unpaid) than boys of the same age group did, especially adolescents (aged 18 to 21). This can have implications for schooling, training, public activities and play, and can lead to gender inequalities later in life. 


\section{CARE WORK}

Because care work is complex and intense, interventions that address heavy and unequal unpaid care work must involve different actors and work on different levels. For example, that care tasks are carried out simultaneously suggests that providing equipment for any single task le.g. improved cooking stoves) cannot be expected to reduce the overall hours that women spend on care. Even with reductions in time spent on housework, women may increase time on people care, especially if public care services are inaccessible. Governments and the private sector must play a role in the provision of services, infrastructure and equipment that can reduce the time required for unpaid care work. Redistribution requires community engagement and public communications to promote new social norms, and increasing the commitment of men and boys to share care work.

\section{INFRASTRUCTURE AND TIME- AND LABOUR-SAVING EQUIPMENT}

The 2017 HCS implies that a single intervention providing access to an improved water source (i.e. not a natural source like a river or springl could be a powerful factor associated with lower workloads for women. The research found that in households with access to improved water sources, women in the three countries reported spending an average of 1 to 4 hours a day less on any care than women in households without improved water sources. Improved access to water was also associated with more leisure hours for women in Uganda and Zimbabwe but a slight decrease in women's leisure hours in the Philippines. Children also benefit from improved water sources: in the study areas in Uganda and Zimbabwe, it is associated with boys and girls spending more time on leisure. Additional analysis conducted with data from the 2017 HCS shows that improved access to water is associated with a reduction in the time women spent in multi-tasking of care activities and with girls sleeping longer hours in Uganda and studying longer in Zimbabwe. ${ }^{3}$

The report recommends that government, private sector and development actors prioritize poor households' access to affordable services and infrastructure related to water, to fulfil national and international commitments to reduce heavy workloads of unpaid care work, especially for women and girls.

Electricity infrastructure is not consistently related to a reduction of women's care hours in all countries. Electric light can extend the hours in which families are able to do housework. In Zimbabwe, it is associated with more primary and any care hours for women, and less sleep time for women in Uganda. However, in the Philippines, electricity access is associated with women spending fewer hours on primary and any care, more hours on leisure and a more equal distribution of care hours within the household. The same can be said about access to health facilities: in Zimbabwe, it seems to reduce workloads; but for other countries it points to an increase in any care work and/or primary care.
Access to childcare facilities was only reported by $9 \%$ to $20 \%$ of households interviewed. This access is associated with boys spending more time in school in the Philippines and girls spending more hours on studying at home in Zimbabwe, as compared to households without access to childcare services. Additional analysis shows an association between access to childcare facilities and an increase in time reported on primary care and multi-tasking for women in Uganda and Zimbabwe, and girls and boys reporting less time on paid work in Uganda. ${ }^{4}$

Time- and labour-saving equipment (TLSE) can be associated with reduction and redistribution of unpaid care work. This influence varies according to country and the type of equipment in question. Findings show that technology is a factor that, in some cases, can be associated with lower hours of women's unpaid care work and men reporting spending more time on care. For example, men spent more time on water collection if the household owned more water-related equipment, and more time on primary care if the household had more fuel-related equipment. It is possible that in households where men spend more time on care work, more money is invested in TLSE. More research is needed to understand social norms and perceptions related to types of equipment and types of unpaid care work, and how technology can be used to challenge perceptions and promote redistribution of care work.

\section{WOMEN'S WELLBEING}

Unequal care work can affect the wellbeing of women and their families. The findings show an association between more hours of care work and women reporting that they experienced harm linked to these tasks, in Uganda and Zimbabwe. Women who reported longer hours of care work experienced more time constraints (e.g. not having time for personal care or unable to fulfil expectations to provide a meal), with $8 \%$ to $15 \%$ of women reporting that they had left a child under six without any supervision during the previous week. Water collection and doing laundry appear to have a significant impact on women's wellbeing. The survey shows that $74 \%$ of the women in the study areas in the Philippines and $19 \%$ of the women in the Zimbabwe sample reported an injury, illness, disability or other physical or mental harm related to these tasks.

The report recommends that governments and the private sector take responsibility for gendered inequality in the household and in the economy through investments in care-related services and infrastructure, especially water access, and time- and labour-saving equipment to reduce long hours of care work and to address 'occupational health and safety' risks and 'lost work time' for women carers. It also calls for more research to investigate the impact of public services and infrastructure on women's time use and wellbeing to inform more deliberate gender-transformative programmes and public policies. 


\section{SOCIAL NORMS AND PERCEPTIONS}

The HCS found that there are two elements in understanding the role of social norms in shaping attitudes about unpaid care work: what people think others do and approve of, and what they personally believe is acceptable and tell others to do.

The report recommends combining investments in infrastructure, service provision or time- and labour-saving equipment with initiatives that address the social norms that might inhibit women and men from redistributing unpaid care work within the household. Further research is needed to understand what kinds of social norms interventions are most effective for promoting equal sharing of responsibility of care between men and women.

Overall, women and men perceive care work differently. Men generally perceive care work as a less valuable activity than women do, but improved perceptions of the value of care have the potential to increase men's participation in care. Valuing care activities is associated with more hours per day of any care responsibility for men in Uganda and more primary care hours for men in Zimbabwe. However, the research does not clarify the direction of causality: whether valuing care work more leads to increasing participation in care work, or whether men and women who do more care work value it more.

\section{What matters most is not what people think community members do, but what they think community members believe. In Uganda and Zimbabwe, women and men were most likely to say that men would do care work in situations where the community considered it acceptable. This finding is emphasized by the fact that we do not find an association between perceptions of other men's involvement in care work and men's care-work hours for the Philippines and Zimbabwe.}

In fact, the large majority of respondents approved or strongly approved of couples sharing care and productive work: $72 \%$ to $92 \%$ of men and $77 \%$ to $87 \%$ of women. This finding leads to the recommendation that initiatives can play a role in publicizing the discrepancy between beliefs about care in the community and actual community behaviour.

Programmes can highlight the fact that male participation in care work is widely accepted by individuals, and that men are more likely to engage in care work if their fathers engaged in care activities when they were children. The role of male 'care champions', in this context, is not only to lead by example, but also to engage in dialogue to unveil perceptions and challenge social norms about care work in the community.

Men who approved of an equal division of care and productive work spent more time on any care in the Philippines and on primary and any care in Uganda when compared to men who did not approve of sharing tasks. The direction of causality is unclear. In these same countries, the distribution of primary and any care between spouses is more equal in households where women approved of sharing tasks.

Although most men and women approve of an equal division of care and productive work between men and women, women are still seen as the main contributors to the household wellbeing. In all countries, women wanted girls to help with care work significantly more often than men did. Women and men were least likely to want sons to help with care work. This could lead to the persistence of gender inequalities in unpaid care work. The research findings support interventions designed to encourage the participation of boys and challenge perceptions.

Acceptance of gender-based violence is associated with more unequal division of care work. Men who accepted the beating of women for perceived inadequate provision of care tended to spend less time on any care in the Philippines and Uganda. At the same time, there is an association between women accepting the mocking of men who do unpaid care work and women spending more time on primary care in the Philippines and Zimbabwe and any care in the Philippines and Uganda.

The report recommends closer collaboration between initiatives that address gender-based violence and initiatives that promote positive change in gendered social norms and practices on unpaid care work. A concerted approach in addressing harmful social norms and practices could contribute to minimizing risks of gender-based violence related to the redistribution of unpaid care work within the household while promoting more sustainable, transformative approaches towards gender equality.

\section{INDIVIDUAL AND HOUSEHOLD CHARACTERISTICS} Household characteristics can be more decisive than individual traits in determining patterns of unpaid care work. Development programmes often assume that efforts to increase women's 'agency' lead to women renegotiating responsibility for unpaid care and domestic work. However, consistent with the findings from the $2015 \mathrm{HCS}$, the research shows there is no association between women's decisionmaking ability in the household and equality in care hours. When looking at household characteristics, in all countries, women who had at least one child under six spent about 4 to 5 hours more a day on any care activity than women who did not have a young child. Households where respondents were married reported higher gender inequality in care as a primary activity than households where men and women were unmarried. This finding highlights that initiatives on unpaid care work require active engagement of the whole household, especially men and boys, in promoting redistribution. 


\section{INTRODUCTION}

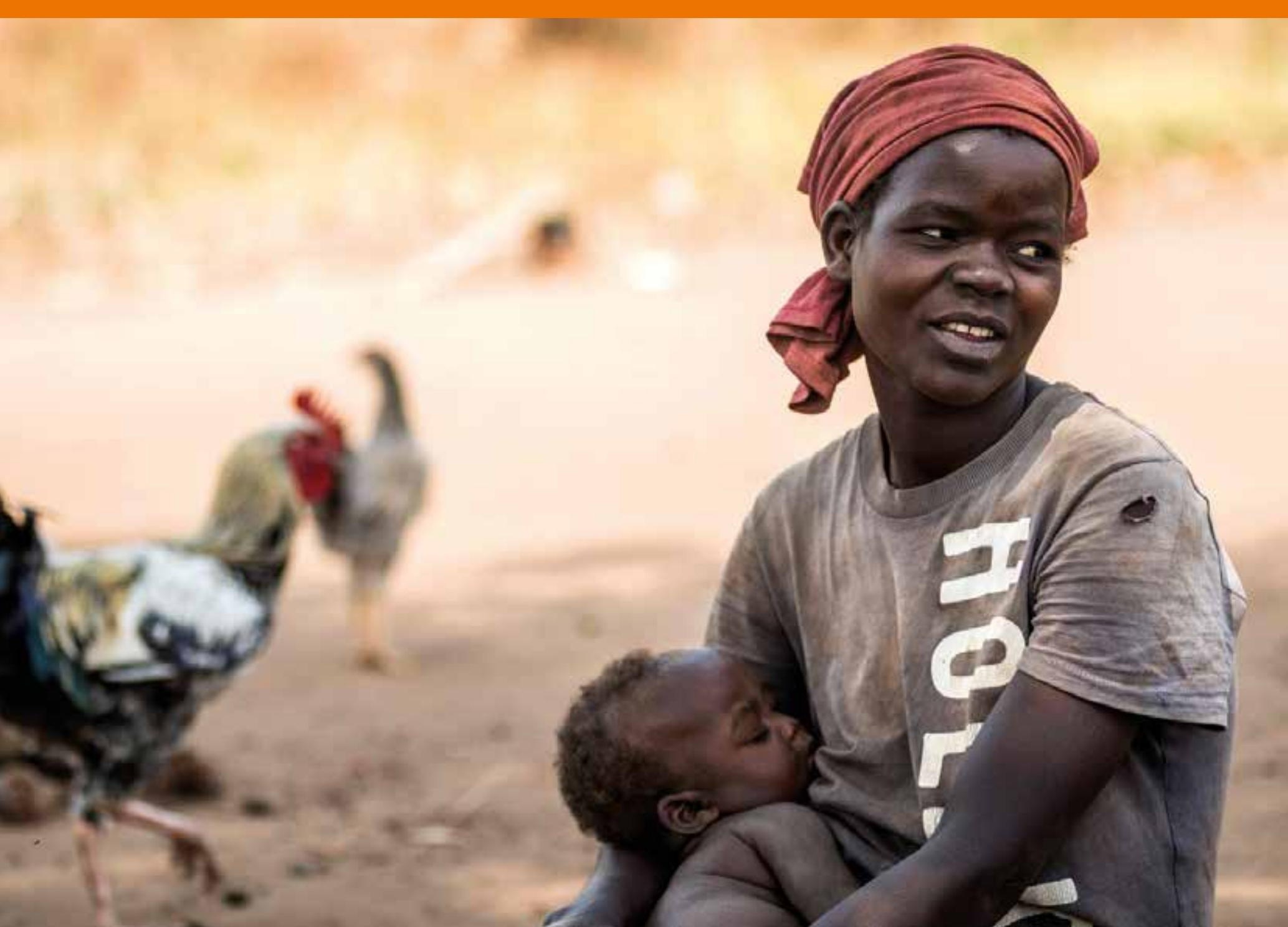


Care work is essential for personal wellbeing and for maintaining societies. But across the world, it is overwhelmingly done by women, which restricts their opportunities for education, employment, political engagement and leisure. In recent years, interest in assessing care work in development policy has increased, but there remains a lack of understanding of the full spectrum of women's work, paid and unpaid. In most countries, men and caregiving are conspicuously absent from the gender equality agenda.

Oxfam considers care a social good - not a burden - and aims to promote more and better quality care as part of development, of overcoming poverty and inequality. Oxfam has long worked on recognizing and addressing care work in programmes promoting gender justice, livelihoods and waged workers' rights, and has been a leader in recent global initiatives to address heavy and unequal care work.

The Women's Economic Empowerment and Care (WE-Care) initiative ${ }^{5}$ started in 2013 with developing approaches to unpaid care in rural communities. In 2014, the WE-Care project Evidence for Influencing Change was launched. Initially, the project aimed to produce new methodologies and context-specific evidence about care work to influence existing development initiatives and policy. In 2016, WE-Care scaled up efforts in Philippines and Zimbabwe, in partnership with the private sector, to provide women with improved access to water, to work on changing perceptions on unpaid care work, and to influence governments and allies in both countries to recognize the importance of the issue. ${ }^{6}$

The WE-Care project involves research, interventions and national-level influencing. In its first phase (2014-2016), WE-Care project activities were embedded in existing 'host programmes' with broader development objectives, such as women's leadership, agricultural enterprises and markets, water and sanitation, or the rights of people living with HIV and AIDS.

In these first years, WE-Care teams demonstrated that heavy and unequal unpaid care work was indeed a significant issue, that local communities in developing countries including men - wanted to work on the issue, and that low-cost approaches could be successful in assessing and addressing unpaid care. It was found to be crucial to work with traditional and religious leaders, local councils and other actors, and to combine a range of interventions le.g. on time- and labour-saving equipment, social norms and public services). WE-Care, together with partner organizations, created compelling 'pilot projects' and promoted 'care' as a social good, i.e. no longer as a 'women's burden'.

The research generated knowledge that informed the second phase (2017-2019) and is being used by local organizations to develop interventions to address problematic aspects of care work and to influence governments and employers, companies and civic leaders to address care work. Project interventions aim to recognize, reduce and redistribute existing unpaid care work within the household, the immediate community, the market and the state.

This report summarizes the findings of the 2017 Household Care Survey (HCS) data collection in districts in the Philippines, Uganda and Zimbabwe. The report proceeds as follows. Section 2 outlines the motivation for this work and the issues that the WE-Care surveys focus on. Section 3 describes the approach and propositions that guide the research design and analysis. The fourth section describes the findings of the 2017 HCS according to the different factors influencing distribution of unpaid care work in the household: household/personal characteristics, access to infrastructure and time- and labour-saving equipment, social norms and perceptions on unpaid care work, women's decision-making power in the household; and women's wellbeing and time constraints related to care work. Section 5 summarizes highlights from the findings and suggestions for future research for the Philippines, Uganda and Zimbabwe, respectively. The conclusion section discusses key policy implications and Section 7 provides recommendations arising from the report'. 


\section{BACKGROUND}

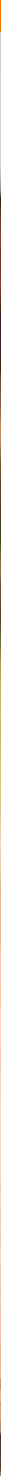




\section{Unpaid care and domestic work has received growing attention from development practitioners in recent years. This section provides a brief overview of the importance of policy making on care work, outlines policy approaches to addressing unpaid care work, and discusses previous rounds of HCS data collection.}

\section{UNPAID CARE AND DOMESTIC WORK}

The term 'unpaid care and domestic work' describes direct care of persons and domestic work for family members and other households (Budlender 2007). It includes activities such as caring for children and the elderly, as well as cleaning, cooking, washing and mending clothes, and fetching water or firewood. In contrast to 'housework' or 'domestic labour', the term 'unpaid care and domestic work' emphasizes that the work is unpaid and does not take place exclusively within households (Esquivel 2013), i.e. it may also take place within the wider community.

Care is essential for human survival and personal wellbeing. It can bring benefits for both care receivers and care givers. For care receivers, it builds their intellectual, physical and emotional capabilities, to the benefit of themselves and others (Folbre 1995; England 2005). However, the benefits of care to society are often not recognized and the provision of care - mostly by women - is often taken for granted.

Across the world, women and girls are often primarily responsible for domestic and caring activities (Ferrant et al. 2014). Women spend on average two to ten times more hours per day than men on unpaid care activities (ibid.). For example, according to the World Health Organization (WHO) and UNICEF's Progress on Sanitation and Drinking Water report (2012), women in 25 sub-Saharan countries spend up to 16 million of their daily working hours collecting water, and children 4 million hours.

Excessive caring duties have been identified as a barrier to various human rights of women and girls, such as the rights to work and social security, and the rights to freedom of speech, association and leisure (Sepulveda Carmona 2014). Heavy care workloads can negatively affect health and wellbeing. Certain activities - for example, fetching water or firewood - can also expose girls and women to the risk of assault. By reducing the time available for study or training, care work can constrain education and personal and professional development. A heavy workload of care provision can also limit women's paid work opportunities and result in long total work hours. Furthermore, heavy and unequal care work can negatively affect women's participation in politics, local leadership and development programmes (Woodroffe and Donald 2014). Care work is often not considered in development policy, with potentially severe consequences for development outcomes (Chopra 2013).

\section{POLICY AND UNPAID CARE WORK}

In 1995, the Beijing Platform for Action appealed for women's contribution in the domestic sectors to be made more visible through time-use studies (UN Women 1995). In recent years, care work has increasingly attracted attention in national and international policy agendas. In 2013, the 19th International Conference of Labour Statisticians adopted a resolution recognizing unpaid care work as one of five types of work (ILO 2013, cited in Samman et al. 2016: 46):

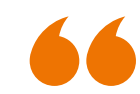

Recognize and value unpaid care and domestic work through the provision of public services,

infrastructure and social protection policies and the promotion of shared responsibility within the

household and the family as nationally appropriate.

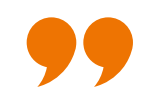

Furthermore, the 2030 Sustainable Development Agenda includes a target on care work under Goal 5, 'Achieve gender equality and empower all women and girls' (Target 5.4).

In September 2015, the UK Department for International Development (DFID) launched a Call to Action, 'Transforming Economies: Empower Women and Girls'. One of three pillars of action for empowerment, based on SDG target 5.4, calls on states, employers and donors to recognize and invest in care, and to increase the evidence base on care work, for example through time-use studies. 


\section{OXFAM'S APPROACH TO UNPAID CARE AND DOMESTIC WORK}

Oxfam's approach affirms that unpaid care and domestic work is a social good, and that it is a societal imperative to ensure more, better quality care of people, rather than considering unpaid care a women's issue, a 'burden' or a barrier to women's paid work. As adequate care is essential to reduce vulnerability, poverty and inequality, and addressing heavy and unequal care is a precondition for women's empowerment, it is also the responsibility of governments and employers to invest in infrastructure and services to facilitate unpaid care and domestic work. Oxfam builds on Dianne Elson's (2008) 'three Rs' framework that seeks to define specific objectives of care interventions.

\section{THE 'FOUR RS' APPROACH}

These objectives are presented in the box below.

1. RECOGNIZE care at household level, in

communities, institutions and policy.

2. REDUCE difficult care work, for example through time- and labour-saving technology and services.

3. REDISTRIBUTE the responsibility, costs and work of care provision from women to men, and from poor families to employers, the state and civil society.

In partnership with ActionAid, Oxfam and the Institute for Development Studies, a fourth ' $R$ ' was proposed:

4. Improve the REPRESENTATION of carers in decision making, so carers' interests and needs are reflected in policies that shape their lives.

The 'four Rs' approach aims to promote recognition of the importance of care work while reducing the drudgery that is often associated with it, and to redistribute responsibility more equally, with the active representation of carers in decision-making spaces.

Heavy and unequal care work should be reduced, redistributed and recognized at multiple levels. Razavi's (2007) 'care diamond' is useful to highlight that unpaid care work is provided, paid for and/or facilitated by four groups of actors: families and households, the state, the market and employers, and civil society groups. It follows that the redistribution of care can take place either within the household and/or between households and outside actors, which calls for the collective responsibility for addressing unpaid care work and unequal distribution of care as a societal issue.

Oxfam's approach has been to develop practical, user-friendly tools and practices that can be implemented by local groups and non-experts in a range of development programmes. WE-Care projects involve both men and women, and work to build effective alliances to coordinate efforts and advocacy to invest in care provision. These alliances include community and youth groups, women's rights organizations, religious and traditional leaders, local government and ministry officials, media representatives, academics and employers. Through this work, Oxfam builds evidence for programme design and policy development, and for public communications to raise awareness about the issues. WE-Care research has found that a combination of factors/initiatives are required for significant and sustainable changes in the level and distribution of care hours in families. Household characteristics, access to timeand labour-saving equipment, public care services and infrastructure, policy change and promotion of positive social norms on sharing care work have all shown to be relevant factors affecting the reduction and redistribution of unpaid care work. Thus the programme does not expect any one factor to make significant changes in care hours, as only a concerted strategy that addresses these different aspects can lead to sustainable results.

WE-Care objectives include: less time spent by poor families and women on arduous domestic tasks; more time for direct care for dependants/family members and for women themselves; more gender-equal sharing of care and domestic work, increasing the participation of men and boys in these tasks; recognition of the significance and value of unpaid care by governments and businesses in their policies and practices; and more investment in infrastructure and care services.

\section{THE HOUSEHOLD CARE SURVEY}

National time-use surveys have documented the extent and inequality of unpaid care activities for decades. Oxfam's motivation to conduct a HCS was to go beyond documenting the status quo, i.e. the problem, to investigate solutions relevant to specific contexts, based on an analysis of the factors associated with more equal patterns of care work and lower workloads. Oxfam's methodologies aim to provide user-friendly and lower-cost tools to enable local practitioners to gather context-specific evidence for programme and policy design. A successful example of such tools is the Rapid Care Analysis (RCA). Through a set of focus group exercises, the RCA provides women, men and practitioners with a space to identify and prioritize practical solutions to address care work collaboratively. The RCA has been used in development programmes in over 20 countries.

The HCS has two aims. First, it generates quantitative evidence for designing district-level programmes and evaluations of effectiveness and impact. Secondly, it produces evidence that is used for national-level policy advocacy. Since 2014, Oxfam has conducted three rounds of HCS data collection.

\section{Household Care Survey 2014}

In the first phase of the We-care project, the HCS was implemented in Colombia, Ethiopia, the Philippines, Uganda and Zimbabwe (June to December 2014). Before the HCS, a RCA was carried out and informed adjustments to the HCS questionnaire.

Between 80 and 500 households in selected communities in the five project countries were interviewed. These added up 


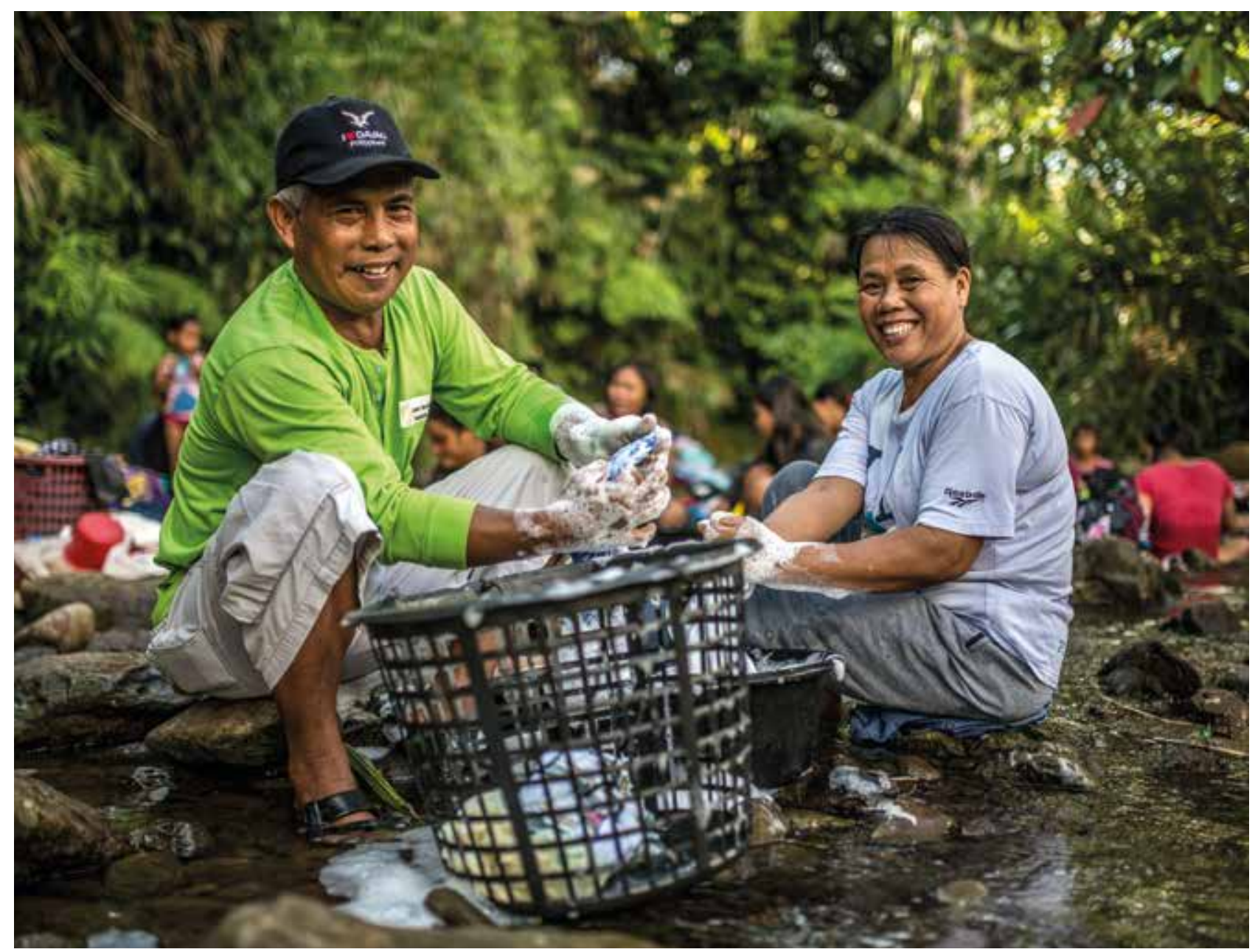

to 1,139 households, with one adult male and one adult female respondent in each household. Data was collected by local research consultants and in collaboration with partner organizations. The key findings are summarized below Iplease see Rost, Bates and Dellepiane 2015 for the full report).

- Women and girls spent significantly more time on care work than men and boys.?

- Women reported that if care work required fewer hours, 9\% to $43 \%$ would spend more time on income-generating activities, and 19\% to $51 \%$ would spend more time on leisure, personal care or religious activities.

- The data showed no consistent association between the amount of care work that women undertook and the following factors: education, relative household wealth, income and savings. This was counter to common assumptions about the process of women's empowerment. These findings indicated that social norms were an important explanatory factor to be explored further.

- Similarly, the data showed inconsistent results about the influence on care hours of access to time-saving equipment such as water taps and fuel-efficient stoves. For example, while fuel-efficient stoves were linked to lower care hours for women in the Philippines and Uganda samples, having an improved stove increased the time women in Zimbabwe spent on care work. This might be explained by women who cook more being more likely to invest in a better stove.

- However, having access to a government-provided/public water source decreased care work in Colombia, Ethiopia and Uganda.

- Women who undertook paid work spent somewhat less time on care as a primary activity but spent an equal amount of time on secondary care, resulting in a longer total work time than women who had less paid or productive work.

- In most countries, women with children aged under six spent more time on secondary care work and on supervision, but not on primary care work.

- Older women tended to have fewer care responsibilities; there was no effect of age for men.

The 2014 research helped Oxfam to develop strategies to address care work in the communities. In 2014-2016, local organizations supported by Oxfam implemented different interventions in the project areas in the five countries. Some interventions aimed to promote positive social norms about care and care roles (e.g. through workshops, community dialogue and training change agents). Other interventions helped households to reduce care work, for example through training on building fuel-efficient stoves or using other time-saving tools. National-level advocacy was also conducted in some of the countries. 


\section{Household Care Survey 2015}

In November/December 2015, a revised version of the HCS was implemented in the same communities as in 2014 . As a follow-up survey, the HCS monitored change and gathered more evidence on how to address care work in the specific contexts. Learning from the first round of data collection led to improvements in the survey instruments, especially on the topic of social norms and perceptions about care. For example, we added vignettes that describe couples with different divisions of labour and asked respondents for their opinion. We also asked people to rank care and paid work activities using activity cards. Since the measurement of children's time use did not provide clear results in the 2014 data collection, we asked women to estimate their children's time use.

In 2015, the country teams were able to interview the same households only in the Ethiopia and Zimbabwe samples, where $85 \%$ of households interviewed in 2014 were reinterviewed. Across the communities in the five countries, 1,123 households with husband and wife were interviewed. Some key findings from the 2015 research across all countries are summarized below (please see Karimli, Samman, Rost and Kidder 2016 for the full report).

-Women spent more time than men on care work and paid work combined.

- Girls (aged 0-17) spent more time than boys on care and education and less time on paid work and leisure.

- In households in which women or men valued care work more, the gender distribution of care work between women/ men and girls/boys was more equal.

- Women's autonomy in decision making was not linked to lower or more equal care burdens.

- In households with electricity, a dustbin or compost pit, women spent fewer hours on care lhaving electricity can facilitate different care activities, such as cooking, ironing or washing clothes. A designated space for rubbish, such as a compost pit or dustbin, can decrease time spent on tidying up and cleaning).

- In households with a water tap on the compound, girls spent fewer hours on care work in general and on water collection in particular.

- Across the five countries, $80 \%$ of women expressed the desire that their husbands would help with one or more care activities - but about $50 \%$ of women who wanted their husbands to help with care work had never asked for such assistance in the month before the interview. Those who had asked for help had received it, at least sometimes, in $90 \%$ of cases.

- There was no clear relationship between participation in the water- and energy-related projects and a redistribution of women's unpaid care hours to men.

- However, participation in Oxfam's norms-related projects was associated with positive views on sharing care tasks and men's relative autonomy in carrying out care, especially when husband and wife had both participated in the training sessions.
Household Care Survey 2017

From April to July 2017, a newly revised HCS was conducted in new communities in the Philippines, Uganda and Zimbabwe. In Uganda, the aim of this round of data collection was to gather evidence for national-level influencing. In the Philippines and Zimbabwe, the 2017 data serves as a baseline for the implementation of an expanded WE-Care programme that integrates access to water infrastructure, time- and laboursaving equipment, and challenging gendered social norms to address heavy and unequal care work.

The 2017 HCS questionnaire was adjusted based on the 2015 survey and to include an expanded section on WASH and access to public services. New questions on water-related infrastructure and water use were added for these countries, such as use of different water sources for distinct waterrelated activities (e.g. laundry) and questions on waterrelated illnesses.

The 2017 HCS directly interviewed children and young people laged 8 to 21) about their time use. ${ }^{8}$ A short questionnaire on young people's time use was administered with two young people for each household, usually the oldest boy and girl, unmarried. The questionnaire was based on 'Young Lives' research by the University of Oxford (Young Lives 2017) and used beans and activity cards to help young people report their time use. Additional training was provided to enumerators on how to conduct the survey with this age group and on ethical considerations when collecting data from children.

Previous qualitative research pointed to seasonal dimensions of care work. The scope of the survey made it impossible to follow the same households throughout the year, but in the 2017 survey some questions were included to ask what time of the year care work and paid work were most difficult.

The questions on social norms were revised to better account for community influence. Based on Cristina Bicchieri's framework of measuring social norms, ${ }^{9}$ we added questions about respondents' expectations of community behaviour l'Out of 5 men in your village we interviewed, how many do you think said that they spent at least an hour on caring for people and domestic work yesterday?'), their personal normative beliefs ('Do you think men in your village should do caring for people and domestic work?') and their expectations of other people's beliefs l'Out of 5 women/men in your village we interviewed, how many do you think said that men should do caring for people and domestic work?'). Some 'why' questions were also added to find out the reasons for care allocations, for example, 'Why would you not like to participate more in [CARE TASK]?'.

The data from the 2017 HCS will inform the baseline for the programme in the Philippines and Zimbabwe, and WE-Care will continue documenting the extent and division of care work in households, changes over time, and perceptions about care and care roles to feed into programming, communication and influencing strategies at all levels. 


\section{CONCEPTUAL FRAMEWORK}

.

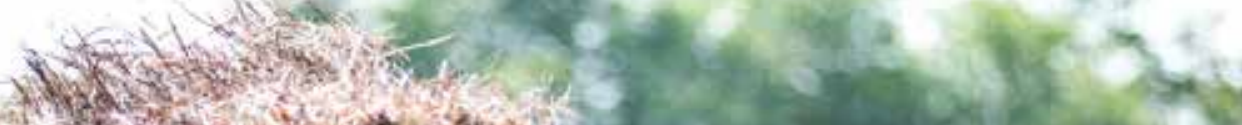

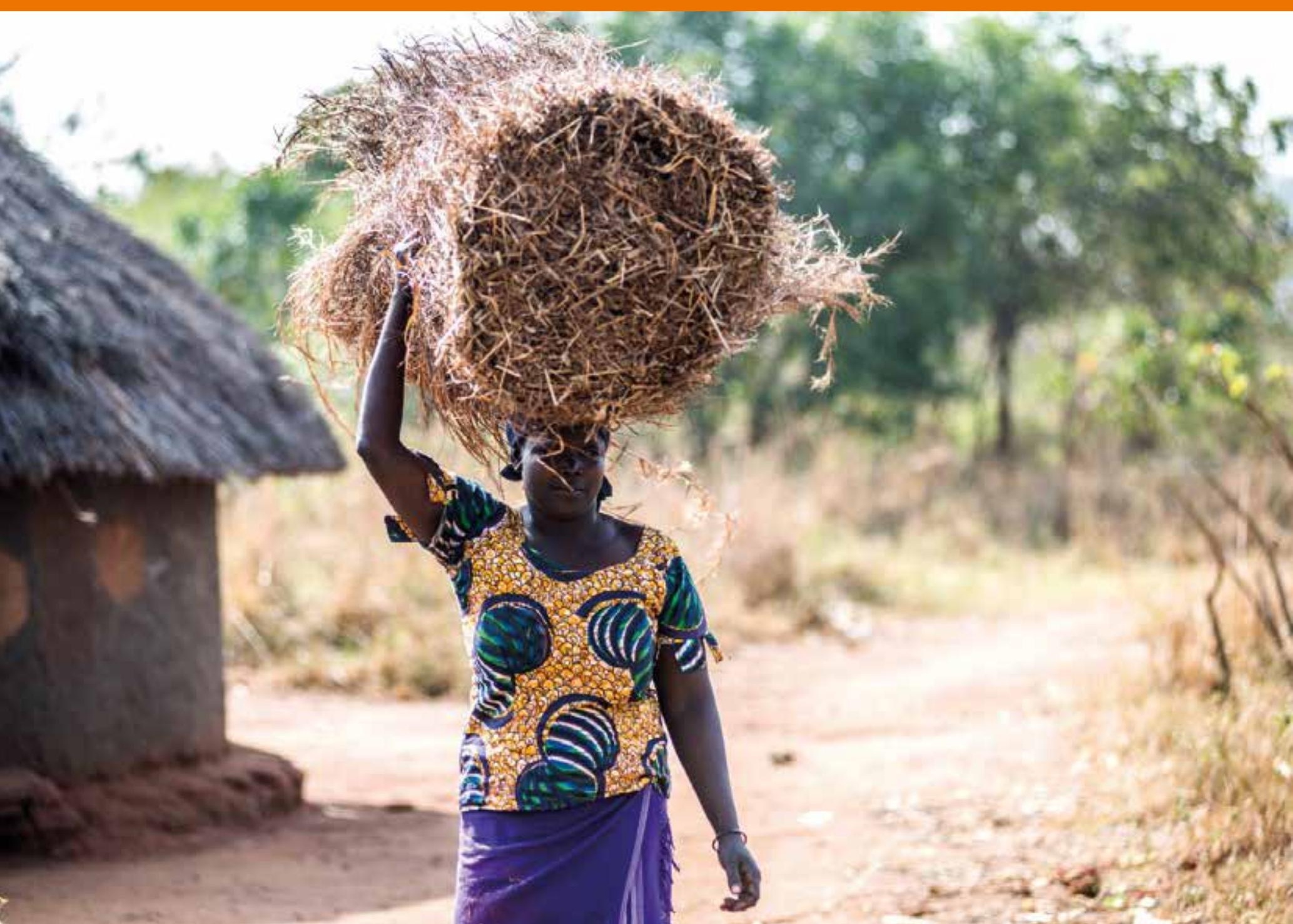


This report focuses on the analysis of the 2017 HCS. Based on the previous Household Care Surveys and related research, this analysis examines eight propositions or hypotheses about possible factors influencing change related to unpaid care work. The propositions are explored using multivariate regression analysis that allows us to look at correlations between different factors.

In this report, we are not yet looking at change over time. The statistically significant associations that we find do not tell us about causality or the direction of causality.

PROPOSITION 1: Improvement in women's status is associated with a more equal distribution of care hours between women and men and with household investments in time-saving technologies and paid care services

It is often believed that if women's position in the household improves - for example, if women have more assets or education - they can bargain for outcomes that are more beneficial for them, such as a more equal distribution of care work. This approach is based on cooperative collective bargaining models that hold that household members reach decisions based on their relative bargaining power (Doss 2011). Following this way of reasoning, we assume that an improvement in women's status could lead to a redistribution of unpaid care tasks from women to men, and to investment in technology that reduces time spent on unpaid care work.

PROPOSITION 2: Recognition of unpaid care work is associated with a more equal distribution of care hours between women and men, and with investments in timesaving technologies and paid care services

Care and domestic activities are often not recognized as work, not perceived as valuable in comparison with productive activities, and are perceived as unskilled. Rather than being understood as labour, care work may be perceived as leisure or offering intrinsic rewards (England and Folbre 1999) and is often less recognized and less monetarily and physically visible than men's work (England 2005). We assume that if unpaid care and domestic work is recognized as valuable and skilled, and if there is awareness of the problematic dimensions of certain ways of providing care, men and boys will undertake more care work, and the household will invest in time- and labour-saving equipment or paid care services. But it might also be the case that men who do more care work perceive care work as more valuable and skilled, and see the problematic dimensions of it.

PROPOSITION 3: Recognition of unpaid care work and redistribution of unpaid care work between women and men is associated with an improvement in the intergenerational redistribution of unpaid care and domestic work It is well recognized that parents influence their children through the transmission of values and perceptions, as well as the experience of certain activities and exposure to behaviours and attitudes. Research has shown that norms and perceptions are passed on from parents to children - for example, childhood exposure to family violence is associated with reported spousal violence or acceptance of genderbased violence (Flake 2005). We assume that parents' divisions of care work and perceptions related to unpaid care and domestic work affect children's engagement in care work.

PROPOSITION 4: Recognition of unpaid care work and more equal distribution of unpaid care work between women and men could lead to improvement in schooling chances and free time for young people, especially for girls Child labour, including household chores, can reduce children's chances to attend school and increase school dropout (Koissy-Kpein 2012) and decrease school performance (Rosati and Rossi 2001). According to some studies, the negative impact of child participation in labour activities on school outcomes is more detrimental for girls than for boys (Ray and Lancaster 2005). Research from the International Men and Gender Equality Survey (IMAGES) suggests that boys who experience a positive caregiving influence from men in the household are more likely to have gender-equitable attitudes, more likely to participate in care work, and less likely to use violence against a female partner later in life (Barker, 2011). We assume that an equal distribution and recognition of unpaid care and domestic work positively affects children's time devoted to schooling, studying at home, or 'doing nothing' and leisure. We suppose that the positive effect will be more significant for girls than boys. ${ }^{10}$

PROPOSITION 5: Access to time- and labour-saving technology and paid care-work services ease time constraints for women and girls

Time- and labour-saving equipment - such as fuel-efficient stoves, food-processing equipment, rainwater-harvesting systems, washing facilities and cleaning equipment - can reduce care workloads. For example, grinding a basin of cassava with a machine takes one minute, compared to two hours by hand (Barwell 1996). We assume that when households have access to time- and labour-saving equipment, the number of hours spent on some unpaid care activities decreases. But the time gained from time- and labour-saving equipment might also be devoted to other care tasks, without any changes in the overall time spent on unpaid care and domestic work. The time saved could also lead to an increase in paid care work or other incomegenerating activities, leisure or doing nothing for women, and an increase in schooling, studying at home, leisure or doing nothing for girls. 
PROPOSITION 6A: Provision of public services and infrastructure improves women's participation in incomegenerating activities and leisure, increases girls' hours spent on schooling and leisure, and increases men's participation in unpaid care work

The provision of public services and infrastructure, such as nearby water sources, quality healthcare services and roads, can have a positive effect on reducing women's workloads. For example, Koolwal and Van de Walle (2013) show that investment in rural water infrastructure can enhance women's participation in market-based activities and also improve girls' schooling. Oxfam's qualitative research found that men are more likely to use water taps on the compound than public water pumps. Health services that encourage men to participate in child health can also positively affect men's involvement in care. We assume that the provision of public services and infrastructure, especially related to water, increases women's time spent on income-generating activities and leisure, and girls' hours spent on schooling and leisure. We also assume that certain designs of infrastructure and services can influence men to participate in unpaid care and domestic work.

PROPOSITION 6B (Philippines and Zimbabwe): Access to improved water sources and water-collection equipment decreases the time women and girls spend on unpaid care work, and increases men's participation in unpaid care work Women and girls represent $70-80 \%$ of the individuals responsible for collecting water in developing countries (Koolwal and Van de Walle 2013). Oxfam's qualitative research found that men will engage in water collection when they have access to certain types of equipment. Some men said they will use bicycles or wheelbarrows to carry water, but will not carry it on their head. We assume that improved access to water and to water-collection equipment leads to a reduction in time spent on unpaid care and domestic work by women and girls and increases men's participation in it.
PROPOSITION 7: Changing social norms and gender stereotypes favours the redistribution of unpaid care work between females and males

The distribution of care work is rooted in social norms that determine the roles and responsibilities of males and females. People tend to adjust their behaviour to what is perceived as acceptable or 'normal' by their community or other reference groups. Social norms are often maintained through sanctions for non-compliance and rewards for compliance. The use of gender-based violence is an example of a sanction for non-compliance with social norms. We assume that a change in social norms about gender roles and responsibilities can lead to a positive change in the redistribution of unpaid care and domestic work from females to males within families.

PROPOSITION 8: A redistribution of unpaid care work between women and men is associated with improvements in the overall wellbeing of women and men and their families Long care hours can have negative implications for women's health and wellbeing and can affect their time available for paid work, education and participation in development activities (Woodroffe and Donald 2014). Long hours required for domestic tasks can also reduce hours available for direct care of children and dependent adults (Samman et al. 2016). Men's participation in some care activities can result in better household relationships and can positively affect men's wellbeing. Hence, a redistribution of care work between women and men can offer society opportunities to provide benefits to women, children and men themselves. We assume that if the division of care tasks is more equal between husband and wife, women's and men's overall wellbeing improve. 


\section{FINDINGS}

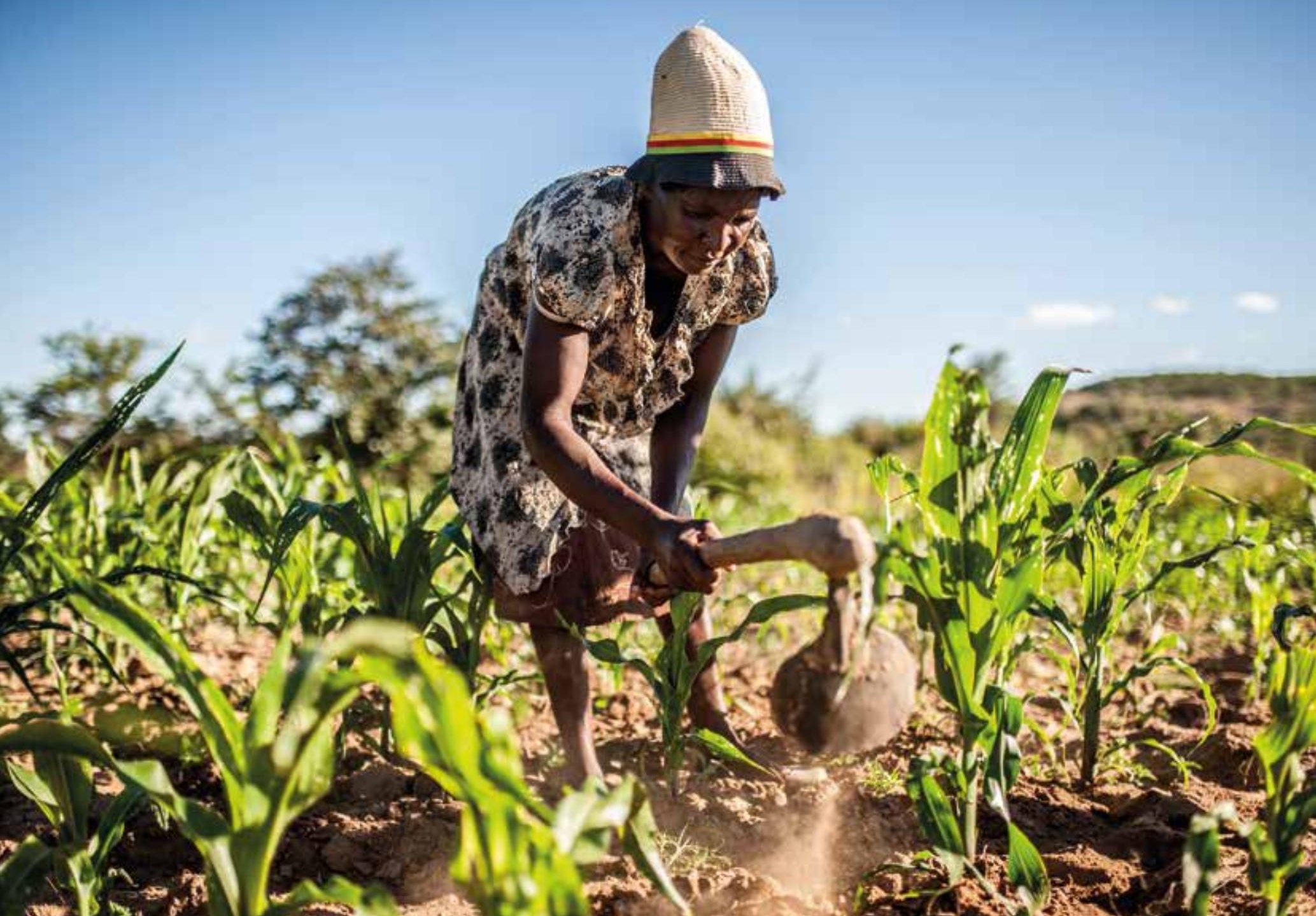


This section outlines the results of the 2017 HCS data analysis. The first part presents a short overview of the sample. The second and third parts describe time use of adults and young people. We then move on to testing the propositions outlined in the previous section, looking at whether infrastructure, time- and labour-saving equipment and other factors influence the allocation of care work. The last part of this section looks at women's wellbeing and time constraints related to care work. Some key tables and graphs are presented in this section, but for more details on the data, including regression analysis results, please see the Appendix.

\section{OVERVIEW OF THE SAMPLE}

The HCS used random sampling to select households to be surveyed in selected districts in the Philippines, Uganda and Zimbabwe. Coordinated by Oxfam country teams and with support from local partners, local enumerators collected the data between April and July 2017. A total of 4,734 respondents were interviewed in the 2017 HCS: 541 in the Philippines, 3,114 in Uganda and 1,079 in Zimbabwe. Table 1 shows how many women, men, girls and boys were interviewed in each country.

\section{TABLE 1: DISTRIBUTION OF RESPONDENTS BY GENDER AND COUNTRY}

\begin{tabular}{|l|l|l|l|l|l|}
\hline & Women & Men & Girls & Boys & Total \\
\hline Philippines & 204 & 209 & 63 & 65 & 541 \\
\hline Uganda & 1,076 & 826 & 636 & 576 & 3,114 \\
\hline Zimbabwe & 408 & 332 & 174 & 165 & 1,079 \\
\hline Total & 1,688 & 1,367 & 873 & 806 & 4,734 \\
\hline
\end{tabular}

Husbands and wives were interviewed in most households. In total, respondents from 1,688 households were surveyed: 204 in the Philippines, 1,076 in Uganda and 408 in Zimbabwe.

The overall demographic characteristics of the respondents are presented below:

- Age: The average age of the women interviewed was 43 in the Philippines, 39 in Uganda and 44 in Zimbabwe. The average age for men was 46 in the Philippines, 44 in Uganda and 51 in Zimbabwe. On average, young people interviewed in the Philippines and Uganda were 13, and 14 in Zimbabwe.

- Household size: The average household consisted of five members in the Philippines, six members in Uganda and five members in Zimbabwe, with minor differences among districts in all the countries.

- Children under six: $52 \%$ of the households in the Philippines, $66 \%$ of the households in Uganda and $59 \%$ of the households in Zimbabwe had at least one child under the age of six living in the household.

- Household members of working age: Across countries, on average, the households had three members of the workingage population (age 15-65) living in the household, with minor differences between districts.

- Marital status: The majority of men and women interviewed were married (in a monogamous or polygamous union); $94 \%$ of women and men interviewed in the Philippines, $79 \%$ of women and $92 \%$ of men interviewed in Uganda, and $82 \%$ of women and $98 \%$ of men interviewed in Zimbabwe were married.

\section{ADULTS' TIME USE}

The methodology used to collect information on adults' time use was the same as in previous Household Care Surveys (Rost, Bates and Dellepiane 2015; Karimli, Samman, Rost and Kidder 2016). Time use was measured with a one-day recall exercise asking respondents to report what they did during each hour of the previous day, starting from $4 a m$. Enumerators noted the relevant activity using pre-determined codes. Since care activities are often carried out at the same time as other activities, they are often omitted when only primary activities are recorded. For this reason, the HCS accounts for secondary activities as well as the supervision of children and dependent adults. For each hour of the day, respondents were asked the following four questions:

- Primary activity: What were you doing yesterday from [TIME]?

- Secondary activity: What else were you doing at the same time? - Supervising children: Were you responsible for looking after a child ( $<18$ years) during that hour?

- Supervising adults: Were you responsible for looking after a dependent adult during that hour?

Based on the answers to these questions, the following time-use indicators were constructed:

- Primary care: the number of hours respondents spent on care work as a primary activity.

- Primary or secondary care: the number of hours respondents spent on care work as either a primary or a secondary activity. 
- Any care: the number of hours respondents spent on care work as either a primary or a secondary or a supervision activity.

- Multi-tasking care: the number of hours respondents spent on doing at least two care activities at the same time (primary, secondary or supervision).

- Ratio of primary care: men's primary care hours divided by women's primary care hours (i.e. a ratio below 1 indicates that men spent fewer hours than women did, and vice versal.

- Ratio of any care: men's any care hours divided by women's any care hours (i.e. a ratio below 1 indicates that men spent fewer hours than women did, and vice versal.

Unequal distribution of unpaid care work was registered in samples from all three countries. Across the study communities, we find that women spent three to six time more hours than men on care work as a primary activity and two to four times as many hours on care any responsibilities. This emphasizes the importance of research on making this gap visible and calls for action from governments, the private sector and civic leaders in different areas to address unequal care work through policies and investments.

\section{CARE WORK}

In line with the findings from the previous HCS reports (Rost, Bates and Dellepiane 2015; Karimli, Samman, Rost and Kidder 2016), the 2017 data shows that women spent more time on all care work indicators than men. Figure 1 summarizes the number of hours women and men spent on primary care, primary or secondary care, any care and multi-tasking care. It is remarkable that women spent about 11 to 12 hours a day being involved in any care responsibility in all countries, and between 4 and 6 hours on care as their primary activity. Across the study communities, women spent about 4 to 6 hours on multi-tasking care, i.e. doing at least two care activities at the same time. This indicates the complexity and intensity of care work. That care tasks are carried out simultaneously suggests that providing equipment or services for any single task (e.g. stoves for cooking) cannot be expected to reduce the overall hours that women spend on care. Reduction, therefore, requires incentives for redistribution of tasks within the household.

More than half of the men in Uganda (74\%) and Zimbabwe $(66 \%)$ were not engaged in any primary care activity the day before the interview. In the Philippines sample, only 19\% of the men recorded zero hours on care as a primary activity. Only $1.5 \%$ of the women interviewed in the Philippines, $7 \%$ of the surveyed women in Uganda and $8 \%$ of the women in Zimbabwe were not engaged in primary care work. A smaller but still significant number of men reported zero hours for any care: $9 \%$ in the Philippines, 52\% in Uganda and 49\% in Zimbabwe.

The data highlights the importance of accounting for simultaneous activities. Care-work time for women increases by 24\% (Philippines), 31\% (Uganda) and 25\% (Zimbabwe) when we account for care work performed as secondary or primary activity, rather than just looking at primary care work. This increase is even more drastic when we account for primary, secondary or supervision care: in this case, care work increases by $85 \%$ for women in the Philippines, by $138 \%$ for women in Uganda and by $133 \%$ for women in Zimbabwe. In

\section{FIGURE 1: PROPORTION OF TIME SPENT BY ADULT WOMEN AND MEN ON PRIMARY CARE, PRIMARY OR SECONDARY CARE, ANY CARE AND MULTI-TASKING CARE, 2017}

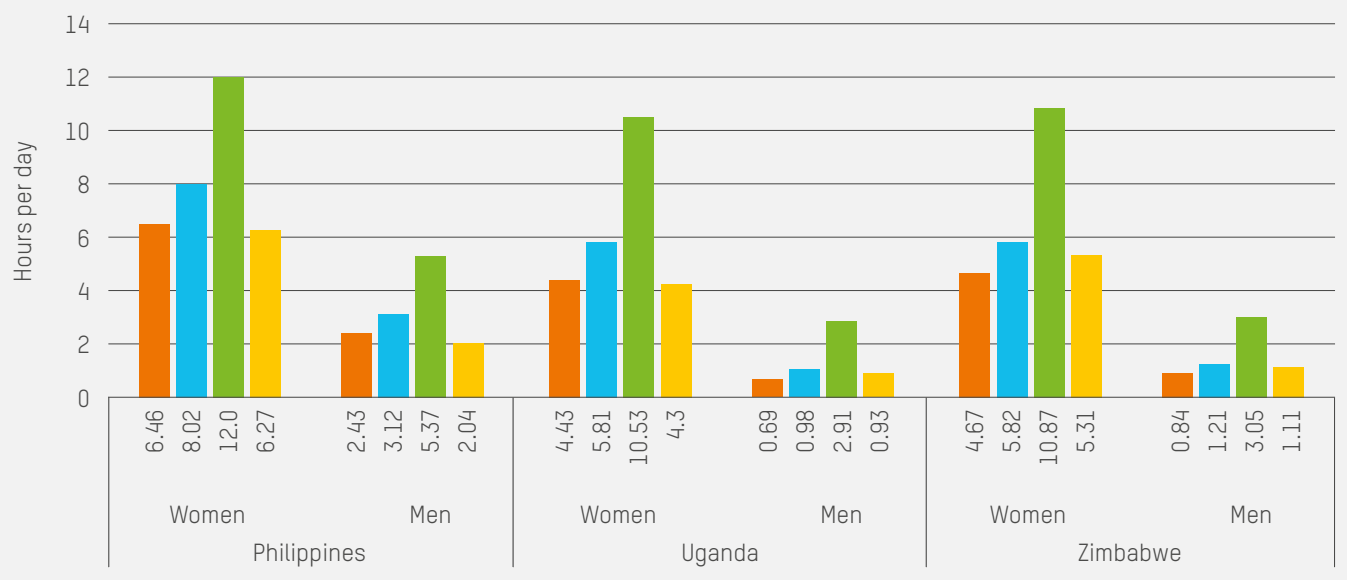


other words, women report twice as many hours of care work when we include secondary and supervision care compared to only looking at primary care work. Interestingly, the observed increase when accounting for secondary and supervision activities is higher for men compared to women. Accounting for secondary and supervision care activities increases men's time spent on care work by $121 \%$ in the Philippines, by $327 \%$ in Uganda and by $263 \%$ in the Zimbabwean sample.

This is confirmed by the finding that the ratio of time women spent on care activities relative to men's care hours decreases when we account for the amount of time spent on secondary care and supervision of dependants compared to only looking at primary care. But it is important to reemphasize that, no matter how significant this increase is, it is still not enough to close the gap in time spent on care work between women and men: men still spent less than half of the time women spent on any care responsibility.
Table 2 shows the women-to-men ratios for primary and any care. We can see that women spent between about three to six times more time than men on primary care and about two to four times more on any care.

Looking at what primary care tasks women and men spent their time on (Table 3), we find that women devoted significantly more hours than men to all care tasks, except for water collection and adult care in the Philippines, adult care in Uganda, shopping in Zimbabwe and community care in all countries. In all country samples, women spent most time on meal preparation (about 3 to 4 hours a day), followed by childcare ( 1 to 2 hours). Of the tasks that men participated in, meal preparation was the task they reported spending most time on in the Philippines and Zimbabwe. Men from the Ugandan sample spent most time on childcare.

TABLE 2: RATIO OF TIME SPENT BY ADULT WOMEN RELATIVE TO TIME SPENT BY ADULT MEN ON PRIMARY AND ANY CARE IN SAMPLES FROM THREE COUNTRIES, 2017

\begin{tabular}{|l|l|l|l|}
\hline \multirow{2}{*}{} & Philippines & Uganda & Zimbabwe \\
\cline { 2 - 4 } & Mean & Mean & Mean \\
\hline Ratio primary care (men to women) & 2.66 & 6.42 & 5.56 \\
\hline Ratio any care (men to women) & 2.23 & 3.62 & 3.56 \\
\hline Observations & 203 & 1,035 & 395 \\
\hline
\end{tabular}

TABLE 3: HOURS SPENT ON DIFFERENT CARE ACTIVITIES BY ADULT WOMEN AND MEN IN SAMPLES FROM THREE COUNTRIES, 2017

\begin{tabular}{|l|l|l|l|l|l|l|}
\hline \multirow{2}{*}{} & \multicolumn{2}{l|}{ Philippines } & \multicolumn{2}{l|}{ Uganda } & \multicolumn{2}{l|}{ Zimbabwe } \\
\cline { 2 - 7 } & Women & Men & Women & Men & Women & Men \\
\hline Water collection & 0.39 & 0.43 & 0.36 & 0.05 & 0.45 & 0.1 \\
\hline Fuel collection & 0.06 & 0.29 & 0.31 & 0.05 & 0.3 & 0.11 \\
\hline Meal preparation & 2.95 & 1.27 & 2.46 & 0.15 & 1.87 & 0.21 \\
\hline Cleaning & 0.77 & 0.1 & 0.48 & 0.09 & 0.94 & 0.13 \\
\hline Preparing clothes & 1.15 & 0.06 & 0.33 & 0.09 & 0.63 & 0.07 \\
\hline Childcare & 1.06 & 0.26 & 0.31 & 0.21 & 0.41 & 0.13 \\
\hline Adult care & 0 & 0 & 0.01 & 0.01 & 0.01 & 0.02 \\
\hline Community care & 0.08 & 0.01 & 0.01 & 0.01 & 0.07 & 0.01 \\
\hline Shopping & 0.09 & 0.01 & 0.15 & 0.03 & 0.1 & 0.08 \\
\hline
\end{tabular}

\section{WATER COLLECTION FOR LAUNDRY}

The HCS 2017 for Zimbabwe and the Philippines paid particular attention to time spent on water-related tasks. In the Philippines and Zimbabwe, $87 \%$ and $76 \%$ of women interviewed said that they did laundry at home, respectively. For the Philippines, women reported an average of 6 minutes and for Zimbabwe 13 minutes to walk from the house to the water source used for laundry, collect the water and bring it home or to the laundry point. To collect water for a single load of laundry, women in the selected communities in the Philippines needed to make five trips and women in the
Zimbabwean sample four trips. This means that, on average, water collection for one load of laundry took 43 minutes for the Philippines and 44 minutes for Zimbabwe. On average, women did laundry three times a week in both countries. This means that per week, women spent 2 hours 7 minutes in the Philippines and 1 hour 57 minutes in Zimbabwe on water collection for laundry. Women used mainly 20 -litre buckets or 20-litre plastic containers (78\% Philippines, 89\% Zimbabwe) to collect water for laundry. Only $14 \%$ in the Philippines and $10 \%$ in Zimbabwe said that they did laundry directly in the 
water source. Qualitative research in the Philippines found that water collection for laundry took even longer than 2 hours a week.

\section{PAID/PRODUCTIVE WORK AND NON-WORK}

Across the study communities, men spent significantly more hours than women on paid and productive work as a primary activity. In the surveyed communities in the Philippines, men spent on average 7 hours 41 minutes on paid/productive work, compared to 2 hours 23 minutes spent on paid/productive work by women. In the study areas in Uganda, men spent 6 hours 56 minutes on paid/productive work, and women 4 hours 9 minutes. In Zimbabwe, men spent 6 hours 10 minutes and women 3 hours 43 minutes on paid/productive work.

Although in the sampled areas in Uganda and Zimbabwe men spent more time than women on paid work, they spent significantly more hours than women on non-work lincluding doing nothing, sleeping, personal care and leisure). In Uganda, men spent 15 hours 23 minutes on non-work and women 14 hours 35 minutes; while in Zimbabwe, men spent 15 hours 41 minutes and women 13 hours 51 minutes on non-work. In the Philippines, women spent more time ( 14 hours 14 minutes) on non-work than men (13 hours 16 minutes).

\section{Total work}

When we consider the total hours of work (care and paid work as a primary activityl, women in the Uganda and Zimbabwe samples spent significantly more hours on total work ( 8 hours 35 minutes in Uganda and 8 hours 23 minutes in Zimbabwe) compared to men (7 hours 38 minutes in Uganda and 7 hours in Zimbabwe). However, women in the Philippines spent less time on total work (8 hours 50 minutes) compared to men (10 hours 7 minutes).

Figure 2 shows the mean number of hours that women and men in the study areas of the three countries spent on paid work, non-work and total work the day before the interview.

\section{FIGURE 2: MEAN HOURS OF PAID WORK, NON-WORK AND TOTAL WORK BY ADULT WOMEN AND MEN IN SAMPLES FROM THREE COUNTRIES, 2017}

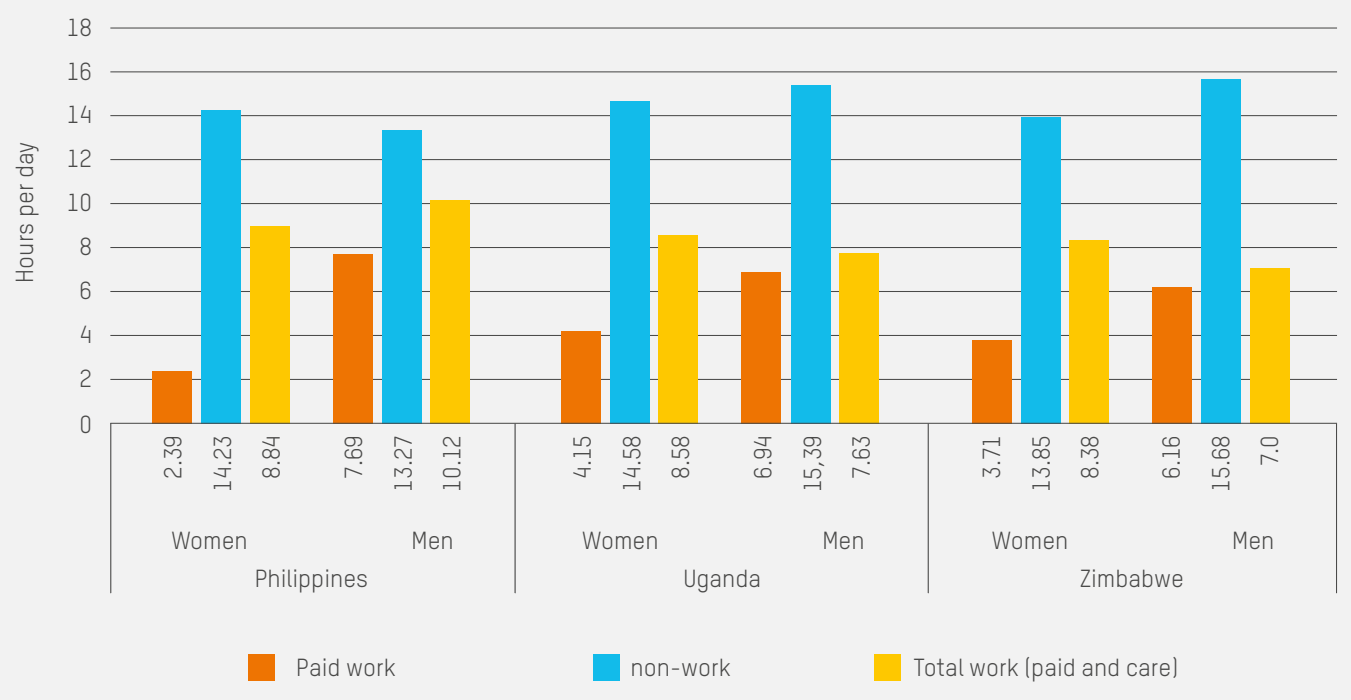

In two study countries, women spent about 2 hours a day more than men on total work. And as the previous section has shown, women also spent many more hours than men on simultaneous supervision. This finding reiterates the importance of addressing unpaid care work as a women's wellbeing issue, as it evidences the intensity of care work carried out by women in the communities sampled. This heavy workload also leaves women with little time for participation in other types of non-work activities (such as education, training, development programmes, leisure, rest), which can affect future opportunities for personal and economic development.

Overall, the findings confirm previous Oxfam and other research showing that women spend significantly more time than men on care work, about five to six times more on primary care. The finding that women often carry out two care activities at the same time suggests that standalone interventions that reduce only one type of care work (e.g. a better stove or childcare services) might reduce multi-tasking care hours, without changing the total number of daily hours women spend on care. 


\section{YOUNG PEOPLE'S TIME USE}

Unlike previous Household Care Surveys, the 2017 HCS interviewed one or two young people per household. The oldest boy and oldest girl between 8 and 21 years old in the household were invited to participate. They were asked to divide 24 beans - representing 24 hours of the previous day - among different activities illustrated by symbols on laminated cards. The activity categories included sleep, work for family business (including agricultural work), paid work, school, studying, meal preparation, fuel collection, water collection, cleaning the house or compound, washing clothes, caring for younger children, caring for adults, leisure and other. Table 4 summarizes the hours boys and girls from different age groups spent on different activities.
Across genders and age groups, young people in the Ugandan and Zimbabwean sample spent a strikingly large number of hours on total work: between 8 and 11 hours for Uganda and between 5 and 10 hours in Zimbabwe. Care work takes up a large proportion of these hours, especially for girls aged 13 to 17 in the Ugandan sample, who spent on average 8 hours a day on care work.

It is especially striking that girls in all countries and of all age groups spent more time than boys on care and total work. An elevated number of hours on total work for this age range can have implications for schooling, training, play and other activities that are beneficial for girls' development, and can reinforce gender inequalities later on in life.

Gender inequalities in care work start early in life and should be tackled at this early stage. Addressing heavy care work of children is essential for their personal development and to reduce gender inequalities.

TABLE 4: HOURS SPENT ON DIFFERENT ACTIVITIES (CARE WORK, PAID WORK, EDUCATION, AND LEISURE AND SLEEP) BY GIRLS AND BOYS (AGED 8 TO 21) IN SAMPLES FROM THREE COUNTRIES, 2017

\begin{tabular}{|c|c|c|c|c|c|c|}
\hline & \multicolumn{2}{|c|}{ Philippines } & \multicolumn{2}{|c|}{ Uganda } & \multicolumn{2}{|c|}{ Zimbabwe } \\
\hline & Girls & Boys & Girls & Boys & Girls & Boys \\
\hline \multicolumn{7}{|l|}{ Ages 8 to 12} \\
\hline Care work & 2.52 & 2.42 & 7.54 & 5.08 & 5.23 & 3.57 \\
\hline Paid/productive work & 0.22 & 0 & 1.62 & 2.88 & 0.4 & 1 \\
\hline Education & 9.61 & 9.15 & 0.94 & 1.01 & 4.34 & 4.4 \\
\hline Leisure and sleep & 11.17 & 11.46 & 13.55 & 14.8 & 13.86 & 14.24 \\
\hline Total work hours (care work and paid/productive work) & 2.74 & 2.42 & 9.16 & 7.96 & 5.63 & 4.57 \\
\hline \multicolumn{7}{|l|}{ Ages 13 to 17} \\
\hline Care work & 4.77 & 3.73 & 7.69 & 4.84 & 6.25 & 5.26 \\
\hline Paid/productive work & 0.09 & 0.59 & 2.42 & 4.34 & 0.96 & 1.48 \\
\hline Education & 9.09 & 8.64 & 1.12 & 1.12 & 4.36 & 4.38 \\
\hline Leisure and sleep & 8.77 & 9.23 & 12.48 & 13.39 & 12.22 & 11.96 \\
\hline Total work hours (care work and paid/productive work) & 4.86 & 4.32 & 10.11 & 9.18 & 7.21 & 6.74 \\
\hline \multicolumn{7}{|l|}{ Ages 18 to 21} \\
\hline Care work & 9.2 & 6.33 & 7.47 & 4.45 & 7.54 & 5.52 \\
\hline Paid/productive work & 1.6 & 3 & 3.47 & 5.32 & 2.51 & 3.39 \\
\hline Education & 1.8 & 3.67 & 0.66 & 1.11 & 2.68 & 1.67 \\
\hline Leisure and sleep & 11.2 & 9.5 & 11.97 & 12.83 & 10.78 & 12.48 \\
\hline Total work hours (care work and paid/productive work) & 10.8 & 9.33 & 10.94 & 9.77 & 10.05 & 8.91 \\
\hline \multicolumn{7}{|l|}{ Ages 8 to 21} \\
\hline Care work & 4.18 & 3.39 & 7.59 & 4.88 & 6.14 & 4.74 \\
\hline Paid/productive work & 0.3 & 0.57 & 2.23 & 3.87 & 1.08 & 1.94 \\
\hline Education & 8.6 & 8.33 & 0.96 & 1.07 & 3.99 & 3.48 \\
\hline Leisure and sleep & 10.12 & 10.33 & 12.88 & 13.91 & 12.53 & 12.95 \\
\hline Total work hours (care work and paid/productive work) & 4.48 & 3.96 & 9.82 & 8.75 & 7.22 & 6.69 \\
\hline
\end{tabular}




\section{AGES 8 TO 12 YEARS}

Looking at children aged 8 to 12 , we find that in the study communities in Uganda and Zimbabwe, girls spent significantly more time than boys on care work: about 7 and 5 hours a day for girls, and 5 and 4 hours for boys in Uganda and Zimbabwe, respectively. Similarly to adults, boys in the Uganda and Zimbabwe samples spent more time on paid work/work for the family business compared to girls. But girls spent more time than boys on total work. In Uganda, girls aged 8 to 12 spent as much as 9 hours and boys about 8 hours a day on paid and care work. In the study areas in Zimbabwe, girls spent 6 hours and boys 5 hours a day on total work. In Uganda, girls also spent less time on leisure than boys of the same age group. In the Philippines, both boys and girls aged 8 to 12 spent about 2.5 hours a day on care work and almost no time on paid work. There are no visible gender differences in the distribution of care work for this age group in the Philippines sample.

\section{AGES 13 TO 17 YEARS}

The same gender differences as for 8- to 12-year-olds can be observed for adolescents aged 13 to 17 in Uganda. Girls spent more time on care work (about 8 hours) than boys (about 5 hours), while boys spent more time than girls on paid work. Boys also spent more time on leisure and sleep, and in total girls spent more hours a day working than boys did. In the Zimbabwean sample, girls aged 13 to 17 spent slightly more time than boys on care work. But there are no other gender differences for this age group. There are no visible gender differences in the distribution of care work in the Philippines data, where girls spent about 5 hours and boys about 4 hours on care.

\section{AGES 18 TO 21 YEARS}

Similarly to the other age groups, in the selected communities in all study countries, girls aged 18 to 21 spent about 2 to 3 hours a day more than boys on care work.

\section{COMPARING AGE GROUPS}

The amount of care work undertaken and gender differences in care work increase with age in the Philippines data. In the Ugandan sample, girls of all age groups did about the same amount of care work, while for boys care work decreases with age. In the study communities in Zimbabwe, care work increases with age for both boys and girls, but it is the most gender equal for children aged 13 to 17 . These findings suggest that even though girls tend to do more care work, how care work is distributed between boys and girls is context and age specific.

\section{ADULTS' CARE WORK AND YOUNG PEOPLE'S TIME USE}

In line with proposition 3 and 4, we tested whether the division of unpaid care work between women and men is associated with boys' and girls' hours spent on care, paid work, education and leisure/sleep. In Zimbabwe and Uganda, children of parents who spent more time on care tended to work more. For Zimbabwe, we find that boys tended to do more care work if their fathers did more care work, about half an hour more for each hour's increase in men's care work. In Uganda, boys' care work is positively associated with mothers' care. Boys and girls in the Ugandan communities and boys in the Zimbabwean sample tended to spend less time on non-work if their mothers and fathers spent more time on care. In the Philippines, women's and men's time use is not associated with boys' and girls' time use.

\section{FACTORS INFLUENCING CARE WORK}

Oxfam believes that a combination of factors/initiatives are required for significant changes in the level and distribution of care hours in families. WE-Care affirms that it is not only important to promote redistribution of care work within the household, for example shift long hours of domestic work from women to men, but that investments by governments and private sector companies in accessible and affordable services and equipment are crucial for reducing heavy care work for women. Based on the propositions outlined in section 3, we performed multiple linear regression analyses, using the statistical software Stata, ${ }^{11}$ to help us understand what factors are associated with care-work distributions between women, men, girls and boys.

When looking at the relationship of time use and potential determinants (e.g. access to water-related infrastructure, women's decision-making power in the household), we always controlled for the following factors: age, education, proportion of females in the household, number of household members, whether the household has at least one child under six years old, household wealth (quintiles for middle, better-off and best-off households) and the location.

As mentioned previously, this report is not yet looking at change over time. The statistically significant associations that we find do not tell us about causality or the direction of causality. Rather, they paint a picture of patterns of care work and different factors (named above) contributing to these patterns. The same analysis was carried out separately for the three countries.

In this section, we report on the significant findings only; if we do not mention the findings for a particular country sample, it means that we did not find a significant association for this sample. The regression tables with more details on the specific models as well as detailed descriptive statistics can be found in the Appendix. 


\section{HOUSEHOLD/PERSONAL CHARACTERISTICS}

Before moving on to look at associations between time- and labour-saving equipment and infrastructure and care work in particular, we explore associations between householdlevel/personal characteristics and care-work hours of adults and young people.

We find that household characteristics influence care-work allocations: having young children and being married increases care work for women, while age decreases it. Men and boys from better-off households spent less time on care.

Consistent with Oxfam's Household Care Surveys conducted in 2014 and 2015, women's patterns of time use are less consistently influenced by individuals' personal characteristics, such as education, and more associated with household-level traits.

\section{Marital status}

In Uganda and Zimbabwe, being married is associated with greater inequality in primary care hours. In the selected communities in Uganda, there is an association between being married and women spending more hours labout 32 minutes morel and men fewer hours labout 1 hour 16 minutes less) on primary care. For Zimbabwe, we find that married men spent less time on primary care. Potentially, marriage reinforces a gender-stereotypical division of labour. In the Philippines, however, married men tended to spend more time on primary care.

\section{Education}

Having received more education is associated with women spending more time on any care in the Philippines study area, and more time on primary and any care in the communities in Uganda. Potentially, women learn values at school that encourage them to provide better care, for example teaching their children certain skills. Education is also associated with men in the Ugandan communities spending slightly more time on primary care.

\section{Age}

In all countries, as age of adults increases, care hours tend to decrease for women. For men, we only find a significant association between age and care work in the Zimbabwean sample, where being older is associated with less primary care work for men.

For both girls and boys interviewed in the Philippines and Zimbabwe, care work seems to be increasing and education hours decreasing as they grow older. Boys and girls surveyed in Uganda and Zimbabwe and boys in the Philippines tend to spend more time on paid/productive work and less time on non-work as they grow older.

\section{Proportion of females}

If the proportion of female members in the household is higher, women and men interviewed in Uganda and men from the Zimbabwean sample tended to spend less time on any care. This might be the case because female household members contribute to care work, so there is less need for men to undertake care work. But we also find a slightly significant association between more females in the household and more hours of primary care work for men in Uganda, which seems counter-intuitive. Potentially, female children in Uganda take on more childcare supervision responsibility, which explains the reduction in any care for women and men, but the overall need for care in the household (e.g. cooking meals, washing clothes) increases, which means that men need to contribute more to primary care work.

In the Philippines, the girls we interviewed tended to spend less time on care if there were more females in the household. In Uganda and Zimbabwe, there is no association between the proportion of females and the care-work hours of children.

\section{Household size}

The number of household members is associated with less primary care for men and fewer any care hours for women in the study community in Uganda, which suggests that household members contribute to care work.

Boys in Uganda spent less time on care and more time on education as the household size increases. This combined with the findings for adults suggests that it is girls who step in to do care work. We do not find an association between household size and adults' or young people's care work in the Philippines and Zimbabwe.

\section{Children under six}

Having at least one child under six years old is associated with large increases in any care hours for women in all three countries. Women who had at least one child under six spent about 4 to 5 hours more on any care than women who did not have a young child. Only in Uganda, we find a positive association between having a young child and men's any care hours labout 2 hours more compared to men without a young child).

Having at least one child aged under six in the household is associated with boys spending more time on care in the study areas in Uganda and Zimbabwe, and with girls and boys spending less time on education in Uganda.

\section{Asset ownership}

Based on answers about asset ownership, we divided households into five wealth categories, with analysis done for middle, better-off and best-off households. We find a tendency for better-off men to spend less time on care. Being in the category in the middle (neither among the poorest nor among the best off) is associated with fewer primary and any care hours for men in the Uganda sample. Belonging to a household classified in the fourth quintile (better off but not the best off) is associated with fewer any care hours for men in Zimbabwe. Being among the households with most assets is associated with less time spent on any care for men interviewed in the Philippines.

Similarly, the wealth indicators are more associated with boys' than with girls' care work. Boys in the study areas in Uganda and Zimbabwe tended to spend less time on care if 


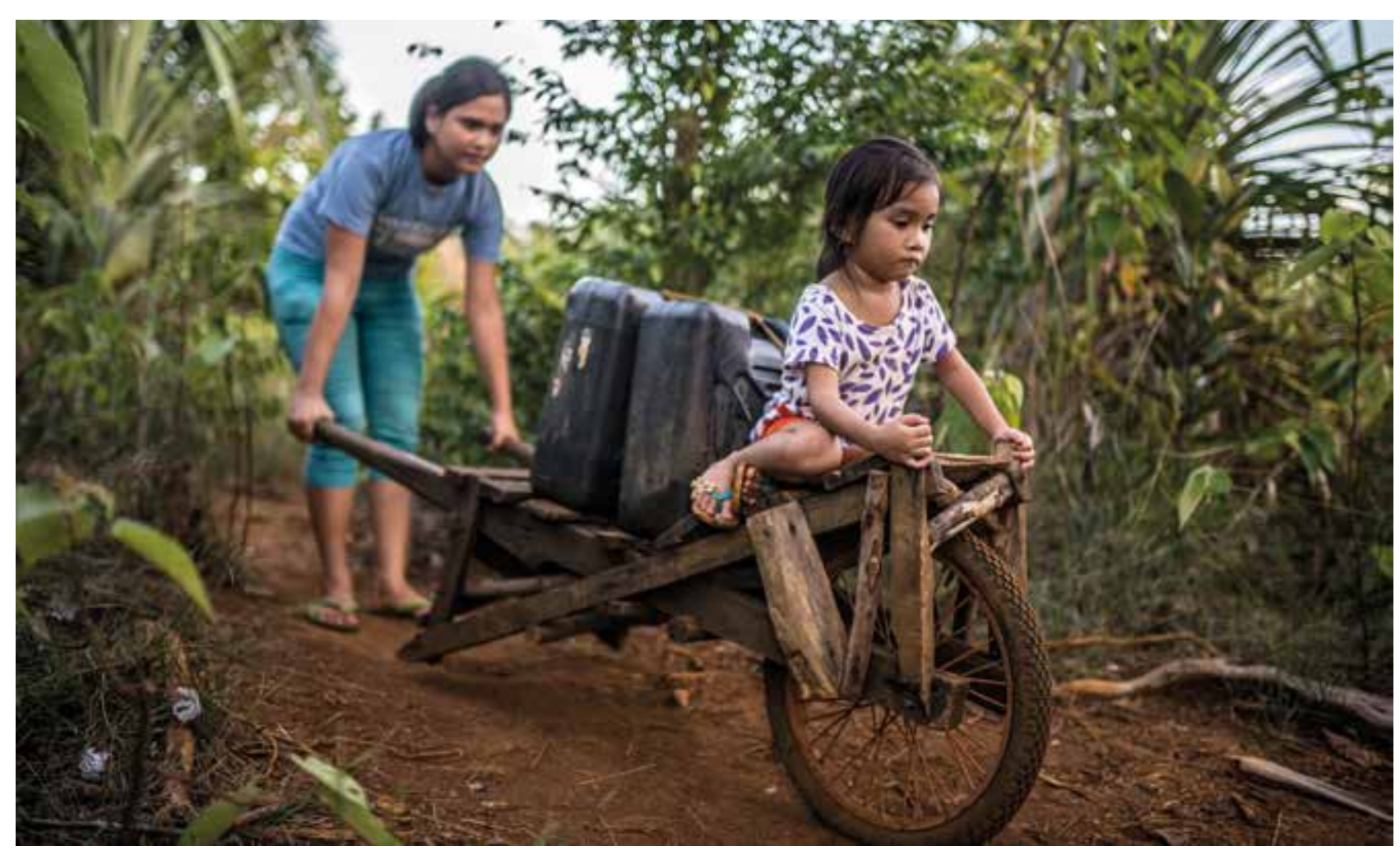

they were in the middle wealth category (Uganda), the second highest (Zimbabwe) or from the best-off households (Uganda and Zimbabwe). In Zimbabwe, being among the best-off households is also associated with both boys and girls spending more time on education.

\section{TIME- AND LABOUR-SAVING EQUIPMENT}

In line with proposition 5, we assessed whether access to time- and labour-saving equipment (TLSE) and paid carework services eases time constraints for women and girls.

We find that ownership of time- and labour-saving equipment is associated with reduced hours of care work for women and girls in several contexts, but under some circumstances equipment also tends to increase care work. It is difficult, however, to assess to what extent equipment reduces care work, since households who generally provide more care might also own more care-related equipment. For example, families who cook more often may be more likely to buy an improved stove than families who cook less.

Overall, the findings suggest that there is potential for policy makers to invest in equipment to help reduce women's workloads and to encourage male participation in care work. However, further research is needed to better understand the relationship between care work and different types of equipment.

Water-related equipment

About $70 \%$ of the surveyed households in Uganda and Zimbabwe and $35 \%$ of households in the Philippines had some kind of container for fetching water. In the Philippines sample, $55 \%$ had a rainwater-harvesting system in place, compared to $33 \%$ in Zimbabwe and $10 \%$ in Uganda. The Philippines is the country where most surveyed households had a water tap on the compound (31\%), compared to $15 \%$ in Uganda and $11 \%$ in Zimbabwe. All the interviewed households in the Philippines, $68 \%$ of the households in Uganda and $75 \%$ of the interviewed households in Zimbabwe had toilets, but the proportion of households with showers is very small in all the countries, at less than $10 \%$.

In the Philippines and Zimbabwe, the HCS had a special focus on water-related questions. Table 5 shows the percentages of households in the Philippines and Zimbabwe that own water-related equipment.

Our analysis finds that for Zimbabwe, owning more waterrelated equipment is associated with men spending more time on water collection as a primary activity and on any care. This might be linked to men finding it more acceptable to fetch water with equipment than to carry water on their heads.

In the study areas in the Philippines, girls and female adolescents (aged 8 to 21) in the household tended to spend less time on water collection if the household owned more water-related equipment.

\section{Fuel-related equipment}

$56 \%$ of the households interviewed in the Philippines, $27 \%$ in Uganda and 38\% in Zimbabwe used a kerosene lamp or battery-powered lamp (dry cell). Less than $1 \%$ of the interviewed households in all three countries owned a generator, and less than $5 \%$ a solar energy system. Firewood 
TABLE 5: OWNERSHIP OF TLSE FOR WATER IN SAMPLES IN PHILIPPINES AND ZIMBABWE, 2017

\begin{tabular}{|l|l|l|}
\hline Type of equipment & Philippines & Zimbabwe \\
\hline More than 4 bottles or buckets & $35 \%$ & $76 \%$ \\
\hline Items used for fetching water & $11 \%$ & $48 \%$ \\
\hline Rainwater-harvesting system/water reservoir & $55 \%$ & $33 \%$ \\
\hline Water tap on compound/homestead & $31 \%$ & $11 \%$ \\
\hline Shower & $3 \%$ & $4 \%$ \\
\hline Toilet & $100 \%$ & $75 \%$ \\
\hline
\end{tabular}

or fuel-efficient stoves were common in the communities in Uganda (60\%), Zimbabwe (41\%) and the Philippines (34\%). In Zimbabwe and the Philippines, about $20 \%$ of the interviewed households had a gas stove, but in Uganda gas stoves were rare $(4 \%)$.

Owning more fuel-related equipment is associated with men spending fewer hours on fuel collection in the Philippines, but there is no such association for women. This might be the case because equipment reduces the time needed for fuel collection, so women carry out the work without asking for help from their husbands. But for Zimbabwe, ownership of fuel-related equipment is associated with men spending more hours on primary care. As with water collection, men in the Zimbabwean communities might be more inclined to participate in care work if they can use technology to assist them. Women interviewed in Uganda spent more time on primary care and any care if they owned more fuel-related equipment. Potentially, owning equipment such as an improved stove encourages women to cook more or to prepare more complicated meals. Women who need to cook more might also be more likely to invest in fuel-related equipment.

In the study areas in Uganda and Zimbabwe, ownership of more fuel-related equipment is associated with girls spending less time on fuel collection.

\section{Meal-preparation equipment}

$67 \%$ of the households in the Philippines, $47 \%$ in Uganda and $16 \%$ in Zimbabwe had a flask for storing liquids or food. But only $17 \%$ of the households in the Philippines, $10 \%$ in Uganda and $14 \%$ in Zimbabwe owned a refrigerator.

We find an association between owning more meal-related equipment and fewer hours of meal preparation, primary and any care for women in the Philippines. But there is no association between meal-preparation equipment and time use in the other contexts.

\section{Cleaning equipment}

$79 \%$ of the households in the Philippines, $32 \%$ in Uganda and $14 \%$ in Zimbabwe had a dustbin or a compost pit to dispose of household waste.
For the Philippines, we find that women spent fewer hours cleaning the house when the household had a dustbin or compost pit and men spent fewer hours on primary care work. In Uganda, men's hours of primary care were higher for those living in a household with a dustbin or compost pit. As with the explanation about water-and fuel-related equipment, ownership of tools might encourage male participation in care work.

\section{Clothes-related equipment}

$54 \%$ of the households interviewed in the Philippines, $11 \%$ in Uganda and $70 \%$ in Zimbabwe had a chest of drawers for storing clothes. About half of the households in all countries owned at least three basins for washing clothes. Quite a high number owned an iron in Zimbabwe (76\%), compared to $38 \%$ in Uganda and $34 \%$ in the Philippines.

Owning more clothes-related equipment is associated with a decrease in women's hours spent on washing, drying and mending clothes in the study areas in Uganda. But we do not find such an association for other countries.

\section{Childcare-related equipment ${ }^{12}$}

$84 \%, 92 \%$ and $78 \%$ of the households with at least one infant in the Philippines, Uganda and Zimbabwe, respectively, had mosquito nets and $79 \%, 44 \%$ and $91 \%$ respectively used nappies for their children.

In Uganda, men with more childcare-related equipment tended to spend less time on primary care but more time on childcare. Similarly, in the Philippines, owning more equipment for childcare is associated with men (but not women) spending more hours on caring for children.

\section{Adult care equipment ${ }^{13}$}

$50 \%$ of the households with at least one member who could not walk or was blind in the Philippines, 59\% in Uganda and $58 \%$ in Zimbabwe had walking sticks, crutches or a wheelchair.

We do not find an association between ownership of adult care equipment and care-work hours of adults, which might be due to the small number of respondents reporting that they had at least one member who could not walk or was blind (5\% in the Philippines, 3\% in Uganda, $8 \%$ in Zimbabwe). 


\section{Paid services}

In general, less than $20 \%$ of the respondents relied on paid care services, such as paying someone to cook, clean or fetch water, with the exception of hair braiding/cutting children's hair, a paid service which was used by $41 \%, 36 \%$ and $21 \%$ of the households in the Philippines, Uganda and Zimbabwe, respectively. The households in Uganda were most likely to rely on paid services compared to the other countries, with the proportion ranging from $18 \%$ for washing and drying clothes to $4 \%$ for adult care. In the Philippines and Zimbabwe, questions on water-related services were asked. Only $6 \%$ of households in the Philippines and $9 \%$ in Zimbabwe had paid someone to wash or dry clothes, and even fewer (2\% in the Philippines, $6 \%$ in Zimbabwe) had paid someone to iron or mend clothes. In both country samples, $7 \%$ had paid someone to fetch water.

We do not find an association between the number of paid services and women's or men's care work, with the exception of the Philippines data, where the number of paid services is associated with fewer any care hours for women.

\section{INFRASTRUCTURE AND SERVICES}

Under proposition 6a, we tested whether the provision of public services (water, electricity, healthcare facilities, childcare facilities) is associated with care work and other time-use indicators of adults and young people laged 8 to 21). We also looked specifically at access to improved water sources for the Philippines and Zimbabwe (proposition 6b).

The findings on infrastructure are important for policy making as they show that public infrastructure, especially access to water, can make a difference in women's workloads. In households with access to improved water sources, women reported spending an average of 1 to 4 hours a day less on any care than women in households without improved water sources. The association between less time spent on unpaid care work and electricity, healthcare and childcare exists, but varies in each country context. We also find some positive effects of access to infrastructure on children's care workloads.

\section{Water}

Access to water can potentially reduce time spent on water collection and indirectly facilitate other care activities, such as cooking, washing clothes, cleaning and childcare. 59.5\% of the households in the Philippines and $46.5 \%$ in Zimbabwe used different sources of water for different purposes, such as for drinking, cooking, cleaning, bathing and laundry. Most households used an improved water source li.e. not a natural source like a river or spring) for at least one purpose $194 \%$ in the Philippines, 77\% in Uganda and 72\% in Zimbabwe). Respondents were most likely to use improved water for drinking ( $81 \%$ in Zimbabwe; $71 \%$ in the Philippines). They were least likely to use improved water for laundry $146 \%$ in the Philippines; $50.5 \%$ in Zimbabwe).

For all three countries, we find that access to an improved water source is associated with women reporting less time spent on any care: about 1 hour less in the Philippines, 2 hours less in Uganda and 4 hours less in Zimbabwe compared to households without an improved water source. Access to an improved water source is also associated with women reporting more leisure hours in the surveyed households in Uganda and Zimbabwe (by about half an hour). In the Philippines, however, access to an improved water source is associated with a slight decrease in women's leisure hours. Men interviewed in Uganda and Zimbabwe with improved access to water also spent less time on any care. In the Philippines and Uganda, the distribution of any care hours between women and men is more equal where there is access to an improved water source.

In the study areas in Uganda and Zimbabwe, both girls and boys tended to spend more time on leisure where there was improved water access. But strangely, we also find for the Zimbabwean sample that both boys and girls spent less time at school in households with improved water access. In the Philippines, sons also spent less time on studying when the household had access to an improved water source. These findings require further investigation and consideration.

\section{Electricity}

Electricity can be used for equipment that reduces care work, such as stoves, refrigerators, washing machines etc., but in rural households with limited access to such equipment it is often primarily used for lighting. $88 \%$ of the households in the Philippines, $33.5 \%$ in Uganda and $12.5 \%$ in Zimbabwe had access to electricity, of which $32 \%, 70 \%$ and $48 \%$, respectively for the Philippines, Uganda and Zimbabwe, reported that it was government-provided.

The analysis suggests that access to electricity is associated with more primary and any care hours for women in Zimbabwe. Women from the Ugandan sample living in a household with access to electricity also spent significantly less time sleeping compared to women without access to electricity. A similar finding was found in the HCS 2014, and women informants in qualitative research explained that with electric light, care tasks did not need to be done as intensively before dark, as they could leave some tasks to do later in the evening. However, in the Philippines electricity access is associated with women spending fewer hours on primary and any care and more hours on leisure, and with a more equal distribution of any care between men and women. Potentially, in the Philippines electricity is used for equipment that reduces care work, while in the other countries it is mostly used for lighting le.g. the Philippines is the country with the highest number of households owning a refrigerator).

We find an association between access to electricity and boys spending less time on care and more time on studying in Uganda. Boys in Zimbabwe and girls in the Philippines with access to electricity also spent more time on studying. Lighting might allow children to study later in the evening rather than doing care work le.g. laying the beds, doing the dishes). But in the Philippines, boys spent more time on care 
when there was electricity in the household. It might be the case that in this context, electric light in the evening allows girls to study, which increases boys' care workload.

\section{Healthcare facilities}

Healthcare facilities can reduce the time spent on caring for ill household members. The large majority of households in the Philippines (86\%), Uganda (96\%) and Zimbabwe (96\%) reported using healthcare facilities when household members were ill. The facilities were primarily governmentprovided $198 \%$ in the Philippines, $81 \%$ in Uganda, $74 \%$ in Zimbabwe). On average, it took women 18 minutes to walk to the nearest healthcare facility in the Philippines, 50 minutes in Uganda and 49 minutes in Zimbabwe.

There are inconsistent findings on the influence of healthcare on care-work hours. In Zimbabwe, access to healthcare facilities seems to reduce workloads; it is associated with more hours of leisure for men, more hours of sleep and fewer hours of paid work for women, and with a more equal distribution of any care between men and women. But for the other countries we find that healthcare services are associated with higher workloads for women. Use of healthcare facilities is associated with an increase in women's any care work in the Philippines and Uganda (by about 2 hours), and with an increase in women's primary care in the Philippines (by about 1 hour). At times of sickness, women are often primarily responsible for taking children and dependent adults to the hospital and following up on their treatment, which might explain why women did more care work if they used healthcare facilities. In the Philippines sample, the use of healthcare services is associated with men spending less time on primary and any care. But in the Ugandan sample, men's any care hours are higher and paid work hours lower for men with access to healthcare compared to those without.

In the study communities in Uganda, both boys and girls tended to spend less time on care in households that had access to healthcare facilities. In the Philippines, access to healthcare facilities is associated with more care hours for girls and fewer care hours for boys. Potentially, girls are more likely than boys to look after ill household members.

\section{Childcare facilities}

Childcare facilities can reduce parents' workloads; however, on their own they might not reduce primary care hours. A reason why we do not find a strong association between childcare facilities and reduced care work for women in most contexts might be that childcare is carried out at the same time as other care activities, which means that childcare alone does not reduce women's overall hours of care.
Only 20\% of the households interviewed in the Philippines, $9 \%$ in Uganda and 20\% in Zimbabwe used childcare facilities for at least one of their children; $100 \%$ of the facilities in the Philippines, $56 \%$ in Uganda and $12 \%$ in Zimbabwe were government-provided.

In the Philippines, having at least one child under six in a daycare centre is associated with fewer primary care hours for men and more sleep for women. For Zimbabwe, there is an association between using childcare facilities and men sleeping less. It might be the case that only some children are enrolled in daycare, which leaves women's hours looking after the other children unchanged. This means that childcare facilities are necessary but not sufficient.

The use of childcare facilities is associated with boys interviewed in the Philippines spending more hours on school, and girls in Zimbabwe spending more hours on studying at home.

\section{Roads}

Better roads can make it easier to access infrastructure and services, but can also increase the risk of accidents. On average, it took women 14 minutes in the Philippines, 56 minutes in Uganda and 24 minutes in Zimbabwe to walk from their house to the nearest all-season road.

We find that if the nearest road was further away, the hours that women in the Philippines and Zimbabwe spent on any care and the hours that women in Uganda spent on primary care decrease. Potentially, this is linked to nearby roads requiring closer supervision of children to ensure their safety.

\section{Marketplace}

A closer marketplace can make it easier for people to access services, sell products and shop for household supplies. On average, it took women 25 minutes in the Philippines, 44 minutes in Uganda and 30 minutes in Zimbabwe to reach the nearest marketplace from their house.

A longer walk to the nearest marketplace is associated with more any care hours for women in the Philippines and Zimbabwe, and with more primary care hours for women in the Uganda study areas. There is also an association between a longer walking time to the nearest marketplace and fewer hours of any care for men in the Philippines and Zimbabwe. Potentially, women take their children with them to the market when they sell products or buy household supplies. This could explain why their time looking after children increases and their husbands' supervision care hours are reduced when the walk to the market takes longer. 


\section{A CLOSER LOOK: DIRECT IMPACTS OF ACCESS TO PUBLIC SERVICES AND CARE-RELATED INFRASTRUCTURE ON ADULT'S AND CHILDREN'S TIME USE AND SECONDARY IMPACTS ON WOMEN'S WELLBEING AND EMPOWERMENT}

Oxfam's research team used the 2017 HCS data to conduct additional data analysis with a focus on the sub-Saharan African countries, i.e. Uganda and Zimbabwe. This analysis resulted in a paper (to be launched in February 2018) that, using access to key public services and care-related infrastructure as a proxy for public investments, investigates the direct impact of access to improved water, electricity, healthcare and childcare on adults' and children's time use, and secondary impacts on women's wellbeing and empowerment. Compared to the 2017 HCS report, the data analysis for this paper involved controlling for additional variables such as women's income, as well as analysing the indirect association between women's decision-making and influencing power and the ratio of care hours between men and women (as a proxy for shared distribution of care work within the household).

In convergence with the findings from the 2017 HCS report, this additional analysis shows that access to improved water sources not only has the potential to reduce the time women spend on primary care work, but can also impact on time spent on multi-tasking of care activities in Uganda and Zimbabwe. For children's time use, the analysis shows that beyond the increase in leisure time reported, access to water is associated with girls sleeping more in Uganda and studying more in Zimbabwe.

As this reports shows, access to electricity is associated with women reporting less sleeping time in Uganda. The supplementary analysis reinforced this finding and also unveils an association between access to electricity and an increase in the time men spend on primary care for that country. More in-depth analysis of electricity use in Uganda shows that this finding could be a result of the majority of households in Uganda using electricity for lighting purposes, making it possible for both men and women to do care work and other tasks after dark. In Uganda, electricity is also associated with boys spending less time on care work and more time studying.

The additional findings reinforce the 2017 HCS report results that show access to childcare is associated with women reporting more hours of any care responsibilities, and demonstrate that the same is true for multi-tasking of care activities in Uganda and Zimbabwe. For children's time use, the new findings show an association between use of childcare facilities and girls and boys reporting less time on paid work in Uganda.

Interestingly, the additional analysis does not find an association between access to public services and a more equitable distribution of unpaid care work in the household sample from Uganda and Zimbabwe. At the same time, it finds an association between positive social norms on unpaid care work and a more equal gendered distribution of care work. In Uganda, a more equal gendered distribution of care work is associated with women reporting a stronger sense of decision-making and influencing power in the household.

In close alignment with the 2017 HCS report, these findings call for a systemic approach to unpaid care work that looks at increasing public investment for reducing hours spent on care work, but also interventions that can address the negative social norms limiting a fairer redistribution of care work within the household. As the evidence shows, this holistic approach can lead to positive impacts on women's health and wellbeing, and their decision-making and influencing power, and can contribute to their children's wellbeing.

Note: A complete account of the findings of the additional analysis performed with data from the 2017 HCS is available in Parvez, A., Remme, J.A., Koissy-Kpein, S. and Rost, L. (2018) 'Exploring the need for gender-equitable fiscal policies for a human economy: evidence from Uganda and Zimbabwe', forthcoming. 


\section{SOCIAL NORMS AND PERCEPTIONS}

Social norms and gender stereotypes are often essential factors maintaining women's roles as carers, and they also provide the context for the use of infrastructure and equipment that could impact on distribution of care tasks. As outlined by proposition 7, we believe that changing social norms and gender stereotypes favours the redistribution of unpaid care work between females and males. The 2017 HCS looks at several measures of social norms and perceptions. They can be divided into the following five categories:

1. Perceptions of care work

2. Views on the division of labour

3. Men's childhood exposure to care work

4. Community expectations

5. Acceptability of gender-based violence related to care

For all the analysis on social norms and perceptions, it is essential to emphasize that we want to look at patterns of relationships between social norms and care work, and do not claim causality. It is hard for us to know what leads to what - i.e. whether social norms determine what people do or whether people have more positive views towards an equal distribution of care work because of what they do.

\section{Perceptions of care work}

This section focuses on perceptions of care work. As suggested in proposition 2, we investigated whether people's perceptions of care work are associated with their participation in it and with investment in time- and laboursaving equipment. In line with propositions 3 and 4, we also asked whether the recognition of unpaid care work is associated with boys' and girls' hours spent on care, paid work, education and leisure/sleep.
We find a tendency of men and women spending more time on care work if they considered care work more valuable and skilled and were aware of the problematic nature of care. But we cannot be certain of the sequencing of perceptions and behaviour. Men's participation in care activities may precede their perception of higher value or skills required for a care task, rather than the other way around.

The findings on the perceptions of care work are important because they emphasize that the recognition of care work as a valuable and skilled task, and of its problematic nature, has the potential to increase men's participation in care. However, the relationship between perceptions of and engagement in care might be two-way, and further research is needed to explore this connection.

\section{Care work as valued}

The HCS questionnaire included an exercise where men and women were given 12 cards with symbols for different paid and care-work activities. ${ }^{14}$ They were then asked to rank the activity cards from the most valuable activity to the least valuable activity. On a second round, ranking was done from the activity that requires most skills to the activity that requires least skills.

Table 6 lists the care activities that women and men in the three samples considered most valuable (1) to least valuable (6). Generally, meal preparation and caring for children were the two care activities that respondents selected as most valuable, and caring for adults and washing clothes were most often considered the least valuable care activities.

Overall, we find that women valued care activities more than men did in all countries, except caring for adults lelderly, ill and/or disabled household members) in the Philippines and

\section{TABLE 6: RANKING OF CARE ACTIVITIES ACCORDING TO THE VALUE ATTRIBUTED TO THEM BY ADULT WOMEN AND MEN IN SAMPLES FROM THREE COUNTRIES, 2017}

\begin{tabular}{|c|c|c|c|c|c|c|}
\hline & \multicolumn{2}{|l|}{ Philippines } & \multicolumn{2}{|l|}{ Uganda } & \multicolumn{2}{|l|}{ Zimbabwe } \\
\hline & Women & Men & Women & Men & Women & Men \\
\hline 1 & Meal preparation & Meal preparation & Meal preparation & $\begin{array}{l}\text { Caring for } \\
\text { children }\end{array}$ & $\begin{array}{l}\text { Caring for } \\
\text { children }\end{array}$ & $\begin{array}{l}\text { Caring for } \\
\text { children }\end{array}$ \\
\hline 2 & $\begin{array}{l}\text { Washing and } \\
\text { drying clothes }\end{array}$ & $\begin{array}{l}\text { Fuel and water } \\
\text { collection }\end{array}$ & $\begin{array}{l}\text { Caring for } \\
\text { children }\end{array}$ & Meal preparation & Meal preparation & Caring for adults \\
\hline 3 & $\begin{array}{l}\text { Cleaning the } \\
\text { house }\end{array}$ & $\begin{array}{l}\text { Cleaning the } \\
\text { house }\end{array}$ & $\begin{array}{l}\text { Cleaning the } \\
\text { house }\end{array}$ & $\begin{array}{l}\text { Cleaning the } \\
\text { house }\end{array}$ & $\begin{array}{l}\text { Cleaning the } \\
\text { house }\end{array}$ & $\begin{array}{l}\text { Fuel and water } \\
\text { collection }\end{array}$ \\
\hline 4 & $\begin{array}{l}\text { Caring for } \\
\text { children }\end{array}$ & $\begin{array}{l}\text { Caring for } \\
\text { children }\end{array}$ & $\begin{array}{l}\text { Fuel and water } \\
\text { collection }\end{array}$ & Caring for adults & $\begin{array}{l}\text { Fuel and water } \\
\text { collection }\end{array}$ & Meal preparation \\
\hline 5 & $\begin{array}{l}\text { Fuel and water } \\
\text { collection }\end{array}$ & $\begin{array}{l}\text { Washing and } \\
\text { drying clothes }\end{array}$ & $\begin{array}{l}\text { Washing and } \\
\text { drying clothes }\end{array}$ & $\begin{array}{l}\text { Fuel and water } \\
\text { collection }\end{array}$ & $\begin{array}{l}\text { Washing and } \\
\text { drying clothes }\end{array}$ & $\begin{array}{l}\text { Cleaning the } \\
\text { house }\end{array}$ \\
\hline 6 & Caring for adults & Caring for adults & Caring for adults & $\begin{array}{l}\text { Washing and } \\
\text { drying clothes }\end{array}$ & Caring for adults & $\begin{array}{l}\text { Washing and } \\
\text { drying clothes }\end{array}$ \\
\hline
\end{tabular}


Zimbabwe, and fuel and water collection in the Philippines. We find that if men valued care activities less in comparison to women, the division of care work between men and women tended to be more unequal. As mentioned above, we cannot be sure that positive perceptions of the value of care among men leads to a more equal distribution of care, or whether men who undertake more care value it more.

We find for all samples that women valued care activities more than paid activities, and men valued paid activities more than care activities. We find an association between women valuing care work more compared to paid work and more hours of primary care for women in all three samples and more hours of any care for women in Uganda and Zimbabwe. If men valued care work more compared to paid work, they tended to spend more time on any care in Uganda and more time on primary care in Zimbabwe.

We also looked at whether women's and men's valuing of care activities is associated with ownership of related equipment, but we did not find any association for all three countries.

For young people, we find that if women valued care work less compared to paid work, girls in Uganda and Zimbabwe tended to spend less time on care, and girls in the Philippines and Zimbabwe tended to spend more time on education. If men valued care work less compared to paid work, girls in the Philippines sample also spent less time on care work. This suggests that valuing paid work more than care work might mean women and men encourage girls to spend time on school rather than care.

\section{Care work as skilled}

Table 7 shows how men and women ranked care activities from those requiring most skills (1) to those requiring least skills (6). Caring for children was the activity that was most often ranked as requiring most skills, and washing clothes was most often considered to require least skills.

Similarly to perceptions on the value of care, men thought that care activities required fewer skills than women did. Looking at individual care activities, women were more likely than men to think that care activities required skills for all activities, except for water/fuel collection and caring for adults in the Philippines and Uganda. But the relationship between the distribution of care work and perceptions of care activities as requiring skills is less straightforward than is the case with perceptions of the value of care. If men compared to women thought that adult care required fewer skills, the distribution of care between women and men was less equal in the Philippines (any care) and Zimbabwe (primary and any care). The same was the case for fuel/water collection (primary and any care) and washing clothes (any care) in the Philippines.

But we also find the opposite to be true. For example, the distribution between men and women of primary care in the Philippines and of any care in Zimbabwe tended to be more equal if men in the Philippines sample thought that meal preparation required fewer skills than women did, and if men in Zimbabwe considered childcare less skilled than women considered it. Although the associations exist, they are inconclusive at this point in showing how perceptions of the skills required to do care work relate to willingness to engage in care tasks.

Both men and women considered paid work activities to be more skilled than care work. Similarly to perceptions of value, there seems to be a tendency of women and men spending

\section{TABLE 7: RANKING OF CARE ACTIVITIES ACCORDING TO THE PERCEIVED SKILLS REQUIRED TO PERFORM THEM BY ADULT WOMEN AND MEN IN SAMPLES FROM THREE COUNTRIES, 2017}

\begin{tabular}{|c|c|c|c|c|c|c|}
\hline & \multicolumn{2}{|l|}{ Philippines } & \multicolumn{2}{|l|}{ Uganda } & \multicolumn{2}{|l|}{ Zimbabwe } \\
\hline & Women & Men & Women & Men & Women & Men \\
\hline 1 & Meal preparation & $\begin{array}{l}\text { Fuel and water } \\
\text { collection }\end{array}$ & $\begin{array}{l}\text { Caring for } \\
\text { children }\end{array}$ & $\begin{array}{l}\text { Caring for } \\
\text { children }\end{array}$ & $\begin{array}{l}\text { Caring for } \\
\text { children }\end{array}$ & Caring for adults \\
\hline 2 & $\begin{array}{l}\text { Washing and } \\
\text { drying clothes }\end{array}$ & Meal preparation & Meal preparation & Meal preparation & Caring for adults & $\begin{array}{l}\text { Caring for } \\
\text { children }\end{array}$ \\
\hline 3 & $\begin{array}{l}\text { Fuel and water } \\
\text { collection }\end{array}$ & $\begin{array}{l}\text { Caring for } \\
\text { children }\end{array}$ & Caring for adults & Caring for adults & Meal preparation & $\begin{array}{l}\text { Fuel and water } \\
\text { collection }\end{array}$ \\
\hline 4 & $\begin{array}{l}\text { Caring for } \\
\text { children }\end{array}$ & $\begin{array}{l}\text { Cleaning the } \\
\text { house }\end{array}$ & $\begin{array}{l}\text { Cleaning the } \\
\text { house }\end{array}$ & $\begin{array}{l}\text { Cleaning the } \\
\text { house }\end{array}$ & $\begin{array}{l}\text { Cleaning the } \\
\text { house }\end{array}$ & Meal preparation \\
\hline 5 & $\begin{array}{l}\text { Cleaning the } \\
\text { house }\end{array}$ & Caring for adults & $\begin{array}{l}\text { Washing and } \\
\text { drying clothes }\end{array}$ & $\begin{array}{l}\text { Fuel and water } \\
\text { collection }\end{array}$ & $\begin{array}{l}\text { Fuel and water } \\
\text { collection }\end{array}$ & $\begin{array}{l}\text { Cleaning the } \\
\text { house }\end{array}$ \\
\hline 6 & Caring for adults & $\begin{array}{l}\text { Washing and } \\
\text { drying clothes }\end{array}$ & $\begin{array}{l}\text { Fuel and water } \\
\text { collection }\end{array}$ & $\begin{array}{l}\text { Washing and } \\
\text { drying clothes }\end{array}$ & $\begin{array}{l}\text { Washing and } \\
\text { drying clothes }\end{array}$ & $\begin{array}{l}\text { Washing and } \\
\text { drying clothes }\end{array}$ \\
\hline
\end{tabular}


more time on care work if they considered it to be more skilled. In the selected communities in the Philippines, there is an association between men thinking that care activities require more skills compared to paid work and more hours for men spent on primary care and any care. In Uganda, women who thought that care required more skills compared to paid work also spent more time on any care. Again, we cannot tell for sure whether perceptions of care precede participation in it, or if it is the other way around.

For most care activities, we do not find an association between perceptions of care activities as skilled and ownership of related equipment.

\section{Care tasks considered problematic}

Women and men were asked which domestic work or care activity they found most problematic for their family in terms of mobility, health and time burden. They were able to select only one activity from the list given (see table below), or none. It is important to emphasize that with this question we wanted to see which care activity was considered to be most difficult rather than conveying a message that all care work is problematic. Women respondents in the Philippines chose washing clothes and men chose water collection as most problematic. In the Ugandan sample, water collection was selected as the most problematic care activity by women and meal preparation by men; while in Zimbabwe, both women and men considered fuel collection the most problematic activity for their family in terms of mobility, health and time burden. Table 8 shows which activities were selected as most problematic by women and men.

We find that if women thought that a care activity was problematic they did more any care in the Philippines and Zimbabwe, and more primary and any care in Uganda, compared to women who said that no care activity was problematic in terms of mobility, health and time burden. There is also a significant association between women considering care work problematic and their husbands spending more time on any care (Uganda) and primary and any care (Zimbabwe). Similarly, if men thought at least some care work was problematic, they did more any care in the communities in Uganda and Zimbabwe, and women also did more any care in Zimbabwe. However, we also find an association between men considering care problematic and fewer primary care hours for men in the Philippines. Similarly to the findings on value and skill, we cannot tell for sure whether care is considered problematic because people engage in it, whether people engage in it because they think it is problematic, or whether people don't think it is problematic because they don't engage in it.

We also looked at whether perceptions of specific care activities being problematic is associated with ownership of related equipment, but we did not find any association in all three countries.

\section{Views on the division of labour}

To understand how people's views about the division of labour influence the distribution of care tasks in the household, we asked questions about the following areas:

- Views on vignettes that describe different divisions of labour.

- Contribution of household members to the household wellbeing.

- Satisfaction with the division of tasks.

- Perceptions about who should help women with care.

The analysis of views of the division of labour has shown that social norms have a strong role in shaping what people do and what they think people should do. Despite higher workloads, women were less often considered to be the main contributors to the household wellbeing than men. At the same time, women often said they were satisfied with the division of labour. Even though the majority thought that generally men should do care work, more respondents wanted girls rather than husbands to help with care. This suggests that it is important to change not only men's views, but also women's views about the value of care and men's participation in care work.

TABLE 8: CARE ACTIVITIES VIEWED AS MOST PROBLEMATIC BY ADULT WOMEN AND MEN IN SAMPLES FROM THREE COUNTRIES, 2017

\begin{tabular}{|l|l|l|l|l|l|l|}
\hline & \multicolumn{2}{|l}{ Philippines } & Uganda & \multicolumn{2}{l|}{ Zimbabwe } \\
\cline { 2 - 7 } & Women & Men & Women & Men & Women & Men \\
\hline Water collection & $30 \%$ & $42 \%$ & $20 \%$ & $14 \%$ & $25 \%$ & $18 \%$ \\
\hline Fuel collection & $16 \%$ & $24 \%$ & $17 \%$ & $9 \%$ & $32 \%$ & $27 \%$ \\
\hline Meal preparation & $1 \%$ & $5 \%$ & $9 \%$ & $20 \%$ & $3 \%$ & $5 \%$ \\
\hline House cleaning & $1 \%$ & $1 \%$ & $3 \%$ & $4 \%$ & $5 \%$ & $3 \%$ \\
\hline Washing clothes & $32 \%$ & $11 \%$ & $17 \%$ & $16 \%$ & $4 \%$ & $5 \%$ \\
\hline Drying, ironing clothes & $0 \%$ & $1 \%$ & $\mathrm{n} / \mathrm{a}$ & $\mathrm{n} / \mathrm{a}$ & $0 \%$ & $1 \%$ \\
\hline Caring for children & $13 \%$ & $9 \%$ & $19 \%$ & $24 \%$ & $6 \%$ & $7 \%$ \\
\hline Caring for adults & $3 \%$ & $5 \%$ & $5 \%$ & $4 \%$ & $13 \%$ & $15 \%$ \\
\hline Caring for community & $0 \%$ & $0 \%$ & $3 \%$ & $2 \%$ & $2 \%$ & $4 \%$ \\
\hline None & $4 \%$ & $2 \%$ & $7 \%$ & $7 \%$ & $10 \%$ & $15 \%$ \\
\hline
\end{tabular}




\section{Contribution to the household wellbeing}

Women and men were asked who they felt made the most significant contribution to their household's wellbeing. They were able to select between themselves, their partner, another man or another woman, or 'other'. In the Philippines, significantly more men (59\%) than women (11\%) recognized women as the main contributors to the household wellbeing. This might be linked to the Philippines' long history of women in paid work and the significant migration of women as domestic workers with major flows of remittances. In Uganda, significantly more women (39\%) than men (23\%) recognized women as the main contributors. In Zimbabwe, about a quarter of the women and men interviewed considered women as the main contributors.

We do not find an association between care/paid work and whether women and men considered women to be the main contributors to the household wellbeing. In Uganda, exceptionally, men who thought women contributed the most to the household spent less time on paid work, and women who considered themselves the main contributors to the household wellbeing spent less time on any care.

\section{Satisfaction with the division of labour in the household}

Even though women interviewed in Uganda and Zimbabwe spent more time on total work than men, across the three countries the majority of women said that they were satisfied with the division of tasks in their households. Only 16\%, 26\% and $23 \%$ of the women in the communities in the Philippines, Uganda and Zimbabwe, respectively, were unsatisfied with the division of tasks. But in Uganda and Zimbabwe, fewer men than women were unsatisfied with the division of labour: $14 \%$ and $12 \%$, respectively. Table 9 summarizes women's and men's satisfaction with the division of labour in the study areas in the three countries.

We find an association between women being satisfied with the division of labour and spending fewer hours on primary care in the data for Uganda and Zimbabwe. We also find an association between men being satisfied with the division of labour and spending more hours on any care in Uganda. As any care mostly consists of childcare, looking after children might positively affect men's satisfaction.

Views on vignettes that describe different divisions of labour Three different vignettes describing different divisions of labour were read out to women and men, and respondents were asked what they thought of the particular division of tasks. The first vignette describes a situation where the woman does farm and care work, and the man does paid work. The second vignette describes a man and woman sharing productive and care work. The third one depicts a couple where the wife does most paid and care work. The vignettes from the women's perspective are listed in Figure 3.

\section{TABLE 9: SATISFACTION WITH THE DIVISION OF LABOUR BY ADULT WOMEN AND MEN IN SAMPLES FROM THREE COUNTRIES, 2017}

\begin{tabular}{|l|l|l|l|l|l|l|}
\hline & Philippines & Uganda & Zimbabwe \\
\cline { 2 - 7 } & Women & Men & Women & Men & Women & Men \\
\hline No & $16.2 \%$ & $16.7 \%$ & $25.8 \%$ & $13.6 \%$ & $22.6 \%$ & $11.8 \%$ \\
\hline Yes & $83.8 \%$ & $83.3 \%$ & $74.2 \%$ & $86.4 \%$ & $77.4 \%$ & $88.2 \%$ \\
\hline
\end{tabular}

\section{FIGURE 3: VIGNETTES ON DIVISION OF LABOUR (WOMEN'S PERSPECTIVE)}

SUSAN: My husband Brian works as a carpenter, he leaves the house early and comes back in the evening. After preparing breakfast for my family, I work in the field in the mornings. I return to prepare lunch for my children. I fetch water and firewood, make sure the house and compound are clean. When my husband comes back from work he is very tired. I bring him water to wash his hands and serve him food. I do the dishes and prepare the beds for all of us.

SARAH: Ever since we got together, my husband John and me have shared responsibilities. We get up around the same time, prepare breakfast, clean the house and help the children. We work on our farm together. When we come home from the field, he carries the vegetables and I carry some firewood. We both go and fetch water whenever we need it. I take the lead on cooking but my husband helps me chopping vegetables and cleaning the kitchen and compound.

KATHERINE: I do a lot of work. I work on the farm and do all the housework, bathing the children, collecting water and fuel, cleaning, cooking, making sure the house is okay. My husband Michael does some agricultural work and some casual labour. He often meets up with friends to chat or relax. Usually he does not help me with my work. But sometimes he might get water or cook if I am sick or not at home.

NOTE: The vignettes for men use exactly the same wording, but are framed from the men's perspective. 
Across the countries, more than half of respondents approved or strongly approved of the first vignette describing a gendered division of labour. About $65 \%$ of women and men interviewed in Uganda and Zimbabwe and about 53\% of women and men in the Philippines approved of a division where the man did paid work and the woman care work.

The large majority of respondents approved or strongly approved of couples sharing care and productive work (vignette 2). For men, the percentages of approval were 92\% in the Philippines, $72 \%$ in Uganda and $77 \%$ in Zimbabwe. For women, the percentages ranged from $87 \%$ in the Philippines to $78 \%$ in Zimbabwe and $77 \%$ in Uganda.

A much smaller proportion of women and men approved of vignette 3 , which describes a division where most work is left to women: $13 \%$ of the women and $15 \%$ of the men interviewed in the Philippines, $33 \%$ of the women and $38 \%$ of the men interviewed in Zimbabwe, and $71 \%$ of the women and the men interviewed in Uganda approved or strongly approved of this vignette.

We find that compared to men who did not approve of sharing tasks, men who approved of an equal division spent more time on any care in the Philippines and on primary and any care in Uganda. We also find that the distribution of primary and any care between spouses is more equal in households where women approve of sharing tasks in the Philippines and Uganda. There is no association between approval of sharing tasks and the distribution of care work in Zimbabwe.

\section{Perceptions about who should help women with care}

Women and men were asked from whom women should mainly receive help with caring for people and domestic work. The options were no one, husband, girls, boys, other women, other men and 'other'. Respondents were able to select two options. In the Philippines, women and men thought that women should mainly receive help with care from husbands (about 90\%), while in Uganda men (62\%) and women $(67 \%)$ selected girls as the first choice of helpers with care. In Zimbabwe, women most often wanted help with care from daughters $(66 \%)$, while men said that women should receive help with care from husbands (71\%). In all countries, significantly more women than men wanted girls to help with care work. Women and men were least likely to want sons to help with care work. This could lead to favouring the persistence of gender inequalities in unpaid care and domestic work, and suggests the need for interventions that encourage the participation of boys in care work.

We find an association between men saying that husbands should help women with care and them spending less time on primary care in the Philippines. In this context, men who do not engage in care might feel that they should help more. In the study areas in Uganda, the opposite is the case: men who said that men should help women with care spent more time on primary and any care compared to those men who said that men should not help with care. Men might participate more in care because they personally believe that

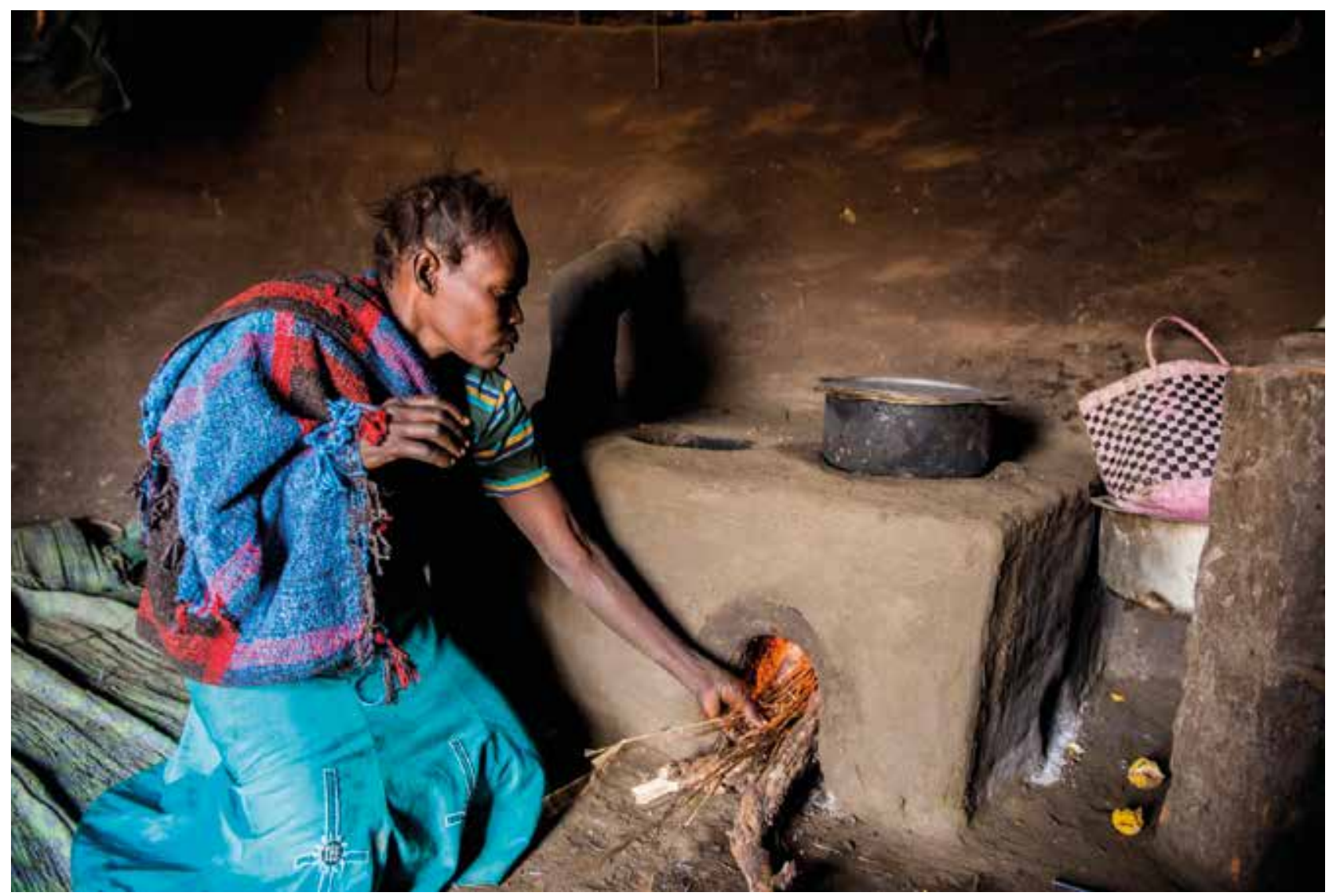


TABLE 10: SHARE OF ADULT MEN WHO REPORTED CHILDHOOD EXPOSURE TO CARE WORK (SEEING FATHER'S ENGAGEMENT IN CARE WORK OR WERE TAUGHT TO DO CARE WORK) IN SAMPLES FROM THREE COUNTRIES, 2017

\begin{tabular}{|c|c|c|c|c|c|c|c|c|c|c|c|c|}
\hline & \multicolumn{4}{|c|}{ Philippines } & \multicolumn{4}{|c|}{ Uganda } & \multicolumn{4}{|c|}{ Zimbabwe } \\
\hline & \multicolumn{2}{|c|}{ Father } & \multicolumn{2}{|c|}{ Taught } & \multicolumn{2}{|c|}{ Father } & \multicolumn{2}{|c|}{ Taught } & \multicolumn{2}{|c|}{ Father } & \multicolumn{2}{|c|}{ Taught } \\
\hline & No. & $\%$ & No. & $\%$ & No. & $\%$ & No. & $\%$ & No. & $\%$ & No. & $\%$ \\
\hline \multicolumn{13}{|l|}{ Meal preparation } \\
\hline Sometimes/frequently & 194 & 92.82 & 198 & 94.73 & 299 & 36.5 & 502 & 61.29 & 181 & 54.68 & 263 & 79.45 \\
\hline Total & 209 & 100 & 209 & 100 & 819 & 100 & 819 & 100 & 331 & 100 & 331 & 100 \\
\hline \multicolumn{13}{|l|}{ Cleaning } \\
\hline Sometimes/frequently & 190 & 90.91 & 204 & 97.61 & 377 & 46.04 & 589 & 71.92 & 168 & 50.75 & 238 & 71.9 \\
\hline Total & 209 & 100 & 209 & 100 & 819 & 100 & 819 & 100 & 331 & 100 & 331 & 100 \\
\hline \multicolumn{13}{|l|}{ Washing clothes } \\
\hline Sometimes/frequently & 164 & 78.47 & 197 & 94.26 & 375 & 45.79 & 578 & 70.57 & 169 & 51.06 & 254 & 76.74 \\
\hline Total & 209 & 100 & 209 & 100 & 819 & 100 & 819 & 100 & 331 & 100 & 331 & 100 \\
\hline \multicolumn{13}{|l|}{ Childcare } \\
\hline Sometimes/frequently & 30 & 14.36 & 27 & 12.92 & 239 & 29.18 & 193 & 23.57 & 103 & 31.12 & 67 & 20.24 \\
\hline Total & 209 & 100 & 209 & 100 & 819 & 100 & 819 & 100 & 331 & 100 & 331 & 100 \\
\hline
\end{tabular}

they should, or perhaps they think that other men should also engage in care because they do so themselves. In Uganda, there is also an association between women wanting help from husbands and men spending more time on primary and any care. Again, we cannot be sure whether women wanting help leads to men helping, or whether women with husbands who help think it is more acceptable to do so.

\section{Men's childhood exposure to care work}

The finding that childhood exposure to care work seems to increase men's reported hours of care work later in life draws attention to the importance of fathers as role models for their boys in engaging on unpaid care.

Social norms and perceptions are often passed on through generations. In the HCS, men respondents were asked about care work in their childhood. Information was collected about whether their fathers or other men in their home engaged in care work (meal preparation, cleaning the house, washing clothes, childcare), and on whether male respondents were taught to perform these tasks.

In the Philippines communities, more than $80 \%$ of the men said that they were taught to do at least one care activity when they were children, and $70 \%$ had observed their fathers or another male household member doing at least one care task sometimes or frequently. Men had mainly been exposed to other men cooking (93\%) and had mostly been taught to do cleaning $(98 \%)$.

In Uganda and Zimbabwe, 50\% and 63\% of male adult respondents respectively had been taught to do at least one care task, but only $35 \%$ and $40 \%$, respectively, had seen their fathers doing care work. Men in the Uganda and Zimbabwe samples had mainly been exposed to male participation in childcare (71\% Uganda and 69\% Zimbabwe) and had also mainly been taught to care for children $177 \%$ Uganda and $80 \%$ Zimbabwe). Table 10 summarizes how many men had seen male members doing care work when they were children or teenagers, and had been taught to do care work as children.

\section{Fathers doing care work}

We find that whether their fathers engaged in care work when the interviewed men were children influences the amount of time men spent on care work later in life. There is an association between fathers having been involved in meal preparation and men spending more time on any care in Uganda. For washing clothes, there is an association between fathers washing clothes and men spending more time on any care in the Philippines and Uganda. We also find an association between fathers looking after children and men spending more time on any care in Uganda and Zimbabwe. If fathers did at least one care activity sometimes or frequently when men were young, men tended to spend more time on any care in the study communities in the Philippines and Uganda. But surprisingly, in the Philippines sample, men tended to spend less time on primary care if their fathers used to prepare meals.

\section{Men having been taught to do care work}

We also find a positive correlation between men having been taught to cook as children and their time spent on any care in Uganda. Men from the Ugandan sample who learned how to wash clothes as children also spent more time on any care. There is also an association between men having been taught to do at least one care activity when they were children and spending more time on any care in Uganda. But in the Zimbabwean sample, men who learned how to wash clothes as children spent less time on primary care. 
Community expectations

In the HCS 2017, we added some new questions on community expectations and personal views, based on Cristina Bicchieri's framework (2017) of measuring social norms. We asked respondents the following questions:

- What they think others do (empirical expectations): Out of five men in your village we interviewed, how many do you think said that they spent at least an hour on caring for people and domestic work yesterday?

\section{- What they think others should do (personal normative}

beliefs): Do you think men in your village should do caring for people and domestic work?

\section{- What they think others think people should do (normative} expectations): Out of five women/men in your village we interviewed, how many do you think said that men should do caring for people and domestic work?
To look at whether community expectations matter for personal behaviour, we added the following questions:

- If nobody were to know that you/your husband did caring for people and domestic work, would you do it/would you want him to do it more?

- We also randomly read out one of the four vignettes to assess community impact on behaviour (summarized in Figure 4), and asked:

- Given what Simon has learned, how likely is Simon to do care work?

- Given what Doris has learned, how likely is Doris to want Simon to do care work?

Getting the community to accept men's engagement in unpaid care work is important for redistribution. We find that men underestimated the amount of time other men spent on care and other men's approval of sharing tasks. What community members found acceptable seems to matter more in determining personal behaviour than what community members actually did.

\section{FIGURE 4: VIGNETTES TO ASSESS COMMUNITY IMPACT ON PERSONAL BEHAVIOUR}

\begin{tabular}{|c|c|c|}
\hline & LOW NORMATIVE EXPECTATIONS & HIGH NORMATIVE EXPECTATIONS \\
\hline $\begin{array}{l}\text { LOW EMPIRICAL } \\
\text { EXPECTATIONS }\end{array}$ & $\begin{array}{l}1 \\
\text { Simon and Doris live together in a nearby } \\
\text { village. In the past, no men in their } \\
\text { village used to do caring for people and } \\
\text { domestic work. Simon and Doris have } \\
\text { learned that FEW MEN in their village } \\
\text { now do caring for people and domestic } \\
\text { work, and at the same time FEW PEOPLE } \\
\text { say that men should do caring for people } \\
\text { and domestic work. }\end{array}$ & $\begin{array}{l}2 \\
\text { Simon and Doris live together in a nearby } \\
\text { village. In the past, no men in their } \\
\text { village used to do caring for people and } \\
\text { domestic work. Simon and Doris have } \\
\text { learned that FEW MEN in their village } \\
\text { now do caring for people and domestic } \\
\text { work, but at the same time ALMOST ALL } \\
\text { say that men should do caring for people } \\
\text { and domestic work. }\end{array}$ \\
\hline $\begin{array}{l}\text { HIGH EMPIRICAL } \\
\text { EXPECTATIONS }\end{array}$ & $\begin{array}{l}3 \\
\text { Simon and Doris live together in a } \\
\text { nearby village. In the past, no men in } \\
\text { their village used to do caring for } \\
\text { people and domestic work. Simon and } \\
\text { Doris have learned that ALMOST ALL } \\
\text { MEN in their village now do caring for } \\
\text { people and domestic work, but at the } \\
\text { same time FEW PEOPLE say that men } \\
\text { should do caring for people and } \\
\text { domestic work. }\end{array}$ & $\begin{array}{l}4 \\
\text { Simon and Doris live together in a } \\
\text { nearby village. In the past, no men in } \\
\text { their village used to do caring for } \\
\text { people and domestic work. Simon and } \\
\text { Doris have learned that ALMOST ALL } \\
\text { men in their village now do caring for } \\
\text { people and domestic work, and at the } \\
\text { same time ALMOST ALL say that men } \\
\text { should do caring for people and } \\
\text { domestic work. }\end{array}$ \\
\hline
\end{tabular}




\section{Empirical and normative expectations}

In the study areas in the Philippines and Uganda, men estimated fewer men to have spent at least an hour on care work the previous day than the actual number of men who said they engaged in care. $57 \%$ of the men interviewed in the Philippines and $39 \%$ of the men in Uganda said that men in their village spent at least one hour on caring for people and domestic work the day before the interview, in contrast to $91 \%$ (Philippines) and 49\% (Uganda) of the men reporting to have spent at least one hour on care work (primary or any care) the previous day. In Zimbabwe, about half of the men reported spending time on care work, and men said that about half of the men in their village did at least some care work.

In all countries, a large majority of men approved of men doing care work, but did not think that other men would approve. While $97 \%$ of the men in the Philippines, $79 \%$ of the men in Uganda and $86 \%$ of the men interviewed in Zimbabwe answered that men should do care work, only $60 \%$ (Philippines), 36\% (Uganda) and 47\% (Zimbabwe) of men thought that men in their community would approve of men doing care work. For those men who said that men should not do caring for people and domestic work, the reason that was selected by far the most often in all three countries was: 'It is a women's task/it is not a man's task' (50\% Philippines, $75 \%$ Uganda, 71\% Zimbabwe).

The discrepancy between men's involvement in care and views of men's care-work time is emphasized by the fact that we do not find an association between views of other men's involvement in care work and men's care-work hours for the Philippines and Zimbabwe. For Uganda, we find a significant association between more men thinking that men spent at least one hour on care the day before the interview and more any care-work hours for men.

\section{The influence of community expectations on personal behaviour}

In all three countries, the majority of women said that they would like their husband to do care work if no one were to know that he did care work (63\% Philippines, 66\% Uganda, $59 \%$ Zimbabwe).

In the study areas in Uganda and Zimbabwe, community expectations seem to influence behaviour. Women and men were most likely to say that men would do care work if all men in the community did care work and almost all thought that men should do care work (vignette 4), or if few men did care work but almost all thought men should do care work (vignette 2). This suggests that what matters in determining whether men do care work is more what other people think should be done than what they actually do. In the Philippines, the large majority of respondents said that men should do care work, irrespective of what vignette was read out to them. Table 11 summarizes the percentage of women and men saying that Simon would be likely or very likely to do care work and that Doris would be likely or very likely to want Simon to do care work, given the specific vignettes.

\section{TABLE 11: PROPORTION OF ADULT WOMEN AND MEN WHO CONSIDER COMMUNITY EXPECTATIONS WHEN DEFINING PERSONAL BEHAVIOUR ON UNPAID CARE WORK IN SAMPLES FROM THREE COUNTRIES, 2017}

\begin{tabular}{|c|c|c|c|c|c|c|c|c|c|c|c|c|}
\hline & \multicolumn{4}{|c|}{ Philippines } & \multicolumn{4}{|l|}{ Uganda } & \multicolumn{4}{|c|}{ Zimbabwe } \\
\hline & \multicolumn{2}{|c|}{$\begin{array}{l}\text { Man likely to do } \\
\text { care work }\end{array}$} & \multicolumn{2}{|c|}{$\begin{array}{l}\text { Woman likely to } \\
\text { want man to do } \\
\text { care work }\end{array}$} & \multicolumn{2}{|c|}{$\begin{array}{l}\text { Man likely to do } \\
\text { care work }\end{array}$} & \multicolumn{2}{|c|}{$\begin{array}{l}\text { Woman likely to } \\
\text { want man to do } \\
\text { care work }\end{array}$} & \multicolumn{2}{|c|}{$\begin{array}{l}\text { Man likely to do } \\
\text { care work }\end{array}$} & \multicolumn{2}{|c|}{$\begin{array}{l}\text { Woman likely to } \\
\text { want man to do } \\
\text { care work }\end{array}$} \\
\hline & Women & Men & Women & Men & Women & Men & Women & Men & Women & Men & Women & Men \\
\hline $\begin{array}{l}\text { (1) Few men do care } \\
\text { work and few people } \\
\text { think men should do } \\
\text { care work }\end{array}$ & $100.00 \%$ & $94.73 \%$ & $100.00 \%$ & $98.25 \%$ & $61.64 \%$ & $69.31 \%$ & $73.88 \%$ & $77.73 \%$ & $75.00 \%$ & $82.72 \%$ & $89.77 \%$ & $90.13 \%$ \\
\hline $\begin{array}{l}\text { (2) Few men do care } \\
\text { work, almost all } \\
\text { think men should do } \\
\text { care work }\end{array}$ & $93.33 \%$ & $97.78 \%$ & $96.67 \%$ & $100 \%$ & $67.15 \%$ & $66.5 \%$ & $82.48 \%$ & $80.3 \%$ & $78.9 \%$ & $78.2 \%$ & $88.99 \%$ & $92.31 \%$ \\
\hline $\begin{array}{l}\text { (3) Almost all men do } \\
\text { care work, few } \\
\text { people think men } \\
\text { should do care work }\end{array}$ & $95.65 \%$ & $100 \%$ & $97.83 \%$ & $98.3 \%$ & $64.66 \%$ & $73.8 \%$ & 77.51 & $80.35 \%$ & $72.81 \%$ & $82.83 \%$ & $81.56 \%$ & $91.92 \%$ \\
\hline $\begin{array}{l}\text { (4) Almost all men do } \\
\text { care work, almost all } \\
\text { think men should do } \\
\text { care work }\end{array}$ & $98.18 \%$ & $100 \%$ & $100 \%$ & $100 \%$ & $75.25 \%$ & $77.29 \%$ & 80.85 & $85.95 \%$ & $76.63 \%$ & $80.82 \%$ & $91.59 \%$ & $89.05 \%$ \\
\hline
\end{tabular}


The results on community expectations are important in the sense that they highlight that it is not necessarily the case that men personally do not accept doing care work, but what community members would approve of is perceived as more important. In other words, what matters most is not what people think community members do, but what they think community members believe. Policies and initiatives that uncover the discrepancy between beliefs about the community and actual community behaviour and views could help open people's eyes to the fact that male participation in care work is widely accepted.

\section{Acceptability of gender-based violence related to care}

Community sanctions can be powerful in maintaining social norms and, as the study finds, the gendered division of care work. The findings show that generally, if gender-based violence was accepted, men tended to do less care work and women tended to do more care work. Significantly, about a third of Zimbabwean and Ugandan respondents accepted mocking men for performing care tasks or beating/criticizing women for inadequate provision of care.

The HCS asked men and women whether they thought it was acceptable to mock or shame a man for performing different care tasks /cooking, caring for children, fetching water/fuel, etc.). The questionnaire also asked women and men whether they thought it was acceptable to harshly criticize/shout at a woman and beat a woman in various situations describing inadequate provision of care le.g. if she spoiled/burnt/failed to cook a meal) and leaving the house without asking.

\section{Shaming men for doing care work}

In the selected communities in the Philippines, $95 \%$ of women and $87 \%$ of men found it unacceptable to mock men for engaging in care activities. But about $27 \%$ of women and men in the Ugandan and $28 \%$ of women and men in the Zimbabwean communities thought that it was acceptable to mock men for doing at least one care activity. These findings highlight that community backlash still seems to represent an important barrier to men's participation in care work in these two contexts.

Accepting mocking men for doing care work tends to reinforce the gendered division of care work. In the Philippines sample, men spent less time on any care if they thought it was acceptable to mock men for doing care work. There is also an association between women accepting mocking of men and women spending more time on primary care in the Philippines and Zimbabwe and on any care in the Philippines and Uganda.

\section{Criticizing or shouting at women for not doing care work}

Similar to the findings on mocking men, about $93 \%$ of men and women interviewed in the Philippines found it unacceptable to harshly criticize a woman for not providing adequate care. But in Uganda and Zimbabwe, a significant number of women and men respondents thought it was acceptable to harshly criticize and shout at women because of insufficient care. $24 \%$ of the women and $22 \%$ of the men interviewed in Uganda found harsh criticism or shouting at a woman acceptable in at least one of the described situations. In Zimbabwe, men (40\%) significantly more often than women (33\%) found it acceptable to criticize women for not doing care work.

For the Uganda study areas, we find that men who thought it was acceptable to harshly criticize women for not doing care work tended to spend less time on any care. However, for the Philippines and Zimbabwe, we find that men who thought such criticism was acceptable spent more time on any care. Potentially, men in these contexts feel more entitled to criticize their wives for not doing care work if they are participating in this type of work themselves.

\section{Beating women for not doing care work}

Again, the Philippines sample is mostly opposed to beating women for not doing care: about $99 \%$ of women and men interviewed in the Philippines found beating unacceptable. But over a third of women and men in the communities in Uganda and Zimbabwe accepted physical violence against women because of insufficient care. Surprisingly, in Uganda, women (36\%) and men (34\%) found it more acceptable to beat a woman than to harshly criticize a woman. In Zimbabwe, $23 \%$ of the surveyed women and $20 \%$ of the men believed beating women to be acceptable in at least one of the described situations.

Acceptance of beating is associated with a more unequal division of care work. We find an association between women interviewed in Uganda accepting beating and spending more hours on primary care. Men who accepted beating of women in response to perceived inadequate provision of care also tended to spend less time on primary and any care in the Philippines and any care in Uganda.

Table 12 summarizes respondents' views of acceptance of mocking men and shaming/criticizing women for at least one of the described situations. For details on acceptance of specific situations, please see the Appendix.

The analysis on social norms has shown that it is crucial to understand the local normative context in which policies on care work are embedded. What people think others do and approve of, and what they personally believe is acceptable, determines what they do and tell others to do. Interventions that improve access to infrastructure and equipment, with a focus on reduction and redistribution of unpaid care work, are likely to be more successful if social norms and perceptions of the community are acknowledged. 
TABLE 12: SHARE OF ADULT WOMEN AND MEN IN SAMPLES FROM THREE COUNTRIES WHO FELT GENDERBASED VIOLENCE/HARSH CRITICISM WAS AN ACCEPTABLE RESPONSE TO WOMEN'S PERCEIVED FAILURE TO CARRY OUT AT LEAST ONE CARE-RELATED TASK, OR THAT MOCKING WAS AN ACCEPTABLE RESPONSE TO MEN'S ENGAGEMENT IN AT LEAST ONE CARE-RELATED TASK, 2017

\begin{tabular}{|l|l|l|l|l|l|l|}
\hline & \multicolumn{2}{|l|}{ Philippines } & Uganda & \multicolumn{2}{l|}{ Zimbabwe } \\
\hline Type of violence/criticism & Women & Men & Women & Men & Women & Men \\
\hline Mocking men & $5 \%$ & $13 \%$ & $26 \%$ & $27 \%$ & $28 \%$ & $29 \%$ \\
\hline Beating women & $2 \%$ & $1 \%$ & $36 \%$ & $34 \%$ & $23 \%$ & $20 \%$ \\
\hline Criticizing women & $8 \%$ & $5 \%$ & $24 \%$ & $22 \%$ & $33 \%$ & $40 \%$ \\
\hline Observations & 184 & 196 & 969 & 749 & 400 & 326 \\
\hline
\end{tabular}

\section{WOMEN'S DECISION MAKING}

Proposition 1 suggests that an improvement in women's status is associated with a more equal distribution of care hours between women and men. Based on the Women's Empowerment in Agriculture Index (IFPRI 2012), the questionnaire presented different areas of decision making and asked women, 'Who normally makes most of the decisions about this area?' and, if the answer was not the woman herself, 'To what extent do you think you can influence or change their decision?'. Areas of decision making included decisions about children's schooling and health, decisions on how time is spent or decisions on large purchases, to name a few. Based on answers to these questions, we constructed a decision-making and influencing scale. ${ }^{15}$

The 2015 HCS data analysis indicated that decision making was not significantly or consistently related to the level and distribution of care hours, suggesting that 'care is a special case' in decision making, and that social norms may be more powerful drivers of the gendered distribution of care hours than women's decision-making power.

The 2017 HCS findings suggest that women generally had control over their own time and the undertaking of domestic tasks independently or jointly with someone else, but a significant minority of women were not involved in decisions on loans, purchases and, most interestingly, on the number of children they wanted to have. Similarly to the HCS 2015 findings, we find that the relationship between decision making and care-work allocation is not consistent, in contrast to common beliefs among development

practitioners. This might be linked to the role of social norms in reinforcing gendered divisions of labour. However, we find that women with more of a say in the household are more likely to own time- and labour-saving equipment, especially water-related equipment, which has been found to reduce women's care work. In the context of strong social norms, it might be easier and more socially acceptable for women to negotiate for investment in equipment than for their husbands' engagement in care.

$97 \%$ of the women in the Philippines, $91 \%$ of the women interviewed in Uganda and $92 \%$ of the women in Zimbabwe made decisions about their own time alone or together with someone else. $91 \%, 87 \%$ and $88 \%$ of the women in the Philippines, Uganda and Zimbabwe, respectively, made decisions independently or jointly about which family members should do domestic tasks. But a significant number of women were not involved in decisions on loans $120 \%$ Philippines, 50\% Uganda, 40\% Zimbabwe), large purchases (20\% Philippines, 44\% Uganda, 31\% Zimbabwe) and even the number of children they wanted to have $16 \%$ Philippines, $38 \%$ Uganda, 28\% Zimbabwe). The finding that about a third of the women in all three countries were not able to contribute to the decision on the number of children they had is interesting. As shown in previous sections, the size of the household is associated with unequal distribution of unpaid care work, as is the existence of children aged under six. If these factors are considered, more power over this decision could have the potential to reduce care workloads for women.

In the communities in the Philippines and Zimbabwe, on average women were involved in eight out of ten decisions. In Uganda, they were on average engaged in seven out of ten decisions. The women interviewed in the Philippines had the highest average score for decision making (0.84 out of 1 ), while the women in Uganda had the lowest score 10.71 out of 1). However, when we add to the decision-making scale a measure for whether women were able to influence decisions, women in Zimbabwe recorded the highest score (1.39 out of 3) and women in the Philippines the lowest score (1.05 out of 3). Across the three countries, some women were not involved in any decisions at all and could not influence decisions, while others were engaged in all the decisions.

The relationship between decision making and care-work allocation is not consistent. On the one hand, we find that a higher score in the decision-making and influencing scale for women is associated with a more equal distribution of any care between women and men in Uganda and Zimbabwe. At the same time, we find an association between a higher decision-making and influencing score and more hours of any care for women in the Philippines and Zimbabwe.

But there are interesting results on the relationship between women's decision making and access to time- and laboursaving equipment. Higher scores in the women's decision- 
making and influencing scale are associated with ownership of more water-related equipment in all three countries. In addition to water-related equipment, in the selected communities in Uganda, a higher decision-making and influencing score for women is also associated with owning more fuel-related equipment. In the Philippines, women's decision making is associated with more cleaning- and washing-related equipment, but it is also found to be associated with less childcare-related equipment.

\section{WELLBEING, TIME CONSTRAINTS AND CARE WORK}

Heavy and unequal care work can negatively affect women's health and wellbeing. If women are overworked and inadequate care is provided, other household members, especially children, might also experience harm. This section provides an overview of the 2017 HCS data on women's wellbeing and time constraints with the provision of care.

\section{WOMEN'S WELLBEING}

In line with proposition 8, we assume that a more equal distribution of unpaid care work between women and men is associated with improvements in the overall wellbeing of women (and men).

For Uganda and Zimbabwe, more hours of care work are associated with women reporting more illness and injuries related to it. We find that over a third of women in Uganda and Zimbabwe and over two-thirds of women in the Philippines had experienced an injury, illness, disability or other physical or mental harm from their unpaid domestic work or caring for people in the last 12 months. This harm was perceived as having a long-term effect for about half of the women affected. The large majority of women were also concerned that their unpaid care work would cause them harm in the future. In this context, policies and initiatives that address women's heavy and unequal care work can contribute to women's wellbeing.
$77 \%$ of the women interviewed in the Philippines, $33 \%$ of the women in Uganda and $38 \%$ of the women in Zimbabwe reported having experienced an injury, illness, disability or other physical or mental harm from their unpaid domestic work or caring for people in the last 12 months. Out of those women, $43 \%$ in the Philippines, $58 \%$ in Uganda and $54 \%$ in Zimbabwe said that the harm had a long-term effect. The large majority of women in all three countries were concerned that their care and domestic work would cause them harm in the future $181 \%$ in the Philippines, $94 \%$ in Uganda and $93 \%$ in Zimbabwe). Table 13 summarizes the percentages of women who had experienced harm related to unpaid care, the long-term effect of this and women's concerns about future harm linked to care work.

The type of harm caused by care work was mainly backache and headache in all the countries. $70 \%$ of the women interviewed in the Philippines, $57 \%$ of the women in Uganda and $61 \%$ of the women in Zimbabwe reported backache linked to their unpaid domestic work or caring for people in the last 12 months. Headaches linked to care work were reported by $47 \%$ of women in the Philippines, $20 \%$ of women in Uganda and $28 \%$ of women interviewed in Zimbabwe.

For the Philippines and Zimbabwe, additional questions were asked on water-related harm. 10\% of women interviewed in the Philippines and 5\% in Zimbabwe reported that a household member had suffered from a water-related illness in the last seven days. Regarding water collection for laundry, $74 \%$ of the women in the study areas in the Philippines and 19\% of the women in Zimbabwe reported an injury, illness, disability or other physical or mental harm from collecting water or doing laundry. The women mainly reported backache (83\% in the Philippines and 69\% in Zimbabwe) and headache $129 \%$ in the Philippines and 22\% in Zimbabwe).

We looked at whether women's primary or any care hours the day before the interview are associated with women reporting an injury, illness, disability or other physical or mental harm from their unpaid domestic work or caring for people in the last year. In Uganda and Zimbabwe, we find an association between more hours of primary and any care and women reporting that they had experienced harm linked to care work.

TABLE 13: PROPORTION OF ADULT WOMEN WHO REPORTED HARM RELATED TO UNPAID CARE WORK IN SAMPLES FROM THREE COUNTRIES, 2017

\begin{tabular}{|l|l|l|l|}
\hline & Philippines & Uganda & Zimbabwe \\
\hline Experienced harm from care work & $76.47 \%$ & $32.77 \%$ & $37.99 \%$ \\
\hline Harm had long-term effect & $42.31 \%$ & $58.12 \%$ & $53.55 \%$ \\
\hline Concerned that care work will cause harm in future & $80.88 \%$ & $94.14 \%$ & $91.91 \%$ \\
\hline
\end{tabular}




\section{TIME CONSTRAINTS}

The HCS accounts for negative consequences linked to limited time to perform care work, asking women several questions about time constraints and how it affects different care activities (e.g. childcare, adult care, cooking, washing clothes).

Women who spent more time on care work experienced more time constraints with care. We find that due to heavy workloads, a minority of women respondents reported that it was impossible to avoid leaving dependants alone.

Heavy and unequal care not only affects women's wellbeing but can also have negative consequences for children and dependent adults. Policies that reduce the drudgery of care, for example through providing infrastructure and equipment, can be beneficial not only for women but also for their children and other family members.

In the previous week, $15 \%$ of the women interviewed in the Philippines, $11 \%$ of the women in Uganda and $8 \%$ of the women in the Zimbabwe sample had left a child aged under six without supervision. Fewer women reported having left a dependent adult alone without supervision (10\% Philippines, 10\% Uganda, $5 \%$ Zimbabwe). $6 \%$ in the Philippines, $16 \%$ in Uganda and 12\% in Zimbabwe reported that dependants had injured themselves in the last week. Dependants of $5 \%$ (Philippines), 16\% (Uganda) and $23 \%$ (Zimbabwe) of the women had damaged something in the last week. About a third of the women in all three countries also reported that they had not had time for cooking, washing clothes and personal care in the last week.
We looked at whether women's primary and any care hours are associated with leaving children and dependent adults alone and with children or dependent adults damaging something or having an accident. We find that women who spent more time on care work experienced more time constraints with care. Long hours of care might mean more domestic work and less time and attention for dependants. We find an association between more any care hours for women and leaving a dependent adult alone in the Philippines and Uganda. In Zimbabwe, the opposite is the case: women who reported more primary care hours tended to be less likely to leave a dependent adult alone. It might be that part of their primary care hours entails looking after a dependent adult. There is no association between women's care hours and the likelihood of leaving children alone.

If women spent more time on primary or any care in the Uganda study areas and any care in Zimbabwe, children or dependent adults were more likely to have had an injury in the last week. Similarly, children or dependent adults were more likely to have damaged something if women spent more time on primary care in Uganda and any care in Uganda and Zimbabwe. There are two possible explanations for these findings. On the one hand, women who do more domestic work might have less time and attention to give to dependants. On the other hand, mothers of children who are more likely to injure themselves or break things (e.g. are more clumsy or reckless) might spend more time looking after them.

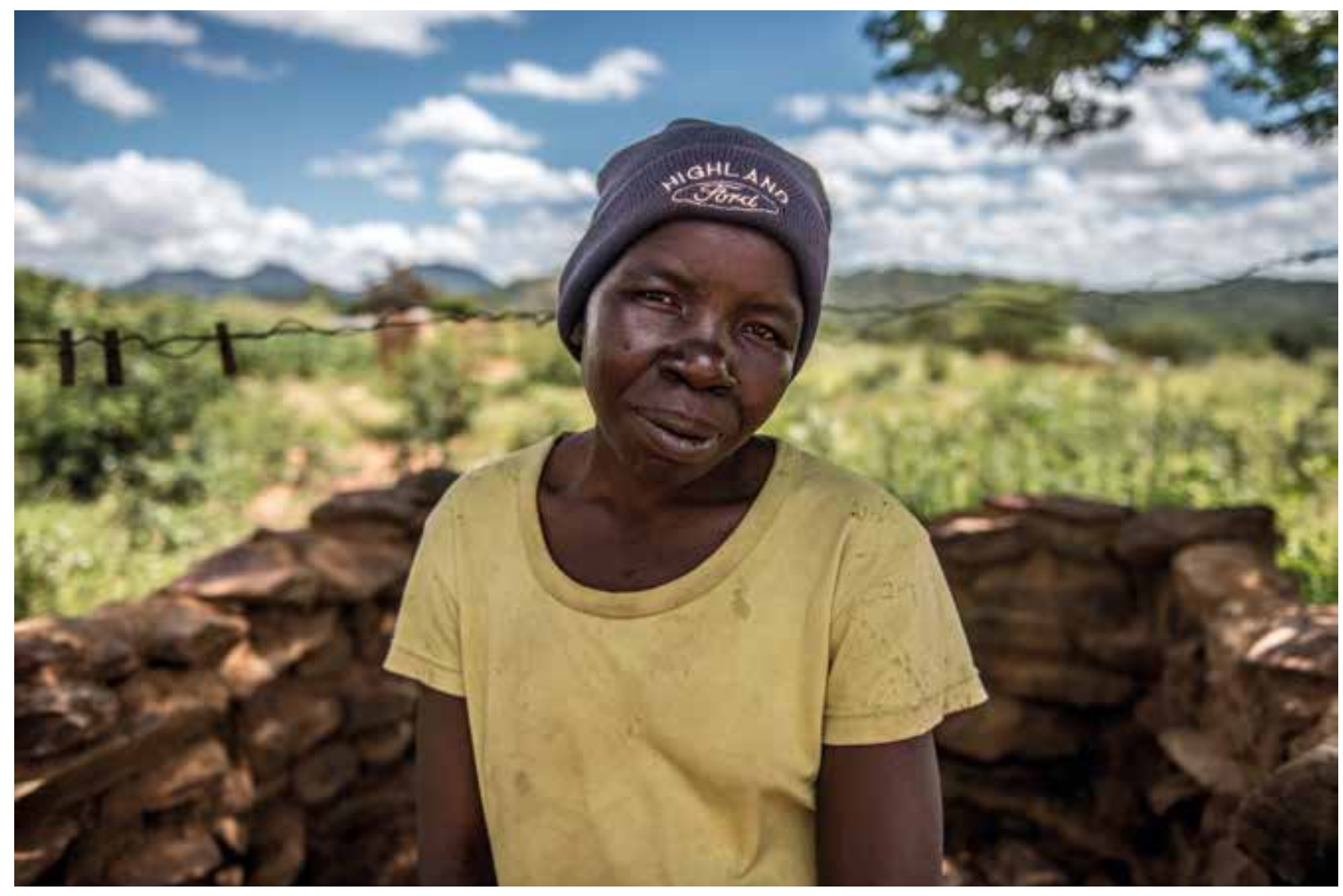




\section{HIGHLIGHTS AND SUGGESTIONS}

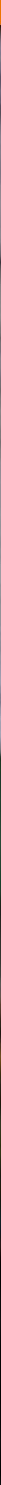




\section{This section presents some key interesting or surprising findings from each of the study countries that would be interesting to explore further.}

\section{PHILIPPINES}

- Women in the Philippines spent more time on care work than women in the other settings. But men also tended to spend most time on care work compared to other men: about 3 hours on primary care and 6 hours on any care. It would be interesting to explore why there is such a high demand for care in the surveyed communities in the Philippines.

- Men on average spent 1 hour 16 minutes a day on cooking, which seems surprisingly high compared to other countries and to previous HCS research. This finding contradicts the qualitative research finding that men are more likely to fetch water than to cook. It would be interesting to investigate this further and find out what type of men engage in cooking.

- Women spent over 2 hours a week collecting water for laundry. We could further explore if other household members also contribute to water collection for laundry, and what the total household time spent on water collection for laundry is.

- Women only spent about 2 hours a day on paid work, which is less than in the communities interviewed in Uganda and Zimbabwe. It would be interesting to explore what barriers women face to entering paid work.

- Children and adolescents reported working less than in the other two contexts, and gender differences were not so pronounced. It would be interesting to explore whether women get help with care work from other people le.g. maids, relatives).

- Qualitative research could try to understand why more educated women spent more time on care work.

- It would be interesting to explore why better-off men spent less time on care.

- Owning more equipment for childcare is associated with men spending more hours on caring for children in the Philippines. Qualitative research could explore reasons for this finding.
-We find that women with access to improved water spent less time on leisure, but the distribution of any care hours between women and men is more equal. This seems contradictory, and further research could try to clarify this finding.

- In contrast to what we would expect under proposition 6a, use of healthcare facilities is associated with an increase in women's care work hours. It would be useful to ask more detailed questions about healthcare to better understand this relationship.

- Further research could look into why having at least one child in a daycare centre is associated with fewer primary care hours for men but not for women.

- We find that women who live closer to an all-season road spent more time on any care. We hypothesized that the opposite would be true, as roads can improve access to services. Might it be the case that roads nearby require more childcare supervision because of the risk of road accidents? - The distribution of care between men and women tended to be more equal if men thought that meal preparation required fewer skills than women believed to be the case. This seems counter-intuitive and calls for further investigation.

- In the Philippines, the large majority of respondents said that men should do care work irrespective of whether men in the community engaged in care work and of whether community members thought it was acceptable for men to do care work. Is this the case because community members' behaviour and views do not matter to personal behaviour, or has it something to do with social desirability bias during the interview? 


\section{UGANDA}

- It would be interesting to find out why men spent three times more time on any care than on primary care. Is it more acceptable to do care while doing another primary activity? Or is looking after children more acceptable than doing other care activities?

- Further research could look into whether men are aware of the fact that they spent less time than women on total work, and investigate how this relates to normative ideas of masculinity.

- Girls and boys of all age groups in Uganda spent surprisingly many hours on care (and paid work). It is important to look into this and find out what triggers, and could potentially reduce, such long working hours for children.

- It is interesting that being married is associated with greater inequality in care work. Further research could investigate whether the type or length of marriage matters.

- We find that more educated women spent more time on care work. Qualitative research could try to understand whether this is the case, and why.

- Men's hours of primary care are higher for those living in a household with a dustbin or compost pit. Is this the case because households where men do more care work are more likely to invest in time- and labour-saving equipment?

- Electricity decreases women's sleeping time. Is this linked to electricity being used for lighting, thereby increasing the time available for other activities?
- In contrast to what we would expect under proposition 6a, availability of healthcare facilities is associated with an increase in women's and men's care-work hours. It would be useful to ask more detailed questions about healthcare to better understand this relationship.

- More detailed analysis on childcare facilities could help to clarify why we did not find an effect of childcare services on care-work hours. Is it the case that households that invest in childcare have higher expectations of how to care for their children and thus spend more time looking after children when they are at home? Or are women with more demand for childcare more likely to send their children to childcare services, which means that they still have more total childcare hours than women who have less demand for childcare? Is it to do with the fact that childcare is carried out at the same time as other tasks? Or because not all the children in the household are enrolled in daycare?

-We find that women who live closer to an all-season road spent more time on primary care. We hypothesized that the opposite would be true, as roads can improve access to services. Might it be the case that roads nearby require more childcare supervision because of the risk of road accidents? - Further research could investigate why women and men found it more acceptable to beat a woman than to harshly criticize a woman for perceived inadequate provision of care.

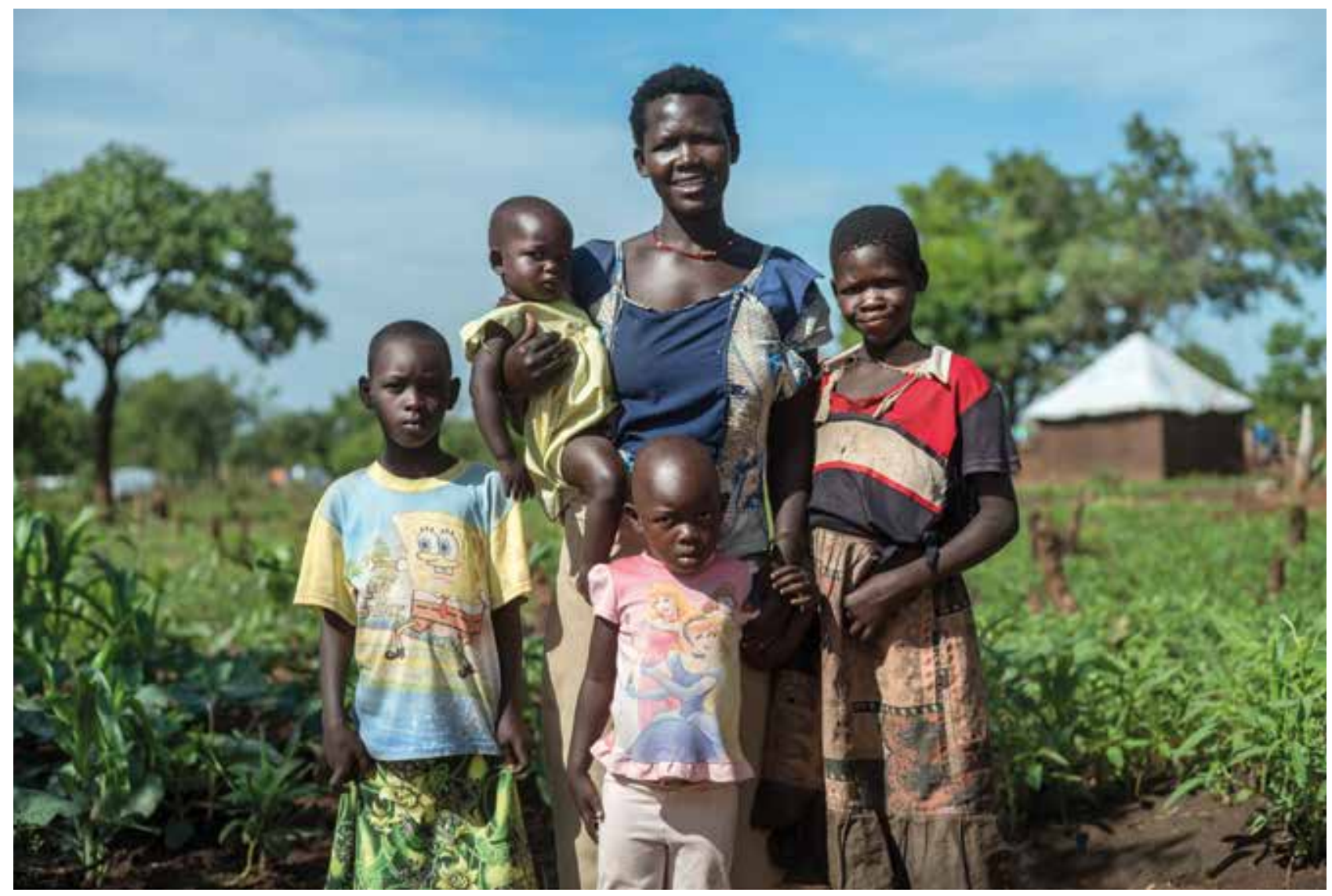




\section{ZIMBABWE}

- It would be interesting to find out why men spent three times more time on any care than on primary care. Is it more acceptable to do care while doing another primary activity? Or is looking after children more acceptable than doing other care activities?

- A surprising finding is that both boys and girls spent less time on school in households with improved water access. This needs further investigation.

- Women spent over 2 hours a week collecting water for laundry. We could further explore if other household members also contribute to water collection for laundry, and what the total household time spent on water collection for laundry is.

- Further research could look into whether men are aware of the fact that they spent less time on total work than women, and investigate how this relates to normative ideas of masculinity. - Girls and boys of all age groups spent many hours on care land paid work). It is important to look into this and find out what triggers, and what could reduce, such long working hours for children.

- It is interesting that being married is associated with greater inequality in care work. Further research could investigate whether the type or length of marriage matters.

- We find that men spent more time on water collection/primary care if the household owned water-/fuel-related equipment. It would be interesting to explore what kind of equipment encourages men to participate in care, and why.

- Access to electricity is associated with longer care hours for women. Is this the case because with electric light women can carry out care tasks later in the evening? Is electricity also used for equipment that reduces care work?

- Further research could explore why use of healthcare facilities is associated with a more equal distribution of any care between men and women. Are men more likely to look after the sick if they have access to healthcare facilities?

- More detailed analysis on childcare facilities could help to clarify why we did not find an effect of childcare services on care-work hours. Is it the case that households that invest in childcare have higher expectations of how to care for their children and thus spend more time looking after children when they are at home? Or are women with more demand for childcare more likely to send their children to childcare services, which means that they still have more total childcare hours than women who have less demand for childcare? Is it to do with the fact that childcare is carried out at the same time as other tasks? Or because not all of the children in a household are enrolled in daycare?

-We find that women who live closer to an all-season road spent more time on any care. We hypothesized that the opposite would be true, as roads can improve access to services. What could be possible explanations for this finding? Might it be the case that roads nearby require more childcare supervision because of the risk of road accidents?

- The distribution of care between men and women tended to be more equal if men thought that meal preparation and childcare required fewer skills than women perceived to be the case. This seems counter-intuitive and calls for further investigation.

- If men thought that cleaning required fewer skills than women believed to be the case, households owned more cleaning equipment. But if men thought meal preparation required fewer skills than women did, households owned less equipment related to meal preparation. These two findings are contradictory. Further research shedding light on the relationship between perceptions of care and investment in time- and labour-saving equipment would be useful.

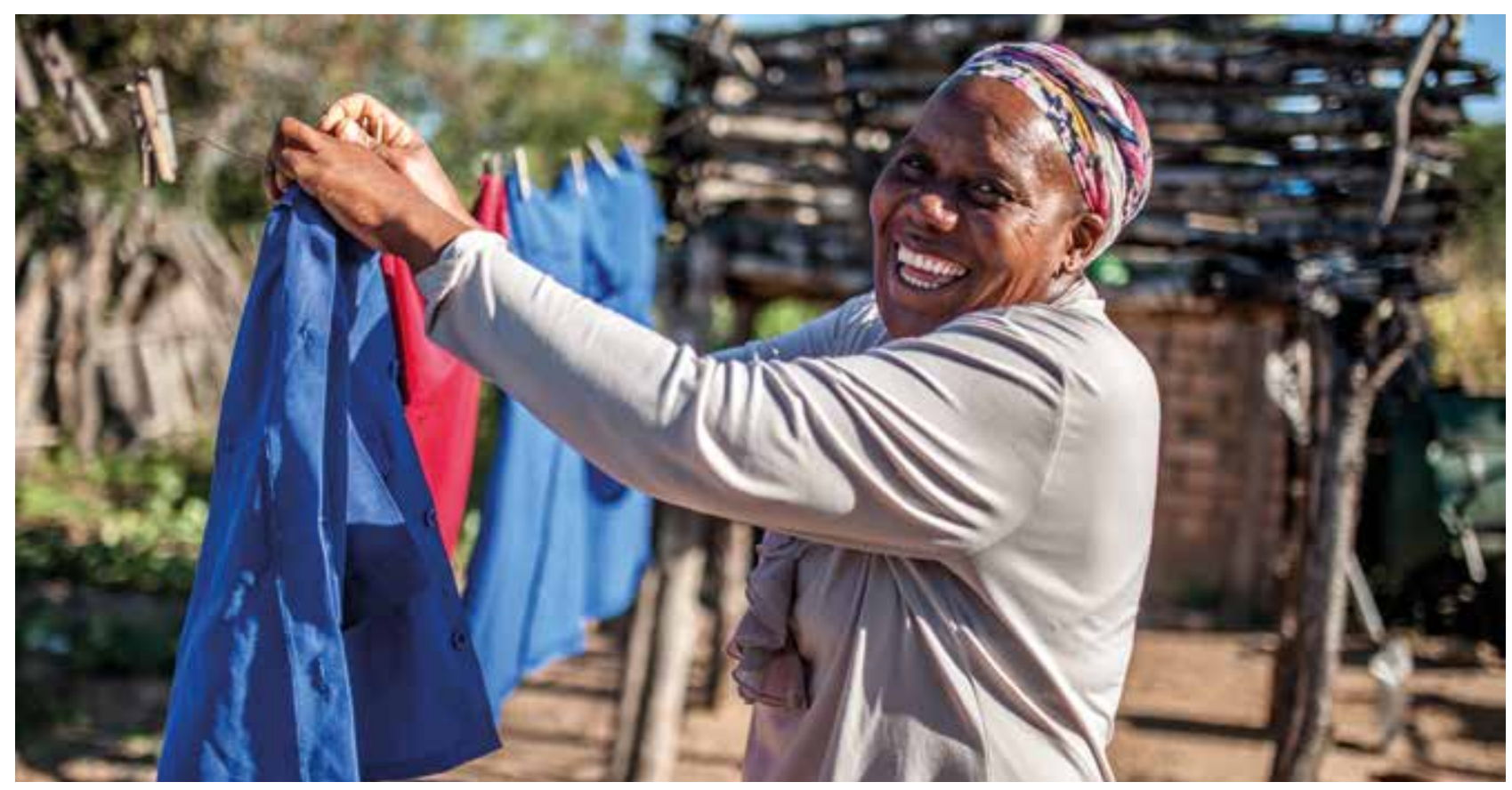




\section{CONCLUSION}

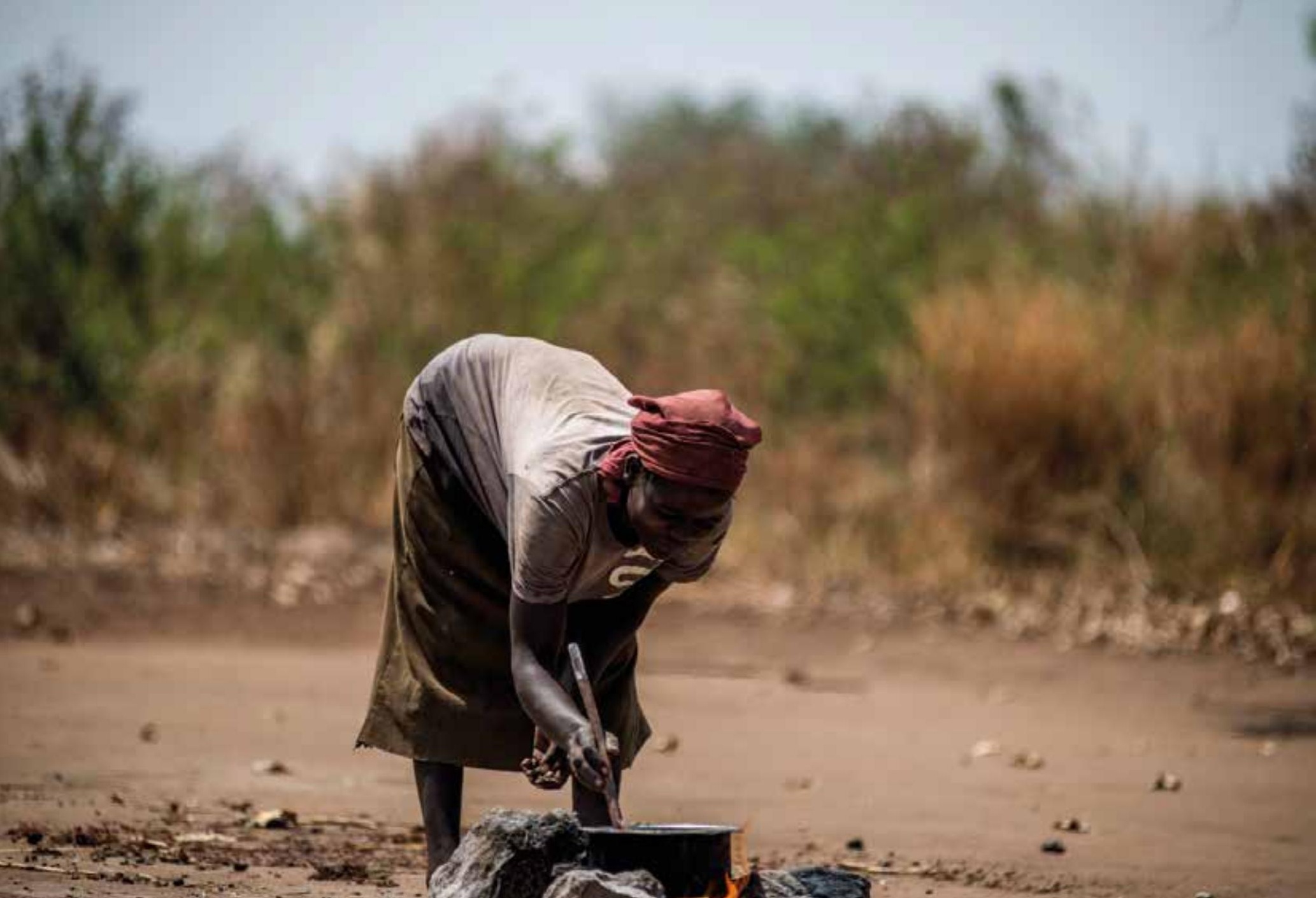


The 2017 HCS data stresses the need to address unpaid care work in economic and development policy and practice. It emphasizes the potential of time- and laboursaving equipment and public infrastructure and services to bring about positive change in care-work patterns. But the evidence also highlights that, to be effective, change in care work requires positive shifts in social norms that encourage male participation in unpaid care and domestic work.

Women interviewed in the samples from the Philippines, Uganda and Zimbabwe spent more time on all care work indicators than men: about 11 to 12 hours a day on any care, which is more than twice as much as men in the Philippines sample, and more than three times as much as men interviewed in Uganda and Zimbabwe. Boys and especially girls also contributed a significant amount of their time to care work from a young age, and gender disparities in the distribution of unpaid care work are found in all age groups.

We find that heavy care workloads can negatively affect women's health. A significant number of women in all study areas reported that they had experienced an injury, illness, disability or other physical or mental harm from their unpaid domestic work or caring for people in the last 12 months. Women who spent more time on care work were more likely to report harm related to care in Uganda and Zimbabwe. Heavy care workloads also made it impossible for a proportion of women respondents to avoid leaving children and dependants alone without supervision.

We find that ownership of care-related equipment, especially water-related equipment, can significantly reduce hours spent on care work. It is interesting that in some contexts men were also more likely to engage in care if equipment was available. Overall, the findings on time- and labour-saving equipment show that equipment that reduces time spent on fuel collection, meal preparation, cleaning and preparing clothes can make a difference. But the findings also show that while these single pieces of equipment are necessary, they are not sufficient; real reductions in women's care-work time are expected when multiple types of time- and laboursaving equipment are present, when public services are improved and when men are sharing the responsibility for care.

Public services and infrastructure also have great potential to reduce heavy care work for women. The finding on access to an improved water source in relation to women's care hours is especially significant. Access to an improved water source is associated with 1 to 4 hours less reported time spent on care work. On access to electricity, the report shows that while minimal access to electricity only appears to lengthen care hours (because with electric light more care tasks can be done after dark), potentially, where electricity is used for equipment that reduces care work, women will spend fewer hours on care and more on leisure. The use of healthcare facilities is associated with more care hours in some contexts, and with fewer care hours in others. For childcare facilities, we only find an association with reduced care-work hours in the Philippines.

Despite the potential of infrastructure and equipment to reduce inequality in care work, the findings emphasize the need to also address social norms and perceptions about care work to encourage male participation in care work and achieve long-term change.

The report highlights that according to the responses on social norms, what matters most to determine whether men do care work is what other people think should be done, rather than what they actually do. Most men want to do care and believe in sharing; the obstacle is their perception that others do not approve. Revealing the discrepancy between what people think the community does and thinks, and what the community actually does and thinks, can potentially open people's eyes and encourage male participation in care work. The second key finding on social norms is that men are more likely to engage in care work if their fathers engaged in care activities when they were children. At the same time, we find that men and women often do not want to involve their sons in care work. Finally, the report shows that acceptance of gender-based violence is associated with women doing more and men doing less care work. Encouraging male participation in care work from a young age, together with activities that mobilize community members to show their support for an equal gendered distribution of unpaid care work can help to bring about change, and ultimately have a positive impact on possible drivers of gender-based violence in the community.

Although development practitioners may expect that women with significant agency will negotiate housework with other family members, the study - in line with our previous Household Care Surveys - did not find a consistent association between women's decision making and carework hours. However, this research finds an association between women's decision-making power and ownership of time- and labour-saving equipment, indicating an additional potential avenue of change. Even where men's participation in care work remains low due to social norms, raising women's agency and awareness of the benefits of such equipment might help to reduce their workloads. It is also interesting that the effect of decision-making power on ownership of time- and labour-saving equipment was especially significant for water-related equipment, which is the type of equipment that was found to be most significant in reducing care workloads. 


\section{RECOMMENDATIONS}

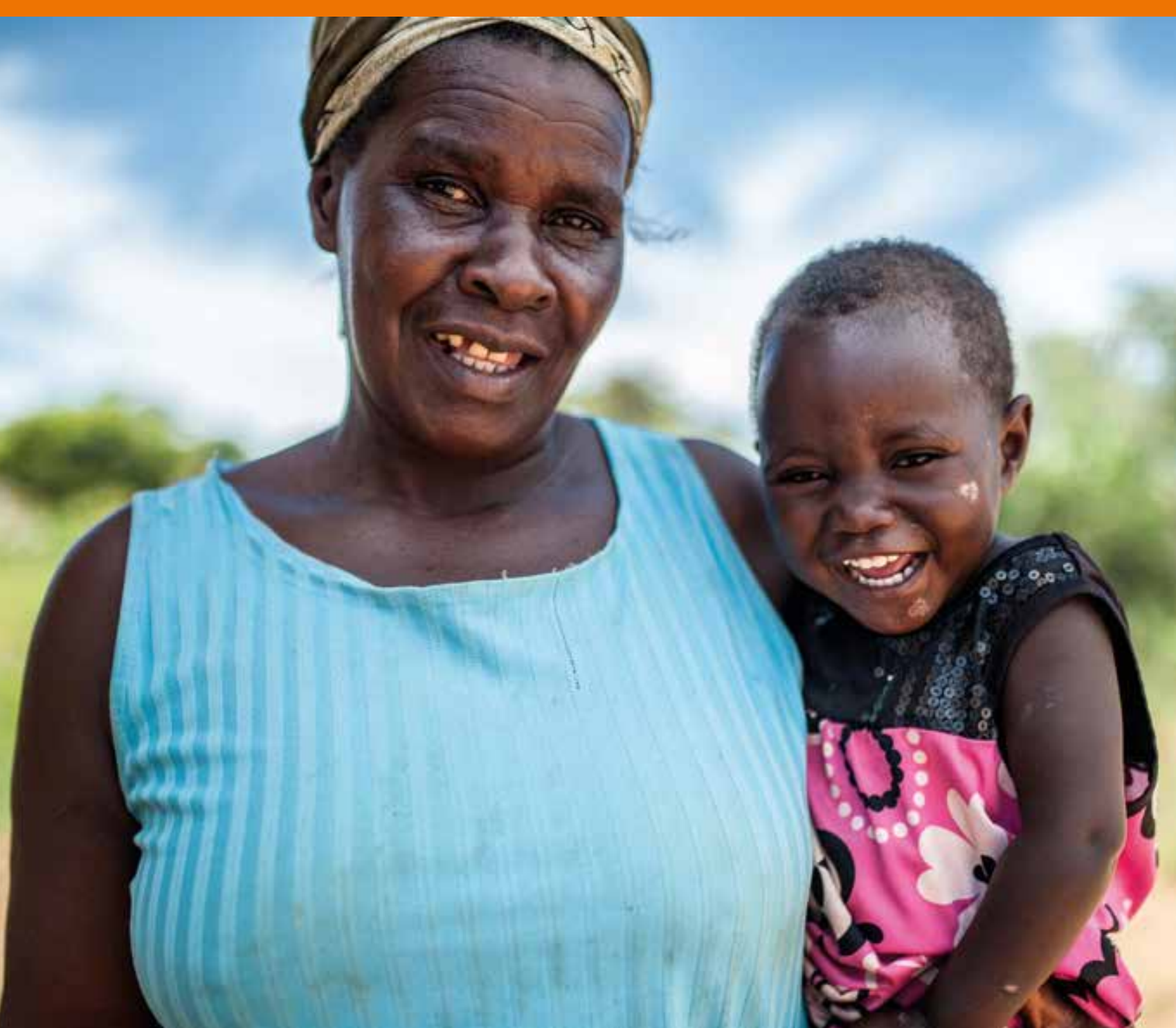




\section{The 2017 HCS shows that interventions that reduce women's care workloads}

contribute to their wellbeing and reduce time poverty. Here we present some recommendations for government and private sector decision makers, development practitioners and researchers in the area, as well as other relevant stakeholders interested in the issue.

- The report recommends that governments and private sector actors take responsibility for gendered inequality in the household and in the economy through investments in care-related services and infrastructure, especially water access, and time- and labour-saving equipment to reduce long hours of care work and to address 'occupational health and safety' risks and 'lost work time' for women carers.

- The report recommends that government, private sector and development actors prioritize poor households' access to affordable services and infrastructure related to water, to fulfil national and international commitments to reduce heavy workloads of unpaid care work, especially for women and girls.

- The report findings call for more research to investigate the impact of public services and infrastructure on women's time use and wellbeing to inform more deliberate gender-transformative programmes and public policies.
- The report recommends combining investments in infrastructure, service provision or time- and laboursaving equipment with initiatives that address the social norms that might inhibit women and men from redistributing unpaid care work within the household. Further research is needed to understand what kinds of social norms interventions are most effective for promoting equal sharing of responsibility of care between men and women.

- Programmes can highlight the fact that male participation in care work is widely accepted by individuals, and that men are more likely to engage in care work if their fathers engaged in care activities when they were children. The role of male 'care champions', in this context, is not only to lead by example, but to engage in dialogue to unveil perceptions and challenge social norms about care work in the community.

- The report recommends closer collaboration between initiatives that address gender-based violence and initiatives that promote positive change in gendered social norms and practices on unpaid care work. A concerted approach in addressing harmful social norms and practices could contribute to minimizing risks of gender-based violence related to the redistribution of unpaid care work within the household while promoting more sustainable, transformative approaches towards gender equality. 


\section{BIBLIOGRAPHY}

International Food Policy Research Institute (IFPRI) (2012) 'The Women's Empowerment in Agriculture Index', Washington D.C.: International Food Policy Research Institute.

Bicchieri, C. (2017) 'Norms in the Wild: How to Diagnose, Measure, and Change Social Norms', New York: Oxford University Press.

Budlender, D. (2007) 'A critical review of selected time use surveys', Gender and Development Programme Paper 2, July 2007, Geneva: UNRISD.

Chopra, D. (2013) 'A feminist political economy analysis of public policies related to care: A thematic review', Institute of Development Studies: Evidence Report 9: 1-26.

Elson, D. (2008) 'The Three R's of Unpaid Work: Recognition, Reduction and Redistribution', paper presented at the Expert Group Meeting on Unpaid Work, Economic Development and Human Wellbeing, UNDP, New York, November 2008.

England, P. (2005) 'Emerging theories of care work', Annual Review of Sociology 3: 381-99.

England, P. and Folbre, N. (1999) 'The Cost of Caring', The ANNALS of the American Academy of Political and Social Science 561(1): 39-5.

Esquivel, V. (2013) 'Care in Households and Communities: Background Paper on Conceptual Issues', Oxfam research reports, Oxford: Oxfam GB.

Ferrant, G., Pesando, M.L. and Nowacka, K. (2014) 'Unpaid Care Work: The Missing Link In The Analysis of Gender Gaps in Labour Outcomes'. Retrieved from: https://www.oecd.org/ dev/development-gender/Unpaid_care_work.pdf

Flake, D.F. (2005) 'Individual, Family, and Community Risk Markers for Domestic Violence in Peru'. Violence Against Women 11(3): 353-373.

Folbre, N. (1995) "“Holding hands at midnight": The Paradox of Caring Labor'. Feminist Economics 1(1): 73-92.

Karimli, L., Samman, E., Rost, L. and Kidder, T. (2016) 'Factors and Norms Influencing Unpaid Care Work: Household Survey Evidence from Five Rural Communities in Colombia, Ethiopia, the Philippines, Uganda and Zimbabwe', Oxfam research reports, Oxford: Oxfam GB.

Koissy-Kpein, S.A. (2012) 'Gender and Competition between Economic and Non-Economic Labour and Schooling:

Evidence from EPAM MALI' African Development Review, 24(1): $1-17$.
Koolwal, G. and Van de Walle, D. (2013) 'Access to Water, Women's Work, and Child Outcomes', Economic Development $\delta$ Cultural Change 61: 369-405.

Mehretu, A. and Mutambirwa, C. (1992) Time and Energy Costs of Distance in Rural Life Space of Zimbabwe: Case Study in the Chiduku Communal Area', Social Science Medicine 34: 17-24.

Ray, R. and Lancaster, G. (2005) ‘The Impact of Children's Work on Schooling: Multi-country Evidence', International Labour Review, 144: 189-210.

Razavi, S. (2007) 'The Political and Social Economy of Care in a Development Context: Conceptual Issues, Research Questions and Policy Options', Geneva: UNRISD.

Rosati, F.C. and Rossi, M. (2001) 'Children's Working Hours, School Enrolment and Human Capital Accumulation: Evidence from Pakistan and Nicaragua', Understanding Children's Work (UCDW Project). Retrieved from: http://www.ucw-project.org/ attachment/workinghours_humancapital.pdf

Rost, L., Bates, K. and Dellepiane, L. (2015) 'Women's economic empowerment and care: Evidence for influencing baseline research report', Oxfam research reports, Oxford: Oxfam GB.

Samman, E. et al. (2016) 'Women's work: Mothers, children and the global childcare crisis', London: ODI.

Rost, L. (forthcoming), 'Mothers or children? Challenges with measuring children's time use in Uganda'.

Sepulveda Caramona, M. (2014) ‘Unpaid work, poverty and women's human rights', New York: United Nations.

UN Women (1995) 'Fourth world conference on women: Beijing declaration', http://www.un.org/womenwatch/daw/beijing/ beijingdeclaration.html (last accessed July 2017).

World Health Organization and UNICEF (2012) 'Progress on Sanitation and Drinking Water', https://www.unicef.org/ media/files/JMPreport2012.pdf (last accessed November 2017).

Woodroffe, J. and Donald, K. (2014) 'Unpaid care: A priority for the post-2015 development goals and beyond', Briefings 6 , July 2014, London: Gender and Development Network.

Young Lives (2017) Young Lives website: http:/ / www. younglives.org.uk/ 


\section{NOTES}

${ }^{1}$ For more, please see the UN Special Rapporteur's report on extreme poverty and human rights (2013): http:/ / api.ning. com/files/M7-ZTbQuBuzk5RmRgodjDx3XtpmhVsIIGVv48AilQH26DkAAASbtQMxzrUoVQMhu*LmyhOMNOrZ6gLMUMQXCkk7fWbhqda6Z/UnpaidcarereportA.68.293_EN.pdf

2 For brevity, findings are discussed as for 'these countries', when they should always be understood as the findings for the survey samples from districts in the three countries.

3 In Parvez, A. Remme, J. A. Koissy-Kpein, S. and Rost, L. (2018) 'Exploring the need for gender-equitable fiscal policies for a human economy: evidence from Uganda and Zimbabwe', forthcoming.

${ }^{4}$ Ibid., forthcoming.

${ }^{5}$ The major partners for WE-Care have been Hewlett for research/advocacy and Unilever, along with smaller foundations (e.g. Garden Trust).

${ }^{6}$ Unilever's laundry brand SURF is working with Oxfam combining our scale, expertise and resources to deliver a pioneering partnership and global programme. This will challenge limiting social norms and ensure that unpaid care work undertaken by women around the world is recognized and valued, and that difficult tasks, especially laundry, are reduced so that women and girls have the time to claim their rights and unlock their full potential.

${ }^{7}$ In the 2014 HCS, the measurement of children's time use was rather limited, as the survey only asked parents to estimate the time their children spent on care activities.

8 In the 2015 HCS, children's time use was reported by their mothers. Low reported hours of children's time use and discussions with the country teams led to the conclusion that mothers under-reported hours of children's care work. In Uganda, where children of some of the households were interviewed separately, it was found that children reported significantly higher hours of care work than their mothers reported them doing (Rost, forthcoming). These discrepancies between the reporting of a child and his/her mother indicated the need for a new methodology to capture children's time use.

${ }^{9}$ The approach we used is well explained in Cristina Bicchieri's free online courses on measuring social norms.

See: https://www.coursera.org/learn/norms and https:// www.coursera.org/learn/change
${ }^{10}$ The children were on vacation during the period of the HCS in Uganda, so we cannot assess their time spent on schooling.

${ }^{11}$ The aim of this report is to be accessible and to be written in non-technical language. This is why we keep explanations of the data analysis methodology to a minimum. To analyse the findings we used: (1) univariate analyses to describe a specific variable le.g. mean, standard deviation, minimum, maximum); (2) bivariate analyses to test whether differences among women (girls) and men (boys) are statistically significant (i.e. comparison tests with unequal variance); (3) linear regression analysis to assess the relationship between a defined dependent variable $Y$ (e.g. hours of care work) and independent variables $X$.

12 We did not conduct analysis for the relationship of childcare-related equipment and young people's time spent on childcare because of the low number of observations.

${ }^{13}$ We did not carry out any analysis to look at the relationship of adult care equipment on young people's time spent on adult care because of the low number of observations.

${ }^{14}$ The 12 tasks are: meal preparation; drying/processing an agricultural product; caring for elderly, ill or disabled household members; planting/harvesting crops; caring for children; house construction/repair; cleaning the house or compound; carpentry/making furniture; fuel or water collection; selling products/trading; taking care of farm animals; washing clothes.

${ }^{15}$ We computed two decision-making scores, as follows: (1) Decision-making score: for each area of decision making, we defined a binary variable which takes the value 1 if the woman is involved in decision making independently or jointly. The decision-making score represents the mean number of decision-making areas that women were involved in. (2) Decision-making and influencing score: for each area of decision making, 0 is assigned if a woman is not involved and cannot influence decisions, 1 is assigned if a woman is involved but cannot influence decisions, 2 is assigned if a woman is not involved but can influence decisions, and 3 is assigned if a woman is involved and can influence decisions. The decision-making and influencing score is the mean score of all areas of decision making combined. 


\section{APPENDIX}

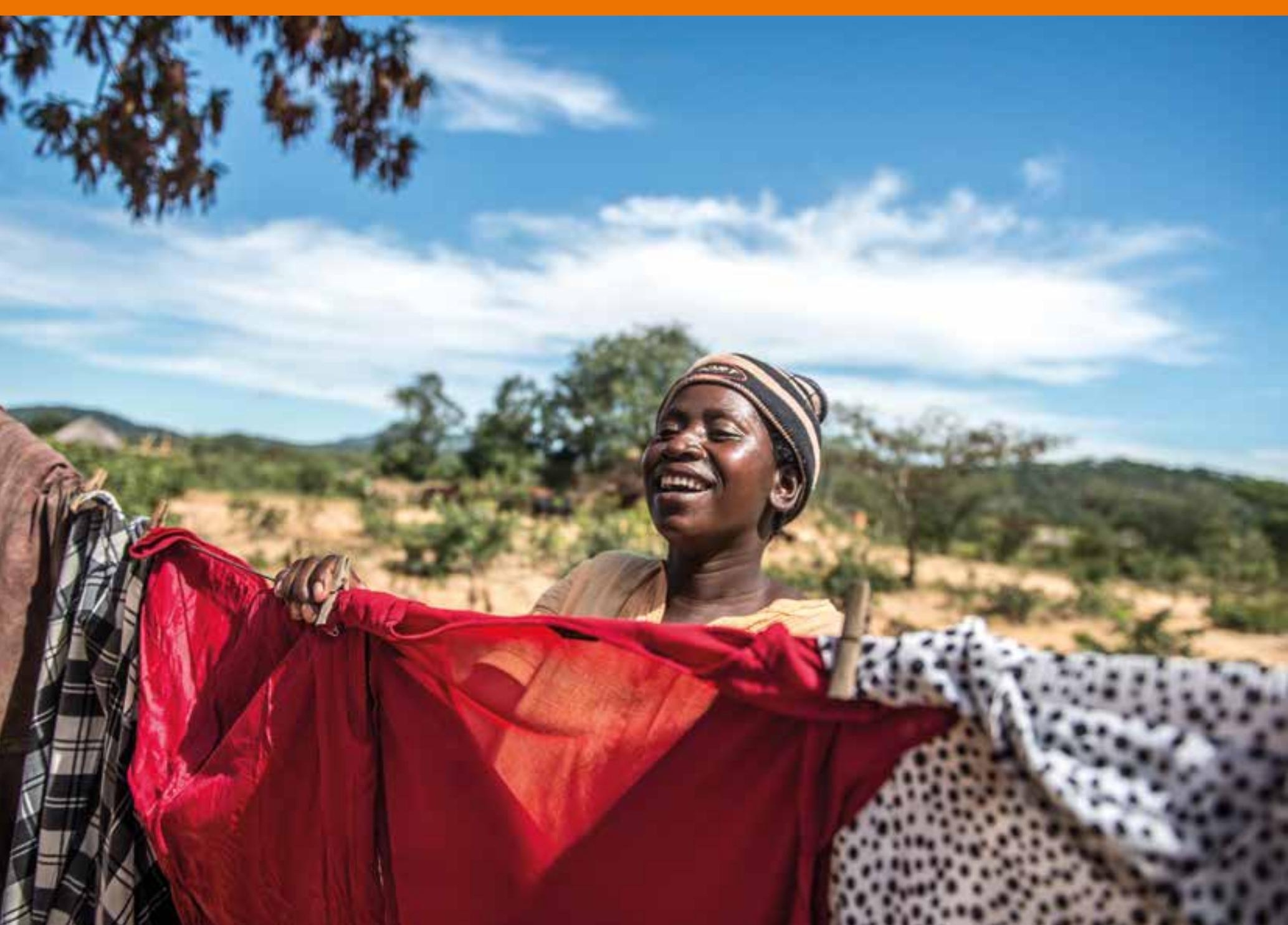


DESCRIPTIVE STATISTICS TABLES

DEMOGRAPHIC CHARACTERISTICS OF SURVEY RESPONDENTS BY COMMUNITY, IN SAMPLES FROM THREE COUNTRIES, 2017

\begin{tabular}{|c|c|c|c|c|c|c|c|c|c|c|c|c|c|c|c|c|c|c|}
\hline & \multicolumn{6}{|c|}{ Philippines } & \multicolumn{6}{|c|}{ Uganda } & \multicolumn{6}{|c|}{ Zimbabwe } \\
\hline & 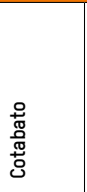 & 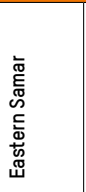 & $\stackrel{Ð}{ \pm}$ & 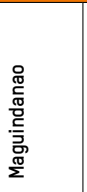 & 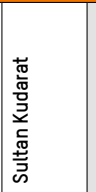 & 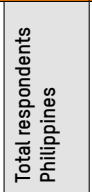 & $\begin{array}{l}\text { 홍 } \\
\text { 음 }\end{array}$ & $\begin{array}{l}\mathbb{J} \\
\text { dy }\end{array}$ & 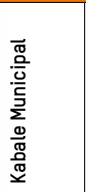 & 变 & $\begin{array}{l}\frac{0}{0} \\
\frac{0}{2} \\
\frac{2}{2}\end{array}$ & 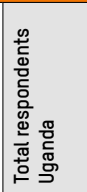 & 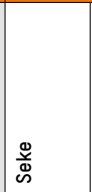 & 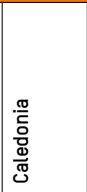 & $\overline{\mathrm{a}}$ & 疍 & 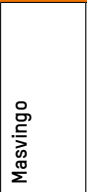 & 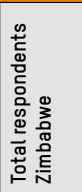 \\
\hline \multicolumn{19}{|c|}{ Number of households } \\
\hline Women & 60 & 90 & 23 & 15 & 16 & 204 & 396 & 308 & 52 & 205 & 115 & 1076 & 93 & 111 & 54 & 56 & 94 & 408 \\
\hline$\%$ & 50.00 & 50.00 & 43.40 & 51.72 & 51.61 & 49.39 & 56.25 & 58.44 & 60.47 & 54.52 & 55.02 & 56.57 & 60.39 & 55.50 & 51.43 & 53.85 & 53.11 & 55.14 \\
\hline Men & 60 & 90 & 30 & 14 & 15 & 209 & 308 & 219 & 34 & 171 & 94 & 826 & 61 & 89 & 51 & 48 & 83 & 332 \\
\hline$\%$ & 50.00 & 50.00 & 56.60 & 48.28 & 48.39 & 50.61 & 43.75 & 41.56 & 39.53 & 45.48 & 44.98 & 43.43 & 39.61 & 44.50 & 48.57 & 46.15 & 46.89 & 44.86 \\
\hline Total adults & 120 & 180 & 53 & 29 & 31 & 413 & 704 & 527 & 86 & 376 & 209 & 1902 & 154 & 200 & 105 & 104 & 177 & 740 \\
\hline Girls & 16 & 13 & 30 & 3 & 1 & 63 & 319 & 130 & 26 & 104 & 57 & 636 & 46 & 40 & 34 & 16 & 38 & 174 \\
\hline$\%$ & 39.02 & 56.52 & 51.72 & 75.00 & 50.00 & 49.22 & 52.30 & 55.08 & 50.98 & 50.49 & 52.29 & 52.48 & 52.27 & 56.34 & 60.71 & 43.24 & 44.71 & 51.63 \\
\hline Boys & 25 & 10 & 28 & 1 & 1 & 65 & 291 & 106 & 25 & 102 & 52 & 576 & 42 & 31 & 22 & 21 & 47 & 163 \\
\hline$\%$ & 60.98 & 43.48 & 48.28 & 25.00 & 50.00 & 50.78 & 47.70 & 44.92 & 49.02 & 49.51 & 47.71 & 47.52 & 47.73 & 43.66 & 39.29 & 56.76 & 55.29 & 48.37 \\
\hline Total children & 41 & 23 & 58 & 4 & 2 & 128 & 610 & 236 & 51 & 206 & 109 & 1212 & 88 & 71 & 56 & 37 & 85 & 337 \\
\hline \multicolumn{19}{|c|}{ Number of female only households } \\
\hline Total & \begin{tabular}{|l|l|}
60 \\
\end{tabular} & \begin{tabular}{|l|l|}
90 \\
\end{tabular} & 23 & 15 & 16 & 204 & 396 & 308 & 52 & 205 & 115 & 1076 & 93 & 111 & 54 & 56 & 94 & 408 \\
\hline \multicolumn{19}{|c|}{ Number of family members } \\
\hline Mean & 4.56667 & 5.41111 & 6.30435 & 6.6 & 6.25 & 5.41667 & 6.5303 & 4.60065 & 4.78846 & 5.57073 & 5.50435 & 5.6013 & 5.56522 & 4.52252 & 5.98148 & 4.89286 & 6.07447 & 5.36118 \\
\hline $\begin{array}{l}\text { Standard } \\
\text { Deviation }\end{array}$ & 1.69112 & 2.37446 & 1.7693 & 2.74643 & 2.56905 & 2.26081 & 2.21881 & 2.17618 & 2.22584 & 2.1898 & 2.07903 & 2.32438 & 2.00167 & 1.68872 & 2.36716 & 1.98795 & 2.57047 & 2.20272 \\
\hline Min-Max & 2 & 2 & 4 & 3 & 3 & 2 & 1 & 1 & 1 & 1 & 2 & 1 & 2 & 2 & 2 & 2 & 2 & 2 \\
\hline Max & 9 & 15 & 10 & 12 & 12 & 15 & 15 & 12 & 10 & 13 & 12 & 15 & 14 & 11 & 12 & 10 & 13 & 14 \\
\hline Total & |60 & 90 & 23 & 15 & 16 & 204 & 396 & 308 & 52 & 205 & 115 & 1076 & 92 & 111 & 54 & 56 & 94 & 407 \\
\hline \multicolumn{19}{|c|}{ Households with children aged under 6} \\
\hline $\begin{array}{l}\text { No child } \\
\text { age }<=6\end{array}$ & \begin{tabular}{|l|l|}
39 \\
\end{tabular} & \begin{tabular}{|l|l|}
39 \\
\end{tabular} & 8 & 9 & 3 & 98 & 110 & 124 & 21 & 73 & 43 & 371 & 37 & 36 & 21 & 29 & 46 & 169 \\
\hline$\%$ & 65.00 & 43.33 & 34.78 & 60.00 & 18.75 & 48.04 & 27.78 & 40.26 & 40.38 & 35.61 & 37.39 & 34.48 & 39.78 & 32.43 & 38.89 & 51.79 & 48.94 & 41.42 \\
\hline $\begin{array}{l}\text { Has at least } \\
\text { one under } 6 \\
\text { child }\end{array}$ & 21 & 51 & 15 & 6 & 13 & 106 & 286 & 184 & 31 & 132 & 72 & 705 & 56 & 75 & 33 & 27 & 48 & 239 \\
\hline$\%$ & 35.00 & 56.67 & 65.22 & 40.00 & 81.25 & 51.96 & 72.22 & 59.74 & 59.62 & 64.39 & 62.61 & 65.52 & 60.22 & 67.57 & 61.11 & 48.21 & 51.06 & 58.58 \\
\hline Total & 60 & 90 & 23 & 15 & 16 & 204 & 396 & 308 & 52 & 205 & 115 & 1076 & 93 & 111 & 54 & 56 & 94 & 408 \\
\hline \multicolumn{19}{|c|}{ Number of children aged under 14 per household } \\
\hline Mean & 1.52 & 2.12 & \begin{tabular}{|l|l|l}
1.96 \\
\end{tabular} & 2.27 & 2.31 & 1.95 & 3.64 & 1.86 & 1.73 & 2.48 & 2.23 & 2.67 & 2.41 & 1.84 & 2.37 & 1.70 & 2.23 & 2.11 \\
\hline $\begin{array}{l}\text { Standard } \\
\text { Deviation }\end{array}$ & 1.42 & 1.54 & 1.15 & 1.44 & 0.95 & 1.44 & 1.99 & 1.49 & 1.34 & 1.71 & 1.49 & 1.89 & 1.52 & 1.26 & 1.59 & 1.40 & 1.69 & 1.51 \\
\hline Min & 0 & 0 & 0 & 0 & 1 & 0 & 0 & 0 & 0 & 0 & 0 & 0 & 0 & 0 & 0 & 0 & 0 & 0 \\
\hline Max & 6 & 6 & 4 & 5 & 4 & 6 & 11 & 7 & 5 & 8 & 5 & 11 & 8 & 5 & 7 & 6 & 7 & 8 \\
\hline Total & \begin{tabular}{|l|l|l|l}
60 \\
\end{tabular} & 90 & 23 & 15 & 16 & 204 & 396 & 308 & 52 & 205 & 115 & 1076 & 93 & 111 & 54 & 56 & 94 & 408 \\
\hline \multicolumn{19}{|c|}{ Number of members aged 15-64 per household } \\
\hline Mean & 2.85 & 3.14 & 4.30 & 4.07 & 3.69 & 3.30 & 2.71 & 2.66 & 2.87 & 2.81 & 2.92 & 2.75 & 2.81 & 2.63 & 3.11 & 2.48 & 3.44 & 2.90 \\
\hline $\begin{array}{l}\text { Standard } \\
\text { Deviation }\end{array}$ & 1.25 & 1.63 & 1.92 & 2.22 & 2.09 & 1.71 & 1.65 & 1.41 & 1.57 & 1.54 & 1.55 & 1.55 & 1.40 & 1.05 & 1.48 & 1.41 & 1.60 & 1.41 \\
\hline Min & 0 & 1 & 2 & 1 & 1 & 0 & 0 & 0 & 1 & 0 & 0 & 0 & 0 & 1 & 0 & 0 & 0 & 0 \\
\hline Max & 6 & 8 & 8 & 8 & 8 & 8 & 10 & 9 & 7 & 7 & 8 & 10 & 10 & 7 & 7 & 7 & 8 & 10 \\
\hline Total & |60 & 90 & 23 & 15 & 16 & 204 & 396 & 308 & 52 & 205 & 115 & 1076 & 93 & 111 & 54 & 56 & 94 & 408 \\
\hline \multicolumn{19}{|c|}{ Number of members aged +65 per household } \\
\hline Mean & 0.20 & 0.13 & 0.04 & 0.27 & 0.25 & 0.16 & 0.17 & 0.07 & 0.19 & 0.26 & 0.36 & 0.18 & 0.31 & 0.05 & 0.50 & 0.71 & 0.40 & 0.34 \\
\hline $\begin{array}{l}\text { Standard } \\
\text { Deviation }\end{array}$ & 0.51 & 0.45 & 0.21 & 0.59 & 0.45 & 0.46 & 0.43 & 0.29 & 0.49 & 0.55 & 0.68 & 0.47 & 0.59 & 0.26 & 0.77 & 1.22 & 0.68 & 0.73 \\
\hline Min & 0 & 0 & 0 & 0 & 0 & 0 & 0 & 0 & 0 & 0 & 0 & 0 & 0 & 0 & 0 & 0 & 0 & 0 \\
\hline Max & 2 & 2 & 1 & 2 & 1 & 2 & 2 & 2 & 2 & 2 & 3 & 3 & 2 & 2 & 2 & 8 & 2 & 8 \\
\hline Total & 60 & 90 & 23 & 15 & 16 & 204 & 396 & 308 & 52 & 205 & 115 & 1076 & 93 & 111 & 54 & 56 & 94 & 408 \\
\hline
\end{tabular}


TIME USE OF ADULT WOMEN AND MEN, IN SAMPLES FROM THREE COUNTRIES, 2017

\begin{tabular}{|c|c|c|c|c|c|c|c|c|c|}
\hline & \multicolumn{3}{|c|}{ Philippines } & \multicolumn{3}{|c|}{ Uganda } & \multicolumn{3}{|c|}{ Zimbabwe } \\
\hline & Mean $\mathrm{F}$ & Mean M & T-value & Mean $\mathrm{F}$ & Mean M & T-value & Mean $\mathrm{F}$ & Mean $M$ & T-value \\
\hline \multicolumn{10}{|c|}{ Time use of adult women and men (hours) } \\
\hline Care as a primary activity & 6.46 & 2.43 & $16.91^{* * *}$ & 4.43 & 0.69 & $37.00^{* * *}$ & 4.67 & 0.84 & $21.77^{* * *}$ \\
\hline $\begin{array}{l}\text { Care as primary or secondary } \\
\text { activity }\end{array}$ & 8.02 & 3.12 & $17.2^{* * *}$ & 5.81 & 0.98 & $37.92^{* * *}$ & 5.82 & 1.21 & $21.49 * * *$ \\
\hline Any care responsibility & 12 & 5.37 & $12.49 * * *$ & 10.53 & 2.91 & $26.24^{* * *}$ & 10.87 & 3.05 & $15.85^{* * *}$ \\
\hline Multi-tasking care & 6.27 & 2.04 & $12.76^{* * *}$ & 4.3 & 0.93 & $17.75^{* * *}$ & 5.31 & 1.11 & $12.27^{* * *}$ \\
\hline Paid/productive work. & 2.39 & 7.69 & $-15.84^{* * *}$ & 4.15 & 6.94 & $-14.68 * * *$ & 3.71 & 6.16 & $-8.14^{* * *}$ \\
\hline $\begin{array}{l}\text { Total work (care and productive as } \\
\text { a primary activity) }\end{array}$ & 8.84 & 10.12 & $-3.98^{* * *}$ & 8.58 & 7.63 & $5.06^{* * *}$ & 8.38 & 7.00 & $4.54^{* * *}$ \\
\hline $\begin{array}{l}\text { Non-work (leisure+sleep+personal } \\
\text { care) }\end{array}$ & 14.23 & 13.27 & $3.05^{* * *}$ & 14.58 & 15.39 & $-4.82 * * *$ & 13.85 & 15.68 & $-6.31^{* * *}$ \\
\hline \multicolumn{10}{|c|}{ Hours on different care activities as primary activity } \\
\hline Water collection & 0.39 & 0.43 & -0.47 & 0.36 & 0.05 & $13.53^{* * *}$ & 0.45 & 0.1 & $8.73^{* * *}$ \\
\hline Fuel collection & 0.06 & 0.29 & $-3.93 * * *$ & 0.31 & 0.05 & $10.35^{* * *}$ & 0.3 & 0.11 & $4.29 * * *$ \\
\hline Meal preparation & 2.95 & 1.27 & $13.32^{* * *}$ & 2.46 & 0.15 & $41.75^{* * *}$ & 1.87 & 0.21 & $20.25 * * *$ \\
\hline Cleaning the house & 0.77 & 0.1 & $10.58^{* * *}$ & 0.48 & 0.09 & $15.51^{* * *}$ & 0.94 & 0.13 & $12.07^{* * *}$ \\
\hline Washing and drying clothes & 1.15 & 0.06 & $10.72^{* * *}$ & 0.33 & 0.09 & $7.15^{* * *}$ & 0.63 & 0.07 & $9.53^{* * *}$ \\
\hline Childcare & 1.06 & 0.26 & $5.77^{* * *}$ & 0.31 & 0.21 & $2.14^{* *}$ & 0.41 & 0.13 & $5.23^{* * *}$ \\
\hline Adult care & 0 & 0 & . & 0.01 & 0.01 & 0.61 & 0.01 & 0.02 & -0.61 \\
\hline Community care & 0.08 & 0.01 & 0.99 & 0.01 & 0.01 & 0.36 & 0.07 & 0.01 & $2.17^{* *}$ \\
\hline Shopping household supplies & 0.09 & 0.01 & $2.29 * *$ & 0.15 & 0.03 & $8.41^{* * *}$ & 0.1 & 0.08 & 0.7 \\
\hline No care as primary activity & Women & Men & Total & Women & Men & Total & Women & Men & Total \\
\hline Total & 3 & 39 & 42.00 & 73 & 602 & 675 & 32 & 218 & 250 \\
\hline$\%$ & 1.47 & 18.66 & 10.17 & 6.82 & 73.5 & 35.71 & 7.86 & 65.86 & 33.88 \\
\hline
\end{tabular}


TIME USE FOR WATER-RELATED TASKS FOR ADULT WOMEN AND MEN IN PHILIPPINES AND ZIMBABWE, IN SAMPLES FROM TWO COUNTRIES, 2017

\begin{tabular}{|c|c|c|c|c|c|c|c|c|c|}
\hline \multicolumn{5}{|l|}{ Philippines } & \multicolumn{5}{|l|}{ Zimbabwe } \\
\hline Community & Mean & Total & Min & $\operatorname{Max}$ & Community & Mean & Total & Min & Max \\
\hline \multicolumn{10}{|c|}{ Time to collect water for laundry (hours) } \\
\hline Cotabato & 2.91667 & 48 & 0 & 30 & Seke & 9.15663 & 83 & 0 & 60 \\
\hline Eastern Samar & 6.06329 & 79 & 0 & 40 & Caledonia & 5.58586 & 99 & 0 & 65 \\
\hline Leyte & 17.8261 & 23 & 0 & 40 & Bubi & 32.5778 & 45 & 0 & 180 \\
\hline Maguindanao & 2.27273 & 11 & 0 & 5 & Gutu & 10.0263 & 38 & 0 & 30 \\
\hline Sultan Kudarat & 5.73333 & 15 & 0 & 30 & Masvingo & 16 & 45 & 0 & 90 \\
\hline Total & 6.47727 & 176 & 0 & 40 & Total & 12.5161 & 310 & 0 & 180 \\
\hline \multicolumn{10}{|c|}{ Average time spent to collect water for laundry (time to collect *number of trips needed) for one load of laundry (hours) } \\
\hline Cotabato & 20.16667 & 48 & 0 & 300 & Seke & 45.48193 & 83 & 0 & 480 \\
\hline Eastern Samar & 27.78481 & 79 & 0 & 400 & Caledonia & 19.0303 & 99 & 0 & 195 \\
\hline Leyte & 156.3043 & 23 & 0 & 400 & Bubi & 99.6 & 45 & 0 & 720 \\
\hline Maguindanao & 15.45455 & 11 & 0 & 50 & Gutu & 34.55263 & 38 & 0 & 120 \\
\hline Sultan Kudarat & 36.93333 & 15 & 0 & 300 & Masvingo & 51.35556 & 45 & 0 & 240 \\
\hline Total & 42.51136 & 176 & 0 & 400 & Total & 44.40323 & 310 & 0 & 720 \\
\hline \multicolumn{10}{|c|}{ Average time spent to collect water for laundry per week laverage time to collect water for laundry times number of laundry loads per week) (hours) } \\
\hline Cotabato & 91.47917 & 48 & 0 & 1500 & Seke & 98.75904 & 83 & 0 & 960 \\
\hline Eastern Samar & 81.68354 & 79 & 0 & 1200 & Caledonia & 82.16162 & 99 & 0 & 1260 \\
\hline Leyte & 395.2174 & 23 & 0 & 1440 & Bubi & 260.4667 & 45 & 0 & 2880 \\
\hline Maguindanao & 73.09091 & 11 & 0 & 210 & Gutu & 66.71053 & 38 & 0 & 360 \\
\hline Sultan Kudarat & 105.3333 & 15 & 0 & 900 & Masvingo & 123.9778 & 45 & 0 & 720 \\
\hline Total & 126.8068 & 176 & 0 & 1500 & Total & 116.6645 & 310 & 0 & 2880 \\
\hline
\end{tabular}

TIME USE OF GIRLS AND BOYS, IN SAMPLES FROM THREE COUNTRIES, 2017

\begin{tabular}{|c|c|c|c|c|c|c|c|c|c|}
\hline & \multicolumn{3}{|c|}{ Philippines } & \multicolumn{3}{|c|}{ Uganda } & \multicolumn{3}{|c|}{ Zimbabwe } \\
\hline & Girls & Boys & T-Value & Girls & Boys & T-Value I & Girls & Boys & T-Value \\
\hline \multicolumn{10}{|l|}{ Aged 8 to 12 (hours) } \\
\hline Care work & 2.52 & 2.42 & 0.24 & 7.54 & 5.08 & $8.31^{* * *}$ & 5.23 & 3.57 & $3.52^{* * *}$ \\
\hline Paid/productive work & 0.22 & 0 & $2.47 * *$ & 1.62 & 2.88 & $-5.26^{* * *}$ & 0.4 & 1 & $-2.44^{* *}$ \\
\hline Education & 9.61 & 9.15 & 0.95 & 0.94 & 1.01 & -0.36 & 4.34 & 4.4 & -0.08 \\
\hline Leisure and sleep & 11.17 & 11.46 & -0.41 & 13.55 & 14.8 & $-4.22 * * *$ & 13.86 & 14.24 & -0.49 \\
\hline Total work hours & 2.74 & 2.42 & 0.76 & 9.16 & 7.96 & $3.8^{* * *}$ & 5.63 & 4.57 & $1.89 *$ \\
\hline \multicolumn{10}{|l|}{ Aged 13 to 17 (hours) } \\
\hline Care work & 4.77 & 3.73 & 1.64 & 7.69 & 4.84 & $9.48 * * *$ & 6.25 & 5.26 & $1.68^{*}$ \\
\hline Paid/productive work & 0.09 & 0.59 & -1.33 & 2.42 & 4.34 & $-6.98^{* * *}$ & 0.96 & 1.48 & -1.6 \\
\hline Education & 9.09 & 8.64 & 0.44 & 1.12 & 1.12 & 0.01 & 4.36 & 4.38 & -0.02 \\
\hline Leisure and sleep & 8.77 & 9.23 & -0.46 & 12.48 & 13.39 & $-3.63^{* * *}$ & 12.22 & 11.96 & 0.36 \\
\hline Total work hours & 4.86 & 4.32 & 0.73 & 10.11 & 9.18 & $3.05^{* * *}$ & 7.21 & 6.74 & 0.69 \\
\hline \multicolumn{10}{|l|}{ Aged 18 to 21 (hours) } \\
\hline Care work & 9.2 & 6.33 & 1.38 & 7.47 & 4.45 & $5.98^{* * *}$ & 7.54 & 5.52 & $3.1^{* * *}$ \\
\hline Paid/productive work & 1.6 & 3 & -0.62 & 3.47 & 5.32 & $-4.07^{* * *}$ & 2.51 & 3.39 & -1.41 \\
\hline Education & 1.8 & 3.67 & -0.68 & 0.66 & 1.11 & -1.34 & 2.68 & 1.67 & 1.25 \\
\hline Leisure and sleep & 11.2 & 9.5 & 1.36 & 11.97 & 12.83 & $-2.17^{* *}$ & 10.78 & 12.48 & $-2.4^{* *}$ \\
\hline Total work hours & 10.8 & 9.33 & 0.67 & 10.94 & 9.77 & $2.34^{* *}$ & 10.05 & 8.91 & 1.43 \\
\hline
\end{tabular}


TLSE AND PAID SERVICES AVAILABLE IN THE HOUSEHOLDS IN THE SAMPLE, IN SAMPLES FROM THREE COUNTRIES, 2017

\begin{tabular}{|c|c|c|c|c|c|c|}
\hline & \multicolumn{2}{|c|}{ Philippines } & \multicolumn{2}{|c|}{ Uganda } & \multicolumn{2}{|c|}{ Zimbabwe } \\
\hline & $\%$ & $\begin{array}{l}\text { Total } \\
\text { households }\end{array}$ & $\%$ & $\begin{array}{l}\text { Total } \\
\text { households }\end{array}$ & $\%$ & $\begin{array}{l}\text { Total } \\
\text { households }\end{array}$ \\
\hline \multicolumn{7}{|l|}{ Water } \\
\hline More than 4 bottles or buckets & 35 & 204 & & & 76 & 408 \\
\hline Items used for fetching water & 11 & 204 & & & 48 & 408 \\
\hline Rainwater harvesting system/water reservoir & 55 & 204 & 10 & 1071 & 33 & 408 \\
\hline Water tap on compound/homestead & 31 & 204 & 15 & 1071 & 11 & 408 \\
\hline Shower & 3 & 204 & 6 & 1066 & 4 & 408 \\
\hline Toilet & 100 & 204 & 68 & 1069 & 75 & 408 \\
\hline 51 jerrycan & & & 78 & 1071 & & \\
\hline 101 jerrycan & & & 79 & 1071 & & \\
\hline 201 jerrycan & & & 79 & 1071 & & \\
\hline Transport for fetching water (e.g. bicycle. cart) & 10 & 1071 & & & & \\
\hline \multicolumn{7}{|l|}{ Fuel } \\
\hline Axe & 44 & 204 & 49 & 1071 & 77 & 408 \\
\hline Kerosene lamp/dry cell & 56 & 204 & 27 & 1071 & 38 & 408 \\
\hline Kerosene lamp & 20 & 204 & & & & \\
\hline Dry cell & & & 32 & 1071 & & \\
\hline Solar lamp/electric lamp & & 9 & 1071 & 30 & 408 & \\
\hline Solar lamp & 41 & 204 & 23 & 1069 & & \\
\hline Electric lamp & 87 & 204 & & & & \\
\hline Solar system/biogas system & 2 & 204 & 5 & 1071 & & \\
\hline Generator & 1 & 204 & & 1071 & 8 & 408 \\
\hline Firewood or charcoal-efficient stove & 34 & 204 & 60 & 1071 & 41 & 408 \\
\hline Gas stove & 16 & 204 & 4 & 1071 & 24 & 40 \\
\hline \multicolumn{7}{|l|}{ Food preparation } \\
\hline Flask for liquids/food & 67 & 204 & 47 & 1071 & 16 & 408 \\
\hline Refrigerator & 17 & 204 & 10 & 1071 & 14 & 408 \\
\hline \multicolumn{7}{|l|}{ Clean space } \\
\hline Dustbin/compost pit & 79 & 204.00 & 32 & 1071 & 91 & 408 \\
\hline \multicolumn{7}{|l|}{ Clothes } \\
\hline Suitcase & 25 & 204 & 49 & 1071 & & \\
\hline Chest of drawers/wardrobe for clothes & 54 & 204 & 11 & 1071 & 70 & 408 \\
\hline Flat iron/charcoal iron & 34 & 204 & 38 & 1071 & 76 & 408 \\
\hline At least 3 basins & 45 & 204 & 55 & 1071 & 56 & 408 \\
\hline \multicolumn{7}{|l|}{ Childcare } \\
\hline Mosquito net for children & 84 & 57 & 92 & 382 & 78 & 82 \\
\hline Nappies & 79 & 57 & 44 & 382 & 91 & 82 \\
\hline \multicolumn{7}{|l|}{ Adult care } \\
\hline Walking sticks/crutches/wheelchair & 45 & 11.00 & 59 & 32 & 58 & 33 \\
\hline \multicolumn{7}{|l|}{ Paid services } \\
\hline Cleaning the house or compound & 4 & 204 & 11 & 1071 & 9 & 408 \\
\hline Transporting food & & 204 & 15 & 1071 & 5 & 408 \\
\hline Cooking, serving food & 1 & 204 & 10 & 1071 & 4 & 408 \\
\hline Grinding & 10 & 204 & 14 & 1071 & 17 & 408 \\
\hline Washing and drying clothes & 6 & 204 & 18 & 1071 & 9 & 408 \\
\hline Ironing and mending clothes & 2 & 204 & & & 6 & 408 \\
\hline Fetching water & 7 & 204 & 16 & 1071 & 7 & 408 \\
\hline Fetching firewood & 5 & 204 & 12 & 1071 & 10 & 408 \\
\hline Childcare (including daycare) & 2 & 204 & 10 & 1071 & 8 & 408 \\
\hline Hair braiding/cutting children's hair & 41 & 204 & 36 & 1071 & 21 & 408 \\
\hline Care of dependent adults & 1 & 204 & 4 & 1071 & 2 & 408 \\
\hline
\end{tabular}


INFRASTRUCTURE AVAILABLE TO HOUSEHOLDS IN THE SAMPLE AND THEIR SOURCE, IN SAMPLES FROM THREE COUNTRIES, 2017

\begin{tabular}{|c|c|c|c|c|c|c|}
\hline & \multicolumn{2}{|c|}{ Philippines } & \multicolumn{2}{|c|}{ Uganda } & \multicolumn{2}{|c|}{ Zimbabwe } \\
\hline & No. & $\%$ & No. & $\%$ & No. & $\%$ \\
\hline Use different sources of water for different activities & 204 & 59 & & & 407 & 46 \\
\hline Use an improved water source & 509 & 94.09 & 824 & 76.9 & 294 & 72 \\
\hline Government-provided & 0 & 0 & 600 & 72.8 & 98 & 70.5 \\
\hline Improved water source for drinking & 121 & 71 & & & 189 & 81 \\
\hline Improved water source for cooking & 121 & 60 & & & 189 & 81 \\
\hline Improved water source for cleaning & 121 & 50 & & & 189 & 60 \\
\hline Improved water source for bathing & 121 & 47 & & & 189 & 57 \\
\hline Improved water source for laundry & 121 & 46 & & & 189 & 50 \\
\hline Electricity & 179 & 87.7 & 358 & 33.4 & 50 & 12.2 \\
\hline Government-provided & 57 & 31.8 & 249 & 69.5 & 24 & 48 \\
\hline Family usually use health facilities when household members are ill & 175 & 85.7 & 1021 & 95.3 & 391 & 96 \\
\hline Government-provided & 171 & 97.7 & 829 & 81.1 & 287 & 73.4 \\
\hline \multicolumn{7}{|l|}{ Transport to the nearest health facility } \\
\hline Walking & 58 & 33.1 & & & 269 & 68.8 \\
\hline Cycling & 1 & 0.5 & & & & \\
\hline Motorbike (own) & 30 & 17.1 & & & & \\
\hline Motorbike (paid service) & 68 & 38.8 & & & & \\
\hline Car lown) & 1 & 0.5 & & & 12 & 3 \\
\hline Car (paid service) & 1 & 0.5 & & & 34 & 8.7 \\
\hline Public transport & 10 & 5.7 & & & 67 & 17.1 \\
\hline Other & 6 & 3.4 & & & 9 & 2.3 \\
\hline Total & 175 & 100 & & & 391 & 100 \\
\hline Childcare facilities available near your house & 32 & 15.6 & 151 & 14.1 & & \\
\hline Family usually use childcare facilities & 29 & 90.6 & & & & \\
\hline Government-provided & 3 & 100 & 84 & 55.6 & & \\
\hline Using daycare for at least one child & 41 & 20.1 & 101 & 9.3 & 83 & 20.3 \\
\hline
\end{tabular}

NOTE: Not all the data was recorded for all countries, and the list of services was reviewed and adapted with country teams to better represent the context of each country. For the Philippines and Zimbabwe, the variable 'improved water source' takes the value $l$ if the household uses an improved water source for at least one purpose. In Uganda, it takes the value 1 if respondents answered yes to the question on whether they used an improved water source. 
VALUES AND SKILLS ATTRIBUTED TO 12 TYPES OF TASKS

(6 PRODUCTIVE TASKS AND 6 CARE TASKS), IN SAMPLES FROM THREE COUNTRIES, 2017

\begin{tabular}{|c|c|c|c|c|c|c|c|c|c|}
\hline & \multicolumn{3}{|c|}{ Philippines } & \multicolumn{3}{|l|}{ Uganda } & \multicolumn{3}{|c|}{ Zimbabwe } \\
\hline & mean $\mathrm{F}$ & mean $M$ & T-value & mean $\mathrm{F}$ & mean $M$ & T-value & mean $\mathrm{F}$ & mean $M$ & T-value \\
\hline \multicolumn{10}{|l|}{ Value attributed to care tasks } \\
\hline Meal preparation & 3.04 & 4.91 & $-6.38^{* * *}$ & 3.88 & 6.62 & $-16.99^{* * *}$ & 4.38 & 7.19 & $-11.19 * * *$ \\
\hline Cleaning the house & 4.07 & 6.09 & $-7.87^{* * *}$ & 5.61 & 7.07 & $-10.26^{* * *}$ & 5.22 & 7.56 & $-9.96 * * *$ \\
\hline Caring for children & 4.51 & 6.65 & $-6.73^{* * *}$ & 4.04 & 4.99 & $-7.12^{* * *}$ & 4.18 & 5.15 & $-4.31 * * *$ \\
\hline Caring for adults & 8.45 & 8.66 & -0.76 & 8.01 & 7.48 & $4.07^{* * *}$ & 6.69 & 6.45 & 1.03 \\
\hline Fuel and water collection & 5.29 & 5.11 & 0.58 & 6.93 & 7.90 & $-7.17^{* * *}$ & 6.46 & 6.95 & $-2.52^{* *}$ \\
\hline Washing and drying clothes & 3.39 & 7.40 & $-14.03^{* * *}$ & 7.15 & 8.38 & $-8.63^{* * *}$ & 6.69 & 9.21 & $-11.75^{* * *}$ \\
\hline \multicolumn{10}{|l|}{ Skills attributed to care tasks } \\
\hline Meal preparation & 5.02 & 6.55 & $-4.61^{* * *}$ & 6.50 & 7.22 & $-4.34^{* * *}$ & 7.06 & 8.50 & $-5.64^{* * *}$ \\
\hline Cleaning the house & 6.99 & 7.91 & $-2.99 * * *$ & 8.12 & 8.26 & -0.95 & 7.29 & 8.52 & $-5.17 * * *$ \\
\hline Caring for children & 6.79 & 7.83 & $-3.49 * * *$ & 5.83 & 6.09 & $-1.78^{*}$ & 5.68 & 6.54 & $-3.90 * * *$ \\
\hline Caring for adults & 7.82 & 7.92 & -0.30 & 7.58 & 7.56 & 0.16 & 5.95 & 6.18 & -1.05 \\
\hline Fuel and water collection & 5.84 & 6.36 & -1.58 & 8.81 & 8.78 & 0.25 & 7.84 & 8.24 & $-1.90^{*}$ \\
\hline Washing and drying clothes & 5.60 & 8.29 & $-8.09 * * *$ & 8.59 & 8.87 & $-2.13^{* *}$ & 8.36 & 9.74 & $-6.78^{* * *}$ \\
\hline \multicolumn{10}{|c|}{ Recognition of problematic nature of housework (the higher the number the more problematic) } \\
\hline Water collection & 0.30 & 0.42 & $-2.39 * *$ & 0.20 & 0.14 & $3.20^{* * *}$ & 0.25 & 0.18 & $2.33^{* * *}$ \\
\hline Fuel collection & 0.16 & 0.24 & $-1.97^{* *}$ & 0.17 & 0.09 & $5.12^{* * *}$ & 0.32 & 0.27 & 1.51 \\
\hline Meal preparation & 0.01 & 0.05 & $-2.33^{* *}$ & 0.09 & 0.20 & $-6.81^{* * *}$ & 0.03 & 0.05 & -1.48 \\
\hline House cleaning & 0.01 & 0.01 & 0.47 & 0.03 & 0.04 & -1.28 & 0.05 & 0.03 & 1.42 \\
\hline Washing clothes & 0.32 & 0.11 & $5.42 * *$ & 0.17 & 0.16 & 0.65 & 0.04 & 0.05 & -0.59 \\
\hline Caring for children & 0.13 & 0.09 & 1.34 & 0.19 & 0.24 & $-2.91 * * *$ & 0.06 & 0.07 & -0.30 \\
\hline Caring for adults & 0.03 & 0.05 & -0.91 & 0.05 & 0.04 & 0.73 & 0.13 & 0.15 & -0.92 \\
\hline Caring for community & 0.00 & 0.00 & 1.00 & 0.03 & 0.02 & 1.16 & 0.02 & 0.04 & -0.91 \\
\hline Drying and ironing clothes & 0.00 & 0.01 & -1.42 & & & & 0.00 & 0.01 & -0.66 \\
\hline \multicolumn{10}{|c|}{ Ratio of care to paid work for value and skills } \\
\hline Ratio care/paid work value & 0.6 & 1.09 & $-13.51^{* * *}$ & 0.92 & 1.32 & $-17.07^{* * *}$ & 0.81 & 1.34 & $-14.23^{* * *}$ \\
\hline Ratio care/paid work skills & 1.08 & 1.46 & $-7.07^{* * *}$ & 1.52 & 1.62 & $-3.84^{* * *}$ & 1.32 & 1.72 & $-9.01^{* * *}$ \\
\hline
\end{tabular}

NOTE: If the numbers or ratio for value and skills are larger, it means that care work is seen as less valued/skilled.

RECOGNITION OF WOMEN'S CONTRIBUTION TO THE HOUSEHOLD, IN SAMPLES FROM THREE COUNTRIES, 2017

\begin{tabular}{|l|l|l|l|l|l|l|l|l|l|l|}
\hline & \multicolumn{3}{l|}{ Uganda } & \multicolumn{3}{l|}{ Zimbabwe } \\
\cline { 2 - 11 } & mean F & mean M & T-value & mean $\mathrm{F}$ & mean M & T-value & mean $\mathrm{F}$ & mean M & T-value \\
\hline Woman as main contributor & 0.11 & 0.59 & $-11.29^{* * *}$ & 0.39 & 0.23 & $7.55^{* * *}$ & 0.26 & 0.25 & 0.1062 \\
\hline
\end{tabular}

PERCEPTIONS OF WHO SHOULD HELP WITH CARE WORK, IN SAMPLES FROM THREE COUNTRIES, 2017

\begin{tabular}{|l|l|l|l|l|l|l|l|l|l|l|}
\hline & \multicolumn{3}{|l}{ Philippines } & \multicolumn{3}{l|}{ Uganda } & \multicolumn{3}{l|}{ Zimbabwe } \\
\cline { 2 - 12 } & Women & Men & T-value & Women & Men & T-value & Women & Men & T-value \\
\hline No one & 0.00 & 0.01 & -1.42 & 0.00 & 0.00 & -0.71 & 0.02 & 0.02 & 0.61 \\
\hline Husband & 0.92 & 0.91 & 0.28 & 0.55 & 0.57 & -0.86 & 0.64 & 0.71 & $-2.13^{* *}$ \\
\hline Girls & 0.45 & 0.33 & $2.53^{* * *}$ & 0.67 & 0.62 & $2.23^{* *}$ & 0.66 & 0.58 & $2.19^{* *}$ \\
\hline Boys & 0.28 & 0.22 & 1.39 & 0.45 & 0.43 & 0.73 & 0.39 & 0.41 & -0.40 \\
\hline Other women & 0.01 & 0.02 & -0.35 & 0.18 & 0.18 & 0.07 & 0.10 & 0.13 & -1.00 \\
\hline Other men & 0.02 & 0.01 & 0.41 & 0.05 & 0.05 & 0.21 & 0.02 & 0.03 & -0.90 \\
\hline Other & 0.01 & 0.02 & -0.79 & 0.02 & 0.01 & 1.51 & 0.01 & 0.01 & 0.22 \\
\hline Total female & 0.45 & 0.33 & $2.43^{* * *}$ & 0.70 & 0.65 & $2.06^{* *}$ & 0.69 & 0.62 & $1.93^{*}$ \\
\hline
\end{tabular}


PERCEPTIONS ON SATISFACTION WITH THE DIVISION OF TASKS,

IN SAMPLES FROM THREE COUNTRIES, 2017

\begin{tabular}{|c|c|c|c|c|c|c|}
\hline \multirow{3}{*}{ How satisfied are you with this division of tasks? } & \multicolumn{6}{|c|}{ Philippines } \\
\hline & \multicolumn{2}{|c|}{ Women } & \multicolumn{2}{|l|}{ Men } & \multicolumn{2}{|c|}{ Total } \\
\hline & No. & $\%$ & No. & $\%$ & No. & $\%$ \\
\hline Unsatisfied & 6 & 2.9 & 1 & 0.5 & 7 & 1.7 \\
\hline Fairly satisfied & 27 & 13.2 & 34 & 16.3 & 61 & 14.8 \\
\hline Satisfied & 152 & 74.5 & 156 & 74.6 & 308 & 74.6 \\
\hline Very satisfied & 19 & 9.3 & 18 & 8.6 & 37 & 9 \\
\hline Total & 204 & 100 & 209 & 100 & 413 & 100 \\
\hline
\end{tabular}

\begin{tabular}{|c|c|c|c|c|c|c|}
\hline \multirow{3}{*}{ How satisfied are you with this division of tasks? } & \multicolumn{6}{|c|}{ Uganda } \\
\hline & \multicolumn{2}{|c|}{ Women } & \multicolumn{2}{|l|}{ Men } & \multicolumn{2}{|l|}{ Total } \\
\hline & No. & $\%$ & No. & $\%$ & No. & $\%$ \\
\hline Unsatisfied & 89 & 10.5 & 17 & 2.3 & 106 & 6.6 \\
\hline Fairly satisfied & 129 & 15.3 & 86 & 11.4 & 215 & 13.4 \\
\hline Satisfied & 443 & 52.4 & 410 & 54.3 & 853 & 53.3 \\
\hline Very satisfied & 184 & 21.8 & 242 & 32.1 & 426 & 26.6 \\
\hline Total & 845 & 100 & 755 & 100 & 1.600 .00 & 100 \\
\hline
\end{tabular}

\begin{tabular}{|c|c|c|c|c|c|c|}
\hline \multicolumn{7}{|c|}{ Zimbabwe } \\
\hline \multirow[t]{2}{*}{ How satisfied are you with this division of tasks? } & \multicolumn{2}{|c|}{ Women } & \multicolumn{2}{|c|}{ Men } & \multicolumn{2}{|c|}{ Total } \\
\hline & No. & $\%$ & No. & $\%$ & No. & $\%$ \\
\hline Unsatisfied & 28 & 6.9 & 6 & 1.8 & 34 & 4.6 \\
\hline Fairly satisfied & 64 & 15.7 & 33 & 10 & 97 & 13.1 \\
\hline Satisfied & 188 & 46.2 & 162 & 48.9 & 350 & 47.4 \\
\hline Very satisfied & 127 & 31.2 & 130 & 39.3 & 257 & 34.8 \\
\hline Total & 407 & 100 & 331 & 100 & 738 & 100 \\
\hline
\end{tabular}


MEN'S CHILDHOOD EXPOSURE TO UNPAID CARE AND DOMESTIC WORK, IN SAMPLES FROM THREE COUNTRIES, 2017

\begin{tabular}{|c|c|c|c|c|c|c|c|c|c|c|c|c|}
\hline & \multicolumn{4}{|c|}{ Philippines } & \multicolumn{4}{|c|}{ Uganda } & \multicolumn{4}{|c|}{ Zimbabwe } \\
\hline & \multicolumn{2}{|c|}{$\begin{array}{l}\text { Father performed } \\
\text { the task }\end{array}$} & \multicolumn{2}{|c|}{$\begin{array}{l}\text { Taught to do the } \\
\text { task as child }\end{array}$} & \multicolumn{2}{|c|}{$\begin{array}{l}\text { Father performed } \\
\text { the task }\end{array}$} & \multicolumn{2}{|c|}{$\begin{array}{l}\text { Taught to do the } \\
\text { task as child }\end{array}$} & \multicolumn{2}{|c|}{$\begin{array}{l}\text { Father performed } \\
\text { the task }\end{array}$} & \multicolumn{2}{|c|}{$\begin{array}{l}\text { Taught to do the } \\
\text { task as child }\end{array}$} \\
\hline & No. & $\%$ & No. & $\%$ & No. & $\%$ & No. & $\%$ & No. & $\%$ & No. & $\%$ \\
\hline \multicolumn{13}{|c|}{ Meal preparation } \\
\hline Never & 4 & 1.9 & 3 & 1.4 & 413 & 50.4 & 228 & 27.8 & 134 & 40.4 & 60 & 18.1 \\
\hline Hardly ever & 11 & 5.2 & 8 & 3.8 & 107 & 13 & 89 & 10.8 & 16 & 4.8 & 8 & 2.4 \\
\hline Sometimes & 131 & 62.6 & 103 & 49.2 & 240 & 29.3 & 359 & 43.8 & 115 & 34.7 & 120 & 36.2 \\
\hline Frequently & 63 & 30.1 & 95 & 45.4 & 59 & 7.2 & 143 & 17.4 & 66 & 19.9 & 143 & 43.2 \\
\hline Total & 209 & 100 & 209 & 100 & 819 & 100 & 819 & 100 & 331 & 100 & 331 & 100 \\
\hline \multicolumn{13}{|l|}{ Cleaning } \\
\hline Never & 4 & 1.9 & 3 & 1. & 328 & 40 & 159 & 19.4 & 139 & 41.9 & 73 & 22 \\
\hline Hardly ever & 15 & 7.1 & 2 & 0.9 & 114 & 13.9 & 71 & 8.6 & 24 & 7.2 & 20 & 6 \\
\hline Sometimes & 149 & 71.2 & 118 & 56.4 & 260 & 31.7 & 376 & 45.9 & 101 & 30.5 & 104 & 31.4 \\
\hline Frequently & 41 & 19.6 & 86 & 41.1 & 117 & 14.2 & 213 & 26 & 67 & 20.2 & 134 & 40.4 \\
\hline Total & 209 & 100 & 209 & 100 & 819 & 100 & 819 & 100 & 331 & 100 & 331 & 100 \\
\hline \multicolumn{13}{|c|}{ Washing clothes } \\
\hline Never & 13 & 6.2 & 5 & 2.3 & 324 & 39.5 & 164 & 20 & 142 & 42.9 & 61 & 18.4 \\
\hline Hardly ever & 32 & 15.3 & 7 & 3.3 & 120 & 14.6 & 77 & 9.4 & 20 & 6 & 16 & 4.8 \\
\hline Sometimes & 137 & 65.5 & 135 & 64.5 & 293 & 35.7 & 377 & 46.0 & 93 & 28.1 & 107 & 32.3 \\
\hline Frequently & 27 & 12.9 & 62 & 29.6 & 82 & 10 & 201 & 24.5 & 76 & 22.9 & 147 & 44.4 \\
\hline Total & 209 & 100 & 209 & 100 & 819 & 100 & 819 & 100 & 331 & 100 & 331 & 100 \\
\hline \multicolumn{13}{|l|}{ Childcare } \\
\hline Never & 9 & 4.3 & 7 & 3.3 & 190 & 23.2 & 146 & 17.8 & 89 & 26.8 & 54 & 16.3 \\
\hline Hardly ever & 21 & 10 & 20 & 9.5 & 49 & 5.9 & 47 & 5.7 & 14 & 4.2 & 13 & 3.9 \\
\hline Sometimes & 130 & 62.2 & 114 & 54.5 & 354 & 43.2 & 346 & 42.2 & 121 & 36.5 & 114 & 34.4 \\
\hline Frequently & 49 & 23.4 & 68 & 32.5 & 226 & 27.5 & 280 & 34.1 & 107 & 32.3 & 150 & 45.3 \\
\hline Total & 209 & 100 & 209 & 100 & 819 & 100 & 819 & 100 & 331 & 100 & 331 & 100 \\
\hline \multicolumn{13}{|c|}{ At least one care activity } \\
\hline & 146 & 69.8 & 170 & 81.3 & 202 & 24.6 & 410 & 50 & 132 & 39.8 & 208 & 62.8 \\
\hline
\end{tabular}


PERCEPTIONS ON DIVISION OF LABOUR IDIVIDED DISTRIBUTION OF WORK, SHARED DISTRIBUTION OF WORK AND UNEQUAL DISTRIBUTION OF WORK) IN SAMPLES FROM THREE COUNTRIES, 2017

\begin{tabular}{|c|c|c|c|c|c|c|c|c|c|c|c|c|}
\hline & \multicolumn{4}{|c|}{ Philippines } & \multicolumn{4}{|l|}{ Uganda } & \multicolumn{4}{|c|}{ Zimbabwe } \\
\hline & Women & $\%$ & Men & $\%$ & Women & $\%$ & Men & $\%$ & Women & $\%$ & Men & $\%$ \\
\hline Strongly approve & 13 & 6.3 & 10 & 4.7 & 150 & 14 & 133 & 16.2 & 49 & 12 & 35 & 10.5 \\
\hline Approve & 93 & 45.5 & 104 & 49.7 & 530 & 49.4 & 415 & 50.6 & 216 & 53 & 176 & 53.1 \\
\hline Disapprove & 69 & 33.8 & 87 & 41.6 & 299 & 27.9 & 213 & 26 & 129 & 31.7 & 111 & 33.5 \\
\hline Strongly disapprove & 29 & 14.2 & 8 & 3.8 & 92 & 8.5 & 58 & 7 & 13 & 3.1 & 9 & 2.7 \\
\hline Total & 204 & 100.0 & 209 & 100.0 & 1071 & 100.0 & 819 & 100.0 & 407 & 100.0 & 331 & 100.0 \\
\hline \multicolumn{13}{|c|}{ Approval of vignette that describes couple sharing care and paid work } \\
\hline Strongly approve & 88 & 43.1 & 65 & 31.1 & 378 & 35.2 & 232 & 28.3 & 119 & 29.2 & 111 & 33.5 \\
\hline Approve & 90 & 44.1 & 127 & 60.7 & 445 & 41.5 & 355 & 43.3 & 196 & 48.1 & 142 & 42.9 \\
\hline Disapprove & 20 & 9.8 & 14 & 6.7 & 160 & 14.9 & 156 & 19 & 61 & 14.9 & 55 & 16.6 \\
\hline Strongly disapprove & 6 & 2.9 & 3 & 1.4 & 88 & 8.2 & 76 & 9.2 & 31 & 7.6 & 23 & 6.9 \\
\hline Total & 204 & 100.0 & 209 & 100.0 & 1071 & 100.0 & 819 & 100.0 & 407 & 100.0 & 331 & 100.0 \\
\hline \multicolumn{13}{|c|}{ Approval of vignette that describes couple where woman does most of the care and paid work } \\
\hline Strongly approve & 4 & 1.9 & 4 & 1.9 & 138 & 12.8 & 104 & 12.7 & 22 & 5.4 & 9 & 2.7 \\
\hline Approve & 22 & 10.7 & 28 & 13.4 & 622 & 58 & 475 & 58 & 112 & 27.5 & 116 & 35 \\
\hline Disapprove & 91 & 44.6 & 109 & 52.1 & 251 & 23.4 & 200 & 24.4 & 180 & 44.2 & 151 & 45.6 \\
\hline Strongly disapprove & 87 & 42.6 & 68 & 32.5 & 60 & 5.6 & 40 & 4.8 & 93 & 22.8 & 55 & 16.6 \\
\hline Total & 204 & 100.0 & 209 & 100.0 & 1071 & 100.0 & 819 & 100.0 & 407 & 100.0 & 331 & 100.0 \\
\hline
\end{tabular}


PERCEPTIONS OF COMMUNITY EXPECTATIONS ABOUT UNPAID CARE WORK FOR ADULT WOMEN AND MEN, IN SAMPLES FROM THREE COUNTRIES, 2017

\begin{tabular}{|c|c|c|c|c|c|c|}
\hline & \multicolumn{2}{|c|}{ Philippines } & \multicolumn{2}{|l|}{ Uganda } & \multicolumn{2}{|c|}{ Zimbabwe } \\
\hline & No. & $\%$ & No. & $\%$ & No. & $\%$ \\
\hline \multicolumn{7}{|c|}{ Out of $5 \mathrm{men}$ in your village we interviewed, how many do you think said that they spent at least an hour on caring for people and domestic work yesterday? (men only) } \\
\hline 0 & 3 & 0.7 & 425 & 22.5 & 103 & 14 \\
\hline 1 & 58 & 14 & 442 & 23.4 & 85 & 11.5 \\
\hline 2 & 114 & 27.6 & 513 & 27.1 & 217 & 29.4 \\
\hline 3 & 130 & 31.5 & 281 & 14.9 & 210 & 28.5 \\
\hline 4 & 37 & 9 & 154 & 8.1 & 45 & 6.1 \\
\hline 5 & 71 & 17.2 & 75 & 4 & 78 & 10.6 \\
\hline Total & 413 & 100 & 1.890 .00 & 100 & 738 & 100 \\
\hline \multicolumn{7}{|c|}{ Men report not doing any care (primary or any care) or at least one hour of care the day before the survey (men only) } \\
\hline No care & 19 & 9.1 & 421 & 51 & 161 & 48.5 \\
\hline At least 1 hour of care & 190 & 90.9 & 398 & 48.6 & 170 & 51.36 \\
\hline Total & 209 & 100 & 819 & 100 & 331 & 100 \\
\hline \multicolumn{7}{|c|}{ Out of $5 \mathrm{men}$ in your village we interviewed, how many do you think said that men should do caring for people and domestic work? (men only) } \\
\hline 0 & 2 & 0.5 & 411 & 21.7 & 113 & 15.3 \\
\hline 1 & 44 & 10.7 & 373 & 19.7 & 75 & 10.2 \\
\hline 2 & 99 & 24 & 584 & 30.9 & 211 & 28.6 \\
\hline 3 & 151 & 36.6 & 303 & 16 & 202 & 27.4 \\
\hline 4 & 46 & 11.1 & 102 & 5.4 & 46 & 6.2 \\
\hline 5 & 71 & 17.2 & 117 & 6.2 & 91 & 12.3 \\
\hline Total & 413 & 100 & 1.890 .00 & 100 & 738 & 100 \\
\hline \multicolumn{7}{|c|}{ Out of 5 women in your village we interviewed, how many do you think said that men should do caring for people and domestic work? (women only) } \\
\hline 0 & 1 & 0.2 & 187 & 9.9 & 38 & 5.1 \\
\hline 1 & 5 & 1.2 & 158 & 8.4 & 14 & 1.9 \\
\hline 2 & 11 & 2.7 & 295 & 15.6 & 58 & 7.9 \\
\hline 3 & 38 & 9.2 & 322 & 17 & 164 & 22.2 \\
\hline 4 & 45 & 10.9 & 316 & 16.7 & 114 & 15.4 \\
\hline 5 & 313 & 75.8 & 612 & 32.4 & 350 & 47.4 \\
\hline Total & 413 & 100 & 1.890 .00 & 100 & 738 & 100 \\
\hline \multicolumn{7}{|c|}{ Do you think men in your village should do caring for people and domestic work? (women only) } \\
\hline No & 14 & 3.4 & 388 & 20.5 & 102 & 13.8 \\
\hline Yes & 399 & 96.6 & 1.502 .00 & 79.5 & 636 & 86.2 \\
\hline Total & 413 & 100 & 1.890 .00 & 100 & 738 & 100 \\
\hline \multicolumn{7}{|c|}{ Why should men not do caring for people and domestic work? } \\
\hline Because it would not be the right thing to do & 0 & 0 & 21 & 5.4 & 11 & 10.8 \\
\hline It's a woman's task/it's not a man's task & 7 & 50 & 289 & 74.5 & 72 & 70.6 \\
\hline Men don't know how to do it & 1 & 7.14 & 25 & 6.4 & 4 & 3.9 \\
\hline The community would disapprove & 0 & 0 & 18 & 4.6 & 9 & 8.8 \\
\hline Other & 6 & 42.9 & 35 & 9 & 6 & 5.9 \\
\hline Total & 14 & 100 & 388 & 100 & 102 & 100 \\
\hline \multicolumn{7}{|c|}{ If nobody were to know that your husband did caring for people and domestic work, would you want him to do it more? (women only) } \\
\hline No & 75 & 36.8 & 287 & 34 & 166 & 40.8 \\
\hline Yes & 129 & 63.2 & 558 & 66 & 241 & 59.2 \\
\hline Total & 204 & 100 & 845 & 100 & 407 & 100 \\
\hline
\end{tabular}


PERCEPTIONS OF COMMUNITY EXPECTATIONS ABOUT UNPAID CARE WORK (VIGNETTE 2) FOR ADULT WOMEN AND MEN, IN SAMPLES FROM THREE COUNTRIES, 2017

\begin{tabular}{|c|c|c|c|c|c|c|c|c|c|c|c|c|}
\hline & \multicolumn{4}{|c|}{ Philippines } & \multicolumn{4}{|l|}{ Uganda } & \multicolumn{4}{|c|}{ Zimbabwe } \\
\hline & \multicolumn{2}{|c|}{$\begin{array}{l}\text { Man will do } \\
\text { care work }\end{array}$} & \multicolumn{2}{|c|}{$\begin{array}{l}\text { Woman will want } \\
\text { man to do care } \\
\text { work }\end{array}$} & \multicolumn{2}{|c|}{$\begin{array}{l}\text { Man will do } \\
\text { care work }\end{array}$} & \multicolumn{2}{|c|}{$\begin{array}{l}\text { Woman will want } \\
\text { man to do care } \\
\text { work }\end{array}$} & \multicolumn{2}{|c|}{$\begin{array}{l}\text { Man will do } \\
\text { care work }\end{array}$} & \multicolumn{2}{|c|}{$\begin{array}{l}\text { Woman will want } \\
\text { man to do care } \\
\text { work }\end{array}$} \\
\hline & Women & Men & Women & Men & Women & Men & Women & Men & Women & Men & Women & Men \\
\hline \multicolumn{13}{|c|}{ Vignette 1 (few men do care work and few people think men should do care work) } \\
\hline Not likely at all & 0 & 1 & & & 30 & 14 & 15 & 4 & 2 & 0 & & \\
\hline$\%$ & 0 & 1.7 & & & 12.2 & 6.9 & 6.1 & 1.9 & 2.2 & 0 & & \\
\hline Not likely & 0 & 2 & 0 & 1 & 64 & 48 & 49 & 41 & 20 & 14 & 9 & 8 \\
\hline$\%$ & 0 & 3.5 & 0 & 1.7 & 26.1 & 23.7 & 20 & 20.3 & 22.7 & 17.2 & 10.2 & 9.8 \\
\hline Likely & 20 & 19 & 9 & 15 & 132 & 121 & 147 & 110 & 50 & 46 & 52 & 41 \\
\hline$\%$ & 46.5 & 33.3 & 20.9 & 26.3 & 53.8 & 59.9 & 60 & 54.4 & 56.8 & 56.7 & 59 & 50.6 \\
\hline Very likely & 23 & 35 & 34 & 41 & 19 & 19 & 34 & 47 & 16 & 21 & 27 & 32 \\
\hline$\%$ & 53.4 & 61.4 & 79.0 & 71.9 & 7.7 & 9.4 & 13.8 & 23.2 & 18.1 & 25.9 & 30.6 & 39.5 \\
\hline Total & 43 & 57 & 43 & 57 & 245 & 202 & 245 & 202 & 88 & 81 & 88 & 81 \\
\hline \multicolumn{13}{|c|}{ Vignette 2 (few men do care work, almost all think men should do care work) } \\
\hline Not likely at all & 2 & 0 & 1 & 0 & 19 & 12 & 9 & 3 & 2 & 3 & 1 & 1 \\
\hline$\%$ & 3.3 & 0 & 1.6 & 0 & 6.9 & 5.9 & 3.2 & 1.4 & 1.8 & 3.8 & 0.9 & 1.2 \\
\hline Not likely & 2 & 1 & 1 & 0 & 71 & 56 & 39 & 37 & 21 & 14 & 11 & 5 \\
\hline$\%$ & 3.3 & 2.2 & 1.6 & 0 & 25.9 & 27.5 & 14.2 & 18.2 & 19.2 & 17.9 & 10 & 6.4 \\
\hline Likely & 14 & 12 & 6 & 5 & 164 & 111 & 175 & 111 & 57 & 44 & 52 & 40 \\
\hline$\%$ & 23.3 & 26.6 & 10 & 11.1 & 59.8 & 54.6 & 63.8 & 54.6 & 52.2 & 56.4 & 47.7 & 51.2 \\
\hline Very likely & 42 & 32 & 52 & 40 & 20 & 24 & 51 & 52 & 29 & 17 & 45 & 32 \\
\hline$\%$ & 70 & 71. & 86.6 & 88.8 & 7.3 & 11.8 & 18.6 & 25.6 & 26.6 & 21.7 & 41.2 & 41 \\
\hline Total & 60 & 45 & 60 & 45 & 274 & 203 & 274 & 203 & 109 & 78 & 109 & 78 \\
\hline \multicolumn{13}{|c|}{ Vignette 3 (almost all men do care work, few people think men should do care work) } \\
\hline Not likely at all & & & & & 13 & 11 & 4 & 12 & 4 & 2 & 1 & 1 \\
\hline$\%$ & & & & & 5.2 & 4.8 & 1.61 & 5.24 & 3.8 & 2 & 0.9 & 1 \\
\hline Not likely & 2 & 0 & 1 & 1 & 75 & 49 & 52 & 33 & 24 & 15 & 18 & 7 \\
\hline$\%$ & 4.3 & 0 & 2.1 & 1.6 & 30.1 & 21.4 & 20.8 & 14.4 & 23.3 & 15.1 & 17.4 & 7 \\
\hline Likely & 11 & 19 & 5 & 5 & 134 & 143 & 135 & 132 & 51 & 56 & 42 & 40 \\
\hline$\%$ & 23.9 & 32.2 & 10.8 & 8.4 & 53.8 & 62.4 & 54.2 & 57.6 & 49.5 & 56.5 & 40.7 & 40 \\
\hline Very likely & 33 & 40 & 40 & 53 & 27 & 26 & 58 & 52 & 24 & 26 & 42 & 51 \\
\hline$\%$ & 71.7 & 67.8 & 86.9 & 89.8 & 10.8 & 11.3 & 23.2 & 22.7 & 23.3 & 26.2 & 40.7 & 51.5 \\
\hline Total & 46 & 59 & 46 & 59 & 249 & 229 & 249 & 229 & 103 & 99 & 103 & 99 \\
\hline \multicolumn{13}{|c|}{ Vignette 4 (almost all men do care work, almost all think men should do care work) } \\
\hline Not likely at all & & & & & 16 & 8 & 11 & 3 & 7 & 4 & 4 & 1 \\
\hline$\%$ & & & & & 5.2 & 4.3 & 3.63 & 1.62 & 6.54 & 5.48 & 3.7 & 1.3 \\
\hline Not likely & 1 & 0 & & & 59 & 34 & 47 & 23 & 18 & 10 & 5 & 7 \\
\hline$\%$ & 1.8 & 0 & & & 19.4 & 18.3 & 15.51 & 12.43 & 16.82 & 13.7 & 4.6 & 9.5 \\
\hline Likely & 15 & 17 & 9 & 5 & 160 & 101 & 140 & 90 & 57 & 40 & 54 & 32 \\
\hline$\%$ & 27.2 & 35.4 & 16.3 & 10.4 & 52.8 & 54.5 & 46.2 & 48.65 & 53.27 & 54.79 & 50.4 & 43.8 \\
\hline Very likely & 39 & 31 & 46 & 43 & 68 & 42 & 105 & 69 & 25 & 19 & 44 & 33 \\
\hline$\%$ & 70.9 & 64.5 & 83.6 & 89.5 & 22.4 & 22.7 & 34.65 & 37.3 & 23.36 & 26.03 & 41.1 & 45.2 \\
\hline Total & 55 & 48 & 55 & 48 & 303 & 185 & 303 & 185 & 107 & 73 & 107 & 73 \\
\hline
\end{tabular}


PERCEIVED ACCEPTABILITY OF VIOLENCE AGAINST WOMEN RELATED TO PERCEIVED FAILURES IN CARERELATED TASKS, IN SAMPLES FROM THREE COUNTRIES, 2017

\begin{tabular}{|c|c|c|c|c|c|c|c|c|c|c|c|c|c|c|c|c|c|c|}
\hline & \multicolumn{6}{|c|}{ Philippines } & \multicolumn{6}{|c|}{ Uganda } & \multicolumn{6}{|c|}{ Zimbabwe } \\
\hline & \multicolumn{3}{|c|}{$\begin{array}{l}\text { Acceptance of } \\
\text { beating }\end{array}$} & \multicolumn{3}{|c|}{$\begin{array}{l}\text { Acceptance of } \\
\text { criticism }\end{array}$} & \multicolumn{3}{|c|}{ Acceptance of beating } & \multicolumn{3}{|c|}{$\begin{array}{l}\text { Acceptance of } \\
\text { criticism }\end{array}$} & \multicolumn{3}{|c|}{ Acceptance of beating } & \multicolumn{3}{|c|}{$\begin{array}{l}\text { Acceptance of } \\
\text { criticism }\end{array}$} \\
\hline & 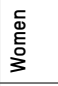 & $\frac{c}{\Sigma}$ & 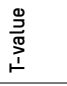 & 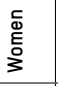 & $\stackrel{c}{\Sigma}$ & 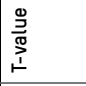 & 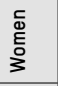 & $\frac{c}{\infty}$ & 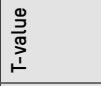 & 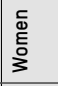 & $\stackrel{\complement}{\stackrel{c}{\Sigma}}$ & $\begin{array}{l}0 \\
\stackrel{0}{3} \\
\stackrel{0}{0} \\
\stackrel{1}{1} \\
\end{array}$ & 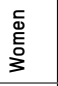 & $\stackrel{\complement}{\Sigma}$ & 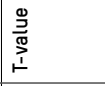 & 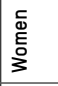 & $\frac{c}{\Sigma}$ & 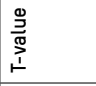 \\
\hline $\begin{array}{l}\text { If she spoiled/burnt/failed to cook a } \\
\text { meal }\end{array}$ & 0.00 & 0.00 & . & 0.01 & 0.02 & -1.30 & 0.51 & 0.57 & $-2.69 * *$ & 0.27 & 0.30 & -1.34 & 0.03 & 0.03 & -0.22 & 0.10 & 0.15 & $-2.24 * * *$ \\
\hline $\begin{array}{l}\text { If she disobeyed her husband/uncle/ } \\
\text { father/ brother }\end{array}$ & 0.00 & 0.00 & . & 0.03 & 0.03 & 0.11 & 0.08 & 0.07 & 1.13 & 0.37 & 0.42 & $-2.45^{* *}$ & 0.07 & 0.09 & -1.20 & 0.18 & 0.26 & $-2.51^{* * *}$ \\
\hline If she spent money without asking & 0.01 & 0.01 & 0.04 & 0.02 & 0.01 & 0.52 & 0.20 & 0.20 & 0.36 & 0.35 & 0.43 & $-3.45 * * *$ & 0.08 & 0.10 & -0.73 & 0.20 & 0.27 & $-2.28^{* * *}$ \\
\hline $\begin{array}{l}\text { If she failed to care well for the } \\
\text { children }\end{array}$ & 0.02 & 0.00 & $1.74^{*}$ & 0.03 & 0.03 & 0.10 & 0.17 & 0.17 & -0.32 & 0.40 & 0.43 & -1.40 & 0.05 & 0.09 & $-2.31 * * *$ & 0.16 & 0.23 & $-2.17^{* * *}$ \\
\hline $\begin{array}{l}\text { If she left a dependent/ill adult } \\
\text { unattended }\end{array}$ & 0.01 & 0.00 & 1.00 & 0.05 & 0.01 & $2.21 * *$ & 0.23 & 0.19 & $1.80^{*}$ & 0.31 & 0.34 & -1.42 & 0.05 & 0.06 & -0.68 & 0.17 & 0.19 & -0.98 \\
\hline $\begin{array}{l}\text { If she did not prepare her husband/ } \\
\text { uncle/father/ brother's bath }\end{array}$ & 0.00 & 0.00 & . & 0.02 & 0.00 & $1.74^{*}$ & 0.15 & 0.14 & 0.65 & 0.24 & 0.28 & -1.74 & 0.05 & 0.04 & 0.87 & 0.15 & 0.17 & -0.88 \\
\hline $\begin{array}{l}\text { If she failed to fetch water/firewood } \\
\text { for her husband/uncle/father/ brother }\end{array}$ & 0.00 & 0.00 & . & 0.02 & 0.00 & $1.74^{*}$ & 0.11 & 0.08 & $2.25^{* *}$ & 0.24 & 0.27 & -1.20 & 0.01 & 0.03 & $-2.12 * * *$ & 0.07 & 0.10 & -1.10 \\
\hline If she left the house without asking & 0.01 & 0.01 & 0.04 & 0.03 & 0.02 & 1.10 & 0.09 & 0.07 & 1.36 & 0.40 & 0.47 & $-2.70^{* * *}$ & 0.16 & 0.13 & 1.04 & 0.23 & 0.30 & $-2.21^{* * *}$ \\
\hline
\end{tabular}

PERCEIVED ACCEPTABILITY OF MOCKING MEN INVOLVED IN CARE, IN SAMPLES FROM THREE COUNTRIES, 2017

\begin{tabular}{|l|l|l|l|l|l|l|}
\hline & \multicolumn{3}{|l}{ Philippines } & Uganda & Zimbabwe \\
\cline { 2 - 8 } & Women & Men & Women & Men & Women & Men \\
\hline No. & 10 & 26 & 249 & 203 & 112 & 94 \\
\hline$\%$ & 5.4 & 13.2 & 25.7 & 27.1 & 28 & 28.8 \\
\hline Total & 184 & 196 & 969 & 749 & 400 & 326 \\
\hline
\end{tabular}

NOTE: The percentages show respondents' views of acceptance of mocking for at least one care activity.

WOMEN'S DECISION-MAKING POWER IN THE HOUSEHOLD, IN SAMPLES FROM THREE COUNTRIES, 2017

\begin{tabular}{|c|c|c|c|c|c|c|c|c|c|c|c|c|c|c|c|}
\hline & \multicolumn{5}{|c|}{ Philippines } & \multicolumn{5}{|c|}{ Uganda } & \multicolumn{5}{|c|}{ Zimbabwe } \\
\hline & Mean & Total & & & & Mean & Total & & & & Mean & Total & & & \\
\hline Child health & 0.83 & 204 & & & & 0.59 & 1071 & & & & 0.81 & 407 & & & \\
\hline Own health & 0.91 & 204 & & & & 0.80 & 1071 & & & & 0.78 & 407 & & & \\
\hline Daily purchase & 0.86 & 204 & & & & 0.84 & 1071 & & & & 0.91 & 407 & & & \\
\hline Large purchase & 0.80 & 204 & & & & 0.56 & 1071 & & & & 0.69 & 407 & & & \\
\hline Number of children & 0.84 & 204 & & & & 0.62 & 1071 & & & & 0.72 & 407 & & & \\
\hline Loan & 0.80 & 204 & & & & 0.50 & 1071 & & & & 0.60 & 407 & & & \\
\hline Travel & 0.81 & 204 & & & & 0.76 & 1071 & & & & 0.82 & 407 & & & \\
\hline Own time & 0.97 & 204 & & & & 0.91 & 1071 & & & & 0.92 & 407 & & & \\
\hline Domestic tasks & 0.91 & 204 & & & & 0.87 & 1071 & & & & 0.88 & 407 & & & \\
\hline \multirow[t]{2}{*}{ Income-generating tasks } & 0.74 & 204 & & & & 0.68 & 1071 & & & & 0.73 & 407 & & & \\
\hline & Mean & SD & Min & Max & No. & Mean & SD & Min & Max & No. & Mean & SD & Min & Max & No. \\
\hline $\begin{array}{l}\text { No. of areas that women decide on } \\
\text { alone or jointly mean }\end{array}$ & 0.84 & 0.23 & 0 & 1 & 204 & 0.71 & 0.27 & 0 & 1 & 1071 & 0.78 & 0.24 & 0 & 1 & 407 \\
\hline $\begin{array}{l}\text { Decision-making and influencing } \\
\text { score mean }\end{array}$ & 1.05 & 0.87 & 0 & 3.00 & 204 & 1.24 & 0.86 & 0 & 3 & 1076 & 1.39 & 1.02 & 0 & 3 & 408 \\
\hline
\end{tabular}


WOMEN'S REPORTED HARM, INJURIES OR ILLNESSES RELATED TO CARE WORK, IN SAMPLES FROM THREE COUNTRIES, 2017

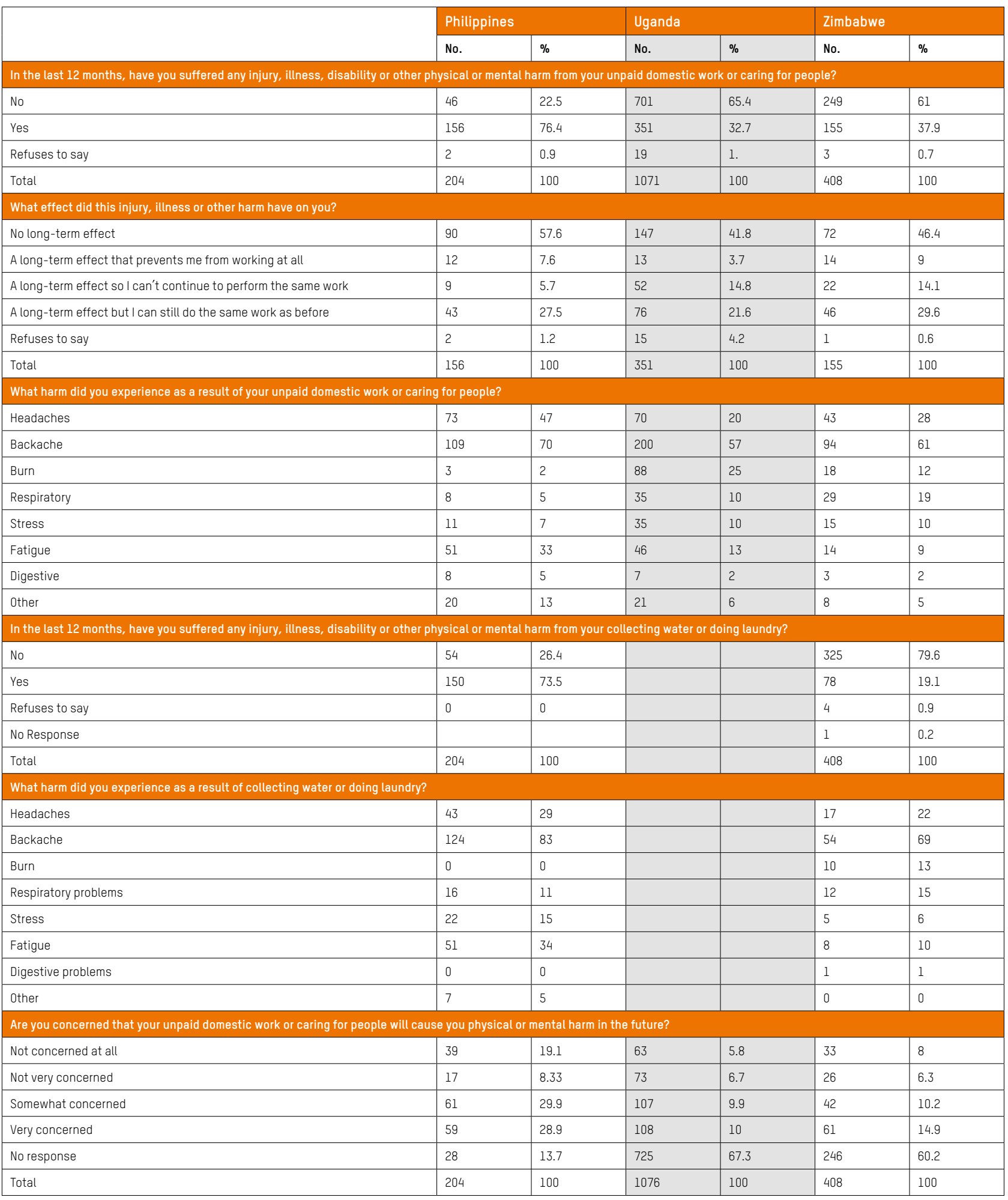

Note: Not all data was recorded for all countries. Information on injury, illness, disability or other physical or mental harm from collecting water or doing laundry was collected for Philippines and Zimbabwe only. 
WOMEN'S REPORTED TIME CONSTRAINTS RELATED TO CARE WORK IN SAMPLES FROM THREE COUNTRIES, 2017

\begin{tabular}{|c|c|c|c|c|c|c|}
\hline & \multicolumn{2}{|c|}{ Philippines } & \multicolumn{2}{|c|}{ Uganda } & \multicolumn{2}{|c|}{ Zimbabwe } \\
\hline & No. & $\%$ & No. & $\%$ & No. & $\%$ \\
\hline \multicolumn{7}{|c|}{ In the last 7 days, how often have you left a dependent adult alone, knowing that there was no one else looking after her or him? } \\
\hline Never & 74 & 36.27 & 750 & 70.03 & 262 & 64.22 \\
\hline At least once & 6 & 2.94 & 66 & 6.16 & 10 & 2.45 \\
\hline At least once a day & 1 & 0.49 & 9 & 0.84 & 2 & 0.49 \\
\hline Several times a day & 1 & 0.49 & 9 & 0.84 & 1 & 0.25 \\
\hline Not applicable & 122 & 59.8 & 237 & 22.13 & 133 & 32.6 \\
\hline Total & 204 & 100 & 1071 & 100 & 408 & 100 \\
\hline \multicolumn{7}{|c|}{ In the last 7 days, how often have you left a child (under 6 years old) alone, knowing that there was no one else looking after her or him? } \\
\hline Never & 124 & 60.78 & 879 & 82.07 & 310 & 75.98 \\
\hline At least once & 19 & 9.31 & 79 & 7.38 & 17 & 4.17 \\
\hline At least once a day & 3 & 1.47 & 17 & 1.59 & 3 & 0.74 \\
\hline Several times a day & 0 & 0 & 12 & 1.12 & 6 & 1.47 \\
\hline Not applicable & 58 & 28.43 & 84 & 7.84 & 72 & 17.65 \\
\hline Total & 204 & 100 & 1071 & 100 & 408 & 100 \\
\hline \multicolumn{7}{|c|}{ In the last 7 days, has any household member suffered from a water-related illness? } \\
\hline Never & 176 & 86.27 & 356 & 87.25 & 240 & 89.55 \\
\hline At least once & 18 & 8.82 & 16 & 3.92 & 24 & 8.96 \\
\hline At least once a day & 2 & 0.98 & 4 & 0.98 & 2 & 0.75 \\
\hline Several times a day & 0 & 0 & 0 & 0 & 0 & 0 \\
\hline Not applicable & 8 & 3.92 & 32 & 7.84 & 2 & 0.75 \\
\hline Total & 204 & 100 & 408 & 100 & 268 & 100 \\
\hline \multicolumn{7}{|c|}{ In the last 7 days, how often have children/dependent adults in your household injured themselves in an accident? (e.g. falling down, cuts, burns) } \\
\hline Never & 76 & 93.83 & 681 & 83.15 & 233 & 86.94 \\
\hline At least once & 5 & 6.17 & 112 & 13.68 & 28 & 10.45 \\
\hline At least once a day & 0 & 0 & 11 & 1.34 & 2 & 0.75 \\
\hline Several times a day & 0 & 0 & 7 & 0.85 & 3 & 1.12 \\
\hline Not applicable & & & 8 & 0.98 & 2 & 0.75 \\
\hline Total & 81 & 100 & 819 & 100 & 268 & 100 \\
\hline \multicolumn{7}{|c|}{ In the last 7 days, how often have children/dependent adults in your household broken or damaged anything? } \\
\hline Never & 76 & 93.83 & 680 & 83.03 & 311 & 76.23 \\
\hline At least once & 4 & 4.94 & 107 & 13.06 & 59 & 14.46 \\
\hline At least once a day & & & 11 & 1.34 & 16 & 3.92 \\
\hline Several times a day & & & 8 & 0.98 & 20 & 4.9 \\
\hline Not applicable & 1 & 1.23 & 13 & 1.59 & 2 & 0.49 \\
\hline Total & 81 & 100 & 819 & 100 & 408 & 100 \\
\hline \multicolumn{7}{|c|}{ In the last 7 days, how often have you not had enough time to cook food when you were supposed to? } \\
\hline Never & 133 & 65.2 & 676 & 63.12 & 311 & 76.23 \\
\hline At least once & 59 & 28.92 & 243 & 22.69 & 59 & 14.46 \\
\hline At least once a day & 7 & 3.43 & 47 & 4.39 & 16 & 3.92 \\
\hline Several times a day & 2 & 0.98 & 88 & 8.22 & 20 & 4.9 \\
\hline Not applicable & 3 & 1.47 & 17 & 1.59 & 2 & 0.49 \\
\hline Total & 204 & 100 & 1071 & 100 & 408 & 100 \\
\hline \multicolumn{7}{|c|}{ In the last 7 days, how often have you not had enough time to wash family members' clothes when you were supposed to? } \\
\hline Never & 109 & 53.43 & 633 & 59.1 & 302 & 74.02 \\
\hline At least once & 74 & 36.27 & 234 & 21.85 & 68 & 16.67 \\
\hline At least once a day & 18 & 8.82 & 68 & 6.35 & 22 & 5.39 \\
\hline Several times a day & 1 & 0.49 & 114 & 10.64 & 12 & 2.94 \\
\hline Not applicable & 2 & 0.98 & 22 & 2.05 & 4 & 0.98 \\
\hline Total & 204 & 100 & 1071 & 100 & 408 & 100 \\
\hline \multicolumn{7}{|c|}{ In the last 7 days, how often have you not had enough time to bathe a dependent household member when you were supposed to? } \\
\hline Never & 129 & 63.24 & & & 312 & 76.47 \\
\hline At least once & 35 & 17.16 & & & 37 & 9.07 \\
\hline At least once a day & 1 & 0.49 & & & 9 & 2.21 \\
\hline Several times a day & 0 & 0 & & & 4 & 0.98 \\
\hline Not applicable & 39 & 19.12 & & & 46 & 11.27 \\
\hline Total & 204 & 100 & & & 408 & 100 \\
\hline \multicolumn{7}{|c|}{ In the last 7 days, how often have you not had enough time for personal care and hygiene? } \\
\hline Never & 139 & 68.14 & 735 & 68.63 & 330 & 80.88 \\
\hline At least once & 57 & 27.94 & 147 & 13.73 & 57 & 13.97 \\
\hline At least once a day & 5 & 2.45 & 32 & 2.99 & 9 & 2.21 \\
\hline Several times a day & 2 & 0.98 & 152 & 14.19 & 9 & 2.21 \\
\hline Not applicable & 1 & 0.49 & 5 & 0.47 & 3 & 0.74 \\
\hline Total & 204 & 100 & 1071 & 100 & 408 & 100 \\
\hline
\end{tabular}

Note: Not all data was recorded for all countries. Information on lack of time to bathe a dependent household member was collected for Philippines and Zimbabwe only 


\section{REGRESSION ANALYSIS TABLES}

\section{REGRESSION RESULTS FOR ASSOCIATION BETWEEN HOUSEHOLD CHARACTERISTICS AND ADULT WOMEN AND MEN CARE TIME}

\begin{tabular}{|c|c|c|c|c|c|c|c|c|c|c|c|c|}
\hline \multirow{3}{*}{ Variables } & \multicolumn{4}{|c|}{ Philippines } & \multicolumn{4}{|l|}{ Uganda } & \multicolumn{4}{|l|}{ Zimbabwe } \\
\hline & \multicolumn{2}{|c|}{ Primary care } & \multicolumn{2}{|l|}{ Any care } & \multicolumn{2}{|l|}{ Primary care } & \multicolumn{2}{|l|}{ Any care } & \multicolumn{2}{|l|}{ Primary care } & \multicolumn{2}{|l|}{ Any care } \\
\hline & Women & Men & Women & Men & Women & Men & Women & Men & Women & Men & Women & Men \\
\hline \multirow[t]{2}{*}{ married } & -0.565 & $1.208^{* *}$ & 0.245 & 1.596 & $0.539 * *$ & $-1.260 * * *$ & 0.624 & 0.596 & 0.238 & $-1.111^{* *}$ & 0.385 & -2.634 \\
\hline & (0.918) & (0.581) & (1.843) & (1.274) & $(0.223)$ & (0.324) & (0.559) & (0.604) & $(0.435)$ & (0.520) & $(1.060)$ & (3.448) \\
\hline \multirow[t]{2}{*}{ age_adult } & $-0.042^{* *}$ & 0.017 & $-0.089 * *$ & 0.047 & $-0.023^{* * *}$ & 0.002 & $-0.044^{* * *}$ & -0.011 & $-0.029 * *$ & $-0.016 * * *$ & $-0.086 * * *$ & -0.027 \\
\hline & (0.020) & (0.015) & $(0.044)$ & (0.031) & (0.006) & (0.003) & (0.017) & (0.014) & (0.013) & $(0.006)$ & (0.030) & (0.017) \\
\hline \multirow[t]{2}{*}{ education } & -0.133 & 0.009 & $0.482^{*}$ & 0.312 & 0.130 & $0.103^{*}$ & $0.373^{* *}$ & 0.265 & 0.080 & -0.085 & -0.199 & -0.399 \\
\hline & (0.137) & (0.099) & (0.280) & (0.261) & (0.082) & (0.053) & (0.181) & (0.199) & (0.147) & (0.092) & (0.367) & $(0.253)$ \\
\hline \multirow[t]{2}{*}{ Prop_fem } & -0.335 & 0.372 & -3.255 & -0.897 & -0.344 & $0.521^{*}$ & $-1.931^{*}$ & $-2.645^{* *}$ & -0.905 & -0.461 & -2.933 & $-3.177 * *$ \\
\hline & (1.192) & (0.730) & (2.196) & (1.776) & (0.427) & (0.301) & (1.040) & (1.327) & $(0.803)$ & (0.396) & (1.952) & $(1.451)$ \\
\hline \multirow[t]{2}{*}{ Hh_size } & -0.026 & -0.029 & -0.021 & 0.075 & -0.041 & $-0.052^{* *}$ & $-0.217^{* *}$ & -0.164 & 0.042 & 0.024 & 0.140 & -0.066 \\
\hline & (0.089) & $(0.060)$ & (0.170) & (0.141) & (0.042) & $(0.026)$ & (0.105) & (0.111) & (0.089) & $(0.036)$ & (0.182) & $(0.144)$ \\
\hline \multirow[t]{2}{*}{ under_6 } & 0.620 & 0.428 & $4.632^{* * *}$ & 1.265 & 0.159 & -0.024 & $4.614^{* * *}$ & $1.936 * * *$ & 0.221 & -0.002 & $3.594^{* * *}$ & 1.006 \\
\hline & (0.478) & (0.311) & (0.942) & $(0.826)$ & (0.195) & (0.125) & $(0.453)$ & (0.462) & (0.341) & (0.217) & (0.827) & (0.626) \\
\hline \multirow[t]{2}{*}{ hh_middle } & -0.376 & -0.713 & -0.495 & -1.074 & -0.247 & $-0.428 * * *$ & -0.564 & $-1.054^{*}$ & -0.524 & -0.214 & -0.404 & -0.560 \\
\hline & (0.633) & (0.471) & (1.147) & (1.015) & (0.231) & (0.156) & (0.578) & (0.612) & $(0.453)$ & $(0.210)$ & (1.129) & (0.746) \\
\hline \multirow[t]{2}{*}{ hh_richer } & -0.322 & -0.633 & -0.687 & -0.631 & 0.242 & -0.214 & 0.632 & -0.889 & -0.060 & 0.036 & -0.883 & $-0.945^{*}$ \\
\hline & $(0.534)$ & (0.396) & (1.128) & (1.198) & (0.244) & (0.180) & (0.598) & (0.551) & (0.398) & (0.220) & (0.994) & (0.562) \\
\hline \multirow[t]{2}{*}{ hh_richest } & -0.270 & -0.628 & -0.435 & $-1.663^{*}$ & 0.200 & -0.184 & -0.043 & 0.337 & 0.219 & 0.222 & 0.308 & 0.086 \\
\hline & (0.638) & (0.391) & (1.383) & (0.945) & (0.282) & (0.177) & $(0.666)$ & (0.629) & $(0.504)$ & $(0.321)$ & (1.105) & $(0.816)$ \\
\hline \multirow[t]{2}{*}{ district2 } & -0.418 & $0.910 * * *$ & 0.798 & $2.769 * * *$ & $-0.738^{* *}$ & 0.249 & $-3.204^{* * *}$ & $-2.160 * * *$ & -0.367 & $0.735^{* *}$ & 0.871 & $1.858^{* *}$ \\
\hline & $(0.501)$ & (0.348) & (1.097) & (0.982) & (0.325) & $(0.216)$ & $(0.733)$ & $(0.820)$ & (0.459) & $(0.304)$ & (1.186) & $(0.854)$ \\
\hline \multirow[t]{2}{*}{ district 3} & -0.612 & -0.356 & 0.194 & -0.832 & -0.449 & $1.132^{*}$ & $-3.438 * * *$ & $-1.906 *$ & -0.254 & -0.006 & -0.469 & 0.494 \\
\hline & (0.920) & $(0.426)$ & (1.386) & (1.035) & $(0.475)$ & (0.589) & (1.009) & (1.019) & $(0.574)$ & (0.197) & (1.321) & (1.053) \\
\hline \multirow[t]{2}{*}{ district 4} & 0.053 & $1.132^{* *}$ & -1.814 & -0.103 & $-1.816^{* * *}$ & 0.174 & $-4.453 * * *$ & $-2.360 * * *$ & $-1.743 * * *$ & 0.224 & $-4.663 * * *$ & -0.032 \\
\hline & $(0.760)$ & (0.521) & (1.317) & (0.982) & $(0.247)$ & (0.143) & (0.653) & (0.619) & $(0.474)$ & (0.215) & (1.096) & (0.724) \\
\hline \multirow[t]{2}{*}{ district 5} & 0.842 & 0.576 & -1.686 & 1.449 & $-0.988^{* * *}$ & 0.007 & $-4.702^{* * *}$ & $-2.816^{* * *}$ & 0.508 & $0.491^{*}$ & -1.076 & 0.641 \\
\hline & (0.924) & (0.587) & (1.648) & $(1.480)$ & (0.301) & (0.172) & $(0.734)$ & (0.661) & (0.449) & (0.265) & (1.037) & (0.643) \\
\hline \multirow[t]{2}{*}{ Constant } & $9.709 * * *$ & 0.126 & $12.970 * * *$ & -0.607 & $5.669 * * *$ & $1.600 * * *$ & $13.134^{* * *}$ & $4.825^{* * *}$ & $5.991^{* * *}$ & $2.726^{* * *}$ & $14.724^{* * *}$ & $8.878 * * *$ \\
\hline & $(1.506)$ & $(0.954)$ & (3.720) & (2.578) & $(0.513)$ & (0.368) & (1.323) & (1.009) & (1.207) & $(0.675)$ & (2.849) & (3.298) \\
\hline Observations & 204 & 209 & 204 & 209 & 1.071 & 819 & 1.076 & 826 & 402 & 324 & 403 & 325 \\
\hline$R$-squared & 0.097 & 0.106 & 0.301 & 0.127 & 0.097 & 0.121 & 0.210 & 0.078 & 0.103 & 0.076 & 0.212 & 0.083 \\
\hline
\end{tabular}

NOTES: Robust standard errors in parentheses; ${ }^{* * *} p<0.01 .{ }^{* *} p<0.05 .{ }^{*} p<0.10$. The model includes the following control variables: age, education, the proportion of females in the household, the number of household members, whether the household has at least one child under six years old, the household wealth (quintiles for middle, richer and richest income households) and the district. 


\section{REGRESSION RESULTS FOR ASSOCIATION BETWEEN HOUSEHOLD CHARACTERISTICS AND GIRLS AND BOYS}

TIME USE

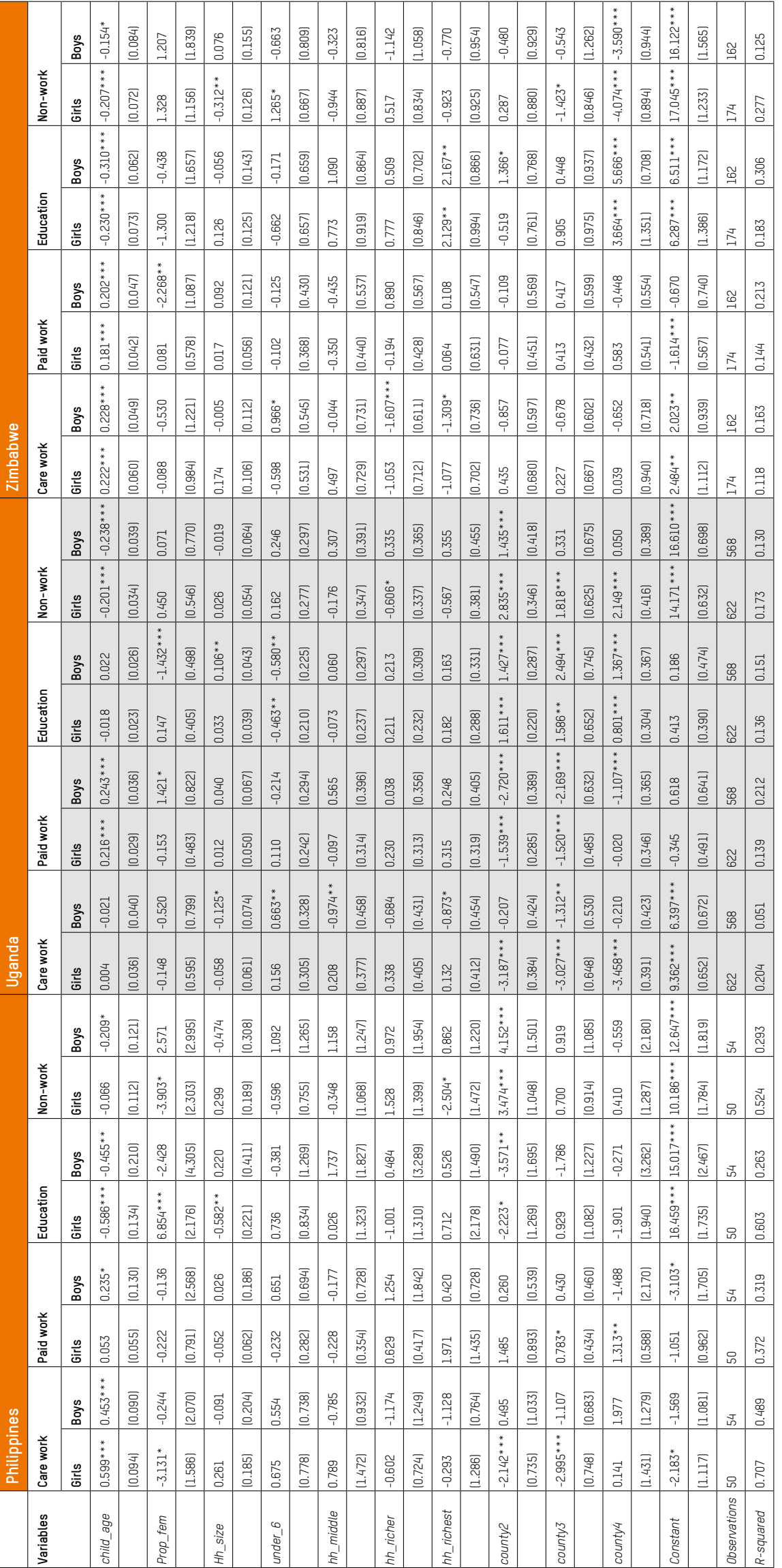


REGRESSION RESULTS FOR ASSOCIATION BETWEEN ADULTS' CARE TIME AND GIRLS' AND BOYS' TIME USE

\begin{tabular}{|c|c|c|c|c|c|c|c|c|}
\hline \multirow[b]{2}{*}{ Variables } & \multicolumn{2}{|c|}{ Care work } & \multicolumn{2}{|c|}{ Paid work } & \multicolumn{2}{|l|}{ Education } & \multicolumn{2}{|l|}{ Non-work } \\
\hline & Girls & Boys & Girls & Boys & Girls & Boys & Girls & Boys \\
\hline & \multicolumn{8}{|c|}{ Philippines } \\
\hline \multirow[t]{2}{*}{ Primary care men } & -0.038 & -0.126 & -0.036 & -0.001 & -0.100 & -0.396 & 0.248 & 0.406 \\
\hline & (0.196) & (0.146) & (0.056) & (0.104) & (0.232) & (0.262) & (0.188) & (0.248) \\
\hline \multirow[t]{2}{*}{ Primary care women } & -0.013 & -0.137 & 0.027 & -0.040 & -0.019 & 0.316 & -0.027 & -0.108 \\
\hline & (0.125) & $(0.084)$ & (0.058) & (0.096) & (0.135) & (0.229) & $(0.110)$ & (0.196) \\
\hline \multirow[t]{2}{*}{ Constant } & -2.060 & -1.368 & -1.053 & $-3.133^{*}$ & $16.737^{* * *}$ & $16.259 * * *$ & $9.719 * * *$ & $11.550 * * *$ \\
\hline & (1.319) & (1.134) & (1.062) & (1.702) & (1.988) & (2.502) & (2.075) & (1.952) \\
\hline Observations & 50 & 54 & 50 & 54 & 50 & 54 & 50 & 54 \\
\hline$R$-squared & 0.707 & 0.518 & 0.375 & 0.322 & 0.605 & 0.337 & 0.542 & 0.343 \\
\hline
\end{tabular}

\begin{tabular}{|c|c|c|c|c|c|c|c|c|}
\hline & Uganda & & & & & & & \\
\hline \multirow[t]{2}{*}{ Primary care men } & 0.152 & 0.138 & -0.054 & $-0.199 *$ & 0.243 & $0.278^{* *}$ & $-0.330 * * *$ & $-0.222 * *$ \\
\hline & $(0.136)$ & $(0.094)$ & (0.068) & (0.102) & (0.150) & (0.135) & $(0.077)$ & (0.100) \\
\hline \multirow[t]{2}{*}{ Primary care women } & 0.062 & $0.102^{*}$ & 0.035 & 0.030 & $0.059 *$ & 0.012 & $-0.140 * * *$ & $-0.099 * *$ \\
\hline & $(0.045)$ & $(0.054)$ & (0.037) & (0.047) & (0.033) & $(0.037)$ & $(0.043)$ & $(0.048)$ \\
\hline \multirow[t]{2}{*}{ Constant } & $9.152^{* * *}$ & $6.116^{* * *}$ & -0.420 & 0.637 & 0.183 & 0.042 & $14.642 * * *$ & $16.920 * * *$ \\
\hline & (0.667) & (0.683) & (0.501) & (0.651) & (0.380) & $(0.475)$ & (0.658) & (0.703) \\
\hline Observations & 622 & 568 & 622 & 568 & 622 & 568 & 622 & 568 \\
\hline$R$-squared & 0.210 & 0.059 & 0.140 & 0.217 & 0.161 & 0.168 & 0.208 & 0.144 \\
\hline
\end{tabular}

\begin{tabular}{|c|c|c|c|c|c|c|c|c|}
\hline \multicolumn{9}{|c|}{ Zimbabwe } \\
\hline \multirow[t]{2}{*}{ Primary care men } & 0.028 & $0.458^{* * *}$ & 0.036 & 0.057 & 0.440 & 0.008 & -0.411 & $-0.756 * * *$ \\
\hline & $(0.284)$ & (0.168) & (0.182) & (0.111) & (0.287) & (0.262) & (0.337) & (0.186) \\
\hline \multirow[t]{2}{*}{ Primary care women } & -0.047 & 0.062 & 0.014 & 0.047 & 0.046 & 0.041 & -0.039 & $-0.200^{*}$ \\
\hline & $(0.086)$ & (0.093) & (0.045) & (0.058) & $(0.110)$ & $(0.100)$ & (0.098) & (0.114) \\
\hline \multirow[t]{2}{*}{ Constant } & $2.564^{* *}$ & $1.876^{* *}$ & $-1.652^{* * *}$ & -0.785 & $6.060 * * *$ & $6.409 * * *$ & $17.252^{* * *}$ & $16.605^{* * *}$ \\
\hline & (1.127) & (0.942) & (0.590) & (0.771) & $(1.400)$ & (1.225) & $(1.230)$ & (1.557) \\
\hline Observations & 174 & 162 & 174 & 162 & 174 & 162 & 174 & 162 \\
\hline$R$-squared & 0.120 & 0.213 & 0.145 & 0.217 & 0.195 & 0.307 & 0.288 & 0.204 \\
\hline
\end{tabular}

NOTES: Robust standard errors in parentheses; ${ }^{* * *} p<0.01 .{ }^{* *} p<0.05 .{ }^{*} p<0.10$. The model includes the following control variables: age, education, the proportion of females in the household, the number of household members, whether the household has at least one child under six years old, the household wealth (quintiles for middle, richer and richest income households) and the district. 
REGRESSION RESULTS FOR ASSOCIATION BETWEEN OWNERSHIP OF TLSE AND TIME USE PER TYPE OF TASK (ADULTS)

\begin{tabular}{|c|c|c|c|c|c|c|}
\hline & \multicolumn{2}{|c|}{ Philippines } & \multicolumn{2}{|l|}{ Uganda } & \multicolumn{2}{|c|}{ Zimbabwe } \\
\hline & Women & Men & Women & Men & Women & Men \\
\hline & \multicolumn{6}{|c|}{ Water collection hours } \\
\hline \multirow[t]{2}{*}{ Water equip. } & -0.020 & -0.041 & -0.021 & 0.002 & -0.028 & $0.045^{* *}$ \\
\hline & $(0.056)$ & $(0.049)$ & $(0.016)$ & $(0.006)$ & $(0.033)$ & (0.019) \\
\hline \multirow[t]{2}{*}{ Constant } & $0.941^{* * *}$ & 0.183 & $1.030 * * *$ & $0.243 * * *$ & $0.667 * * *$ & $0.374^{* *}$ \\
\hline & $(0.340)$ & (0.382) & $(0.130)$ & $(0.068)$ & (0.249) & $(0.166)$ \\
\hline Observations & 204 & 209 & 1.071 & 819 & 402 & 324 \\
\hline \multirow[t]{2}{*}{$R$-squared } & 0.056 & 0.065 & 0.254 & 0.057 & 0.163 & 0.056 \\
\hline & \multicolumn{6}{|c|}{ Fuel collection hours } \\
\hline \multirow[t]{2}{*}{ Fuel equip. } & 0.007 & $-0.088^{* *}$ & 0.011 & -0.002 & -0.004 & 0.047 \\
\hline & $(0.020)$ & $(0.040)$ & (0.013) & (0.013) & (0.035) & (0.029) \\
\hline \multirow[t]{2}{*}{ Constant } & 0.075 & 0.366 & $0.817^{* * *}$ & $0.208^{* * *}$ & $0.802 * * *$ & $0.283^{*}$ \\
\hline & (0.127) & $(0.368)$ & (0.120) & $(0.076)$ & (0.298) & $(0.158)$ \\
\hline Observations & 204 & 209 & 1.071 & 819 & 402 & 324 \\
\hline \multirow[t]{2}{*}{$R$-squared } & 0.046 & 0.122 & 0.245 & 0.028 & 0.066 & 0.036 \\
\hline & \multicolumn{6}{|c|}{ Meal preparation hours } \\
\hline \multirow[t]{2}{*}{ Meal equip. } & $-0.423 * *$ & $-0.244^{*}$ & 0.053 & 0.013 & 0.133 & 0.001 \\
\hline & $(0.186)$ & $(0.135)$ & $(0.127)$ & $(0.053)$ & (0.129) & $(0.055)$ \\
\hline \multirow[t]{2}{*}{ Constant } & $4.900 * * *$ & -0.024 & $2.700^{* * *}$ & $0.605^{* * *}$ & $2.867 * * *$ & $1.292 * * *$ \\
\hline & (0.772) & (0.542) & (0.330) & (0.184) & (0.566) & $(0.423)$ \\
\hline Observations & 204 & 209 & 1.071 & 819 & 402 & 324 \\
\hline \multirow[t]{2}{*}{$R$-squared } & 0.142 & 0.115 & 0.045 & 0.106 & 0.089 & 0.152 \\
\hline & \multicolumn{6}{|c|}{ Cleaning hours } \\
\hline \multirow[t]{2}{*}{ Clean equip. } & $-0.357^{* *}$ & 0.071 & -0.035 & -0.005 & 0.164 & 0.104 \\
\hline & (0.149) & (0.056) & (0.049) & $(0.040)$ & (0.175) & $(0.126)$ \\
\hline \multirow[t]{2}{*}{ Constant } & 0.541 & -0.008 & $0.452^{* * *}$ & $0.261 * * *$ & $0.809 *$ & 0.490 \\
\hline & (0.504) & (0.147) & (0.128) & (0.092) & (0.421) & (0.320) \\
\hline Observations & 204 & 209 & 1.071 & 819 & 402 & 324 \\
\hline \multirow[t]{2}{*}{$R$-squared } & 0.095 & 0.075 & 0.046 & 0.072 & 0.104 & 0.038 \\
\hline & \multicolumn{6}{|c|}{ Clothes preparation hours } \\
\hline \multirow[t]{2}{*}{ Clothes equip. } & -0.076 & -0.004 & $-0.150 * *$ & 0.035 & 0.003 & -0.007 \\
\hline & (0.122) & $(0.018)$ & (0.066) & (0.063) & $(0.087)$ & (0.033) \\
\hline \multirow[t]{2}{*}{ Constant } & 1.168 & 0.087 & 0.134 & $0.229 *$ & $1.517^{* * *}$ & -0.196 \\
\hline & (0.722) & (0.133) & (0.136) & (0.130) & (0.430) & $(0.134)$ \\
\hline Observations & 204 & 209 & 1.071 & 819 & 402 & 324 \\
\hline \multirow[t]{2}{*}{$R$-squared } & 0.199 & 0.033 & 0.141 & 0.058 & 0.144 & 0.047 \\
\hline & \multicolumn{6}{|c|}{ Childcare hours } \\
\hline Child equip. & 0.171 & $0.561^{* *}$ & 0.056 & $0.205^{* *}$ & 0.052 & -0.127 \\
\hline & $(0.488)$ & $(0.246)$ & $(0.093)$ & $(0.094)$ & $(0.234)$ & $(0.278)$ \\
\hline Constant & $4.720^{*}$ & -0.453 & 0.007 & 0.137 & -0.864 & 0.438 \\
\hline & (2.511) & (1.213) & (0.382) & (0.254) & (2.348) & (0.599) \\
\hline Observations & 57 & 44 & 382 & 269 & 80 & 70 \\
\hline$R$-squared & 0.397 & 0.447 & 0.065 & 0.062 & 0.316 & 0.095 \\
\hline
\end{tabular}

NOTES: Robust standard errors in parentheses; ${ }^{* * *} p<0.01 .{ }^{* *} p<0.05 .{ }^{*} p<0.10$. The model includes the following control variables: age, education, the proportion of females in the household, the number of household members, whether the household has at least one child under six years old, the household wealth (quintiles for middle, richer and richest income households) and the district. 
REGRESSION RESULTS FOR ASSOCIATION BETWEEN OWNERSHIP OF TLSE AND CARE WORK (ADULTS)

\begin{tabular}{|c|c|c|c|c|c|c|c|c|c|c|c|c|}
\hline \multirow{3}{*}{ Variables } & \multicolumn{4}{|c|}{ Philippines } & \multicolumn{4}{|l|}{ Uganda } & \multicolumn{4}{|c|}{ Zimbabwe } \\
\hline & \multicolumn{2}{|c|}{ Primary care } & \multicolumn{2}{|l|}{ Any care } & \multicolumn{2}{|c|}{ Primary care } & \multicolumn{2}{|l|}{ Any care } & \multicolumn{2}{|c|}{ Primary care } & \multicolumn{2}{|l|}{ Any care } \\
\hline & Women & Men & Women & Men & Women & Men & Women & Men & Women & Men & Women & Men \\
\hline \multirow[t]{2}{*}{ Water coll. } & -0.003 & -0.256 & -0.003 & 0.121 & -0.032 & -0.294 & -0.032 & -0.015 & 0.174 & 0.308 & 0.174 & $0.218^{* *}$ \\
\hline & (0.209) & (0.396) & (0.209) & (0.162) & $(0.075)$ & $(0.201)$ & $(0.075)$ & $(0.058)$ & (0.153) & $(0.390)$ & $(0.153)$ & (0.109) \\
\hline \multirow[t]{2}{*}{ Fuel coll. } & -0.129 & -0.076 & -0.129 & -0.119 & $0.172^{* *}$ & -0.145 & $0.172^{* *}$ & 0.013 & 0.040 & $0.452^{*}$ & 0.040 & 0.067 \\
\hline & (0.209) & $(0.454)$ & (0.209) & (0.155) & $(0.077)$ & (0.153) & (0.077) & $(0.051)$ & (0.130) & (0.266) & $(0.130)$ & $(0.073)$ \\
\hline \multirow[t]{2}{*}{ Meal prep. } & $-0.803^{* *}$ & -0.180 & $-0.803^{* *}$ & -0.157 & -0.213 & 0.619 & -0.213 & -0.046 & 0.107 & -0.281 & 0.107 & -0.182 \\
\hline & (0.367) & $(0.627)$ & (0.367) & (0.247) & (0.196) & $(0.406)$ & (0.196) & (0.148) & (0.271) & [0.692] & $(0.271)$ & (0.193) \\
\hline \multirow[t]{2}{*}{ Cleaning } & -0.117 & $-1.925^{*}$ & -0.117 & -0.464 & -0.124 & $1.588^{* * *}$ & -0.124 & 0.155 & 0.217 & 0.400 & 0.217 & 0.349 \\
\hline & (0.490) & (1.042) & (0.490) & $(0.340)$ & $(0.184)$ & $(0.514)$ & $(0.184)$ & (0.159) & $(0.540)$ & (0.949) & $(0.540)$ & (0.306) \\
\hline \multirow[t]{2}{*}{ Clothes prep. } & 0.157 & -0.515 & 0.157 & 0.008 & -0.047 & 0.417 & -0.047 & 0.065 & -0.005 & 0.216 & -0.005 & 0.149 \\
\hline & (0.277) & (0.529) & (0.277) & (0.219) & (0.197) & (0.352) & (0.197) & (0.161) & (0.236) & (0.446) & (0.236) & (0.179) \\
\hline \multirow[t]{2}{*}{ Washing } & 0.253 & -0.007 & 0.253 & -0.404 & -0.072 & -0.406 & -0.072 & 0.048 & 0.093 & -0.580 & 0.093 & -0.224 \\
\hline & (0.422) & (0.865) & (0.422) & (0.412) & $(0.210)$ & $(0.510)$ & $(0.210)$ & (0.123) & (0.335) & (0.581) & (0.335) & (0.229) \\
\hline \multirow[t]{2}{*}{ Constant } & $9.930 * * *$ & -0.846 & $9.930 * * *$ & 0.214 & $5.579 * * *$ & $5.056^{* * *}$ & $5.579 * * *$ & $1.665^{* * *}$ & $5.491 * * *$ & $8.632 * * *$ & $5.491 * * *$ & $2.719 * * *$ \\
\hline & (1.531) & (2.526) & (1.531) & (0.996) & (0.521) & (1.039) & (0.521) & (0.379) & (1.370) & (3.292) & (1.370) & $(0.667)$ \\
\hline Observations & 204 & 209 & 204 & 209 & 1.071 & 826 & 1.071 & 819 & 402 & 325 & 402 & 324 \\
\hline \multirow[t]{2}{*}{$R$-squared } & 0.128 & 0.172 & 0.128 & 0.132 & 0.103 & 0.096 & 0.103 & 0.122 & 0.109 & 0.106 & 0.109 & 0.121 \\
\hline & \multicolumn{12}{|c|}{ Childcare equipment } \\
\hline \multirow[t]{2}{*}{ Childcare } & 0.302 & $2.393^{*}$ & 0.302 & 0.155 & -0.036 & $-0.966 *$ & -0.036 & -0.022 & 0.477 & -1.462 & 0.477 & 0.183 \\
\hline & $(1.111)$ & (1.230) & (1.111) & $(0.260)$ & (0.275) & (0.554) & (0.275) & (0.108) & (0.959) & (2.262) & (0.959) & (0.139) \\
\hline \multirow[t]{2}{*}{ Constant } & 6.884 & 0.607 & 6.884 & 0.089 & $5.670 * * *$ & $10.299 * * *$ & $5.670 * * *$ & $1.669 * * *$ & 1.103 & 0.308 & 1.103 & $2.632 * * *$ \\
\hline & (4.112) & $(6.420)$ & (4.112) & (1.018) & (1.264) & (3.267) & (1.264) & (0.378) & (5.923) & (6.434) & (5.923) & (0.662) \\
\hline Observations & 57 & 44 & 57 & 209 & 382 & 273 & 382 & 819 & 80 & 70 & 80 & 324 \\
\hline$R$-squared & 0.354 & 0.531 & 0.354 & 0.134 & 0.112 & 0.133 & 0.112 & 0.122 & 0.194 & 0.210 & 0.194 & 0.126 \\
\hline
\end{tabular}

NOTES: Robust standard errors in parentheses; ${ }^{* * *} p<0.01 .{ }^{* *} p<0.05 .{ }^{*} p<0.10$. The model includes the following control variables: age, education, the proportion of females in the

household, the number of household members, whether the household has at least one child under six years old, the household wealth lquintiles for middle, richer and richest income

households) and the district. The model for childcare equipment has fewer observations because the questions were only asked if respondents said that they had infants living with them. 
REGRESSION RESULTS FOR ASSOCIATION BETWEEN OWNERSHIP OF TLSE AND TIME USE PER TYPE OF TASK (YOUNG PEOPLE)

\begin{tabular}{|c|c|c|c|c|c|c|}
\hline & \multicolumn{2}{|c|}{ Philippines } & \multicolumn{2}{|l|}{ Uganda } & \multicolumn{2}{|c|}{ Zimbabwe } \\
\hline & Girls & Boys & Girls & Boys & Girls & Boys \\
\hline & \multicolumn{6}{|c|}{ Water collection hours } \\
\hline \multirow[t]{2}{*}{ Water equip. } & $-0.251^{* *}$ & -0.029 & 0.022 & -0.020 & -0.063 & -0.044 \\
\hline & (0.123) & (0.093) & $(0.033)$ & (0.037) & $(0.058)$ & $(0.056)$ \\
\hline \multirow[t]{2}{*}{ Constant } & 0.273 & $0.644^{*}$ & $2.083^{* * *}$ & $1.629 * * *$ & $0.500^{*}$ & $0.747^{* * *}$ \\
\hline & (0.322) & (0.337) & (0.179) & $(0.201)$ & $(0.296)$ & (0.248) \\
\hline Observations & 50 & 53 & 620 & 568 & 174 & 160 \\
\hline \multirow[t]{2}{*}{$R$-squared } & 0.413 & 0.284 & 0.234 & 0.043 & 0.076 & 0.097 \\
\hline & \multicolumn{6}{|c|}{ Fuel collection hours } \\
\hline \multirow[t]{2}{*}{ Fuel equip. } & -0.021 & -0.115 & $-0.060^{*}$ & 0.028 & $-0.115^{* *}$ & -0.048 \\
\hline & (0.042) & $(0.171)$ & (0.033) & $(0.035)$ & (0.052) & (0.058) \\
\hline \multirow[t]{2}{*}{ Constant } & 0.132 & -0.699 & $2.105^{* * *}$ & $1.156^{* * *}$ & $0.656 *$ & 0.061 \\
\hline & (0.208) & (0.692) & (0.185) & (0.208) & (0.342) & $(0.406)$ \\
\hline Observations & 50 & 53 & 620 & 568 & 174 & 160 \\
\hline \multirow[t]{2}{*}{$R$-squared } & 0.320 & 0.254 & 0.363 & 0.120 & 0.152 & 0.099 \\
\hline & \multicolumn{6}{|c|}{ Meal preparation hours } \\
\hline \multirow[t]{2}{*}{ Meal equip. } & -0.075 & -0.016 & -0.118 & 0.081 & -0.115 & 0.001 \\
\hline & $(0.160)$ & (0.115) & (0.133) & $(0.116)$ & $(0.111)$ & $(0.118)$ \\
\hline \multirow[t]{2}{*}{ Constant } & 0.025 & 0.127 & $1.913^{* * *}$ & $0.975^{* * *}$ & -0.573 & 0.296 \\
\hline & (0.381) & (0.349) & (0.278) & (0.229) & $(0.351)$ & (0.289) \\
\hline Observations & 50 & 53 & 620 & 568 & 174 & 160 \\
\hline \multirow[t]{2}{*}{$R$-squared } & 0.439 & 0.361 & 0.049 & 0.045 & 0.225 & 0.075 \\
\hline & \multicolumn{6}{|c|}{ Cleaning hours } \\
\hline \multirow[t]{2}{*}{ Clean equip. } & 0.128 & -0.377 & -0.016 & 0.112 & 0.061 & $0.377^{* *}$ \\
\hline & (0.279) & (0.263) & (0.072) & (0.082) & (0.237) & (0.166) \\
\hline \multirow[t]{2}{*}{ Constant } & -0.619 & -0.234 & $1.364^{* * *}$ & $0.793 * * *$ & $1.182^{* * *}$ & $0.678^{* *}$ \\
\hline & $(0.410)$ & (0.331) & (0.143) & (0.163) & $(0.340)$ & $(0.304)$ \\
\hline Observations & 50 & 53 & 620 & 568 & 174 & 160 \\
\hline \multirow[t]{2}{*}{$R$-squared } & 0.560 & 0.374 & 0.060 & 0.082 & 0.090 & 0.064 \\
\hline & \multicolumn{6}{|c|}{ Clothes preparation hours } \\
\hline \multirow[t]{2}{*}{ Clothes equip. } & -0.087 & -0.096 & 0.097 & 0.060 & -0.117 & -0.005 \\
\hline & $(0.211)$ & (0.161) & (0.096) & $(0.083)$ & $(0.118)$ & (0.132) \\
\hline \multirow[t]{2}{*}{ Constant } & -0.010 & $-1.142 * *$ & $0.398^{* *}$ & 0.211 & -0.114 & -0.055 \\
\hline & (0.356) & (0.425) & $(0.176)$ & (0.172) & (0.312) & $(0.351)$ \\
\hline Observations & 50 & 53 & 620 & 568 & 174 & 160 \\
\hline$R$-squared & 0.568 & 0.496 & 0.050 & 0.063 & 0.145 & 0.112 \\
\hline
\end{tabular}

NOTES: Robust standard errors in parentheses; ${ }^{* * *} p<0.01 .{ }^{* *} p<0.05 .{ }^{*} p<0.10$. The model includes the following control variables: age, education, the proportion of females in the households, the number of household members, whether the household has at least one child under six years old, the household wealth (quintiles for middle, richer and richest income households) and the district. 
REGRESSION RESULTS FOR ASSOCIATION BETWEEN USE OF PAID CARE SERVICES AND CARE WORK (ADULTS)

\begin{tabular}{|c|c|c|c|c|c|c|c|c|c|c|c|c|}
\hline \multirow{3}{*}{ Variables } & \multicolumn{4}{|c|}{ Philippines } & \multicolumn{4}{|l|}{ Uganda } & \multicolumn{4}{|c|}{ Zimbabwe } \\
\hline & \multicolumn{2}{|c|}{ Primary care } & \multicolumn{2}{|l|}{ Any care } & \multicolumn{2}{|c|}{ Primary care } & \multicolumn{2}{|l|}{ Any care } & \multicolumn{2}{|c|}{ Primary care } & \multicolumn{2}{|l|}{ Any care } \\
\hline & Women & Men & Women & Men & Women & Men & Women & Men & Women & Men & Women & Men \\
\hline \multirow[t]{2}{*}{ Paid services } & -0.087 & -0.080 & $-0.317^{*}$ & -0.020 & -0.011 & 0.019 & 0.014 & 0.026 & 0.009 & -0.003 & -0.012 & -0.060 \\
\hline & (0.086) & (0.064) & $(0.175)$ & (0.153) & (0.019) & (0.013) & (0.037) & (0.029) & (0.033) & $(0.024)$ & (0.075) & $(0.061)$ \\
\hline \multirow[t]{2}{*}{ Constant } & $9.896 * * *$ & 0.191 & $13.654^{* * *}$ & -0.591 & $5.644^{* * *}$ & $1.671^{* * *}$ & $13.168^{* * *}$ & $4.920 * * *$ & $6.008^{* * *}$ & $2.724^{* * *}$ & $14.701^{* * *}$ & $8.827^{* * *}$ \\
\hline & (1.512) & (0.959) & (3.713) & (2.606) & $(0.513)$ & (0.373) & (1.328) & (1.013) & (1.215) & (0.675) & (2.859) & (3.304) \\
\hline Observations & 204 & 209 & 204 & 209 & 1.071 & 819 & 1.076 & 826 & 402 & 324 & 403 & 325 \\
\hline$R$-squared & 0.100 & 0.112 & 0.312 & 0.127 & 0.097 & 0.123 & 0.210 & 0.078 & 0.103 & 0.076 & 0.212 & 0.085 \\
\hline
\end{tabular}

NOTES: Robust standard errors in parentheses; ${ }^{* * *} p<0.01 .{ }^{* *} p<0.05 .{ }^{*} p<0.10$. The model includes the following control variables: age, education, the proportion of females in the households, the number of household members, whether the household has at least one child under six years old, the household wealth (quintiles for middle, richer and richest income households) and the district. 'Paid services' is the number of care-related services that respondents pay for. 
REGRESSION RESULTS FOR ASSOCIATION BETWEEN ACCESS TO INFRASTRUCTURE AND TIME USE (ADULTS)

\begin{tabular}{|c|c|c|c|c|c|c|c|c|c|c|c|}
\hline \multirow[b]{2}{*}{ Variables } & \multicolumn{2}{|l|}{ Any care } & \multicolumn{2}{|c|}{ Primary care } & \multicolumn{2}{|l|}{ Paid } & \multicolumn{2}{|l|}{ Leisure } & \multicolumn{2}{|l|}{ Sleep } & \multirow[t]{2}{*}{ Ratio any } \\
\hline & Women & Men & Women & Men & Women & Men & Women & Men & Women & Men & \\
\hline \multicolumn{12}{|l|}{ Philippines } \\
\hline \multirow[t]{2}{*}{ Water } & $-0.793^{* *}$ & -0.468 & 0.066 & -0.111 & 0.003 & 0.313 & $-0.252^{*}$ & 0.326 & 0.118 & -0.135 & $0.135^{* * *}$ \\
\hline & (0.369) & (0.419) & $(0.226)$ & (0.209) & (0.240) & $(0.448)$ & $(0.144)$ & (0.258) & (0.116) & (0.263) & (0.051) \\
\hline \multirow[t]{2}{*}{ Electricity } & $-1.937 * *$ & 0.200 & $-1.095^{*}$ & 0.336 & 0.370 & -1.091 & $0.882^{* *}$ & 0.086 & -0.467 & 0.015 & $0.441^{* * *}$ \\
\hline & $(0.946)$ & (1.279) & (0.581) & $(0.484)$ & (0.624) & (1.108) & $(0.414)$ & (0.566) & (0.319) & (0.554) & (0.160) \\
\hline \multirow[t]{2}{*}{ Healthcare } & $1.915^{*}$ & $-1.941^{*}$ & $0.789 *$ & $-0.942^{* *}$ & 0.806 & 0.738 & 0.020 & -0.396 & -0.421 & 0.372 & -0.205 \\
\hline & (0.986) & (1.033) & (0.468) & (0.418) & $(0.524)$ & (0.657) & $(0.433)$ & (0.399) & (0.304) & (0.386) & (0.167) \\
\hline \multirow[t]{2}{*}{ Childcare } & -1.752 & 0.615 & -0.444 & $-0.993 * *$ & -0.199 & 1.363 & -0.520 & -0.267 & $0.896 * * *$ & 0.106 & 0.408 \\
\hline & (1.191) & (1.329) & (0.600) & (0.462) & (0.467) & (0.986) & (0.392) & (0.502) & (0.268) & (0.574) & (0.258) \\
\hline \multirow[t]{2}{*}{ Constant } & $14.213^{* * *}$ & -0.015 & $9.540 * * *$ & 0.408 & -1.123 & $10.870^{* * *}$ & 1.269 & 2.297 & $10.684^{* * *}$ & $7.553^{* * *}$ & 0.209 \\
\hline & (3.716) & (3.516) & (1.583) & (1.635) & (1.459) & (3.144) & (1.339) & (1.661) & (0.913) & (1.721) & (0.589) \\
\hline Observations & 204 & 167 & 204 & 167 & 204 & 167 & 204 & 167 & 204 & 167 & 203 \\
\hline R-squared & 0.339 & 0.180 & 0.120 & 0.184 & 0.163 & 0.229 & 0.193 & 0.087 & 0.213 & 0.215 & 0.105 \\
\hline
\end{tabular}

\begin{tabular}{|c|c|c|c|c|c|c|c|c|c|c|c|}
\hline \multicolumn{12}{|l|}{ Uganda } \\
\hline \multirow[t]{2}{*}{ Water } & $-2.136 * * *$ & $-1.845^{* * *}$ & $-0.408^{* *}$ & -0.008 & $0.480 *$ & $0.957^{* *}$ & $0.616 * * *$ & $0.638 * * *$ & -0.113 & -0.233 & $-0.055^{*}$ \\
\hline & (0.509) & (0.621) & (0.195) & (0.145) & (0.269) & $(0.384)$ & $(0.155)$ & $(0.237)$ & (0.144) & $(0.206)$ & (0.028) \\
\hline \multirow[t]{2}{*}{ Electricity } & 0.769 & 0.744 & 0.277 & 0.388 & -0.401 & -1.002 & 0.425 & -0.382 & $-0.559 * * *$ & -0.169 & 0.017 \\
\hline & (0.702) & $(0.831)$ & (0.353) & (0.295) & (0.503) & $(0.646)$ & (0.289) & (0.383) & (0.199) & $(0.294)$ & (0.039) \\
\hline \multirow[t]{2}{*}{ Healthcare } & $2.040 * *$ & $1.740^{*}$ & -0.232 & 0.229 & -0.561 & $-1.542^{* *}$ & -0.272 & -0.496 & $0.615^{*}$ & 0.617 & -0.058 \\
\hline & $(0.856)$ & $(0.973)$ & (0.345) & $(0.163)$ & (0.605) & $(0.690)$ & $(0.350)$ & (0.654) & $(0.351)$ & (0.435) & (0.102) \\
\hline \multirow[t]{2}{*}{ Childcare } & 0.696 & -0.880 & 0.413 & 0.102 & 0.188 & 0.354 & 0.131 & 0.443 & -0.030 & -0.127 & -0.013 \\
\hline & $(0.671)$ & $(0.658)$ & $(0.273)$ & $(0.280)$ & $(0.407)$ & (0.579) & $(0.248)$ & (0.342) & (0.186) & $(0.248)$ & $(0.031)$ \\
\hline \multirow[t]{2}{*}{ Constant } & $12.625^{* * *}$ & $7.312^{* *}$ & $6.174^{* * *}$ & 0.156 & $4.666 * * *$ & $4.114^{* * *}$ & 0.468 & -0.408 & $9.762 * * *$ & $11.000 * * *$ & 0.137 \\
\hline & (1.593) & (3.263) & (0.605) & (0.292) & (0.979) & (1.453) & (0.536) & (0.818) & (0.493) & (2.811) & $(0.111)$ \\
\hline Observations & 1.076 & 688 & 1.071 & 682 & 1.071 & 682 & 1.071 & 682 & 1.071 & 682 & 1.035 \\
\hline R-squared & 0.229 & 0.113 & 0.104 & 0.066 & 0.071 & 0.088 & 0.206 & 0.054 & 0.153 & 0.186 & 0.067 \\
\hline
\end{tabular}

\begin{tabular}{|c|c|c|c|c|c|c|c|c|c|c|c|}
\hline Zimbabwe & & & & & & & & & & & \\
\hline \multirow[t]{2}{*}{ Water } & $-4.242 * * *$ & $-1.247^{*}$ & -0.399 & 0.033 & -0.468 & $-1.024^{*}$ & $0.409 * *$ & 0.351 & 0.037 & 0.275 & -0.004 \\
\hline & $(0.850)$ & (0.692) & $(0.343)$ & (0.219) & (0.393) & (0.568) & (0.168) & $(0.316)$ & $(0.251)$ & (0.358) & -0.06 \\
\hline \multirow[t]{2}{*}{ Electricity } & $1.919 *$ & 1.253 & $0.991^{*}$ & 0.044 & -0.479 & 1.336 & 0.011 & -0.377 & 0.022 & -0.659 & -0.002 \\
\hline & (1.130) & (1.136) & (0.547) & $(0.310)$ & (0.493) & (0.839) & (0.251) & (0.389) & (0.302) & (0.448) & -0.061 \\
\hline \multirow[t]{2}{*}{ Healthcare } & 1.832 & -2.161 & 0.681 & 0.051 & $-1.933^{*}$ & -1.197 & 0.306 & $1.360 * * *$ & $1.046^{* *}$ & 0.809 & $0.119 *$ \\
\hline & (2.261) & (2.008) & $(0.781)$ & $(0.463)$ & (1.095) & (1.497) & $(0.325)$ & $(0.443)$ & $(0.434)$ & (0.541) & -0.063 \\
\hline \multirow[t]{2}{*}{ Childcare } & 1.065 & 0.566 & 0.378 & 0.249 & -0.277 & -1.170 & -0.007 & 0.160 & -0.462 & $-0.786 *$ & 0.026 \\
\hline & (0.998) & (0.869) & (0.452) & (0.289) & (0.508) & $(0.724)$ & (0.206) & (0.387) & (0.296) & {$[0.451)$} & -0.044 \\
\hline \multirow[t]{2}{*}{ Constant } & $16.767^{* * *}$ & $9.629 * * *$ & $6.008^{* * *}$ & $2.124^{* * *}$ & $2.951^{*}$ & $7.089 * * *$ & 0.924 & 1.246 & $7.784^{* * *}$ & $6.408^{* * *}$ & 0.001 \\
\hline & (3.577) & (3.134) & (1.431) & $(0.745)$ & (1.555) & (2.319) & (0.639) & (1.006) & (0.876) & (1.182) & -0.211 \\
\hline Observations & 403 & 292 & 402 & 291 & 402 & 291 & 402 & 291 & 402 & 291 & 390 \\
\hline R-squared & 0.282 & 0.124 & 0.119 & 0.073 & 0.173 & 0.091 & 0.075 & 0.048 & 0.104 & 0.080 & 0.065 \\
\hline
\end{tabular}

NOTES: Robust standard errors in parentheses; ${ }^{* * *} p<0.01 .{ }^{* *} p<0.05 .{ }^{*} p<0.10$. The model includes the following control variables: age, education, the proportion of females in the household, the number of household members, whether the household has at least one child under six years old, the household wealth lquintiles for middle, richer and richest income households) and the district. 
REGRESSION RESULTS FOR ASSOCIATION BETWEEN ACCESS TO INFRASTRUCTURE AND TIME USE (YOUNG PEOPLE]

\begin{tabular}{|c|c|c|c|c|c|c|c|c|c|c|c|c|}
\hline \multirow[t]{2}{*}{ Variables } & \multicolumn{2}{|l|}{ Care } & \multicolumn{2}{|l|}{ Leisure } & \multicolumn{2}{|l|}{ Paid } & \multicolumn{2}{|l|}{ Study } & \multicolumn{2}{|l|}{ School } & \multicolumn{2}{|l|}{ Sleep } \\
\hline & Girls & Boys & Girls & Boys & Girls & Boys & Girls & Boys & Girls & Boys & Girls & Boys \\
\hline \multicolumn{13}{|l|}{ Philippines } \\
\hline \multirow[t]{2}{*}{ Water } & 0.677 & -0.090 & -0.679 & 0.073 & -0.319 & 0.497 & 0.000 & $-0.529 *$ & 0.171 & 0.054 & 0.022 & 0.417 \\
\hline & $(0.708)$ & $(0.604)$ & $(0.822)$ & $(0.468)$ & $(0.467)$ & (0.586) & $(0.196)$ & $(0.286)$ & $(1.127)$ & $(0.865)$ & $(0.593)$ & (0.430) \\
\hline \multirow[t]{2}{*}{ Electricity } & 1.558 & $1.724^{* *}$ & -0.393 & 0.155 & 0.455 & 0.354 & $0.641 * *$ & -0.886 & -1.498 & -1.160 & -0.045 & 1.392 \\
\hline & (0.932) & (0.672) & $(1.010)$ & $(0.987)$ & $(0.623)$ & $(0.701)$ & (0.269) & $(0.640)$ & $(1.441)$ & (1..346) & $(1.105)$ & (1.030) \\
\hline \multirow[t]{2}{*}{ Healthcare } & $3.789^{* * *}$ & $-1.757^{*}$ & -0.248 & -0.359 & -0.672 & 1.237 & $0.841^{*}$ & $-1.776^{* * *}$ & -3.681 & $-5.330 * * *$ & 0.069 & $8.173^{* * *}$ \\
\hline & $(1.076)$ & $(0.926)$ & (1.722) & $(0.723)$ & (1.519) & $(1.210)$ & $(0.401)$ & (0.525) & (2.853) & $(1.840)$ & (2.979) & (1.046) \\
\hline \multirow[t]{2}{*}{ Childcare } & 1.656 & -1.852 & 0.985 & 1.092 & 0.519 & -1.090 & -0.274 & 0.837 & -1.432 & $3.635^{*}$ & -1.460 & $-3.798^{* * *}$ \\
\hline & $(1.167)$ & (1.375) & (2.621) & $(1.160)$ & $(0.976)$ & (1.089) & (0.308) & $(0.660)$ & (2.846) & $(1.775)$ & (1.739) & (1.291) \\
\hline \multirow[t]{2}{*}{ Constant } & $-10.449 * * *$ & -1.791 & $6.154^{*}$ & 3.002 & 0.718 & -5.895 & $2.191^{* *}$ & $8.369^{* * *}$ & $18.182^{* * *}$ & $23.969 * * *$ & 6.028 & -3.672 \\
\hline & (3.458) & (3.615) & (3.152) & (3.915) & (1.972) & (5.922) & (0.911) & (2.239) & (6.011) & (6.792) & (3.774) & (4.102) \\
\hline Observations & 33 & 38 & 33 & 38 & 33 & 38 & 33 & 37 & 33 & 37 & 33 & 37 \\
\hline R-squared & 0.828 & 0.617 & 0.416 & 0.230 & 0.529 & 0.226 & 0.767 & 0.477 & 0.717 & 0.515 & 0.711 & 0.669 \\
\hline
\end{tabular}

\begin{tabular}{|c|c|c|c|c|c|c|c|c|c|c|c|c|}
\hline \multicolumn{13}{|l|}{ Uganda } \\
\hline \multirow[t]{2}{*}{ Water } & 0.279 & -0.419 & $0.447 * *$ & $0.422^{*}$ & -0.022 & -0.020 & -0.171 & $0.148^{*}$ & -0.154 & 0.349 & 0.120 & 0.183 \\
\hline & $(0.319)$ & $(0.359)$ & $(0.216)$ & $(0.250)$ & $(0.087)$ & $(0.149)$ & $(0.110)$ & $(0.086)$ & $(0.234)$ & $(0.237)$ & $(0.193)$ & $(0.196)$ \\
\hline \multirow[t]{2}{*}{ Electricity } & -0.449 & $-1.045^{* *}$ & 0.577 & -0.062 & -0.033 & 0.597 & -0.108 & $0.467^{*}$ & 0.210 & 0.319 & 0.023 & -0.205 \\
\hline & $(0.627)$ & $(0.445)$ & $(0.491)$ & $(0.471)$ & $(0.102)$ & (0.379) & $(0.179)$ & $(0.257)$ & $(0.388)$ & $(0.410)$ & $(0.401)$ & $(0.299)$ \\
\hline \multirow[t]{2}{*}{ Healthcare } & $-1.052^{*}$ & $-2.317^{* * *}$ & 0.036 & 0.786 & 0.154 & -0.267 & 0.256 & 0.053 & 0.173 & 0.205 & 0.272 & 0.452 \\
\hline & $(0.551)$ & $(0.834)$ & $(0.402)$ & $(0.481)$ & $(0.099)$ & $(0.396)$ & $(0.158)$ & (0.192) & $(0.219)$ & $(0.178)$ & $(0.327)$ & $(0.484)$ \\
\hline \multirow[t]{2}{*}{ Childcare } & -0.523 & -0.323 & -0.080 & 0.309 & -0.074 & -0.149 & -0.002 & -0.157 & 0.506 & 0.336 & 0.486 & 0.349 \\
\hline & $(0.430)$ & $(0.476)$ & $(0.306)$ & $(0.416)$ & $(0.089)$ & $(0.213)$ & $(0.149)$ & $(0.179)$ & $(0.421)$ & $(0.396)$ & $(0.347)$ & $(0.294)$ \\
\hline \multirow[t]{2}{*}{ Constant } & $9.877^{* * *}$ & $8.741^{* * *}$ & $3.051^{* * *}$ & $3.811^{* * *}$ & $-0.596^{*}$ & $-1.304^{* *}$ & -0.007 & -0.182 & 0.146 & -0.059 & $11.241^{* * *}$ & $11.505^{* * *}$ \\
\hline & $(0.995)$ & (1.180) & $(0.665)$ & $(0.775)$ & $(0.333)$ & $(0.591)$ & $(0.246)$ & (0.326) & $(0.562)$ & $(0.523)$ & $(0.621)$ & $(0.649)$ \\
\hline Observations & 578 & 524 & 578 & 524 & 578 & 524 & 576 & 524 & 576 & 524 & 576 & 524 \\
\hline R-squared & 0.209 & 0.074 & 0.256 & 0.134 & 0.042 & 0.128 & 0.211 & 0.226 & 0.077 & 0.120 & 0.079 & 0.116 \\
\hline
\end{tabular}

\begin{tabular}{|c|c|c|c|c|c|c|c|c|c|c|c|c|}
\hline \multicolumn{13}{|l|}{ Zimbabwe } \\
\hline \multirow[t]{2}{*}{ Water } & 0.583 & -0.739 & $1.538^{* * *}$ & $2.390^{* * *}$ & -0.012 & $-0.546^{*}$ & $0.424^{* *}$ & -0.124 & $-1.851^{* *}$ & $-1.268^{* *}$ & -0.048 & 0.178 \\
\hline & $(0.591)$ & $(0.602)$ & $(0.437)$ & $(0.478)$ & (0.135) & 10.3071 & $(0.203)$ & $(0.262)$ & $(0.710)$ & $(0.634)$ & $(0.316)$ & $(0.319)$ \\
\hline \multirow[t]{2}{*}{ Electricity } & -0.887 & -1.208 & $1.219 *$ & 1.247 & 0.140 & -0.063 & -0.398 & $1.086^{*}$ & -0.137 & 0.786 & 0.126 & -0.495 \\
\hline & $(0.616)$ & $(0.781)$ & $(0.709)$ & $(0.904)$ & $(0.268)$ & (0.333) & $(0.369)$ & $(0.613)$ & $(0.981)$ & (1.054) & $(0.452)$ & $(0.613)$ \\
\hline \multirow[t]{2}{*}{ Healthcare } & -0.616 & -1.217 & -0.388 & 1.414 & 0.296 & $-1.661^{*}$ & -0.321 & 0.043 & 1.314 & 0.280 & -0.543 & $2.435 * * *$ \\
\hline & (1.112) & (1.079) & (1.015) & (1.404) & $(0.207)$ & $(0.921)$ & $(0.983)$ & $(0.451)$ & (1.084) & (1.183) & $(0.699)$ & $(0.817)$ \\
\hline \multirow[t]{2}{*}{ Childcare } & -0.287 & 0.593 & -0.411 & -0.231 & 0.032 & -0.046 & $0.443 *$ & 0.362 & 0.221 & -0.201 & 0.263 & -0.532 \\
\hline & $(0.791)$ & $(0.548)$ & $(0.614)$ & (0.572) & $(0.171)$ & (0.312) & $(0.267)$ & (0.265) & $(0.896)$ & $(0.637)$ & $(0.458)$ & (0.419) \\
\hline \multirow[t]{2}{*}{ Constant } & $4.087 * * *$ & $5.505^{* * *}$ & $3.353^{*}$ & -0.523 & 1.154 & $2.001^{*}$ & $1.736 * * *$ & $3.996 *$ & $4.979 * * *$ & $10.943^{* * *}$ & $8.155^{* * *}$ & $4.087^{* * *}$ \\
\hline & (1.562) & $(1.638)$ & (1.784) & $(0.385)$ & $(0.973)$ & (1.177) & $(0.662)$ & (2.171) & (1.574) & (1.248) & $(0.938)$ & (1.562) \\
\hline Observations & 142 & 146 & 142 & 146 & 142 & 146 & 140 & 146 & 140 & 146 & 140 & 142 \\
\hline R-squared & 0.220 & 0.358 & 0.274 & 0.080 & 0.152 & 0.246 & 0.183 & 0.214 & 0.357 & 0.111 & 0.131 & 0.220 \\
\hline
\end{tabular}

NOTES: Robust standard errors in parentheses; ${ }^{* * *} p<0.01 .{ }^{* *} p<0.05 .{ }^{*} p<0.10$. The model includes the following control variables: age, education, the proportion of females in the households, the number of household members, whether the household has at least one child under six years old, the household wealth (quintiles for middle, richer and richest income households) and the district. 
REGRESSION RESULTS FOR ASSOCIATION BETWEEN ACCESS TO MARKETS AND ROADS AND CARE WORK (ADULTS)

\begin{tabular}{|c|c|c|c|c|c|c|c|c|c|c|c|c|}
\hline \multirow{3}{*}{ Variables } & \multicolumn{4}{|c|}{ Philippines } & \multicolumn{4}{|l|}{ Uganda } & \multicolumn{4}{|l|}{ Zimbabwe } \\
\hline & \multicolumn{2}{|c|}{ Primary care } & \multicolumn{2}{|l|}{ Any care } & \multicolumn{2}{|c|}{ Primary care } & \multicolumn{2}{|l|}{ Any care } & \multicolumn{2}{|l|}{ Primary care } & \multicolumn{2}{|l|}{ Any care } \\
\hline & Women & Men & Women & Men & Women & Men & Women & Men & Women & Men & Women & Men \\
\hline \multirow[t]{2}{*}{ Road time } & -0.266 & 0.110 & $-0.648 * *$ & -0.053 & $-0.199 * * *$ & -0.034 & 0.195 & -0.062 & -0.266 & 0.110 & $-0.648 * *$ & -0.053 \\
\hline & $(0.175)$ & $(0.114)$ & $(0.280)$ & $(0.256)$ & $(0.071)$ & $(0.047)$ & (0.148) & $(0.120)$ & $(0.175)$ & (0.114) & $(0.280)$ & $(0.256)$ \\
\hline \multirow[t]{2}{*}{ Market time } & 0.294 & -0.012 & $0.880^{* *}$ & $-0.605^{*}$ & $0.154^{* *}$ & 0.037 & 0.212 & -0.206 & 0.294 & -0.012 & $0.880^{* *}$ & $-0.605^{*}$ \\
\hline & (0.193) & (0.139) & $(0.364)$ & (0.349) & $(0.077)$ & (0.042) & (0.178) & (0.154) & (0.193) & (0.139) & $(0.364)$ & (0.349) \\
\hline \multirow[t]{2}{*}{ Constant } & $10.090 * * *$ & -1.266 & $12.627^{* * *}$ & -2.402 & $5.740 * * *$ & 0.283 & $13.299 * * *$ & $8.054^{* *}$ & $10.090 * * *$ & -1.266 & $12.627^{* * *}$ & -2.402 \\
\hline & (1.595) & (1.194) & (3.758) & (2.920) & (0.536) & $(0.315)$ & (1.394) & (3.253) & (1.595) & (1.194) & (3.758) & (2.920) \\
\hline Observations & 186 & 155 & 186 & 155 & 1.014 & 645 & 1.014 & 651 & 186 & 155 & 186 & 155 \\
\hline$R$-squared & 0.143 & 0.127 & 0.351 & 0.156 & 0.111 & 0.074 & 0.219 & 0.098 & 0.143 & 0.127 & 0.351 & 0.156 \\
\hline
\end{tabular}

NOTES: Robust standard errors in parentheses; *** $p<0.01 .{ }^{* *} p<0.05 .^{*} p<0.10$. The model includes the following control variables: age, education, the proportion of females in the household, the number of household members, whether the household has at least one child under six years old, the household wealth (quintiles for middle, richer and richest income households) and the district. The log of 'market time' (number of minutes it takes to walk to the nearest market) and 'road time' (number of minutes it takes to walk to the nearest all-season road) was used.

\section{REGRESSION RESULTS FOR ASSOCIATION BETWEEN PERCEPTIONS OF VALUE AND SKILLS NEEDED TO PERFORM CARE TASKS AND CARE TIME}

\begin{tabular}{|c|c|c|c|c|c|c|}
\hline \multirow[b]{2}{*}{ Variables } & \multicolumn{2}{|l|}{ Philippines } & \multicolumn{2}{|l|}{ Uganda } & \multicolumn{2}{|l|}{ Zimbabwe } \\
\hline & Ratio prim. care & Ratio any care & Ratio prim. care & Ratio any care & Ratio prim. care & Ratio any care \\
\hline \multirow[t]{2}{*}{ Ratio value meal } & $-0.050 * *$ & -0.027 & 0.001 & $-0.013^{* *}$ & -0.015 & -0.009 \\
\hline & $(0.020)$ & $(0.040)$ & $(0.005)$ & $(0.006)$ & $(0.010)$ & $(0.011)$ \\
\hline \multirow[t]{2}{*}{ Ratio value cleaning } & $-0.035^{*}$ & -0.024 & -0.005 & 0.003 & $-0.025^{* *}$ & -0.014 \\
\hline & (0.021) & (0.041) & $(0.006)$ & $(0.010)$ & (0.012) & $(0.010)$ \\
\hline \multirow[t]{2}{*}{ Ratio value childcare } & -0.002 & 0.012 & 0.009 & $-0.019 * *$ & -0.018 & 0.014 \\
\hline & (0.012) & $(0.031)$ & (0.011) & (0.008) & $(0.024)$ & (0.025) \\
\hline \multirow[t]{2}{*}{ Ratio value adult care } & $-0.085^{* *}$ & -0.072 & 0.005 & 0.030 & 0.028 & 0.009 \\
\hline & (0.037) & $(0.056)$ & $(0.016)$ & $(0.021)$ & $(0.027)$ & $(0.021)$ \\
\hline \multirow[t]{2}{*}{ Ratio value fuel/water coll. } & -0.025 & 0.001 & -0.010 & -0.012 & $-0.023^{*}$ & $-0.025^{*}$ \\
\hline & $(0.024)$ & (0.038) & (0.012) & $(0.010)$ & $(0.013)$ & $(0.014)$ \\
\hline \multirow[t]{2}{*}{ Ratio value washing } & -0.019 & -0.014 & 0.008 & 0.014 & $-0.038 * *$ & $-0.028^{*}$ \\
\hline & $(0.020)$ & $(0.030)$ & $(0.014)$ & $(0.011)$ & (0.019) & $(0.016)$ \\
\hline \multirow[t]{2}{*}{ Ratio skills meal } & $0.027^{*}$ & 0.002 & 0.003 & 0.007 & 0.025 & 0.022 \\
\hline & (0.015) & $(0.036)$ & $(0.007)$ & $(0.007)$ & $(0.037)$ & $(0.034)$ \\
\hline \multirow[t]{2}{*}{ Ratio skills cleaning } & 0.008 & 0.087 & 0.001 & 0.006 & -0.008 & -0.015 \\
\hline & (0.021) & (0.079) & $(0.007)$ & (0.012) & (0.019) & $(0.015)$ \\
\hline \multirow[t]{2}{*}{ Ratio skills childcare } & -0.007 & 0.035 & -0.013 & 0.004 & $0.032^{*}$ & 0.011 \\
\hline & (0.027) & $(0.106)$ & $(0.008)$ & $(0.010)$ & $(0.018)$ & $(0.018)$ \\
\hline \multirow[t]{2}{*}{ Ratio skills adult care } & -0.012 & $-0.071^{* * *}$ & 0.015 & 0.007 & $-0.054^{* *}$ & $-0.033^{* *}$ \\
\hline & (0.038) & $(0.020)$ & $(0.020)$ & $(0.014)$ & $(0.026)$ & $(0.017)$ \\
\hline \multirow[t]{2}{*}{ Ratio skill fuel/water coll. } & $-0.047^{* *}$ & $-0.079 * *$ & -0.017 & -0.021 & -0.013 & -0.014 \\
\hline & $(0.020)$ & (0.032) & (0.012) & $(0.015)$ & (0.012) & $(0.014)$ \\
\hline \multirow[t]{2}{*}{ Ratio skills washing } & -0.011 & $-0.052^{*}$ & 0.014 & -0.014 & -0.004 & -0.015 \\
\hline & $(0.016)$ & $(0.027)$ & (0.029) & (0.022) & (0.012) & $(0.010)$ \\
\hline \multirow[t]{2}{*}{ Constant } & 0.390 & $1.204^{*}$ & 0.427 & 0.175 & 0.254 & $0.358^{*}$ \\
\hline & (0.357) & $(0.647)$ & (0.299) & (0.147) & (0.200) & (0.198) \\
\hline Observations & 165 & 166 & 641 & 658 & 268 & 279 \\
\hline$R$-squared & 0.169 & 0.146 & 0.070 & 0.066 & 0.093 & 0.091 \\
\hline
\end{tabular}

NOTES: Robust standard errors in parentheses; ${ }^{* * *} p<0.01 .{ }^{* *} p<0.05 .{ }^{*} p<0.10$. The model includes the following control variables: age, education, the proportion of females in the household, the number of household members, whether the household has at least one child under six years old, the household wealth (quintiles for middle, richer and richest income households) and the district. The ratios represent the value/skills scores for men divided by the scores for women. This means that if the ratio is larger, men value care less than women do. 
REGRESSION RESULTS FOR ASSOCIATION BETWEEN RATIO OF VALUE AND SKILLS NEEDED TO PERFORM CARE TASKS AGAINST PRODUCTIVE TASKS AND CARE TIME

\begin{tabular}{|c|c|c|c|c|c|c|c|c|c|c|c|c|}
\hline \multirow{3}{*}{ Variables } & \multicolumn{4}{|c|}{ Philippines } & \multicolumn{4}{|l|}{ Uganda } & \multicolumn{4}{|l|}{ Zimbabwe } \\
\hline & \multicolumn{2}{|c|}{ Primary care } & \multicolumn{2}{|l|}{ Any care } & \multicolumn{2}{|c|}{ Primary care } & \multicolumn{2}{|l|}{ Any care } & \multicolumn{2}{|c|}{ Primary care } & \multicolumn{2}{|l|}{ Any care } \\
\hline & Women & Men & Women & Men & Women & Men & Women & Men & Women & Men & Women & Men \\
\hline \multirow[t]{2}{*}{ Ratio care value } & $-2.170 * *$ & -0.273 & -1.133 & 0.794 & $-0.540 * * *$ & 0.076 & $-0.673^{*}$ & $-0.981^{* * *}$ & $-1.619 * * *$ & $-0.385^{* *}$ & $-2.003^{* *}$ & $-1.407^{* *}$ \\
\hline & (1.008) & (0.314) & (2.373) & (0.944) & (0.189) & (0.129) & $(0.408)$ & (0.328) & (0.398) & (0.163) & (0.977) & (0.558) \\
\hline \multirow[t]{2}{*}{ Ratio care skills } & 0.183 & $-0.595^{* *}$ & 0.599 & $-1.478 * *$ & 0.217 & 0.075 & $-1.764^{* * *}$ & 0.171 & 0.097 & -0.042 & -0.246 & -0.482 \\
\hline & (0.430) & (0.301) & (0.852) & (0.676) & (0.147) & (0.092) & (0.331) & (0.377) & $(0.273)$ & (0.146) & (0.624) & (0.489) \\
\hline \multirow[t]{2}{*}{ Constant } & $10.938 * * *$ & 1.137 & $13.364^{* * *}$ & 0.717 & $5.869 * * *$ & $1.361^{* * *}$ & $17.286^{* * *}$ & $5.891^{* * *}$ & $7.302^{* * *}$ & $3.407 * * *$ & $17.565^{* * *}$ & $11.951^{* * *}$ \\
\hline & (1.551) & (1.042) & (3.953) & (2.602) & (0.596) & (0.443) & (1.441) & (1.239) & (1.293) & (0.779) & (3.189) & (3.465) \\
\hline Observations & 204 & 209 & 204 & 209 & 1.071 & 819 & 1.071 & 819 & 402 & 324 & 402 & 324 \\
\hline R-squared & 0.116 & 0.136 & 0.305 & 0.147 & 0.105 & 0.122 & 0.234 & 0.087 & 0.135 & 0.095 & 0.223 & 0.112 \\
\hline
\end{tabular}

NOTES: Robust standard errors in parentheses; ${ }^{* * *} p<0.01 .{ }^{* *} p<0.05 .{ }^{*} p<0.10$. The model includes the following control variables: age, education, the proportion of females in the household, the number of household members, whether the household has at least one child under six years old, the household wealth (quintiles for middle, richer and richest income households) and the district. 'Ratio care value/skill' represents the value/skills scores for care divided by the scores for paid work. This means that if the ratio is larger, respondents value care work less than paid work. 
REGRESSION RESULTS FOR ASSOCIATION BETWEEN OWNERSHIP OF TLSE AND PERCEPTIONS OF VALUE OF AND SKILLS NEEDED TO PERFORM CARE TASKS AGAINST PRODUCTIVE TASKS

\begin{tabular}{|c|c|c|c|}
\hline & Philippines & Uganda & Zimbabwe \\
\hline & \multicolumn{3}{|c|}{ No. of fuel-related equipment } \\
\hline \multirow[t]{2}{*}{ Fuel collection problematic } & -0.231 & -0.302 & 0.345 \\
\hline & (0.311) & (0.229) & (0.243) \\
\hline \multirow[t]{2}{*}{ Ratio fuel collection value } & 0.028 & -0.024 & 0.002 \\
\hline & (0.035) & (0.035) & $(0.053)$ \\
\hline \multirow[t]{2}{*}{ Ratio fuel collection skills } & 0.077 & 0.020 & -0.024 \\
\hline & $(0.048)$ & $(0.058)$ & (0.059) \\
\hline \multirow[t]{2}{*}{ Constant } & $1.655^{* * *}$ & -0.200 & $4.790 * * *$ \\
\hline & (0.622) & $(0.723)$ & $(0.505)$ \\
\hline Observations & 167 & 677 & 287 \\
\hline \multirow[t]{2}{*}{$R$-squared } & 0.136 & 0.386 & 0.304 \\
\hline & \multicolumn{3}{|c|}{ No. of cleaning-related equipment } \\
\hline \multirow[t]{2}{*}{ Cleaning problematic } & & 0.240 & 0.112 \\
\hline & & (0.219) & $(0.143)$ \\
\hline \multirow[t]{2}{*}{ Ratio cleaning value } & -0.027 & -0.009 & -0.005 \\
\hline & (0.019) & $(0.008)$ & $(0.007)$ \\
\hline \multirow[t]{2}{*}{ Ratio cleaning skills } & 0.003 & 0.010 & $0.010^{* *}$ \\
\hline & $(0.016)$ & $(0.012)$ & $(0.004)$ \\
\hline \multirow{2}{*}{ Constant } & $0.534^{*}$ & 0.208 & $0.742 * * *$ \\
\hline & (0.292) & $(0.176)$ & $(0.091)$ \\
\hline Observations & 167 & 677 & 287 \\
\hline \multirow[t]{2}{*}{$R$-squared } & 0.190 & 0.201 & 0.144 \\
\hline & \multicolumn{3}{|c|}{ No. of washing-related equipment } \\
\hline \multirow[t]{2}{*}{ Washing problematic } & 0.142 & 0.091 & \\
\hline & (0.302) & $(0.117)$ & \\
\hline Ratio washing value & -0.008 & -0.001 & -0.019 \\
\hline & $(0.027)$ & (0.012) & $(0.021)$ \\
\hline Ratio washing skills & -0.029 & 0.021 & -0.000 \\
\hline & (0.022) & $(0.022)$ & $(0.031)$ \\
\hline Constant & 0.166 & $-0.397^{* * *}$ & $1.803 * * *$ \\
\hline & $(0.486)$ & $(0.134)$ & (0.281) \\
\hline Observations & 167 & 677 & 287 \\
\hline$R$-squared & 0.111 & 0.616 & 0.304 \\
\hline & No. of meal & ent & \\
\hline Meal preparation problematic & & 0.000 & \\
\hline & & $(0.054)$ & \\
\hline Ratio meal preparation value & 0.004 & -0.001 & 0.004 \\
\hline & (0.022) & $(0.004)$ & $(0.010)$ \\
\hline Ratio meal preparation skills & 0.018 & -0.009 & $-0.018^{*}$ \\
\hline & (0.019) & $(0.006)$ & $(0.009)$ \\
\hline Constant & 0.483 & 0.053 & $1.643^{* * *}$ \\
\hline & $(0.403)$ & $(0.151)$ & $(0.180)$ \\
\hline Observations & 167 & 677 & 287 \\
\hline$R$-squared & 0.134 & 0.643 & 0.206 \\
\hline & No. of water & & \\
\hline Water collection problematic & -0.130 & 0.018 & 0.114 \\
\hline & $(0.204)$ & $(0.235)$ & (0.272) \\
\hline Ratio water collection value & 0.037 & -0.018 & -0.047 \\
\hline & $(0.070)$ & (0.032) & $(0.044)$ \\
\hline Ratio water collection skills & -0.028 & -0.008 & 0.059 \\
\hline & $(0.040)$ & $(0.062)$ & $(0.048)$ \\
\hline Constant & $1.331^{* *}$ & $2.179 * * *$ & $2.855^{* * *}$ \\
\hline & $(0.599)$ & $(0.401)$ & $(0.440)$ \\
\hline Observations & 167 & 677 & 287 \\
\hline$R$-squared & 0.131 & 0.529 & 0.232 \\
\hline & No. of childc & & \\
\hline Childcare problematic & 0.663 & -0.110 & \\
\hline & $(0.513)$ & (0.081) & \\
\hline Ratio childcare value & -0.015 & -0.014 & 0.043 \\
\hline & (0.075) & $(0.016)$ & $(0.042)$ \\
\hline Ratio childcare skills & 0.024 & -0.010 & 0.004 \\
\hline & $(0.065)$ & $(0.020)$ & $(0.042)$ \\
\hline Constant & 1.485 & $1.745^{* * *}$ & $2.203^{* * *}$ \\
\hline & (0.982) & $(0.218)$ & $(0.571)$ \\
\hline Observations & 44 & 269 & 68 \\
\hline$R$-squared & 0.417 & 0.353 & 0.182 \\
\hline
\end{tabular}

NOTES: Robust standard errors in parentheses; ${ }^{* * *} p<0.01 .{ }^{* *} p<0.05 .{ }^{*} p<0.10$. The model includes the following control variables: age, education, the proportion of females in the household, the number of household members, whether the household has at least one child under six years old, the household wealth (quintiles for middle, richer and richest income households) and the district. The variables 'xx problematic' take the value 1 if both woman and man in a household selected $x x$ as one of the most problematic care activities; the ratios represent the value/skills scores for men divided by the scores for women. This means that if the ratio is larger, men value care less than women do. 
REGRESSION RESULTS FOR ASSOCIATION BETWEEN PERCEPTIONS OF VALUE AND SKILLS NEEDED TO PERFORM CARE TASKS AND CHILDREN AND ADOLESCENTS' CARE TIME

\begin{tabular}{|c|c|c|c|c|c|c|c|c|}
\hline \multirow[t]{2}{*}{ Variables } & \multicolumn{2}{|l|}{ Care work } & \multicolumn{2}{|l|}{ Paid work } & \multicolumn{2}{|l|}{ Education } & \multicolumn{2}{|l|}{ Education } \\
\hline & Girls & Boys & Girls & Boys & Girls & Boys & Girls & Boys \\
\hline & \multicolumn{8}{|l|}{ Philippines } \\
\hline \multirow[t]{2}{*}{ Ratio value care men } & $-1.350 *$ & -0.905 & $0.490 *$ & -0.247 & 1.762 & -0.416 & -1.019 & 1.053 \\
\hline & (0.793) & (0.792) & (0.288) & $(0.716)$ & (1.137) & (1.696) & $(0.884)$ & (1.077) \\
\hline \multirow[t]{2}{*}{ Ratio value care women } & -0.945 & -2.561 & 0.400 & -0.933 & $3.670^{*}$ & 0.562 & -3.824 & -4.736 \\
\hline & (2.804) & (2.027) & (1.088) & (1.151) & (2.036) & (4.005) & (2.658) & (3.746) \\
\hline \multirow[t]{2}{*}{ Ratio skill care men } & 1.080 & 0.771 & -0.196 & 0.061 & $-2.105^{*}$ & 0.557 & $1.438^{*}$ & -0.718 \\
\hline & $(0.806)$ & (0.667) & $(0.237)$ & $(0.553)$ & (1.144) & $(1.100)$ & $(0.787)$ & (0.977) \\
\hline \multirow[t]{2}{*}{ Ratio skill care women } & -0.553 & 1.124 & 1.441 & -0.836 & -1.413 & -0.229 & 1.132 & 0.481 \\
\hline & (1.012) & (1.259) & (0.883) & $(0.708)$ & (1.364) & (1.477) & (0.982) & (1.537) \\
\hline \multirow[t]{2}{*}{ Constant } & -1.784 & -1.588 & -1.201 & $-3.266 *$ & $15.822 * * *$ & $14.708^{* * *}$ & $10.632^{* * *}$ & $13.379 * * *$ \\
\hline & $(1.071)$ & (1.019) & $(0.934)$ & (1.763) & (1.408) & (2.589] & (1.659) & $(2.044)$ \\
\hline Observations & 50 & 54 & 50 & 54 & 50 & 54 & 50 & 54 \\
\hline$R$-squared & 0.735 & 0.544 & 0.542 & 0.348 & 0.692 & 0.268 & 0.603 & 0.356 \\
\hline & \multicolumn{8}{|l|}{ Uganda } \\
\hline \multirow[t]{2}{*}{ Ratio value care men } & 0.019 & 0.162 & 0.234 & $-0.451^{* *}$ & -0.112 & -0.091 & -0.102 & 0.207 \\
\hline & $(0.241)$ & (0.282) & $(0.201)$ & (0.225) & (0.148) & $(0.200)$ & $(0.218)$ & $(0.244)$ \\
\hline \multirow[t]{2}{*}{ Ratio value care women } & $-0.791^{* * *}$ & 0.127 & $0.672^{* *}$ & 0.172 & 0.062 & -0.054 & 0.219 & $-0.579 *$ \\
\hline & $(0.303)$ & (0.386) & $(0.284)$ & $(0.351)$ & $(0.186)$ & $(0.260)$ & $(0.277)$ & (0.320) \\
\hline \multirow[t]{2}{*}{ Ratio skill care men } & 0.353 & -0.302 & $-0.349 * *$ & 0.307 & 0.097 & 0.245 & 0.005 & -0.286 \\
\hline & $(0.217)$ & (0.238) & (0.172) & (0.203) & $(0.134)$ & (0.182) & $(0.190)$ & (0.212) \\
\hline \multirow[t]{2}{*}{ Ratio skill care women } & 0.204 & $-0.614^{* *}$ & -0.178 & 0.136 & -0.268 & -0.018 & 0.163 & $0.689 * * *$ \\
\hline & $(0.231)$ & $(0.260)$ & (0.178) & $(0.216)$ & $(0.175)$ & (0.139) & (0.229) & (0.232) \\
\hline \multirow[t]{2}{*}{ Constant } & $8.954^{* * *}$ & $6.901^{* * *}$ & -0.205 & 0.569 & 0.497 & 0.027 & $14.157^{* * *}$ & $16.549 * * *$ \\
\hline & (0.722) & $(0.700)$ & (0.511) & $(0.707)$ & $(0.421)$ & (0.546) & (0.709) & $(0.740)$ \\
\hline Observations & 622 & 568 & 622 & 568 & 622 & 568 & 622 & 568 \\
\hline$R$-squared & 0.219 & 0.064 & 0.154 & 0.217 & 0.141 & 0.155 & 0.175 & 0.149 \\
\hline & \multicolumn{8}{|l|}{ Zimbabwe } \\
\hline \multirow[t]{2}{*}{ Ratio value care men } & 0.290 & 0.012 & -0.199 & -0.258 & 0.221 & $-0.854^{*}$ & -0.479 & 0.913 \\
\hline & $(0.497)$ & (0.442) & $(0.236)$ & $(0.283)$ & $(0.696)$ & $(0.461)$ & $(0.637)$ & (0.637) \\
\hline \multirow[t]{2}{*}{ Ratio value care women } & $-1.151^{*}$ & -0.108 & 0.227 & 0.685 & $2.922 * * *$ & 0.700 & $-1.953^{* *}$ & -1.157 \\
\hline & (0.679) & $(0.504)$ & $(0.453)$ & $(0.543)$ & $(1.005)$ & $(0.787)$ & (0.769) & $(0.701)$ \\
\hline \multirow[t]{2}{*}{ Ratio skill care men } & 0.114 & 0.071 & 0.262 & 0.023 & 0.019 & 0.581 & -0.185 & -0.339 \\
\hline & $(0.400)$ & (0.356) & (0.228) & (0.295) & $(0.564)$ & (0.419) & $(0.486)$ & $(0.545)$ \\
\hline \multirow[t]{2}{*}{ Ratio skill care women } & -0.270 & -0.400 & $-0.512^{*}$ & -0.077 & -0.041 & -0.390 & 0.891 & $1.137^{* *}$ \\
\hline & $(0.473)$ & (0.362) & (0.287) & $(0.244)$ & $(0.560)$ & $(0.471)$ & (0.583) & (0.565) \\
\hline \multirow[t]{2}{*}{ Constant } & $2.200^{*}$ & $2.278^{* *}$ & $-1.650 * *$ & -0.758 & $5.729 * * *$ & $6.319 * * *$ & $17.786 * * *$ & $15.658^{* * *}$ \\
\hline & (1.139) & (1.035) & (0.634) & $(0.831)$ & (1.509) & (1.278) & (1.366) & $(1.764)$ \\
\hline Observations & 174 & 162 & 174 & 162 & 174 & 162 & 174 & 162 \\
\hline$R$-squared & 0.141 & 0.171 & 0.167 & 0.227 & 0.238 & 0.323 & 0.320 & 0.165 \\
\hline
\end{tabular}

NOTES: Robust standard errors in parentheses; ${ }^{* * *} p<0.01 .{ }^{* *} p<0.05 .{ }^{*} p<0.10$. The model includes the following control variables: age, education, the proportion of females in the household, the number of household members, whether the household has at least one child under six years old, the household wealth /quintiles for middle, richer and richest income households) and the district. 'Ratio care value/skill' represents the value/skills scores for care divided by the scores for paid work for women and men in the household. This means that if the ratio is larger, respondents value care work less than paid work. 
REGRESSION RESULTS FOR ASSOCIATION BETWEEN PERCEPTIONS OF PROBLEMATIC CARE AND CARE TIME

\begin{tabular}{|c|c|c|c|c|c|c|c|c|c|c|c|c|}
\hline \multirow{3}{*}{ Variables } & \multicolumn{4}{|c|}{ Philippines } & \multicolumn{4}{|l|}{ Uganda } & \multicolumn{4}{|c|}{ Zimbabwe } \\
\hline & \multicolumn{2}{|c|}{ Primary care } & \multicolumn{2}{|l|}{ Any care } & \multicolumn{2}{|c|}{ Primary care } & \multicolumn{2}{|l|}{ Any care } & \multicolumn{2}{|c|}{ Primary care } & \multicolumn{2}{|l|}{ Any care } \\
\hline & Women & Men & Women & Men & Women & Men & Women & Men & Women & Men & Women & Men \\
\hline \multirow{2}{*}{$\begin{array}{l}\text { Problematic for } \\
\text { Women }\end{array}$} & 0.052 & -0.042 & $0.494^{* * *}$ & -0.237 & $0.075^{* *}$ & -0.013 & $0.284^{* * *}$ & $0.486^{* * *}$ & -0.025 & $0.116^{* *}$ & $0.488^{* * *}$ & $0.281^{*}$ \\
\hline & (0.093) & $(0.073)$ & (0.170) & (0.167) & (0.035) & (0.025) & (0.085) & (0.105) & (0.074) & $(0.051)$ & (0.162) & (0.159) \\
\hline \multirow{2}{*}{$\begin{array}{l}\text { Problematic for } \\
\text { Men }\end{array}$} & -0.026 & $-0.144 * *$ & -0.066 & 0.048 & -0.002 & 0.021 & 0.136 & $0.303^{* * *}$ & 0.025 & 0.029 & $0.401^{* * *}$ & $0.266 * *$ \\
\hline & (0.095) & $(0.060)$ & (0.195) & (0.197) & $(0.036)$ & (0.024) & (0.089) & (0.085) & $(0.068)$ & $(0.037)$ & $(0.154)$ & (0.132) \\
\hline \multirow[t]{2}{*}{ Constant } & $9.703 * * *$ & 0.664 & $12.346^{* * *}$ & -0.841 & $5.434^{* * *}$ & $1.526 * * *$ & $12.224^{* * *}$ & $3.761^{* * *}$ & $6.069 * * *$ & $2.612^{* * *}$ & $11.880 * * *$ & $7.803^{* *}$ \\
\hline & (1.548) & $(0.976)$ & (3.582) & (2.763) & (0.522) & (0.382) & (1.351) & (0.971) & (1.283) & (0.680) & (2.798) & (3.042) \\
\hline Observations & 204 & 209 & 204 & 209 & 1.071 & 819 & 1.076 & 826 & 402 & 324 & 403 & 325 \\
\hline$R$-squared & 0.098 & 0.127 & 0.329 & 0.135 & 0.101 & 0.121 & 0.222 & 0.138 & 0.103 & 0.111 & 0.261 & 0.124 \\
\hline
\end{tabular}

NOTES: Robust standard errors in parentheses; ${ }^{* * *} p<0.01 .{ }^{* *} p<0.05 .{ }^{*} p<0.10$. The model includes the following control variables: age, education, the proportion of females in the household, the number of household members, whether the household has at least one child under six years old, the household wealth (quintiles for middle, richer and richest income households) and the district. 'Problematic' takes the value 1 if respondents thought that at least one care activity is problematic.

\section{REGRESSION RESULTS FOR ASSOCIATION BETWEEN APPROVAL OF SHARING TASKS AND CARE TIME}

\begin{tabular}{|c|c|c|c|c|c|c|c|c|c|c|c|c|c|c|c|c|c|c|}
\hline \multirow[b]{3}{*}{ Variables } & \multicolumn{6}{|c|}{ Philippines } & \multicolumn{6}{|l|}{ Uganda } & \multicolumn{6}{|c|}{ Zimbabwe } \\
\hline & \multicolumn{2}{|c|}{ Primary care } & \multicolumn{2}{|l|}{ Any care } & \multirow{2}{*}{$\begin{array}{l}\begin{array}{l}\text { Ratio } \\
\text { prim }\end{array} \\
\text { Ratio } \\
\text { prim }\end{array}$} & \multirow{2}{*}{$\begin{array}{l}\begin{array}{l}\text { Ratio } \\
\text { any }\end{array} \\
\text { Ratio any }\end{array}$} & \multicolumn{2}{|c|}{ Primary care } & \multicolumn{2}{|l|}{ Any care } & \multirow{2}{*}{\begin{tabular}{|l} 
Ratio \\
prim
\end{tabular}} & \multirow{2}{*}{\begin{tabular}{|l|}
$\begin{array}{l}\text { Ratio } \\
\text { any }\end{array}$ \\
Ratio any \\
\end{tabular}} & \multicolumn{2}{|c|}{ Primary care } & \multicolumn{2}{|l|}{ Any care } & \multirow{2}{*}{\begin{tabular}{|l|}
$\begin{array}{l}\text { Ratio } \\
\text { prim }\end{array}$ \\
$\begin{array}{l}\text { Ratio } \\
\text { prim }\end{array}$ \\
\end{tabular}} & \multirow{2}{*}{\begin{tabular}{|l|}
$\begin{array}{l}\text { Ratio } \\
\text { any }\end{array}$ \\
$\begin{array}{l}\text { Ratio } \\
\text { any }\end{array}$
\end{tabular}} \\
\hline & Women & Men & Women & Men & & & Women & Men & Women & Men & & & Women & Men & Women & Men & & \\
\hline \multirow{2}{*}{$\begin{array}{l}\text { Approving } \\
\text { share work }\end{array}$} & 0.325 & -0.062 & $\mid-0.776$ & $1.557^{* *}$ & $0.200^{* * *}$ & $0.464^{* * *}$ & -0.139 & $0.193^{* *}$ & 0.047 & $1.649^{* * *}$ & $0.050^{* * *}$ & $0.098^{* * *}$ & $\mid-0.361$ & -0.095 & 0.201 & -0.732 & 0.015 & 0.036 \\
\hline & $(0.347)$ & (0.358) & $(0.707)$ & $(0.684)$ & $(0.076)$ & $(0.112)$ & $(0.117)$ & $|0.077|$ & $(0.278)$ & $10.230 \mid$ & $|0.018|$ & $(0.015)$ & $\mid(0.232)$ & $\mid(0.157)$ & $(0.534)$ & $(0.503)$ & $(0.054)$ & $(0.038)$ \\
\hline \multirow[t]{2}{*}{ Constant } & $9.182^{* * *}$ & 0.186 & $14.227^{* * *}$ & $\mid-2.116$ & $-0.476^{*}$ & $\mid-0.137$ & $5.815^{* * *}$ & $1.428^{* * *}$ & $13.087^{* * *}$ & $3.331^{* * *}$ & -0.118 & -0.058 & $6.305^{* * *}$ & $2.755^{* * *}$ & $14.555^{* * *}$ & $9.096^{* * *}$ & 0.171 & 0.060 \\
\hline & (1.541) & $(0.973)$ & (3.838) & (2.795) & $\mid(0.278)$ & $|10.533|$ & $(0.528)$ & $|0.378|$ & $(1.344)$ & $|0.956|$ & $\mid(0.078)$ & $|0.058|$ & $\mid(1.202)$ & $\mid(0.672)$ & $\mid(2.890)$ & (3.289) & $(0.195)$ & $(0.200)$ \\
\hline Observations & 204 & 209 & 204 & 209 & 201 & 203 & 1.071 & 819 & 1.076 & 826 & 998 & 1.035 & 402 & 324 & 403 & 325 & 370 & 390 \\
\hline$R$-squared & 0.100 & 0.106 & 0.306 & 0.143 & 0.094 & 0.113 & 0.098 & 0.127 & 0.210 & 0.119 & 0.041 & 0.097 & 0.109 & 0.078 & 0.213 & 0.091 & 0.043 & 0.065 \\
\hline
\end{tabular}

NOTES: Robust standard errors in parentheses; ${ }^{* * *} p<0.01 .{ }^{* *} p<0.05 .{ }^{*} p<0.10$. The model includes the following control variables: age, education, the proportion of females in the household, the number of household members, whether the household has at least one child under six years old, the household wealth lquintiles for middle, richer and richest income households) and the district. 'Approving share work' takes the value 1 if respondents strongly approved or approved of the vignette that described a couple that shared work.

\section{REGRESSION RESULTS FOR ASSOCIATION BETWEEN PERCEIVED CONTRIBUTION TO THE HOUSEHOLD WELLBEING AND TIME USE}

\begin{tabular}{|c|c|c|c|c|c|c|c|c|c|c|c|c|c|c|c|c|c|c|}
\hline \multirow[b]{3}{*}{ Variables } & \multicolumn{6}{|c|}{ Philippines } & \multicolumn{6}{|c|}{ Uganda } & \multicolumn{6}{|c|}{ Zimbabwe } \\
\hline & \multicolumn{2}{|c|}{ Primary care } & \multicolumn{2}{|l|}{ Any care } & \multicolumn{2}{|l|}{ Paid } & \multicolumn{2}{|c|}{ Primary care } & \multicolumn{2}{|l|}{ Any care } & \multicolumn{2}{|l|}{ Paid } & \multicolumn{2}{|c|}{ Primary care } & \multicolumn{2}{|l|}{ Any care } & \multicolumn{2}{|l|}{ Paid } \\
\hline & Women & Men & Women & Men & Women & Men & Women & Men & Women & Men & Women & Men & Women & Men & Women & Men & Women & Men \\
\hline \multirow{2}{*}{$\begin{array}{l}\text { Woman } \\
\text { contributes } \\
\text { more }\end{array}$} & -0.449 & 0.185 & -0.643 & 1.070 & 1.449 & -0.726 & -0.063 & 0.156 & $-0.890^{*}$ & -0.358 & 0.204 & $-1.319 * * *$ & -0.487 & 0.413 & $\mid-0.671$ & 0.327 & 0.660 & 0.115 \\
\hline & (0.692) & (0.294) & $(0.975)$ & $(0.700)$ & $(0.908)$ & $(0.586)$ & $(0.204)$ & $(0.139)$ & $(0.513)$ & $(0.487)$ & $(0.285)$ & $|10.367|$ & $(0.423)$ & $(0.260)$ & $(0.961)$ & $(0.745)$ & $(0.496)$ & $(0.590)$ \\
\hline \multirow[t]{2}{*}{ Constant } & $9.886^{* * *}$ & 0.012 & $9.817^{* * *}$ & -1.999 & -2.091 & $10.430^{* * *}$ & $5.950^{* * *}$ & $1.539^{* * *}$ & $14.605^{* * *}$ & $4.439 * * *$ & $4.380^{* * *}$ & $9.554^{* * *}$ & $6.139 * * *$ & $1.745^{* * *}$ & $15.541^{* * *}$ & $6.888^{* * *}$ & 0.707 & $6.458^{* * *}$ \\
\hline & $(1.569)$ & (0.939) & (3.574) & (2.865) & $(1.576)$ & (2.111) & $(0.540)$ & | (0.382) & $(1.369)$ & (1..071) & (0.787) & (0.924) & (1.551) & $(0.602)$ & $(3.760)$ & (1.908) & $(1.574)$ & (1.773) \\
\hline Observations & 181 & 191 & 181 & 191 & 181 & 191 & 1.024 & 787 & 1.024 & 787 & 1.024 & 787 & 323 & 302 & 323 & 302 & 323 & 302 \\
\hline$R$-squared & 0.090 & 0.126 & 0.270 & 0.156 & 0.176 & 0.173 & 0.101 & 0.127 & 0.219 & 0.077 & 0.066 & 0.090 & 0.099 & 0.092 & 0.249 & 0.094 & 0.157 & 0.061 \\
\hline
\end{tabular}

NOTES: Robust standard errors in parentheses; ${ }^{* * *} p<0.01 .{ }^{* *} p<0.05 .{ }^{*} p<0.10$. The model includes the following control variables: age, education, the proportion of females in the household, the number of household members, whether the household has at least one child under six years old, the household wealth (quintiles for middle, richer and richest income households) and the district. 'Women contributes more' takes the value 1 if respondent thought that a woman contributed most to the household. 
REGRESSION RESULTS FOR ASSOCIATION BETWEEN SATISFACTION WITH THE DIVISION OF LABOUR AND CARE TIME

\begin{tabular}{|c|c|c|c|c|c|c|c|c|c|c|c|c|}
\hline \multirow{3}{*}{ Variables } & \multicolumn{4}{|c|}{ Philippines } & \multicolumn{4}{|l|}{ Uganda } & \multicolumn{4}{|c|}{ Zimbabwe } \\
\hline & \multicolumn{2}{|c|}{ Primary care } & \multicolumn{2}{|l|}{ Any care } & \multicolumn{2}{|c|}{ Primary care } & \multicolumn{2}{|l|}{ Any care } & \multicolumn{2}{|c|}{ Primary care } & \multicolumn{2}{|l|}{ Any care } \\
\hline & Women & Men & Women & Men & Women & Men & Women & Men & Women & Men & Women & Men \\
\hline \multirow[t]{2}{*}{ Satisfied } & -0.246 & 0.027 & -0.395 & 0.566 & $-0.565^{* * *}$ & -0.080 & -0.475 & $1.633^{* * *}$ & $-0.902^{* *}$ & 0.083 & -1.410 & 0.632 \\
\hline & (0.628) & $(0.400)$ & (1.090) & (0.825) & (0.204) & (0.173) & (0.521) & (0.448) & (0.362) & $(0.214)$ & (0.907) & (0.682) \\
\hline \multirow[t]{2}{*}{ Constant } & $9.859 * * *$ & 0.098 & $13.211^{* * *}$ & -1.204 & $6.638^{* * *}$ & 0.433 & $15.109 * * *$ & $4.147^{* * *}$ & $6.438^{* * *}$ & $2.662^{* * *}$ & $16.046 * * *$ & $8.400^{* *}$ \\
\hline & (1.573) & (1.062) & (3.883) & (2.767) & (0.544) & (0.283) & (1.308) & (1.040) & $(1.231)$ & $(0.675)$ & (2.881) & (3.259) \\
\hline Observations & 204 & 209 & 204 & 209 & 845 & 755 & 845 & 755 & 402 & 324 & 402 & 324 \\
\hline$R$-squared & 0.097 & 0.106 & 0.302 & 0.129 & 0.088 & 0.059 & 0.208 & 0.091 & 0.117 & 0.076 & 0.220 & 0.085 \\
\hline
\end{tabular}

NOTES: Robust standard errors in parentheses; *** $p<0.01 .{ }^{* *} p<0.05 .{ }^{*} p<0.10$. The model includes the following control variables: age, education, the proportion of females in the household, the number of household members, whether the household has at least one child under six years old, the household wealth (quintiles for middle, richer and richest income households) and the district. 'Satisfied' takes the value 1 if respondents said they were satisfied or very satisfied with the division of labour

\section{REGRESSION RESULTS FOR ASSOCIATION BETWEEN PERCEPTIONS THAT HUSBANDS SHOULD HELP WITH CARE AND CARE TIME}

\begin{tabular}{|c|c|c|c|c|c|c|c|c|c|c|c|c|}
\hline \multirow[b]{3}{*}{ Variables } & \multicolumn{4}{|c|}{ Philippines } & \multicolumn{4}{|l|}{ Uganda } & \multicolumn{4}{|c|}{ Zimbabwe } \\
\hline & \multicolumn{2}{|c|}{ Primary care } & \multicolumn{2}{|l|}{ Any care } & \multicolumn{2}{|c|}{ Primary care } & \multicolumn{2}{|l|}{ Any care } & \multicolumn{2}{|c|}{ Primary care } & \multicolumn{2}{|l|}{ Any care } \\
\hline & Women & Men & Women & Men & Women & Men & Women & Men & Women & Men & Women & Men \\
\hline \multirow{2}{*}{$\begin{array}{l}\text { Husbands help } \\
\text { care }\end{array}$} & 0.650 & $-0.896 *$ & -0.019 & -0.638 & $0.301^{*}$ & $0.368 * * *$ & $0.684^{*}$ & $2.628 * * *$ & -0.141 & -0.062 & 0.581 & 0.633 \\
\hline & (0.624) & (0.529) & (1.010) & (0.991) & (0.159) & (0.112) & (0.387) & $(0.356)$ & (0.319) & $(0.203)$ & (0.743) & (0.527) \\
\hline \multirow[t]{2}{*}{ Constant } & $9.310 * * *$ & 0.938 & $12.982 * * *$ & -0.029 & $5.477^{* * *}$ & $1.409 * * *$ & $12.724^{* * *}$ & $3.443 * * *$ & $6.089 * * *$ & $2.801^{* * *}$ & $14.339 * * *$ & $8.117^{* *}$ \\
\hline & (1.488) & (1.017) & (3.679) & (2.846) & (0.515) & (0.371) & (1.324) & (0.967) & (1.205) & $(0.725)$ & (2.919) & (3.377) \\
\hline Observations & 204 & 209 & 204 & 209 & 1.071 & 819 & 1.076 & 826 & 402 & 324 & 403 & 325 \\
\hline$R$-squared & 0.100 & 0.120 & 0.301 & 0.128 & 0.100 & 0.132 & 0.212 & 0.128 & 0.103 & 0.076 & 0.214 & 0.085 \\
\hline
\end{tabular}

NOTES: Robust standard errors in parentheses; ${ }^{* * *} p<0.01 .{ }^{* *} p<0.05 .{ }^{*} p<0.10$. The model includes the following control variables: age, education, the proportion of females in the household, the number of household members, whether the household has at least one child under six years old, the household wealth lquintiles for middle, richer and richest income households) and the district. 'Husbands help care' takes the value 1 if respondents selected husbands as one of the people who should help women with care. 
REGRESSION RESULTS FOR ASSOCIATION BETWEEN MEN'S CHILDHOOD EXPOSURE TO FATHERS DOING CARE WORK AND CARE TIME

\begin{tabular}{|c|c|c|c|c|c|c|}
\hline \multirow[b]{2}{*}{ Variables } & \multicolumn{2}{|l|}{ Philippines } & \multicolumn{2}{|l|}{ Uganda } & \multicolumn{2}{|l|}{ Zimbabwe } \\
\hline & Primary care & Any care & Primary care & Any care & Primary care & Any care \\
\hline \multirow[t]{2}{*}{ father_meals } & $-0.581^{* *}$ & 0.251 & 0.078 & $0.804^{* * *}$ & 0.153 & -0.044 \\
\hline & (0.251) & (0.606) & (0.075) & (0.243) & $(0.116)$ & (0.386) \\
\hline \multirow[t]{2}{*}{ father_clean } & -0.106 & 0.319 & -0.065 & 0.329 & -0.047 & -0.318 \\
\hline & $(0.300)$ & (0.823) & $(0.071)$ & (0.200) & (0.137) & (0.452) \\
\hline \multirow[t]{2}{*}{ father_wash } & 0.260 & $0.984^{*}$ & 0.091 & $0.487^{* *}$ & -0.099 & 0.135 \\
\hline & (0.245) & (0.533) & $(0.077)$ & (0.204) & $(0.097)$ & (0.412) \\
\hline \multirow[t]{2}{*}{ father_childcare } & -0.053 & 0.130 & 0.035 & $0.426 * *$ & 0.114 & $0.721^{* *}$ \\
\hline & (0.221) & $(0.464)$ & (0.064) & (0.174) & $(0.106)$ & $(0.345)$ \\
\hline \multirow[t]{2}{*}{ Constant } & 1.361 & -4.109 & $1.448^{* * *}$ & $2.680 * * *$ & $2.436 * * *$ & $7.948 * *$ \\
\hline & $(1.084)$ & (3.413) & (0.369) & (0.951) & $(0.661)$ & (3.187) \\
\hline Observations & 1.361 & -4.109 & $1.448^{* * *}$ & $2.680 * * *$ & $2.436 * * *$ & $7.948 * *$ \\
\hline$R$-squared & $(1.084)$ & (3.413) & (0.369) & (0.951) & $(0.661)$ & (3.187) \\
\hline \multicolumn{7}{|c|}{ Fathers did at least one care activity } \\
\hline \multirow[t]{2}{*}{ Fathers care } & 0.259 & $1.586 * *$ & 0.220 & $4.023 * * *$ & 0.121 & 0.362 \\
\hline & (0.311) & (0.639) & (0.141) & (0.587) & (0.203) & $(0.580)$ \\
\hline \multirow[t]{2}{*}{ Constant } & -0.109 & -2.044 & $1.539 * * *$ & $3.678^{* * *}$ & $2.655^{* * *}$ & $8.674^{* * *}$ \\
\hline & (0.983) & (2.640) & (0.370) & (0.942) & (0.645) & (3.260) \\
\hline Observations & 209 & 209 & 819 & 819 & 324 & 324 \\
\hline$R$-squared & 0.109 & 0.148 & 0.124 & 0.169 & 0.077 & 0.084 \\
\hline
\end{tabular}

NOTES: Robust standard errors in parentheses; ${ }^{* * *} p<0.01 .{ }^{* *} p<0.05 .{ }^{*} p<0.10$. The model includes the following control variables: age, education, the proportion of females in the household, the number of household members, whether the household has at least one child under six years old, the household wealth lquintiles for middle, richer and richest income households) and the district. 'Father meals', 'father clean', 'father childcare' are continuous variables: $0=$ Never, $1=$ Hardly ever, $2=$ Sometimes, $3=$ Frequently.

\section{REGRESSION RESULTS FOR ASSOCIATION BETWEEN MEN BEING TAUGHT TO DO CARE WORK AND CARE TIME}

\begin{tabular}{|c|c|c|c|c|c|c|}
\hline \multirow[b]{2}{*}{ Variables } & \multicolumn{2}{|l|}{ Philippines } & \multicolumn{2}{|l|}{ Uganda } & \multicolumn{2}{|l|}{ Zimbabwe } \\
\hline & Prim. care & Any care & Prim. care & Any care & Prim. care & Any care \\
\hline \multirow[t]{2}{*}{ Father taught to cook meals } & 0.251 & -0.111 & 0.034 & $1.025 * * *$ & 0.182 & -0.043 \\
\hline & (0.312) & $(0.818)$ & (0.065) & (0.189) & $(0.131)$ & (0.536) \\
\hline \multirow[t]{2}{*}{ Father taught to clean } & -0.355 & 0.559 & -0.014 & -0.138 & 0.142 & -0.175 \\
\hline & $(0.403)$ & $(0.887)$ & $(0.076)$ & (0.208) & (0.099) & (0.523) \\
\hline \multirow[t]{2}{*}{ Father taught to wash } & 0.199 & 0.210 & 0.047 & $0.336^{*}$ & $-0.270^{*}$ & 0.045 \\
\hline & $(0.301)$ & $(0.706)$ & (0.079) & (0.197) & $(0.151)$ & $(0.561)$ \\
\hline \multirow[t]{2}{*}{ Father taught to childcare } & -0.150 & 0.665 & 0.014 & 0.141 & -0.024 & 0.119 \\
\hline & (0.232) & $(0.498)$ & $(0.101)$ & $(0.190)$ & $(0.111)$ & (0.373) \\
\hline \multirow[t]{2}{*}{ Constant } & 0.001 & -3.264 & $1.479 * * *$ & $2.742^{* * *}$ & $2.701^{* * *}$ & $9.026 * * *$ \\
\hline & (1.069) & (3.241) & (0.377) & (0.994) & (0.659) & (3.458) \\
\hline Observations & 209 & 209 & 819 & 819 & 324 & 324 \\
\hline \multirow[t]{2}{*}{$R$-squared } & 0.112 & 0.149 & 0.122 & 0.129 & 0.089 & 0.084 \\
\hline & \multicolumn{6}{|c|}{ Men were taught to do at least one care activity } \\
\hline \multirow[t]{2}{*}{ Taught care } & 0.453 & 1.274 & 0.150 & $2.152^{* * *}$ & 0.014 & -0.737 \\
\hline & (0.331) & (0.809) & (0.107) & (0.391) & (0.197) & (0.687) \\
\hline \multirow[t]{2}{*}{ Constant } & -0.380 & -2.032 & $1.504^{* * *}$ & $3.420 * * *$ & $2.717^{* * *}$ & $9.369 * * *$ \\
\hline & (1.009) & $(2.766)$ & (0.369) & (0.962) & (0.679) & (3.316) \\
\hline Observations & 209 & 209 & 819 & 819 & 324 & 324 \\
\hline$R$-squared & 0.113 & 0.137 & 0.123 & 0.113 & 0.076 & 0.087 \\
\hline
\end{tabular}

NOTES: Robust standard errors in parentheses; ${ }^{* * *} p<0.01 .{ }^{* *} p<0.05 .{ }^{*} p<0.10$. The model includes the following control variables: age, education, the proportion of females in the household, the number of household members, whether the household has at least one child under six years old, the household wealth (quintiles for middle, richer and richest income

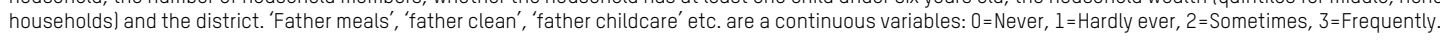


REGRESSION RESULTS FOR ASSOCIATION BETWEEN EMPIRICAL EXPECTATIONS ABOUT MEN'S INVOLVEMENT IN CARE WORK AND CARE TIME

\begin{tabular}{|c|c|c|c|c|c|c|c|c|c|c|c|c|}
\hline \multirow{3}{*}{ Variables } & \multicolumn{4}{|c|}{ Philippines } & \multicolumn{4}{|l|}{ Uganda } & \multicolumn{4}{|c|}{ Zimbabwe } \\
\hline & \multicolumn{2}{|c|}{ Primary care } & \multicolumn{2}{|l|}{ Any care } & \multicolumn{2}{|c|}{ Primary care } & \multicolumn{2}{|l|}{ Any care } & \multicolumn{2}{|c|}{ Primary care } & \multicolumn{2}{|l|}{ Any care } \\
\hline & Women & Men & Women & Men & Women & Men & Women & Men & Women & Men & Women & Men \\
\hline \multirow{2}{*}{$\begin{array}{l}\text { No. Men doing } \\
\text { care }\end{array}$} & -0.264 & -0.017 & -0.465 & -0.065 & -0.039 & 0.024 & $0.619 * * *$ & $1.205^{* * *}$ & 0.123 & 0.064 & 0.043 & 0.146 \\
\hline & (0.161) & $(0.126)$ & $(0.328)$ & (0.369) & $(0.061)$ & $(0.036)$ & (0.153) & (0.185) & (0.109) & (0.052) & (0.241) & (0.188) \\
\hline \multirow[t]{2}{*}{ Constant } & $10.337 * * *$ & 0.183 & $14.078^{* * *}$ & -0.382 & $5.748^{* * *}$ & $1.543^{* * *}$ & $12.578^{* * *}$ & $1.955^{* *}$ & $5.724^{* * *}$ & $2.420 * * *$ & $15.255^{* * *}$ & $8.184^{* *}$ \\
\hline & (1.573) & $(1.014)$ & (3.935) & (2.881) & $(0.520)$ & (0.377) & (1.293) & (0.924) & (1.231) & (0.727) & (2.902) & (3.288) \\
\hline Observations & 204 & 209 & 204 & 209 & 1.071 & 819 & 1.071 & 819 & 402 & 324 & 402 & 324 \\
\hline$R$-squared & 0.110 & 0.106 & 0.310 & 0.127 & 0.097 & 0.121 & 0.226 & 0.160 & 0.106 & 0.079 & 0.214 & 0.085 \\
\hline
\end{tabular}

NOTES: Robust standard errors in parentheses; ${ }^{* * *} p<0.01 .{ }^{* *} p<0.05 .{ }^{*} p<0.10$. The model includes the following control variables: age, education, the proportion of females in the household, the number of household members, whether the household has at least one child under six years old, the household wealth (quintiles for middle, richer and richest income households) and the district. 'Men doing care' takes the values 0 to 5 . 'It is based on the question "Out of 5 men in your village, how many do you think said that they spent at least an hour on caring for people and domestic work yesterday?

REGRESSION RESULTS FOR ASSOCIATION BETWEEN NORMATIVE EXPECTATIONS ABOUT MEN'S CARE WORK AND CARE TIME

\begin{tabular}{|c|c|c|c|c|c|c|c|c|c|c|c|c|}
\hline \multirow{3}{*}{ Variables } & \multicolumn{4}{|c|}{ Philippines } & \multicolumn{4}{|l|}{ Uganda } & \multicolumn{4}{|c|}{ Zimbabwe } \\
\hline & \multicolumn{2}{|c|}{ Primary care } & \multicolumn{2}{|l|}{ Any care } & \multicolumn{2}{|c|}{ Primary care } & \multicolumn{2}{|l|}{ Any care } & \multicolumn{2}{|c|}{ Primary care } & \multicolumn{2}{|l|}{ Any care } \\
\hline & Women & Men & Women & Men & Women & Men & Women & Men & Women & Men & Women & Men \\
\hline \multirow{2}{*}{$\begin{array}{l}\text { Men should do } \\
\text { care }\end{array}$} & -0.229 & -0.017 & $-0.605^{*}$ & -0.014 & $-0.177^{* * *}$ & 0.022 & $0.459 * * *$ & $1.245^{* * *}$ & $0.222^{* *}$ & 0.070 & 0.162 & 0.284 \\
\hline & (0.168) & $(0.148)$ & $(0.357)$ & (0.362) & $(0.060)$ & $(0.034)$ & $(0.151)$ & $(0.190)$ & $(0.094)$ & $(0.054)$ & (0.222) & $(0.194)$ \\
\hline \multirow[t]{2}{*}{ Constant } & $10.174^{* * *}$ & 0.181 & $14.200^{* * *}$ & -0.562 & $6.057^{* * *}$ & $1.555^{* * *}$ & $12.820^{* * *}$ & $2.234^{* *}$ & $5.369^{* * *}$ & $2.453^{* * *}$ & $14.894^{* * *}$ & $7.785^{* *}$ \\
\hline & (1.522) & (1.074) & (3.830) & (3.091) & (0.520) & (0.369) & (1.285) & (0.929) & $(1.224)$ & (0.702) & (2.884) & (3.141) \\
\hline Observations & 204 & 209 & 204 & 209 & 1.071 & 819 & 1.071 & 819 & 402 & 324 & 402 & 324 \\
\hline$R$-squared & 0.105 & 0.106 & 0.314 & 0.127 & 0.105 & 0.121 & 0.220 & 0.171 & 0.115 & 0.080 & 0.215 & 0.088 \\
\hline
\end{tabular}

NOTES: Robust standard errors in parentheses; ${ }^{* * *} p<0.01 .{ }^{* *} p<0.05 .{ }^{*} p<0.10$. The model includes the following control variables: age, education, the proportion of females in the household, the number of household members, whether the household has at least one child under six years old, the household wealth lquintiles for middle, richer and richest income households) and the district. 'Men should do care' takes the value 1 if respondents said that men should do caring for people and domestic work. 
REGRESSION RESULTS FOR ASSOCIATION BETWEEN ACCEPTABILITY OF GENDER-BASED VIOLENCE AND CARE TIME

\begin{tabular}{|c|c|c|c|c|c|c|c|c|c|c|c|c|}
\hline \multirow{3}{*}{ Variables } & \multicolumn{4}{|c|}{ Philippines } & \multicolumn{4}{|l|}{ Uganda } & \multicolumn{4}{|c|}{ Zimbabwe } \\
\hline & \multicolumn{2}{|c|}{ Primary care } & \multicolumn{2}{|l|}{ Any care } & \multicolumn{2}{|c|}{ Primary care } & \multicolumn{2}{|l|}{ Any care } & \multicolumn{2}{|c|}{ Primary care } & \multicolumn{2}{|l|}{ Any care } \\
\hline & Women & Men & Women & Men & Women & Men & Women & Men & Women & Men & Women & Men \\
\hline \multirow{2}{*}{$\begin{array}{l}\text { Acceptance of } \\
\text { beating }\end{array}$} & 0.721 & $-2.654^{* * *}$ & 3.884 & $-7.050 * * *$ & $0.657^{* * *}$ & -0.081 & 0.023 & $-1.667^{* * *}$ & 0.166 & 0.091 & 0.220 & 0.348 \\
\hline & $(1.477)$ & (0.790) & (2.585) & (2.331) & (0.217) & (0.124) & $(0.550)$ & (0.373) & $(0.477)$ & $(0.276)$ & (0.985) & (0.858) \\
\hline \multirow{2}{*}{$\begin{array}{l}\text { Acceptance of } \\
\text { criticism }\end{array}$} & -0.486 & 0.004 & -0.443 & $2.787^{*}$ & 0.169 & -0.195 & -0.740 & $-2.590 * * *$ & -0.043 & 0.337 & 0.160 & $1.421^{*}$ \\
\hline & (0.609) & $(0.737)$ & (1.262) & (1.616) & (0.216) & (0.135) & (0.518) & $(0.443)$ & (0.411) & $(0.230)$ & (0.988) & (0.821) \\
\hline \multirow{2}{*}{$\begin{array}{l}\text { Acceptance of } \\
\text { mocking }\end{array}$} & $3.081 * * *$ & -0.393 & $2.588 * * *$ & $-1.274^{*}$ & 0.041 & -0.098 & $0.840^{*}$ & -0.102 & $0.968^{* * *}$ & -0.279 & 1.093 & -0.630 \\
\hline & (0.557) & (0.347) & (0.868) & (0.719) & (0.195) & (0.144) & $(0.474)$ & (0.339) & (0.360) & (0.193) & (0.892) & (0.685) \\
\hline \multirow[t]{2}{*}{ Constant } & $8.023 * * *$ & 0.159 & $8.517^{* *}$ & -2.026 & $5.494^{* * *}$ & $1.804^{* * *}$ & $14.936 * * *$ & $8.105^{* * *}$ & $5.921 * * *$ & $2.693^{* * *}$ & $14.790^{* * *}$ & $8.324^{* *}$ \\
\hline & (1.905) & (1.094) & (3.910) & (2.706) & $(0.554)$ & (0.399) & (1.475) & (1.237) & $(1.204)$ & (0.703) & (2.889) & (3.298) \\
\hline Observations & 184 & 196 & 184 & 196 & 969 & 749 & 969 & 749 & 396 & 319 & 396 & 319 \\
\hline$R$-squared & 0.156 & 0.127 & 0.318 & 0.179 & 0.137 & 0.141 & 0.218 & 0.173 & 0.126 & 0.089 & 0.217 & 0.103 \\
\hline
\end{tabular}

NOTES: Robust standard errors in parentheses; ${ }^{* * *} p<0.01 .{ }^{* *} p<0.05 .{ }^{*} p<0.10$. The model includes the following control variables: age, education, the proportion of females in the household, the number of household members, whether the household has at least one child under six years old, the household wealth (quintiles for middle, richer and richest income households) and the district. 'Acceptance of beating' takes the value 1 if respondents reported that it was acceptable to beat a woman in at least one of the scenarios. 'Acceptance of criticism' takes the value 1 if respondents reported that it was acceptable to harshly criticize or shout at a woman in at least one of the scenarios. 'Acceptance of mocking' takes the value $l$ if respondents reported that it was acceptable to mock a man in at least one of the scenarios.

REGRESSION RESULTS FOR ASSOCIATION BETWEEN WOMEN'S DECISION-MAKING POWER IN THE HOUSEHOLD AND CARE TIME

\begin{tabular}{|c|c|c|c|c|c|c|c|c|c|c|c|c|}
\hline \multirow[b]{2}{*}{ Variables } & \multicolumn{4}{|c|}{ Philippines } & \multicolumn{4}{|l|}{ Uganda } & \multicolumn{4}{|c|}{ Zimbabwe } \\
\hline & $\begin{array}{l}\text { Prim. } \\
\text { care }\end{array}$ & Any care & $\begin{array}{l}\text { Ratio } \\
\text { prim. }\end{array}$ & $\begin{array}{l}\text { Ratio } \\
\text { any }\end{array}$ & $\begin{array}{l}\text { Prim. } \\
\text { care }\end{array}$ & Any care & $\begin{array}{l}\text { Ratio } \\
\text { prim. }\end{array}$ & $\begin{array}{l}\text { Ratio } \\
\text { any }\end{array}$ & $\begin{array}{l}\text { Prim. } \\
\text { care }\end{array}$ & Any care & $\begin{array}{l}\text { Ratio } \\
\text { prim. }\end{array}$ & $\begin{array}{l}\text { Ratio } \\
\text { any }\end{array}$ \\
\hline \multirow[t]{2}{*}{ Decisions } & 0.004 & $0.079 *$ & 0.001 & 0.014 & -0.008 & 0.037 & 0.000 & $0.005^{* *}$ & -0.016 & $0.129 * * *$ & 0.003 & $0.007^{*}$ \\
\hline & (0.022) & $(0.047)$ & $(0.005)$ & (0.011) & (0.012) & (0.030) & $(0.001)$ & (0.002) & (0.019) & (0.045) & $(0.004)$ & $(0.004)$ \\
\hline \multirow[t]{2}{*}{ Constant } & $9.278^{* * *}$ & $10.828^{* * *}$ & -0.071 & 0.570 & $5.091^{* * *}$ & $13.231^{* * *}$ & -0.059 & 0.022 & $5.255^{* * *}$ & $12.601^{* * *}$ & 0.152 & 0.065 \\
\hline & (1.626) & (3.971) & $(0.300)$ & $(0.636)$ & $(0.666)$ & (1.685) & (0.093) & (0.073) & (1.425) & (3.386) & $(0.217)$ & (0.225) \\
\hline Observations & 192 & 192 & 189 & 191 & 884 & 884 & 828 & 856 & 332 & 332 & 310 & 324 \\
\hline$R$-squared & 0.103 & 0.321 & 0.067 & 0.070 & 0.098 & 0.206 & 0.033 & 0.045 & 0.113 & 0.257 & 0.029 & 0.052 \\
\hline
\end{tabular}

NOTES: Robust standard errors in parentheses; ${ }^{* *} p<0.01 .{ }^{* *} p<0.05 .{ }^{*} p<0.10$. The model includes the following control variables: age, education, the proportion of females in the household, the number of household members, whether the household has at least one child under six years old, the household wealth (quintiles for middle, richer and richest income households) and the district. 'Decisions' is a scale based on whether women can decide on or influence decisions in different areas. For each area of decision making, 0 is assigned if a woman is not involved and cannot influence decisions, 1 is assigned if a woman is involved but cannot influence decisions, 2 is assigned if a woman is not involved but can influence decisions, 3 is assigned if a woman is involved and can influence decisions. 'Decisions' is the mean score of all areas of decision making combined. 
REGRESSION RESULTS FOR ASSOCIATION BETWEEN OWNERSHIP OF TLSE AND WOMEN'S DECISION-MAKING POWER IN THE HOUSEHOLD

\begin{tabular}{|c|c|c|c|}
\hline & Philippines & Uganda & Zimbabwe \\
\hline & \multicolumn{3}{|c|}{ No. of fuel-related equipment items } \\
\hline \multirow[t]{2}{*}{ Decisions } & 0.012 & $0.014^{* * *}$ & 0.012 \\
\hline & (0.011) & $(0.006)$ & (0.009) \\
\hline \multirow[t]{2}{*}{ Constant } & 1.021 & 0.207 & $2.721^{* * *}$ \\
\hline & (0.671) & (0.285) & (0.593) \\
\hline Observations & 192 & 884 & 332 \\
\hline \multirow[t]{2}{*}{$R$-squared } & 0.152 & 0.356 & 0.238 \\
\hline & \multicolumn{3}{|c|}{ No. of cleaning-related equipment items } \\
\hline \multirow[t]{2}{*}{ Decisions } & $0.009 * *$ & 0.001 & -0.002 \\
\hline & $(0.004)$ & (0.002) & (0.002) \\
\hline \multirow[t]{2}{*}{ Constant } & 0.262 & -0.120 & $0.710^{* * *}$ \\
\hline & $(0.246)$ & (0.096) & (0.136) \\
\hline Observations & 192 & 884 & 332 \\
\hline \multirow[t]{2}{*}{$R$-squared } & 0.199 & 0.194 & 0.116 \\
\hline & \multicolumn{3}{|c|}{ No. of washing-related equipment items } \\
\hline \multirow[t]{2}{*}{ Decisions } & $0.018^{* * *}$ & 0.002 & -0.000 \\
\hline & $(0.007)$ & (0.002) & $(0.004)$ \\
\hline \multirow[t]{2}{*}{ Constant } & $-0.741^{*}$ & $-0.325^{* * *}$ & $1.012^{* * *}$ \\
\hline & $(0.437)$ & $(0.094)$ & (0.289) \\
\hline Observations & 192 & 884 & 332 \\
\hline \multirow[t]{2}{*}{$R$-squared } & 0.169 & 0.633 & 0.280 \\
\hline & \multicolumn{3}{|c|}{ No. of meal-preparation equipment items } \\
\hline \multirow[t]{2}{*}{ Decisions } & 0.008 & -0.001 & -0.006 \\
\hline & $(0.006)$ & (0.002) & $(0.004)$ \\
\hline \multirow[t]{2}{*}{ Constant } & 0.108 & $-0.179 *$ & -0.135 \\
\hline & (0.359) & $(0.094)$ & (0.313) \\
\hline Observations & 192 & 884 & 332 \\
\hline \multirow[t]{2}{*}{$R$-squared } & 0.158 & 0.644 & 0.154 \\
\hline & \multicolumn{3}{|c|}{ No. of water-related equipment items } \\
\hline \multirow[t]{2}{*}{ Decisions } & $0.025^{* * *}$ & $0.013^{* *}$ & $0.019 * * *$ \\
\hline & (0.009) & $(0.006)$ & $(0.007)$ \\
\hline \multirow[t]{2}{*}{ Constant } & 0.502 & $1.521^{* * *}$ & $1.191^{* *}$ \\
\hline & (0.593) & $(0.300)$ & (0.511) \\
\hline Observations & 192 & 884 & 332 \\
\hline \multirow[t]{2}{*}{$R$-squared } & 0.183 & 0.518 & 0.269 \\
\hline & \multicolumn{3}{|c|}{ No. of childcare-related equipment items } \\
\hline \multirow[t]{2}{*}{ Decisions } & $-0.039 * * *$ & -0.000 & -0.000 \\
\hline & (0.012) & $(0.004)$ & (0.008) \\
\hline \multirow[t]{2}{*}{ Constant } & $2.922 * * *$ & $1.634^{* * *}$ & $1.828^{* *}$ \\
\hline & (0.719) & $(0.250)$ & (0.725) \\
\hline Observations & 53 & 349 & 73 \\
\hline$R$-squared & 0.510 & 0.360 & 0.178 \\
\hline
\end{tabular}

NOTES: Robust standard errors in parentheses; ${ }^{* * *} p<0.01 .{ }^{* *} p<0.05 .{ }^{*} p<0.10$. The model includes the following control variables: age, education, the proportion of females in the household, the number of household members, whether the household has at least one child under six years old, the household wealth (quintiles for middle, richer and richest income households) and the district. 'Decisions' is a scale based on whether women can decide on or influence decisions in different areas. For each area of decision making, 0 is assigned if a woman is not involved and cannot influence decisions, 1 is assigned if a woman is involved but cannot influence decisions, 2 is assigned if a woman is not involved but can influence decisions, 3 is assigned if a woman is involved and can influence decisions. 'Decisions' is the mean score of all areas of decision making combined. 
REGRESSION RESULTS FOR ASSOCIATION BETWEEN HARM RELATED TO CARE TASKS AND CARE TIME

\begin{tabular}{|c|c|c|c|}
\hline & Philippines & Uganda & Zimbabwe \\
\hline & \multicolumn{3}{|c|}{ Harm experienced due to care } \\
\hline \multirow[t]{2}{*}{ Primary care } & 0.008 & $0.017^{* * *}$ & $0.015^{*}$ \\
\hline & (0.012) & $(0.006)$ & $(0.008)$ \\
\hline \multirow[t]{2}{*}{ Constant } & $0.800 * * *$ & 0.135 & $0.325^{*}$ \\
\hline & $(0.284)$ & (0.097) & $(0.187)$ \\
\hline Observations & 202 & 1.052 & 399 \\
\hline \multirow[t]{2}{*}{$R$-squared } & 0.141 & 0.027 & 0.061 \\
\hline & \multicolumn{3}{|c|}{ Harm experienced due to care } \\
\hline \multirow[t]{2}{*}{ Any care } & 0.003 & $0.004^{*}$ & $0.008^{* *}$ \\
\hline & $(0.007)$ & (0.002) & $(0.004)$ \\
\hline \multirow[t]{2}{*}{ Constant } & $0.838 * * *$ & $0.176^{*}$ & 0.297 \\
\hline & (0.268) & $(0.096)$ & (0.185) \\
\hline Observations & 202 & 1.052 & 399 \\
\hline$R$-squared & 0.139 & 0.021 & 0.065 \\
\hline
\end{tabular}

NOTES: Robust standard errors in parentheses; ${ }^{* * *} p<0.01 .{ }^{* *} p<0.05 .{ }^{*} p<0.10$. The model includes the following control variables: age, education, the proportion of females in the household, the number of household members, whether the household has at least one child under six years old, the household wealth (quintiles for middle, richer and richest income households) and the district. 'Harm experienced due to care' takes the value 1 if women said that they had experienced an injury, illness, disability or other physical or mental harm from their unpaid domestic work or caring for people in the last year. 
REGRESSION RESULTS FOR ASSOCIATION BETWEEN TIME CONSTRAINTS RELATED TO CARE WORK AND CARE TIME

\begin{tabular}{|c|c|c|c|}
\hline & Philippines & Uganda & Zimbabwe \\
\hline & \multicolumn{3}{|c|}{ Adult left alone } \\
\hline \multirow[t]{2}{*}{ Primary care } & -0.002 & $0.008^{* *}$ & $-0.005^{*}$ \\
\hline & $(0.003)$ & $(0.003)$ & $(0.003)$ \\
\hline \multirow[t]{2}{*}{ Constant } & 0.079 & -0.024 & 0.115 \\
\hline & (0.148) & (0.055) & $(0.077)$ \\
\hline Observations & 204 & 1.071 & 402 \\
\hline \multirow[t]{2}{*}{$R$-squared } & 0.081 & 0.041 & 0.048 \\
\hline & \multicolumn{3}{|c|}{ Adult left alone } \\
\hline \multirow[t]{2}{*}{ Any care } & $0.005^{* *}$ & $0.003^{*}$ & -0.001 \\
\hline & $(0.003)$ & $(0.001)$ & $(0.001)$ \\
\hline \multirow[t]{2}{*}{ Constant } & -0.005 & -0.016 & 0.097 \\
\hline & (0.153) & $(0.055)$ & (0.072) \\
\hline Observations & 204 & 1.076 & 403 \\
\hline \multirow[t]{2}{*}{$R$-squared } & 0.098 & 0.040 & 0.043 \\
\hline & \multicolumn{3}{|c|}{ Child left alone } \\
\hline \multirow[t]{2}{*}{ Primary care } & 0.003 & 0.004 & 0.000 \\
\hline & $(0.007)$ & $(0.003)$ & $(0.004)$ \\
\hline \multirow[t]{2}{*}{ Constant } & 0.238 & $0.122^{*}$ & $0.233^{* *}$ \\
\hline & (0.194) & $(0.063)$ & $(0.113)$ \\
\hline Observations & 204 & 1.071 & 402 \\
\hline \multirow[t]{2}{*}{$R$-squared } & 0.162 & 0.022 & 0.029 \\
\hline & \multicolumn{3}{|c|}{ Child left alone } \\
\hline \multirow[t]{2}{*}{ Any care } & 0.006 & -0.001 & 0.001 \\
\hline & $10.004)$ & $(0.001)$ & (0.002) \\
\hline \multirow[t]{2}{*}{ Constant } & 0.193 & $0.147^{* *}$ & $0.211^{*}$ \\
\hline & (0.173) & $(0.064)$ & $(0.116)$ \\
\hline Observations & 204 & 1.076 & 403 \\
\hline \multirow[t]{2}{*}{$R$-squared } & 0.169 & 0.021 & 0.030 \\
\hline & \multicolumn{3}{|c|}{ Child or dependent adult had accident } \\
\hline \multirow[t]{2}{*}{ Primary care } & -0.006 & $0.009 * * *$ & 0.007 \\
\hline & (0.006) & $(0.003)$ & (0.004) \\
\hline \multirow[t]{2}{*}{ Constant } & 0.053 & -0.018 & $0.214^{* *}$ \\
\hline & (0.102) & (0.074) & $(0.100)$ \\
\hline Observations & 204 & 1.071 & 402 \\
\hline$R$-squared & 0.133 & 0.029 & 0.038 \\
\hline & Child or dep & & \\
\hline Any care & -0.005 & $0.005 * * *$ & $0.004^{* *}$ \\
\hline & (0.003) & (0.002) & $(0.002)$ \\
\hline Constant & 0.061 & -0.036 & $0.187^{*}$ \\
\hline & $(0.080)$ & (0.071) & (0.096) \\
\hline Observations & 204 & 1.076 & 403 \\
\hline$R$-squared & 0.148 & 0.035 & 0.045 \\
\hline & Child or dep & thing & \\
\hline Primary care & -0.002 & $0.009 * *$ & 0.003 \\
\hline & $(0.004)$ & $(0.004)$ & $(0.005)$ \\
\hline Constant & 0.055 & -0.078 & 0.146 \\
\hline & $(0.063)$ & (0.072) & $(0.107)$ \\
\hline Observations & 204 & 1.071 & 402 \\
\hline$R$-squared & 0.057 & 0.039 & 0.037 \\
\hline & Child or dep & thing & \\
\hline Any care & -0.002 & $0.003^{* *}$ & $0.004^{* *}$ \\
\hline & (0.002) & $(0.001)$ & $(0.002)$ \\
\hline Constant & 0.067 & -0.065 & 0.096 \\
\hline & $(0.050)$ & (0.072) & (0.103) \\
\hline Observations & 204 & 1.076 & 403 \\
\hline$R$-squared & 0.063 & 0.037 & 0.049 \\
\hline
\end{tabular}

NOTES: Robust standard errors in parentheses; ${ }^{* * *} p<0.01 .{ }^{* *} p<0.05 .{ }^{*} p<0.10$. The model includes the following control variables: age, education, the proportion of females in the household, the number of household members, whether the household has at least one child under six years old, the household wealth lquintiles for middle, richer and richest income households) and the district. 


\section{OXFAM RESEARCH REPORTS}

Oxfam Research Reports are written to share research results, to contribute to public debate and to invite feedback on development and humanitarian policy and practice. They do not necessarily reflect Oxfam policy positions. The views expressed are those of the author and not necessarily those of Oxfam.

For more information. or to comment on this report. Email Andrea Azevedo at aazevedol[oxfam.org.uk

\section{() Oxfam International April 2018}

This publication is copyright but the text may be used free of charge for the purposes of advocacy, campaigning, education and research, provided that the source is acknowledged in full. The copyright holder requests that all such use be registered with them for impact assessment purposes. For copying in any other circumstances, or for re-use in other publications, or for translation or adaptation, permission must be secured and a fee may be charged. Email policyandpractice@oxfam.org.uk

The information in this publication is correct at the time of going to press.

Published by Oxfam GB for Oxfam International in April 2018 under ISBN 978-1-78748-168-8

DOI: $10.21201 / 2017.1671$

Oxfam GB. Oxfam House, John Smith Drive, Cowley, Oxford, 0X4 2JY, UK

\section{OXFAM}

Oxfam is an international confederation of 20 organizations networked together in more than 90 countries as part of a global movement for change to build a future free from the injustice of poverty. Please write to any of the agencies for further information or visit www.oxfam.org

Oxfam America (www.oxfamamerica.org)

Oxfam Australia (www.oxfam.org.au)

Oxfam-in-Belgium (www.oxfamsol.be)

Oxfam Brasil (www.oxfam.org.br)

Oxfam Canada (www.oxfam.ca)

Oxfam France (www.oxfamfrance.org)

Oxfam Germany (www.oxfam.de)

Oxfam GB (www.oxfam.org.uk)

Oxfam Hong Kong (www.oxfam.org.hk)

Oxfam IBIS (Denmark) (http://oxfamibis.dk)

Oxfam India (www.oxfamindia.org)

Oxfam Intermón (Spain) (www.oxfamintermon.org)

Oxfam Ireland (www.oxfamireland.org)

Oxfam Italy (www.oxfamitalia.org)

Oxfam Japan (www.oxfam.jp)

Oxfam Mexico (www.oxfammexico.org)

Oxfam New Zealand (www.oxfam.org.nz)

Oxfam Novib (Netherlands) (www.oxfamnovib.nl)

Oxfam Québec (www.oxfam.qc.ca)

Oxfam South Africa (www.oxfam.org.za)

\section{PHOTOS}

Front cover: Ulita Mutambo and her husband Muchineripi Sibanda hang up laundry outside their home in Ture Village, Zimbabwe.

Photo: Aurelie Marrier d'Unienville/Oxfam

Page 6: Rosalyn Martinez washing clothes with her two daughters, North Tacloban, Philippines. Photo: Aurelie Marrier d'Unienville

Page 11: Grace Aloyo cradles her sleeping baby, Lamwo district, northern Uganda. Photo: Julius Ceaser Kasujja/Oxfam

Page 13: Florence Alur and her husband Zakayo David Opwonya, Uganda. Photo: Julius Ceaser Kasujja/Oxfam

Page 16: Pastora Samson and her husband Romulo Samson wash clothes together at a public laundry site at a local river, Eastern Samar, Philippines. Photo: Aurelie Marrier d'Unienville/Oxfam

Page 18: Grace Aciro transporting hay, Lamwo district, northern Uganda. Photo: Julius Ceaser Kasujja/Oxfam

Page 21: Senia Tanyanyiwa works in her corn field outside her home in the Gutu region of Zimbabwe.

Photo: Aurelie Marrier d'Unienville/Oxfam

Page 29: Shienna Cabus and her four-year-old daughter travel to a local spring to collect water, Eastern Samar, Philippines. Photo: Aurelie Marrier d'Unienville/Oxfam

Page 38: Betty Angeyo cooking on the fuel-efficient stove provided as part of the WE-Care intervention in her community, Lamwo district, northern Uganda. Photo: Julius Ceaser Kasujja/Oxfam

Page 45: Tendai Chauke outside her home in the Masvingo region of Zimbabwe. Photo: Aurelie Marrier d'Unienville/Oxfam

Page 46: Unilever's Esther Marshall attends a fisherfolk association meeting in a community in Eastern Samar, Philippines.

Photo: Aurelie Marrier d'Unienville/Oxfam

Page 48: Beatrice Kaluma, with her four children in Bidi Bidi Refugee Settlement, northern Uganda. Photo: Kieran Doherty/Oxfam

Page 49: Paulina Sibanda hangs up her washing outside her home in Zvishevane region, Zimbabwe.

Photo: Aurelie Marrier d'Unienville/Oxfam

Page 50: Grace Aloyo prepares a family meal outside her home in Lamwo district, northern Uganda.

Photo: Julius Ceaser Kasujja/Oxfam

Page 52: Ana Maronbeze with her granddaughter, Masvingo region, Zimbabwe. Photo: Aurelie Marrier d'Unienville/Oxfam

Page 56: Melody Mutsauki hangs up her washing, Masvingo region, Zimbabwe. Photo: Aurelie Marrier d'Unienville/Oxfam

\section{WE-CARE \\ WOMEN'S \\ ECONOMIC EMPOWERMENT AND CARE}

